\title{
Gene expression profiling of atherosclerosis
}

Citation for published version (APA):

Faber, B. C. G. (2003). Gene expression profiling of atherosclerosis. [Doctoral Thesis, Maastricht University]. Datawyse / Universitaire Pers Maastricht. https://doi.org/10.26481/dis.20030925bf

Document status and date:

Published: 01/01/2003

DOI:

10.26481/dis.20030925bf

Document Version:

Publisher's PDF, also known as Version of record

\section{Please check the document version of this publication:}

- A submitted manuscript is the version of the article upon submission and before peer-review. There can be important differences between the submitted version and the official published version of record.

People interested in the research are advised to contact the author for the final version of the publication, or visit the DOI to the publisher's website.

- The final author version and the galley proof are versions of the publication after peer review.

- The final published version features the final layout of the paper including the volume, issue and page numbers.

Link to publication

\footnotetext{
General rights rights.

- You may freely distribute the URL identifying the publication in the public portal. please follow below link for the End User Agreement:

www.umlib.nl/taverne-license

Take down policy

If you believe that this document breaches copyright please contact us at:

repository@maastrichtuniversity.nl

providing details and we will investigate your claim.
}

Copyright and moral rights for the publications made accessible in the public portal are retained by the authors and/or other copyright owners and it is a condition of accessing publications that users recognise and abide by the legal requirements associated with these

- Users may download and print one copy of any publication from the public portal for the purpose of private study or research.

- You may not further distribute the material or use it for any profit-making activity or commercial gain

If the publication is distributed under the terms of Article $25 \mathrm{fa}$ of the Dutch Copyright Act, indicated by the "Taverne" license above, 


\author{
Gene \\ expression profiling of \\ atherosclerosis
}


\$ B.C.G. Faber, Maastricht 2003

ISBN 90-5278-376-4

Vormgeving: Karin Faber

Druk: Datawyse/ Universitaire Pers Maastricht 


\section{Gene \\ expression profiling of \\ atherosclerosis}

\section{Proefschrift}

ter verkrijging van de graad van doctor aan de Universiteit Maastricht, op gezag van de Rector Magnificus, Prof. dr. A.C. Nieuwenhuijzen Kruseman, wolgens thet besluit van het College van Decanen, in het openbaar te verdedigen op donderdag 25 september 2003 om 14.00 uur door Birgitta Cornelia Geertruida Faber Geboren op 28 oktober 1969 te Eindhoven 


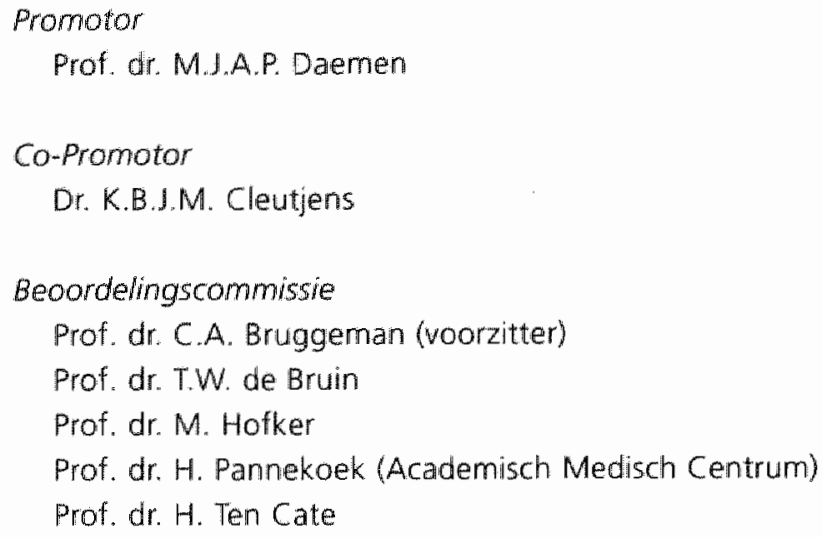

Financial support by the Netherlands Heart Foundation and the Dr. Ir. van de Laar Stichting for the publication of this thesis is gratefully acknowledged. 


\section{Abbreviations}

\begin{tabular}{|c|c|}
\hline AA & amino acid \\
\hline A.AA & abdominal artery aneurysm \\
\hline$A B C A-1$ & ATP binding cassette $\mathrm{A}-1$ tramsporter \\
\hline ACAT & acyl coenzymeA:cholesterol acyitransferase \\
\hline ADRP & adipocyte differentiation related protein \\
\hline AOD & arterial occlusive disease \\
\hline ApoE & apollipoproteim $\mathbb{E}$ \\
\hline ASMA & $\alpha$ smooth muscle actin \\
\hline $\mathrm{bp}$ & base pairs \\
\hline DD & differential display \\
\hline DIG & digoxigenin \\
\hline DDT & dithiothreito \\
\hline DNA & deoxyribonucleic acid \\
\hline ECM & extracellular matrix \\
\hline E.coli & Escherichia coli \\
\hline Gas6 & growthi arrest-specific gene 6 \\
\hline GST & glutathione 5-transferase \\
\hline $\mathrm{HDL}$ & high density lipoprotein \\
\hline HRP & horse raddish peroxidase \\
\hline HSL & hormone sensitive lipase \\
\hline IL & interleukin \\
\hline IFN & interferon \\
\hline kDa & kilo dalton \\
\hline Lif & leukeamia inhibitory factor \\
\hline LDL & low density lipoprotein \\
\hline LDLR & LDL receptor \\
\hline MA & micro array \\
\hline MCP & macrophage chemoattractant protein \\
\hline MPP & macrophage inflammatory protein \\
\hline MMP & matrix metalloproteinase \\
\hline MTE & multiple tissue expression aray \\
\hline OXILL & oxidized $L D L$ \\
\hline PBS & phosphate buffered saline \\
\hline PLAZ & phospholipase A2 \\
\hline PMSF & pheny/methylsulfonyl fluoride \\
\hline PKA & protein kinase $\mathrm{A}$ \\
\hline RNA & ribonucleic acid \\
\hline RTTPCR & reverse transcriptase polymerase chain reaction \\
\hline SAGE & serial analysis of gene expression \\
\hline ScFN & single chain variable fragment \\
\hline SEM & standard error of the mean \\
\hline sic & small inducible cytakine \\
\hline SMC & smooth muscle cell \\
\hline$S R$ & scavenger receptor \\
\hline SSH & suppression subtractive hybridisatio \\
\hline TIMP & tissue inhibitor of matrix metalloproteinase \\
\hline TGF $\beta$ & transforming growth factor $\beta$ \\
\hline VSMC & vascular smooth muscle cells \\
\hline
\end{tabular}





\section{Contents}

Chapter 1 General intraduction

Chapter 2 Genes potentially involved in plaque rupture.

Chapter 3 Identification of genes potentially involved in rupture of human atherosclerotic plaques

Chapter 4 Large scale gene expression profiling

of human atherogenesis.

Chapter 5 Unique gene expression profiles characterize cholesterol challenge and atherosclerotic plaque progression im ApoE deficient mice.

Chapter 6 Disruption of the cathepsin $K$ gene reduces the progression of atherosclerosis.

Chapter 7 Spatio-temporal expression of perilipin, adiposyte differentiation related protein and hormone sensitive lipase in human atherosclerosis.

Chapter 8 Vasculin, a novel protein differentially expressed in human atherogenesis.

Chapter 9 General discussion

Summary 197

Samervatting 201

Dankwoord 206

Curriculum Vitae 209 



\section{CHAPTER 1}

\section{GENERAL INTRODUCTION}




\section{Clinical implications of atherosclerosis}

At the end of the past century atherosclerosis has become the leading cause of death in western society'. The onset of atherosclerosis occurs already in the first decade of life ${ }^{2.3}$. The first clinical manifestations however mainly occur from the fifth or sixth decade : Depending on the artery affected, atherosclerosis can have different clinical manifestations. Atherosclerosis in the coronary arteries can cause angina pectoris and myocardial infarction. Atherosclerosis in the cerebrovascular circulation may lead to a transient ischemic attack or stroke. Claudication and limb-threatening ischemia are the clinical manifestations in the lower extremities, while atherosclerosis in the renal arteries and mesenteric arteries may lead to renal failure and abdominal pain respectively. Strikingly, patients suffering from peripheral atherosclerosis have a comparable risk to die from cardiovascular events as patients suffering from coronary or cerebrovascular disease s. Rupture of an atherosclerotic lesion and subsequent thrombus formation is the underlying process in most acute manifestations. Chronic manifestations are often the result of a growing advanced lesion gradually occluding the lumen.

\section{Lesion devellopment}

The atherosclerotic process is initiated by endothelial dysfunction. Endothelia! dysfunction is caused, among others, by elevated levels of modified low density lipoprotein (LDL), free radicals formed by cigarette smoking, diabetes mellitus and elevated homocysteine concentrations. Increased adhesiveness and permeability are key features of endothelial dysfunction. This results in an increased influx of leukocytes, mainly macrophages and T-cells, and accumulation of lipoproteins in the vascular wall. Macrophages take up the oxidized LDL (oxLDL) and evolve into foam cells. The inflammatory cells in the arterial wall induce a chronic state of inflammation. Furthermore, migration and proliferation of vascular smooth muscle cells (VSMC), the cell type responsible for the synthesis of fibrous tissue, occurs. When lesions evolve, a core of lipids and necrotic tissue is formed. This core is covered with a fibrous cap. When the fibrous cap ruptures, blood will come into contact with the highiy thrombogenic content of the necrotic core and a thrombus is formed ${ }^{6 \cdot n}$. 


\section{Classification of atherosclerotic lesions}

Atherosclerotic lesions are classified according to their morphology. Several histological classifications have been developed. Among others, the Council on Arteriosclerosis, Thrombosis and Vascular Biology of the American Heart Association developed a comprehensive classification s.la:s. Virmani and colleagues is further refined this classification, especially regarding the advanced lesions. The atherosclerotic lesions described in this thesis were characterized according to this refined classification scheme. For reasons of feasibility the atherosclerotic specimens in this thesis are divided into three main categories: the early lesions, the stable lesions and the lesions containing a thrombus.

The group of early lesions contain the following entities: 1) intimal thickening, characterized by the presence of intimal vascular smooth muscle cells (VSMC) in a proteoglycan-rich matrix, 2) pathological intimal thickening, rich in VSMC and proteoglycans, and containing small extracellular lipid pools with sparse macrophages and lymphocytes, and 3) intimal xanthoma's or fatty streaks containing lipid laden macrophages, T-lymphocytes and VSMC in the intima.

The group of stable lesions consists of three different lesion types: the fibrous cap atheroma's, thin fibrous cap atheroma's and the fibrocalcific lesions. Fibrous cap atheroma's are characterized by the presence of a necrotic core that contains cholesterol esters, free cholesterol, phospholipids and triglycerides. The lipid core is covered by a fibrous cap containing VSMC in a proteoglycan-collagen matrix and variable numbers of macrophages and lymphocytes. Thin fibrous cap atheroma's contain a fibrous cap that is less than $65 \mu \mathrm{m}$ thick. The fibrous cap shows a loss of VSMC and extracellular matrix. These lesions are thought to have an increased risk for fibrous cap rupture. Fibrocalcific lesions contain extensive accumulations of calcium in the intima.

The last group comprises the lesions with thrombi and include the ruptured lesions, lesions that show erosion and lesions showing intraplaque haemorrhage. Ruptured lesions have a disrupted fibrous cap and a thrombus that is in contact with the necrotic core is formed. These lesions are often characterized by a large lipid core and a highly inflamed fibrous cap. Lesions that show erosion are characterized by the presence of a thrombus without signs of cap disruption. Erosion is observed on lesions rich in VSMC and extracellular matrix and minimal inflammation. The last member of this group is the lesions that contain intraplaque haemorrhage. 


\section{Hypothesis}

As described earlier in this chapter, three main stages can be recognized in atherosclerosis. These stages comprise early lesions, stable lesions and lesions containing a thrombus. Discrimination of the different stages is based on the morphological characteristics of the lesions. Lesion progression is a dynamic process influenced by inflammation, lipid accumulation and matrix turn-over. Despile our current knowledge on lesion progression is, the molecular mechanisms underlying these processes still remain largely unknown. We hypothesize that each atherosclerotic lesion type is accompanied by a specific gene expression profile. Idientification of these differentially expressed genes may help to dissect the molecular mechanisms involved in lesion progression and to a better molecular characterization of the lesions. To test this hypothesis we pertiormed large scale gene expression studies using suppression subtractive hybridization and DNA micro-array analysis on human atherosclerotic specimens and aortic arches of ApoE deficient mice, a well known model of atherosclerosis.

From these gene expression studies we identified three different sets of genes that were differentially regulated curing atherogenesis: 1) known genes that were previously linked to atherosclerosis 2) known genes that were not previously linked to atherosclerosis 3) novel genes that represent novel proteins involved in atherosclerosis. For subsequent validation studies we selected genes present in each group.

Cathepsin $K$ is a cysteine protease that was already linked to atherosclerosis. The cathepsin K gene was found to be highly upregulated in stable lesions. The role of cathepsin $K$ on atheroslerosis was tested in a murine model for atheroscierosis, the ApoE deficient mice.

Perilipin, a protein involved in the regulation of neutral lipid metabolism, was not previously linked to atherosclerosis. We found perilipin mRNA to be exclusively expressed in lesions containing a thrombus. Expression patterns of perilipin and wo other mediators of neutral lipid metabolism, adipocyte differentiation related protein and hormone sensitive lipase, were assessed during human atherogenesis.

Vasculin represented an EST sequence that was not previously linked to atherosclerosis. Vasculin mRNA was predominantly expressed in lesions containing a thrombus. We further characterized vasculin and studied the expression in human tissue and in particular expression in atherosclerotic lesions.

\section{Outline of this thesis}

In this thesis we describe the identification of genes that are differentially expressed in atherosclerosis. In chapter 2 we describe a review on genes involved in plaque rupture. The first experimental chapter (chapter 3) describes the identification of genes that are differentially expressed between human stable lesions and lesions containing 
a thrombus identified by suppression suppressive hybridisation (SSH). In chapter 4 we use the DNA micro-array technology to isolate genes that are differentially expressed between human early lesions and stable lesions and between stable lesions and lesions containing a thrombus. In addition an expanded analysis of the SSH libraries is presented. The results, obtained by DNA micro-array analysis and SSH are compared to each other. In chapter 5 we describe gene expression profiles during atherogenesis in the ApoE deficient mice a well known model of atherosclerosis. Chapter 6 describes the cathepsin $k m R N A$ and protein expression profiles during human atherogenesis. Furthermore, the effect of genetic disruption of cathepsin $\mathrm{K}$ on lesion development and lesion phenotype was determined in the ApoE deficient mouse. In chapter 7. we studied the MRNA and protein expression pattern of perilipin, a gene preferentially expressed in lesions containing a thrombus, during atherosclerotic lesion development. Additionally, gene expression and protein expression profiles of two other genes involved in neutral lipid metabolism, adipocyte differentiation related protein (ADRP) and hormone sensitive lipase (HSL), were studied Chapter 8 focuses on the novel gene vasculin in human atherogenesis. In chapter 9 the findings as described in this thesis are discussed and future directions are given. 


\section{$=$ References}

1. Lalkosa J6: Future cardiovascular end point studies: where will the research take us? Am $J$ Cardiol 1999,84:454-8.

2. Stary HC: Evolution and progression of atherosclerotic lesions in coronary arteries of children and young adults. Arteriosclerosis 1989, 9:119-32.

3. Stary HC: Macrophage foam cells in the coronary artery intima of human infants. Ann NV Y Acad Sci 1985,454:5-8.

4. Stary HC, Chandler AB, Dinsmore RE, Fuster $V$, Glagow $S$, Insull W, Jr. Rosenfeld ME, Schwartz CJ. Wagner WD. Wissler RW: A definition of advanced types of atherosclerotic lesions and a histological classification of atherosclerosis. A report from the Committee on Vascular Lesions of the Council on Arteriosclerosis. American Heart Association. Arterioscler Thromb Wasc Biol 1995,15:1512-31.

5. Silva JA, White CI: Plaque instability in peripheral vessels. Prog Cardiowasc Dis, 2002,44:429-36.

6. Ross R. Atherosclerosis--an inflammatory disease. N Engl / Med 1999,340:115-26.

7. Lusis AJ: Atherosclerosis. Nature 2000,407:233-41.

8. Libby P: Changing concepts of atherogenesis. I Intern Med 2000,247:349-58.

9. Glass CK, Witztum IL: Atherosclerosis. the road ahead. Cell 2001, 104:503-16.

10. Stary HC, Blankenhorn $\mathrm{DH}_{\text {, }}$ Chandler $\mathrm{AB}$, Glagov S. Insull W, Jr. Richardson $M$, Rosenfeld ME, Schaffer SA, Schwartz CJ. Wagner WD, et al: A defintion of the intima of human arteries and of its atherosclerosis-prone regions. A report from the Committee on Vascular Lesions of the Council on Arteriosclerosis, American Heart Association. Circulation 1992.85:391-405.

11. Stary $H C$, Chandler $A B$, Glagow S, Guyton JR, Insull W, Jr., Rosenfeld ME, Schaffer $S A$, Sctwwartz CI, Wagner WD, Wissler RW: A definition of initial, fatty streak, and intermediate lesions of atherosclerosis. A report from the Committee on Vascular Lesions of the Council on Arteriosclerosis, American Heart Association. Circulation 1994,89:2462-78.

12. Stary HC: Natural history and histological classification of atherosclerotic lesions: an update. Anterioscler Thromb Vasc, Biol 2000,20:1177-8.

13. Virmani $R$, Kolodgie $F D$, Burke $A P$, Farb $A$, Schwartz SM: Lessons from sudden coronary death: al comprehensive morphological classification scheme for atherosclerotic lesions. Arterioscler "Thromb Vasc Biol 2000,20:1262-75.

14. L.ibby P: Inflammation in atherosclerosis. Nature 2002,420:868-74. 



\section{CHAPTER 2}

\section{GENES POTENTIALLY INVOLVED IN PLAQUE RUPTURE}

Birgit C.G. Faber, Sylvia Heeneman, Mat J.A.P. Daemen and Kitty B.J.M. Cleutjens

Department of Pathology, Cardiovascular Research Institute Maastricht (CARIM), University of Maastricht, The Netherlands.

Current Opinion in Lipidology 2002;13:545-552 


\section{$>$ Abstract}

Rupture of an atherosclerotic plaque is the predominant underlying event in the pathogenesis of acute coronary syndromes and stroke. While ruptured plaques are marphologically well described, the precise molecular mechanisms involved in plaque rupture are still incompletely understood. Over the last few years, techniques like micro-array, suppression subtractive hybridization and differential display enabled us to study complex gene expression profiles that occur during the process of atherogenesis. In this review we focus on recent large scale gene expression profiles performed on whole mount vascular specimens. The gene expression profiles on whole mount vascular tissue confirmed that at least three mechanisms are involved in plaque rupture that is: 1) a disturbed balance in extracellular matrix turn-over, 2) disturbed regulation of cell turn-over, 3) processes inwolved in lipid metabolism. Animal models exhibiting features of plaque rupture reflect the involvement of these three mechanisms. The most dramatic mouse phenotypes were observed after interventions in at least two of these mechanisms. The observation of plaque rupture in recent mice models is in dicative for the multifactorial process of plaque rupture. This multifactorial character of plaque rupture suggests that interventions may be most effective when they influence more than one mechianisms at a time. 
Atherosclerosis is a chronic inflammatory disease of the arteries and is characterized by the accumulation of lipids, cells and extracellular matrix in the vessel wall. Although advanced lesions can grow sufficiently large to block blood flow, clinical implications like coronary syndromes and stroke predominantly arise from rupture and subsequent thrombus formation of an atherosclerotic plaque ${ }^{1.2}$. Advanced stable plaques are characterized by a thick fibrous cap, rich in collagen and smooth muscle cells (SMC). while unstable or ruptured plaques contain a thin fibrous cap with a dense inflammatory infiltrate, a large lipid core, a luminal thrombus or plaque erosion and intraplaque heamorrhage ${ }^{\text {ia }}$. Many groups examined several aspects involved in plaque rupture using in vitro assays and animal models. Most of these studies focused on a single molecule or target at a time. During the last few years large scale gene expression techniques, like differential display, serial analysis of gene expression (SAGE), suppression subtractive hybridisation (SSH) and micro-arrays became available. This allowed researchers to study complex gene expression profiles of whole mount atherosclerotic plaques or cells in culture. Table 1 summarises gene expression studies performed on whole mount vascular tissue. From these studies we can conclude that many regulated genes belong to gene families that were already linked to currently established views on mechanisms in plaque rupture. These mechanisms are: 1) a disturbed balance in extracellular matrix turn-over, 2) disturbed regulation of cell turn-over, 3) processes involved in lipid metabolism. In this review we will focus on gene expression data with special emphasis on the three major pathways mentioned above.

Table 1: Lavge scale gene expression studies on whole mount vascular tissues

\section{Study}

Abdominal aorta aneurysm verus arterial occlusive disease, fluman Abdominal aorta aneanym wersus normal artery, (human)

Stable plaques versus ruptured plaques human

Irviracranial anewrysm wersus normal antery (human) Fibrous cap versus media (humant Neorntima versus media (thuman)

Aortia versus wena cava (macaque)

Neointina (rat)

Aorta ApoE-/- versus aorta C57BL/6

\section{Mechanism Involwod}

Extracellular matrix turn-over

Extracellatar matrix turn over

Cell turinover

Lipid rofetabolism

Extracellular matrix turrover

Lipid metabolism

Extrace lullar matrim wurrover

Cell turn-over

Extracelluhar matrix tum-over

Celll turn-over

Extracellular matrix turn-over

Cell turnover

Lipid melabolism

Extracellutar matrix turn-over

Extracellislar manix tum-over

Cell tum-over

Lipind metabolism

\section{Peterence}

14

17

28

29

47

85

86

非

87 


\section{$>$ Extracellular matrix turn-over}

The general concept states that increased matrix metalloproteinase (MMP) activity leads to plaque rupture ". Several MMP family members (MMP-1, MMP-2, MMP-3. MMP-7, MMP-8, MMP-9, MMP-12, MMP-13, MMP-14) are indeed expressed in atherosclerotic lesions and expression of MMP-1, MMP-3 and MMP-9 is increased in the vulnerable shoulder region ${ }^{5}$. The activity of MMPs is counterbalanced by their natural inhibitors the so-called tissue inhibitors of MMPs. (TIMPs) that are also expressed in atherosclerotic lesions. Therefore, matrix degradation in atherosclerotic lesions is not only reflected by the presence of MMPs, but also by the presence of TIMPs ?

MMPS are also inwolved in other vascular diseases like abdominal artery aneurysms (A.AA) and neointima formation. In models of aneurysm formation, results of genetic and pharmacological interventions are quite clear (table 2). Deficiency in MMP-3* and MMP-9 "gene expression or general inhibition of MMP-s ${ }^{\text {in }}$ i: led to a decrease in aneurysm formation or inhibited aneurysm rupture. Only MMP-12 deficiency rendered no effect on aneurysm formation "although MMP-12 expression was enhanced in human AAA specimens $:$. These data imply a beneficial effect of MMP inhibition on aneurysm formation.

Several groups compared gene expression profiles of human vascular specimens derived from normal arteries, arterial occlusive disease (AOD) and AAA. Armstrong et al. ${ }^{14}$ showed no differences in MMP or TIMP expression between AAA and AOD specimens, whille MMP-9 expression was increased in AOD and AAA specimens. compared to normal artery. Other studlies revealed increased expression of MMP-2. MMP-3, MMP-9. TIMP-1 and TIMP-2 in AAA compared to AOD 1\% 16 ir. These findings coordlinate with a decrease in aneurysm formation in MMP-3 and MMP-9 deficient mice ${ }^{B ?}$.

Inhibition of MMPs by either a MMP inhibitor or TMP overexpression decreases neointima formation, mainly due to a decrease in SMC migration and proliferation (table 2). One MMP intervention study showed a decrease in early neointima formation, while long term effects were not observed ". Temporal gene expression proflles in a rat carotid artery injury model showed a tight regulation of MMP expression and genes that modulate MMP expression "This time window is also reflected by the results of the above mentioned MMP inhibition study, in which decreased early neointima formation had no long term effect ${ }^{\text {so. }}$

In contrast to the largely unambiguous effects on aneurysm and neointima formation. MMP intervention studies showed diverse effects on atherogenesis (table 2). Overexpression of MMP-1 resulted in a decreased plaque size 20 . MMP-3 inhibition increased plaque size and progression ${ }^{121}$ while broad range MMP inhibitors had no effect on plaque size ${ }^{30}$. Contrasting results were obtained for MMP-9 overexpression ${ }^{1522}$ and inhibition or promotion of TIMP-1 expression ${ }^{23}{ }^{24}$. The available data suggest that MMP inhibition may lead to progression of atherosclerosis. However, an increase in plaque size does not always imply increased plaque vulnerability and studies on the 
Table 2: The effect of matrix tum over on leston formation

\begin{tabular}{|c|c|c|c|}
\hline & Model & Effects & Refertence \\
\hline Aneurysm & 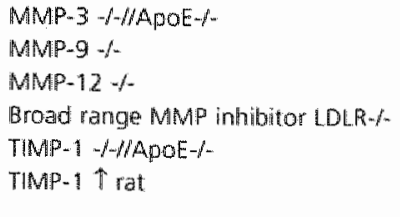 & $\begin{array}{l}\downarrow \text { aneursm } \\
\downarrow \text { aneursm } \\
\leftrightarrow \text { aneulism } \\
\$ \text { aneurism } \\
1 \text { aneurism } \\
\downarrow \text { aneurism }\end{array}$ & $\begin{array}{l}8 \\
9 \\
9 \\
10 \\
23 \\
11\end{array}$ \\
\hline $\begin{array}{l}\text { Neointima } \\
\text { formation }\end{array}$ & $\begin{array}{l}\text { MMP-9 T rat } \\
\text { Broad range MMP inhibitor LDLR-/- } \\
\text { Doxycyclin. MMP inhibition rat } \\
\text { TIMP-1 I human vein } \\
\text { TMMP-2 Thuman vein } \\
\text { TMMP-3 T human and pig vein }\end{array}$ & $\begin{array}{l}\text { I sme migration } \downarrow \text { matrix content } \\
\text { † luminaliameter } \\
\downarrow \text { early alnd } \rightarrow \text { late neointima formation } \\
\downarrow \text { neointima formation } \\
\downarrow \text { neointima formation } \\
\downarrow \text { neointima formation } \\
\downarrow \text { neointima formation }\end{array}$ & $\begin{array}{l}10 \\
89 \\
90 \\
91 \\
92\end{array}$ \\
\hline Remodeling & $\begin{array}{l}\text { MMP-12 } \uparrow \\
\text { MMP inthibitor pig }\end{array}$ & $\begin{array}{l}\text { L lluminal diameter } \\
\downarrow \text { constrictive remodelling }\end{array}$ & $\begin{array}{l}93 \\
94\end{array}$ \\
\hline Atherosclerosis & 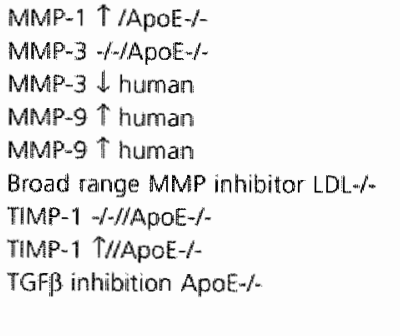 & $\begin{array}{l}\downarrow \text { plaque size } \downarrow \text { collagen content } \\
\uparrow \text { plaque size } \uparrow \text { collagen content } \\
\uparrow \text { plaque progression } \\
\uparrow \text { triple wessel disease } \\
\leftrightarrow \text { coronary artery stenosis } \\
\leftrightarrow \text { plaque size } \\
\downarrow \text { plaque size lipid cone content } \\
\downarrow \text { plaque size collagen content } \\
\uparrow \text { plaque vulnerability. } \\
\text { intraplaque haemorrhage }\end{array}$ & $\begin{array}{l}20 \\
8 \\
21 \\
16 \\
22 \\
10 \\
23 \\
24 \\
32 \\
33\end{array}$ \\
\hline
\end{tabular}

effect of overexpression of MMPs in rupture prone plaques or studies on the effects of MMP inhibition in animal models of plaque rupture are not available yet.

In addition to the MMPs, atherosclerotic lesions also contain cathepsins, a family of lysosomal cysteine proteases displaying elastase activity ${ }^{2526}$. Cathepsin $K$ and $S$ are expressed by SMCs and macrophages in the fibrous cap and in the shoulder regions of the plaque ${ }^{i s}$. while cathepsin $B$ expression is enhanced in highly inflamed plaques of ApoE deficient mice. Interestingly, the cathepsin B activity was visualized in wivo by near-infrared tomography ${ }^{26}$. This technique provides an opportunity to study matrix degrading processes in vivo and may serve as a biomarker for plaque vulnerability.

The strength of the fibrous cap is also influenced by extracellular matrix synthesis". Using SSH we found fibronectin to be one of the genes upregulated in stable compared to ruptured plaques ${ }^{28}$. Furthermore, expression of other genes involved in extracellular matrix remodeling were modulated in AAA ${ }^{14}$, human intracranial aneurysms ${ }^{\text {" }}$ and neointima formation in the rat ". The amount of collagen cross-linking also defines 
fibrous cap strength. Tissue transglutaminase, an enzyme involved in cross-linking of collagen, is expressed during plaque progression ${ }^{30}{ }^{31}$. In addition, using micro-array analysis we found that tissue transglutamase mRNA was downregulated in ruptured plaques (Faber et al. unpublished results) which might be indicative for decreased fibrous cap strength in ruptured plaques.

The involvement of regulators of matrix turn-over in plaque rupture was further substantiated by the inhibition of TGF $\beta$ signalling in ApoE $-\%$ - mice, which resulted in a more vulnerable phenotype ${ }^{32}$ 33. Remarkably, inhibition of TGF $\beta$ signalling, in pre-existing atherosclerosis resulted in more profound effects including intraplaque haemorrhage and fibrin and iron deposition ${ }^{33}$.

In conclusion, both gene expression and intervention studies clearly show that a tight control of matrix turn-over is important in vascular disease and that the effects may be heterogeneous. While MMP inhibition might be beneficial in both aneurysm and neointima formation, the effect of MMPs on atherosclerosis and plaque rupture remains incompletely understood. The current data suggest a stimulatory effect of MMP inhibition on plaque progression, whereas intervention data on plaque rupture are not yet available.

\section{- Cell turn-over}

Apoptosis and DNA synthesis are reported to be low in progression of human atherosclerosis however, changes in the rate of apoptosis have been proposed to play a role in plaque rupture ${ }^{34}$. Several studies reported an increase in macrophage apoptosis in ruptured plaques ${ }^{35}$. In addition, the active form of caspase-1 was restricted to ruptured plaques, whereas stable plaques expressed latent caspase- $1{ }^{36}$. The positive correlation between the amount of apoptotic bodies in the circulation and unstable angina or myocardial infarction may also suggests involvement of apoptosis in plaque rupture ${ }^{3 *}$.

Several mechanisms have been proposed by which apoptosis can increase plaque vulnerability. Apoptosis might decrease the number of collagen producing SMC ${ }^{38}$ and apoptotic bodies might influence plaque progression. Deficient removal of apoptotic bodies can lead to secondary necrosis, increased expression of pro-inflammatory cytokines, increased inflammatory influx and provide a nucleus for plaque calcification is a 4 4. Furthermore, increased phosphatidyl serine content in the outer membrane of apoptotic cells and apoptotic bodies creates a pro-coagulant surface ala

As several recent papers review the role of apoptosis in atherosclerosis and plaque rupture, ${ }^{43} 4$ a 4 al we will mainly focus on regulators of cell cycle progression (table 3). Expression of $\mathrm{p} 53$ is increased by oxLDL ${ }^{45}$ and decreases after lipid lowering ${ }^{46}$.

Furthermore, p53 gene expression was increased in the fibrous cap compared to 
Table 3: Effect of cell turn-over on lesion fomation

\begin{tabular}{|c|c|c|c|}
\hline Gene & Model & Effers & Reference \\
\hline & & & \\
\hline 853 & 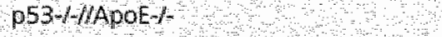 & Tatherosclerosis & 48 \\
\hline$p 53$ & APOE 3 Leiden/ p53/-bonemamow & 1 atherosdenosis & 49 \\
\hline P5O & T p 53 in collar hduced lesion/rApof $t$ & $\triangle$ flbrous badp, plaque nupture & 5 \\
\hline 85 & TpS3 vein graft numan $\mathrm{s}$ & I neolndima fomation & 50 \\
\hline$P 2$ & T p $1 /$ / ApoE $/$, restenosis & A neontime formation & 52 \\
\hline PKCO & $\mathrm{PKCO} /$ vein graft & 1 neointing foumation & 53 \\
\hline Ras & Inhibition In ApoE- - nice & 1 atherosiclerosis & 54 \\
\hline Gas6. & Gas6-//ApDE-/ & $\begin{array}{l}1 \text { plaque wulmerabillyy } \\
\text { Intraplaque heamonthage }\end{array}$ & 56 \\
\hline
\end{tabular}

the media ${ }^{47}$. In mice, p53 deficiency led to increased atherosclerosis or neointima formation ${ }^{48.4950}$. Very recently, an exciting effect of $p 53$ overexpression was observed in collar induced carotid plaques in ApoE- $/$ - mice ${ }^{51}$. In this model, p53 overexpression during preexisting atherosclerosis increased SMC apoptosis in the cap. Due to decreased cellular and extracellular matrix content, the fibrous cap thinned, resulting in spontaneous rupture of the fibrous cap or intraplaque hemorrhage in $40 \%$ of the plaques after hemodynamic challenge.

Other genes involved in proliferation and apoptosis also showed an effect on atherogenesis. Overexpression of $\mathrm{p} 21$, an inhibitor of cell cycle progression, led to decreased restenosis in ApoE-\% mice due to reduced SMC proliferation, reduced macrophage content and enhanced apoptosis ${ }^{52}$. Deficiency in protein kinase $c \delta$, an inhibitor of cell growth and a known promotor of apoptosis, resulted in an accelerated atherosclerosis in a vein graft model ${ }^{53}$. Inhibition of Ras, a protein involved in control of cell growth, differentiation, migration, adhesion and cell survival, reduced both initial and advanced plaques in ApoE- - mice ${ }^{54}$ and suppressed neointima formation in rats ${ }^{53}$.

Furthermore, our group recently showed that ApoE- $/$ mice deficient in Gas6, a regulator of proliferation, exhibited leakage of erythrocytes from plaque microvessels, resulting in platelet, iron and fibrin deposition which are features of intraplaque haemorrhage so.

Although inhibition of cell proliferation in general reduces plaque progression in mice, we have to bear in mind that atherosclerosis in mice is a relatively fast process, while human atherosclerosis develops over decades ${ }^{35}$. Therefore, the effects of cell cycle inhibition cannot be directly extrapolated onto human atherosclerosis. In restenosis, which is a rapid process, cell cycle inhibition might be beneficial. This is reflected by the inhibitory effect on restenosis in patients that received a stent coated with sirolimus, which is an inducer of cell cycle arrest ${ }^{57}$. Since apoptosis is increased in ruptured plaques and plaque rupture occurs after administration of p53 to pre-existing plaques, inhibition of apoptosis in rupture prone plaques might have a stabilizing effect. 


\section{$>$ Lipid metabolism}

A third mechanism proposed to be involved in plaque destabilization comprises processes involved in lipid uptake and efflux in the arterial wall. A large lipid core mechanically weakens the plaque, while ox-LDL is prothrombotic, promotes inflammation and extracellular matrix degradation ${ }^{\text {st }}$. The prominent role of systemic lipid metabolism is illustrated by the fact that genetic disruption of ApoE or LDL receptor (LDLR) or overexpression of a mutant ApoE increase plasima cholestrol levels which results in development of atherosclerotic lesions in mice. At older age some ApoE deficient mice strains show spontaneous rupture of atherosclerotic plaques in the brachiocephalic artery 5 . A schematical overview of the processes involved in lipid uptake, esterification, hydrolysis and reverse cholesterol transport by macrophages are depicted in figure 1.

The first step of intraplaque lipid metabolism is the uptake by scavenger receptors ${ }^{162} 6$. The atherogenic effects of the scavenger receptor was stressed by the marked decrease in plaque development in mice deficient in either scavenger receptor class $A$ (SR-A) ${ }^{54}$ or CD36 ${ }^{65}$. In contrast, SR-A deficiency in ApoE3Leiden mice increased atherosclerosis ${ }^{6 .}$. These data suggest that uptake of lipids is at least in part dependent on the genetic background of the animal tested.

Once inside the cell lipoprotein associated cholesterol esters are hydrolysed in the lysosomes and the resulting free cholesterol is esterified by acy/coenzymeA:cholesterall acyltransferase (ACAT). The importance of esterified cholesteroll accumulation in plaque progression is illustrated by the effect of genetic disruption of the ACAT-1 gene. Complete ACAT-1 inhibition in LDLR-/- and ApoE-/- mice resulted in a reduction of lipid and macrophage content, both features of a more stable plaque phenotype, while excessive cholesterol accumulation was observed in the skin ${ }^{678}$. The effect on plaque development was even more pronounced during partial inhibition of ACAT-1 and ACAT-2 In contrast, maciophage specific ACAT-1 deficiency led to increased free cholesterol levels and increased plaque size ${ }^{*}$. A similar effect was observed in mice overexpressing hormone sensitive lipase (HSL), an enzyme involved in neutral lipid hydrolysis, that developed more advanced plaques ". This implies that increased free cholesterol levels, without sufficient reverse cholesterol transport (discussed below) accelerates atherosclerosis.

Micro-array analysis on oxLDL loaded macrophages revealed a vast upregulation of adipocyte differentiation related protein (ADRP) mRNA, a protein involved in uptake of fatty acids and/or stabilization of the lipid droplet ${ }^{72}$. ADRP mRNA expression was observed in human atherosclerotic plaques *. Involvement of neutral lipid hydrolysis in plaque destabilization was illustrated by a recent differential gene expression study of our group ${ }^{23}$ in which perilipin mRNA was exclusively expressed in ruptured plaques. In adipocytes, perilipin plays a regulatory role in HSL. mediated lipolysis. After adipocyte differentiation perilipin replaces ADRP on the lipid droplet and forms a barrier to HSL mediated lipolysis. Upon lipolytic stimulation perilipin becomes hyperphosphorylated 


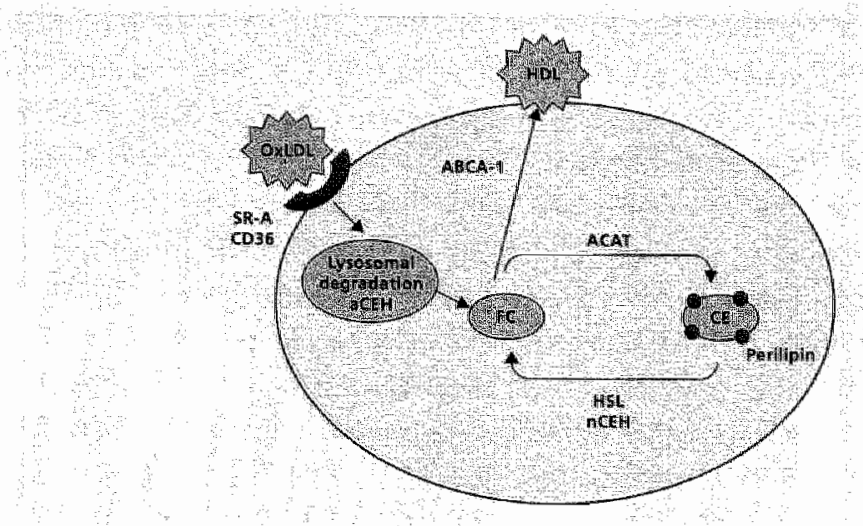

Figure : Schematical overwiew of lipid metabolism in foam cells.

Oxidized $1 D L$ (OxLOL) is taken up wia a scavenger receptor (among others SR-A or CO36). Once inside the cell haid-assochated cholesterol ester is hycholysed by a lysosomal acidic cholesterol aster hydrolase and free cholesterol (fo) is formed. Free chalesterol is modified to cholesterol esters (CE) by acyl coenzyneA chotesterot acylransferase (ACAT). Subsequently, cholesteryl esters can be hydrolysed by a meutral cholesterol ester byotrolase (nCEH) like hormone sensituve lipase an enzyne which function is regulated by peritipin. The Arp binding cassette A-1 transporter (ABCA-1) mediates free cholesterol efflux. Subsequently the free chatesterol 15 transfierred to HOL.

which results in an increased accessibility of the lipid droplet for HSL and subsequent increased lipid hydrolysis ${ }^{74}$. In macrophages however, the presence of an additional neutral cholesterol ester hydrolase (nCEH) is suggested since peritoneal macrophages of HSL deficient mice still show nCEH activity "s. As the molecular identity of this nCEH in macrophages is still unknown, involvement of perilipin in the regulation of this nCEH remains to be elucidated. In human atherosclerotic plaques, perilipin protein expression was observed in foam cells at the rim of the lipid core and shoulder areas of stable plaques. In ruptured plaques however, perilipin was found in macrophages at sites of actual cap rupture ${ }^{75}$. As the phosphorylation status of perilipin within plaque macrophages is unknown, its effect on lipolysis remains to be elucidated. One might speculate that in macrophages, perilipin interferes with the accessibility of the lipid droplet for a nCEH which might result in lipid retention and increased plaque vulnerability. However, perilipin might also acts as a feedback mechanism to prevent excessive formation of free cholesterol that is thought to be toxic to the cell, which may stabilize the plaque.

Tangiers disease, resulting from a ATP binding cassette A-1 (ABCA-1) transporter gene mutation, leads to accelerated atherosclerosis and stresses the importance of reverse cholesterol transport ". Promotion of ABCA-1 transporter by peroxisome proliferator activated receptors, increased cholesterol efflux from macrophages ${ }^{\text {}}$. Since HDL is involved in free cholesterol effiux from the plaque, low plasma concentrations 
of HDL and ApoA1, a component of the HDL complex, are associated with increased risk of myocardial infarction or premature atherosclerosis $\%$. Macrophage specific overexpression of ApOA-1 led to a $85 \%$ reduction of atherosclerosis in mice ${ }^{89}{ }^{83}$. Strikingly, one single dose of recombinant ApoA1 reduced lipid and macrophage content of plaques in ApoE- $/$ mice within $48 \mathrm{~h}$ ez. Disruption of both ApoE- $/$ - and the $H D L$ receptor scavenger receptor $B I$ (SR-BD) had a dramatic effect on plaque development ${ }^{33}$. Plaques were lipid rich, contained fibrin deposition, indicative for plaque haemorrhage, and completely occluded the vessel lumen. As a result these animals developed myocardial infarctions and cardiac dysfunction during hemodynamic stress. These data stress the importance of reverse cholesterol transport in plaque stability.

In conclusion, it is quite evident that recent insights into the regulation and the importance of lipid turn-over within the plaque may provide new targets for interventions, not only in plaque progression but also in the modification of the phenotype of the plaque from an unstable, rupture prone plaque into an advanced but stable plaque. One of these pathways involves turn-over of neutral fats in the plaque which appears to be tightly regulated by molecules such as perilipin, HSL and ADRP.

\section{$>$ Conclusions}

The large scale gene expression studies performed over the last few years rendered, besides known genes in known pathways, up to $40 \%$ of expressed sequence tag (EST) fragments. These genes encode proteins which function is still unknown. Unravelling the function of these genes has the enormous potential to identify new players in old pathways or even complete new pathways involved in plaque destabilization. A drawback of most animal studies is that they study the effect of intervention on plaque formation and progression. A possible effect on plaque destabilization might be overruled by proposed compensatory mechanisms, since mice are highly resistant to plaque rupture. Interference on preexisting atherosclerosis might circumvent these compensatory mechanisms, and thereby induce plaque rupture. The recently described animal models of plaque rupture provide a valuable tool in unravelling the mechanisms involved in plaque rupture, as they enable to validate the effects of compounds or specific interventions on plaque rupture. Remarkably, plaque rupture was more evident in those animal models in which disturbance of two genes was achieved. The pleiotropic effects of statins on plaque stabilization reflect the multifactorial nature of plaque rupture. Statins not only decrease plasma LDL and triglyceride levels, but also decrease, SMC migration and proliferation, platelet activity, MMP expression, inflammation and improve endothelial function ${ }^{84}$. The multifactorial character of plaque rupture suggests that interventions may be most effective when they influence more than one mechanisms at a time. 
1. Ross $\mathbb{R}$ : Atherosclerosis-an inflammatory disease. $N$ Engl $J$ Med 1999,340:115*26.

2. Robbie L, Libby P: Inflammation and atherothrombosis. Ann $\mathbb{N}$ Y Acad 5ci 2001,947; 167-79; discussion 179-80.

3. Virmani $R$, Kolodgie FD, Burke $A P$, Farb $A_{6}$ Schwartz SM: Lessons from sudden coronary death: a comprehensive morphological classification scheme for atherosclerotic lesions. Arterioscler Thromb Wasc Biol 2000,20:1262-75.

4. Libby P, Geng Y, Aikawa M. Schoenbeck U, Mach F, Clinton SK, Sukhova GK, Lee RT: Macrophages and atherosclerotic plaque stability. Curr Opin Lipidol 1996,7:330-5.

5. Galis ZS, Khatri IJ: Matrix metalloproteinases in vascular remodeling and atherogenesis: the good, the bad, and the ugly. Circ Res 2002,90:251-62.

6. Herman MP, Sukhowa GK, Libby P, Gerdes N, Tang N, Horton DB, Kilbride M. Breitbart RE, Chun $M$, Schombeck $U$ : Expression of neutrophil collagenase (matrix metalloproteinase-8) in human atheroma: a novel collagenolytic pathway suggested by transcriptional profiling. Circulation 2001, 104:1899-904.

7. Faia KL, Davis WP, Marone Al. Foxal! TL: Matrix metalloproteinases and tissue inhibitors of metalloproteinases in hamster aortic atherosclerosis: correlation with in-situ zymography. Atherosclerosis 2002,160:325-37.

8. Silence J, Lupu F, Collen D, Lijnen HR: Persistence of atherosclerotic plaque but reduced aneurysm formation in mice with stromelysin-1 (MMP-3) gene inactivation. Arterioscler Thromb Vasc Biol 2001,21:1.440-5.

9. Pyo R, Lee JK, Shipley JM, Curci JA, Mao D, Ziporin SJ, Ennis TL, Shapiro SD, Senior RM, Thompson RW: Targeted gene disruption of matrix metalloproteinase-9 (gelatinase B) suppresses development of experimental abdominal aortic aneurysms. I Clin Invest 2000,105:1641-9.

10. Prescott ME, Sawyer WK, Von Linden-Reed J Jeune M, Chou M, Caplan SL, Jeng Ar: Effect of matrix metalloproteinase inhibition on progression of atherosclerosis and aneurysm in $L D L$ receptor-deficient mice overexpressing MMP-3, MMP-12, and MMP-13 and on restenosis in rats after balloon injury. Ann $N$ Y Acad Sci 1999,878:179-90.

11. Allaire $\mathrm{E}$, Forough $\mathrm{R}$, Clowes $\mathrm{M}$, Starcher $\mathrm{B}$, Clowes $\mathrm{AW}$ : Local owerexpression of TIMP-1 prevents aortic aneurysm degeneration and rupture in a rat model. I Clin invest $1998,102: 1413-20$.

12. Curci JA, Liao S, Huffman MD, Shapiro SD, Thompson RW: Expression and localization of macrophage elastase (matrix metalloproteinase-12) in abdominal aortic aneurysms. I Clin Invest 1998,102:1900-10.

13. Annabi B, Shedid D. Ghosn P. Kenigsberg RL, Desrosiers RR, Bojanowski MW, Beaulieu $E_{\text {. }}$ Nassif $E$, Moumdjian $R$, Beliveau $R$ : Differential regulation of matrix metalloproteinase activities in abdominal aortic aneurysms. ل Vasc Surg 2002,35:539-46.

14. Armstrong PJ, Johanning JM, Calton WC, Jr, Delatore IR, Franklin DP, Han DC, Carey D. Elmore JR: Differential gene expression in human abdominal aorta: Aneurysmal versus occlusive disease. I Vasc Surg 2002,35:346-355. 
15. Yamashita A, Noma T, Nakazawa A, Saito S. Fujioka K, Zempo N, Esato K: Enhanced expression of matrix metalloproteinase-9 in abdominal aortic aneurysms. World I Surg 2001,25:259-65.

16. Zhang B, Ye 5 , Hermarn $S M$, Eriksson $P$, de Maat M. Evans A, Arveiler D. Luc G. Cambien F, Hamsten $A$, Watkins $H$, Heriney AM: Functional polymorphism in the regulatory region of gelatinase $B$ gene in relation to severity of coronary atheroscierosis. Circulation 1999,99:1788-94.

17. Tung WS, Lee JK. Thompson RW: Simultaneous analysis of 1176 gene products in normal human aorta and abdominal aortic aneurysms using a membrane-based complementary DNA expression array. J Vasc Surg 2001,34:143-50.

18. Carrell TW, Burnand KG, Wels GM, Clements IM. Smith A: Stromelysin-1 (matrix metalloproteinase-3) and tissue inhibitor of metalloproteinase-3 are overexpressed in the wall of abdominal aortic aneurysms. Circulation 2002, 105:477 82.

19. Tai JT, Brooks EE, Liang S, Somogyi $R$, Rosete JD. Lawn RM, Shiffman D: Determination of temporal expression patterns for multiple genes in the rat carotid artery injury model. Arterioscler Thromb Vasc Biol 2000,20:2184-91.

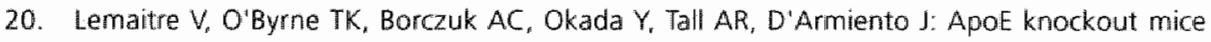
expressing human matrix metalloproteinase-1 in macrophages have less advanced atherosclerosis. J Clin Invest 2001,107:1227-34.

21. Ye S, Watts GF, Mandalia S, Humphries SE, Henney AM: Preliminary report: genetic variation in the human stromelysin promoter is associated with progression of coronary atherosclerosis. Bir Heart J 1995, 73:209-15.

22. Wang J, Warzectha D. Wilcken D, Wang XL: Polymorphism in the gelatinase $B$ gene and the severity of coronary arterial stenosis. Clin Sci (Lond) $2001,101: 87-92$.

23. Silence $)$, Collen D, Lijnen HR: Reduced atherosclerotic plaque but enhanced aneurysm formation in mice with inactivation of the tissue inhibitor of metalloproteinase-1 (TIMP-1) gene. Circ Res 2002,90;897-903.

24. Rouis $M$, Adamy $C$. Duverger $N$, Lesnik $P$, Horellou P, Moreau M, Emmanuel $F$, Caillaud $M_{\text {, }}$ Laplaud PM, Dachet C, Chapman MI: Adenovirus-mediated overexpression of tissue inhibitor of metalloproteinase 1 reduces atherosclerotic lesions in apolipoprotein E-deficient mice. Circulation 1999, 100:533-40.

25. Sukhova GK, Shi GP, Simon DI, Chapman HA, Libby P: Expression of the elastolytic cathepsins $S$ and $K$ in human atheroma and regulation of their production in smooth muscle cells. J Clin Invest $1998,102: 576-83$.

26. Chen J, Tung CH. Mahmood U, Ntziachristos $V$, Gyurko R, Fishman MC. Huang PL, Weissleder $R$ : In vivo imaging of proteolytic activity in atherosclerosis. Circulation 2002, 105:2766-71.

27. Tunon J, Ruiz-Ortega M. Egido J: Regulation of matrix proteins and impact on vascular structure. Curr Hypertens Rep 2000,2:106-13.

28. Faber BC, Cleutjens KB, Niessen RL. Aarts PL, Boon W, Greenberg AS, Kitslaar PJ, Tordoir JH, Daemen MJ: identification of genes potentially involved in rupture of human atherosclerotic plaques. Circ Res 2001,89:547-54. 
29. Peters $D G$, Kassam $A B$, Feingold $E$, Heidrich-O'Hare $E$, Yonas. $H$, Ferrell $R E$, Brulliky $A$ : Molecular anatomy of an intracranial aneurysm: coondinated expression of genes involved in wound healing and tissue remodeling. Stroke 2001,32:1036 42 .

30. Auld GC, Ritchie H, Robbie LA, Booth NA: Thrombin upregulates tissue transglutaminase in endothelial cells: a potential role for tissue transglutaminase in stability of atherosderotic plaque. Arterioscler Thromb Vasc Biol 2001,21:1689-94.

31. Sumi $Y$, Inoue $N$, Azumi $H_{\text {, Seno }} T_{\text {, Okuda }} M$, Hirata $K$, Kawashima $S_{\text {, Hayashi }} Y_{\text {, Itoh }} H_{2}$ Yokoyama $\mathrm{M}$ : Expression of tissue transglutaminase and elafin in human coronary artery: implication for plaque instability. Atherosclerosis 2002, 160:31:9.

32. Mallat Z, Gojova A, Marchiol-Fournigault C, Esposito B, Kamate C, Merval R, Fradellizi D, Tedgui $A_{\text {: }}$ Inhibition of transforming growth factor-beta signaling accelerates atherosclerosis and induces an unstable plaque phenotype in mice. Curc Res 2001,89:930-4.

33. Lutgens $E$, Gijbels $M$, Smook $M_{*}$. Heeringa $P$ "Gotwals $P$, Koteliansky $V_{*}$ Daemen Transforming growth factor-beta mediates balance between inflammation and fibrosis during plaque progression. Arterioscler Thromb Vasc Biol. 2002, 22:975-982.

34. Kockx MM, Herman AG: Apoptosis in atherosclerosis: beneficial or detrimental? Cardiovasc Res 2000,45:736-46.

35. Lutgens E, de Muinck ED, Kitslaar PJ, Tordoir JH, Wellens HJ, Daemen MJ: Biphasic pattern of cell turnover characterizes the progression from fatty streaks to ruptured human atheroscleratic plaques. Cardiovasc Res 1999,41:473-9.

36. Kolodgie FD, Narula J, Burke AP, Haider N, Farb A, Hui-Liang Y, Smialek J, Virmani R: Localization of apoptotic macrophages at the site of plaque rupture in sudden coronary death. Am J Pathol 2000, 157:1259-68.

37. Mallat Z, Benamer $H$, Hugel B, Benessiano J, 5 teg PG, Freyssinet IM, Tedgui A: Elevated levels of shed membrane microparticles with procoagulant potential in the peripheral circulating blood of patients with acute coronary syndromes. Circulation 2000,101:841-3.

38. Bennett MR, Macdonald $K_{x}$ Chan SW, Boyle J, Weissberg PL: Cooperative interactions between $R B$ and $p 53$ regulate cell proliferation, cell senescence, and apoptosis in human vascular smooth muscle celis from atherosclerotic plaques. Circ Res 1998,82:704-12.

39. Huber J, Vales A, Mitulovic G, Blumer M, Schmid R, Witztum IL, Binder BR, Leitinger $N$ : Oxidized membrane vesicles and blebs from apoptotic cells contain biologically active oxidized phospholipids that induce monocyte-endothelial interactions. Arterioscler Thromb Vasc Biol 2002,22:101-7.

40. Mallat 2 , Tedgui A: Current perspective on the role of apoptosis in atherothrombotic disease. Circ Res 2001,88:998-1003.

41. Kolodgie FD, Narula J, Haider N, Virmani R: Apoptosis in atherosclerosis. Does it contribute to plaque instability? Cardiol Clin 2001,19:127-39, ix.

42. Mallat Z. Hugel B, Ohan J, Leseche G, Freyssinet $\mathrm{M}_{x}$ Tedgui A: Shed membrane microparticles with procoagulant potential in human atherosclerotic plaques: a role for apoptosis in plaque thrombogenicity. Circulation $1999,99: 348 \cdot 53$ 
43. Martinet W. Kockx MM: Apoptosis in atherosclerosis: focus on oxidized lipids and inflammation. Curr Opin Lipidol $2001, \$ 2: 535-41$.

44. Rossig L, Dimmeler 5. Zeiher AM: Apoptosis in the wascular wall and atherosclerosis. Basic Res Cardiol 2001,96:11-22.

45. Lee T, Chau Li Fas/Fas ligand-mediated death pathway is inwolved in oxLDL-induced apoptosis in vascular smooth muscle cells. Am J Physiol Cell Physiol 2001,280:C709-18.

46. Martinet W, Knaapen MW, De Meyer GR, Herman AG, Kockx MM: Oxidative DNA damage and repair in experimental atherosclerosis are reversed by dietary lipid lowering. Circ Res 2001,88:733-9.

47. MCCaffrey TA, Fu C, Du B, Eksinar S, Kent KC, Bush H, Jr. Kreiger K, Rosengart T, Cybulsky MI. Silverman ES, Collins $\mathrm{T}$ : High-level expression of Egr.1 and Egr-1-inducible genes in mouse and human atherosclerosis. I Clin Invest 2000, 105:653-62.

48. Guevara NV, Kim HS, Antonova El, Chan L: The absence of p53 accelerates atherosclerosis by increasing cell proliferation in vivo. Nat Med 1999,5:335-9.

49. van Vlijmen BI, Gerritsen G. Franken AL, Boesten LS, Kockx MM, Gijbels M., Vierboom MP. van Eck $M$, van De Water B, van Berkel TJ. Havekes LM: Macrophage p53 deficiency leads to enhanced atherosclerosis in APOE*3-Leiden transgenic mice. Circ Res 2001,88:780-6.

50. George SJ, Angelini GD, Capogrossi MC, Baker AH: Wild-type p53 gene transfer inhibits neointima formation in human saphenous vein by modulation of smooth muscle cell migration and induction of apoptosis. Gene Ther 2001,8:668 76.

51. won der Thusen $\mathrm{HH}$, wan Vlijmen BJ, Hoeben RC, Kockx MM, Havekes LM, wan Berkel TJ, Biessen EA: Induction of atherosclerotic plaque rupture in apolipoprotein E-\% mice after adenovirus-mediated transfer of p53. Circulation 2002,105:2064-70.

52. Condorelli $G$, Aycock JK, Frati G, Napoli $C$ : Mutated p21/WAF/CIP transgene overexpression reduces smooth muscle cell proliferation, macrophage deposition, oxidation-sensitive mechanisms, and restenosis in hypercholesterolemic apolipoprotein E knockout mice. Faseb J 2001.15:2162*70.

53. Leitges M, Mayr M, Braun U, Mayr U, Li C, Pfister G, Ghatfari-Tabrizi N, Baier G, Hu Y, Xu Q: Exacerbated vein graft arteriosclerosis in protein kinase cdelta-mull mice. J Clin Invest 2001,108:1505-12.

54. George J, Afek $A$, Keren P, Herz ! Goldberg I, Haklai R, Kloog Y, Keren G: Functional inhibition of Ras by S-trans, trans-farnesyll thiosalicylic acid attemuates atherosclerosis in apolipoprotein Eknockout mice. Circulation 2002,105:2416-22.

55. Ueno $H$, Yamamoto $H$, Ito $S, L i J$ J, Takeshita A: Adenowirus-mediated transfer of a dominant-negative H-ras suppresses neaintimal formation in balloon-injured arteries in vivo. Arterioscler Thromb Vasc Biol 1997,17:898-904.

56. Lutgens E, Garcia de Frutos P. Apericio C, Moons L, Daemen M, Collen D. Carmeliet P: Gas6-/-/ApoE-/- Mice Develop a Collagen-Rich, Disarganized Plaque Phenotype, Prone to Intria-Plaque Hemorrhage, circulation 2000,102:1138 abstract 170. 
57. Sousa JE, Costa MA, Abizaid AC, Rensing BJ. Abizaid AS, Tanajura LF, Kozuma $K$, Van Langenhove G, Sousa AG, Falotico R, Jaeger J. Popma U., Serruys PW: Sustained suppression of neointimal proliferation by sirolimus-eluting stents: one-year angiographic and intravascular ultrasound follow-up. Circulation 2001,104:2007-11.

58. Lee RT: Plaque stabilization: the role of lipid lowering. Int J Cardiol 2000,74 Suppl 1:511.5.

59. Rosenfeld $M E$, Polinsky $P$, Virmani $\mathbb{R}$. Kauser $K$, Rubanyi $G_{n}$ Schwartz $5 M$ : Advanced atherosclerotic lesions in the innominate artery of the ApoE knockout mouse. Arterioscler Thromb Vasc Biol 2000,20:2587-92.

60. Johnson JL, Jackson CL: Atherosclerotic plaque rupture in the apolipoprotein $E$ knockout mouse. Atherosclerosis 2001,154:399-406.

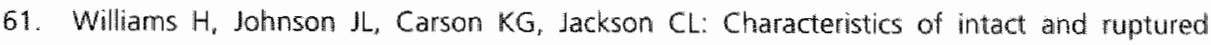
atherosclerotic plaques in brachiocephalic arteries of apolipoprotein $E$ knockout mice. Arterioscler Thromb Vasc Biol 2002, 22:788-92.

62. de Winther MP, Hofker MH: New mouse models from lipoprotein metabolism and atherosclerosis. Curr Opin Lipidol 2002,13:191-7.

63. Linton MF, Fazlo S: Class A scavenger receptors, macrophages, and atherosclerosis. Curr Opin Lipidol 2001, 12:489-95.

64. Sakaguchi H, Takeya M, Suzuki H, Hakamata H, Kodama T, Horiuchi S, Gordon S, van der Laan $U$, Kraall G, Ishibashi S, Kittamura N. Takahashi $K$ : Role of macrophage scavenger receptors in diet-induced atherosclerosis in mice. Lab Invest 1998,78:423-34.

65. Febbraio M, Podrez EA, Smith JD, Hajjar DP, Hazen SL, Hoff HF, Sharma K, Silverstein RL: Targeted disruption of the class B scavenger receptor CD36 protects against atherosclerotic lesion development in mice. J Clin Invest 2000,105:1049-56.

66. de Winther MP, Gijbels MI, van Dijk KW, van Gorp PJ, suzuki H, Kodama T, Frants RR, Havekes LM. Hotker $M H$ : Sicavenger receptor deficiency leads to more complex atherosclerotic lesions in APOE3Leiden transgenic mice. Atherosclerosis 1999, 144:315-21.

67. Accad M, Smith SJ, Newland DL, Sanan DA, King LE, Jr., Linton MF, Fazio S, Farese RV, Jr.: Massive xanthomatosis and altered composition of atherosclerotic lesions in thyperlipidemic mice lacking acyl CoA:cholesterol acyltransferase 1. J Clin linvest 2000, 105:711-9.

68. Yagyu H, Kitamine T, Osuga J, Tozawa R, Chen Z, Kaji Y, Oka T. Perrey S, Tamura Y, Ohash

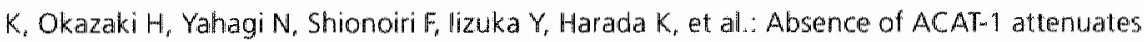
atherosclerosis but causes dry eye and cutaneous xanthomatosis in mice with congenital hyperlipidemia. J Biol Chem 2000,275:21324-30.

69. Kusunoki J, Hansoty DK, Aragane K, Falion JT, Badimon JJ. Fisher EA: Acyl-CoA:cholesterol acyltransferase inhibition reduces atherosclerosis in apolipoprotein E-deficient mice. Circulation 2001, 103:2604-9.

70. Fazio S, Major AS, Swift LL, Gleaves LA, Accad M, Linton MF, Farese RV, Ir.: Increased atherosclerosis in LDL receptor-mull mice lacking ACATI in macrophages. I Clin Invest 2001.107:163-71. 
71. Escary JL, Choy HA, Reve K, Wang XP, Castellani IW, Glass CK, Lusis AJ, Schotz MC: Paradoxical effect on atherosclerosis of hormone-sensitive lipase overexpression in macrophäges, J Lipid Res 1999,40:397-404.

72. Gao J, Serrero G: Adipose differentiation related protein (ADRP) expressed in transfected COS-7 cels selectively stimulates long chain fatty acid uptake. J Biol Chem 1999,274:16825-30.

73. Wang $X$, Reape TI, Li $X$, Rayner $K$, Webb $C L$, Burnand $K G_{*}$ Lysko $P G$ : Induced expression of adipophilin $M R N A$ in human macrophages stimulated with oxidized low-density lipoprotein and in atherosclerotic lesions. FEBS Lett 1999,462:145-50.

74. Souza SC, Muliro KV, Liscum L, Lien P, Yamamoto MT, Schaffer JE, Dallal GE, Wang X. Kraemer FB, Obin M, Greenberg AS: Modulation of hormone-sensitive lipase and protein kinase A-mediated lipolysis by perilipin A in an adenoviral reconstituted system. I Biol Chem $2002,277: 8267-72$.

75. Okazaki H, Osuga II, Tsukamoto K, Isoo N, Kitamine T, Tamura Y, Tomita S, Sekiya M, Yahagi $N$, lizuka $Y$, Ohashi $K$, Harada $K$, Gotoda T, Shimano $H$, Kimura 5, Nagai R, Yamada $N$, Ishibashi S: Elimination of cholesterol ester from macrophage foam cells by adenovirus-mediated gene transfer of hormone-sensitive lipase. I Biol Chem 2002.

76. Faber $B_{x}$ Cleutjens $K$, Boon W, Kitslaar P, Tordoir J Greenberg A, Deamen M: Ruptured plaque specific gene expression: A role for Perilipin ADRP and HSL mediated lipolysis? (Abstract). Circ. 2001, Vol 104:II-10.

77. Rust S, Rosier M, Funke H, Real J, Amoura Z, Piette JC, Deleuze JF, Brewer HB, Duverger N, Denefle $P$. Assmann G: Tangier disease is caused by mutations in the gene encoding ATP-binding cassette transporter 1. Nat Genet 1999,22:352-5.

78. Chinetti $G$, Lestavel 5, Bocher $V$, Remaley AT, Neve B, Torra IP, Teissier $E$, Minnich A, Jaye M, Duverger $\mathbb{N}$, Brewer HB. Fruchart JC, Clavey V, Staels B: PPAR-alpha and PPAR-gamma activators induce cholesterol remowal from human macrophage foam eells through stimulation of the ABCA1 pathway. Nat Med 2001,7:53-8.

79. won Eckardstein A, Nofer JR. Assmann G: High density lipoproteins and arteriosclerosis. Role of cholesterol efflux and reverse cholesterol transport. Arterioscler Thromb Vasc Biol 2001,21:13-27.

80. Ishiguro H. Yoshida H, Major AS. Zhu T. Babaev VR, Linton MF, Fazio S: Retrovirus-mediated expression of apolipoprotein A-t in the macrophage protects against atherosclerosis in vivo. J Biol Chem 2001,276:36742-8

81. Major AS, Dove DE, Ishiguro $H_{*}$ Su YR, Brown AM, Liu L, Carter KJ, Linton MF, Fazio 5: Increased Cholesterol Efflux in Apolipoprotein All (ApoAl)-Producing Macrophages as a Mechanism for Reduced Atherosclerosis in ApoAl((-/)) Mice. Arterioscler Thromb Vasc Biol 2001,21:1790-5

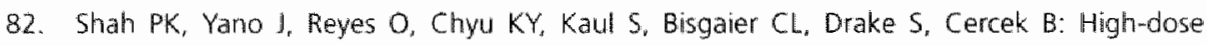
recombinant apolipoprotein A-l(milano) mobilizes tissue cholesterol and rapidly reduces plaque lipid and macrophage content in apolipoprotein e-deficient mice. Potential implications for acute plaque stabilization. Circulation 2001، 103:3047-50. 
83. Braun A, Trigatti BL, Post M.1, Sato K, Simons M, Edelberg JMi, Rosenberg RD, Schrenzel M, Krieger M: Loss of SR-BI expression lleads to the early onset of occlusive atherosclerotic coronary artery disease, spontaneous myocardial infarctions, severe cardiac dysfunction, and premature death in apolipoprotein E-deficient mice. Circ Res 2002,90:270-6.

84. Takemoto $M$, Liao JK: Pleiotropic effects of 3-hydroxy-3-methylglutaryl coenzyme a reductaise inhibitors. Arterioscler Thromb Vasc Biol 2001, 21:1712-9.

85. Zohlnhofer D. Klein CA, Richter T, Brandl R, Murr A, Nuhrenberg T, Schomig A, Baeuerle PA, Neumarn FJ: Gene expression profiling of human stent-induced neointima by CDNA array analysis of microscopic specimens retrieved by helix cutter atherectomy: Detection of FK506-binding protein 12 upregulation. Circulation 2001, 103:1396-402.

86. Adams LD, Geary RL, McManus B, Schwartz SM: A comparison of aorta and vena cava medial message expression by CDNA array analysis identifies a set of 68 consistently differentially expressed genes, all in aortic media. Circ Res 2000,87:623-31.

87. Wuttge DM, Sirsjo A, Eriksson P; Stemme 5: Gene expression in atherasclerotic lesion of ApoE deficient mice. Mol Med 2001,7:383-92.

88. Mason DP, Kenagy RD, Hasenstab D, Bowen-Pope DF, Seifert RA, Coats 5, Hawkins SM, Clowes AW: Matrix metalloproteinase-9 overexpression enhances wascular smooth muscle cell migration and alters remodeling in the injured rat carotid artery. Circ Res 1999,85:1179-85.

89. Bendeck MP, Conte M, Zhang $M$, Nili $N$, Strauss BH, Farwell SM: Doxycycline modulates smooth muscle cell growth, migration, and matrix remodeling after arterial injury. Am J Pathol 2002, 160:1089-95.

90. George SJ, Johnson $\mathrm{L}$, Angelini GD, Newby $\mathrm{AC}$, Baker $\mathrm{AH}$ : Adenovirus-mediated gene transfer of the human TIMP-1 gene inhibits smooth muscle cell migration and neointimal formation in human saphenous wein. Hum Gene Ther 1998,9:867-77.

91. George Si, Baker AH, Angelini GD. Newby AC: Gene transfer of tissue inhibitor of metalloproteinase-2 inhibits metalloproteinase activity and neointima formation in human saphenous veins. Gene Ther 1998,5:1552-60.

92. George SJ, Lloyd CT. Angelini GD. Newby AC. Baker AH: Inthibition of late wein graft neointima formation in human and porcine models by adenowirus-mediated overexpression of tissue inhibitor of metalloproteinase-3. Circulation 2000, 101:296-304.

93. Jormsjo S, Ye S, Moritz J, Walter DH, Dimmeler S, Zeiher AM, Henney A, Hamsten A, Eriksson P: Allele-specific regullation of matrix metalloproteinase-12 gene activity is associated with coronary artery luminal dimensions in diabetic patients with manifest coronary artery disease. Circ Res 2000;86:998-1003.

94. Sierevogel MJ, Velema $E$, de Jaegere PP, de Klein DP* Borst C, Pasterkamp G: Minimal duration of oral matrix metalloproteinase inhibition to prevent constrictive arterial remodeling after balloon dilation in the pig. Radiology 2002,222:468-73. 



\section{CHAPTER 3}

\section{IDENTIFICATION OF GENES POTENTIALLY INVOLVED IN RUPTURE OF HUMAN ATHEROSCLEROTIC PLAQUES}

Birgit CG Faber, Kitty BJM Cleutjens, Ron LJ Niessen; Petra LUW Aarts, Wendy Boon,

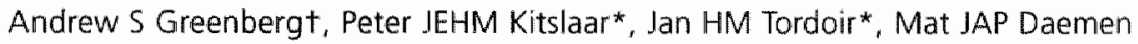

Departments of Pathology and General Surgery* "Cardiovascular Research Institute Maastricht (CARIM), University of Maastricht, The Netherlands. Jean Mayer USDA Human Nutrition Research Center on Aging at Tufts University, Boston, LSAT.

Circ. Res. 2001; $89: 547-554$ 


\section{$>$ Abstract}

Although rupture of an atherosclerotic plaque is the major cause of acute vascular occlusion, the exact molecular mechanisms underlying this process are still poorly understood. In this study we used suppression subtractive hybridization to make an inventory of genes that are differentially expressed in whole-mount human stable and ruptured plaques. Two libraries were generated, one containing 3000 clones upregulated and one containing 2000 clones downregulated in ruptured plaques. Macro-array analysis of 500, randomly chosen clones showed differential expression of 45 clones. Among the 25 clones that showed an at least 2 -fold difference in expression was the gene of perilipin, upregulated in ruptured plaques, and the genes coding for fibronectin and immunoglobulin $\lambda$ chain, which were downregulated in ruptured plaques. Reverse transcriptase-PCR analysis on 10 individual ruptured and 10 individual stable plaques showed a striking consistency of expression for the clones SSH6, present in 8 ruptured and 2 stable plaques, and perilipin, expressed in 8 ruptured and completely absent in stable plaques. Localization studies of both perilipin mRNA and protein revealed expression in cells surrounding the cholesterol clefts and in foam cells of ruptured atherosclerotic plaques. No expression was observed in non diseased artery and only a few cells in the shoulder region of stable plaques tested positive for perilipin. in conclusion, this study shows that it is possible to identify genes that are differentially expressed in whole mount stable or ruptured atherosclerotic plaques. This approach may yield several potential regulators of plaque destabilization. 


\section{Introduction}

Rupture of atherosclerotic plaques is the predominant underlying process in the pathogenesis of acute coronary syndromes and peripheral vascular disease ${ }^{i-2}$. Although the morphology of ruptured plaques is well described 4 , specific markers to identify ruptured plaques or plaques prone to rupture in vivo are not available ${ }^{15}$. One possible explanation for the lack of plaque-type-specific markers is the fact that the exact molecular mechanisms underlying the process of plaque rupture are still largely unknown. In an attempt to shed more light on the possible molecular mechanisms involved in the onset and progression of atherosclerosis, several studies compared gene expression of activated human umbilical vein endothelial cells, vascular smooth muscle cells and cholesterol loaded macrophages with that of non-activated cells ${ }^{*-9}$. These studies in cell lines revealed differential regulation of genes involved in leukocyte trafficking, cell cycle control, and apoptosis. However, expression of these genes in vivo however, remains to be determined. Other groups focused on differences in gene expression between fatty streaks and advanced lesions ${ }^{10}$ and intima and media of human atherosclerotic plaques ". Adams et al. "revealed different gene expression patterns between veins and arteries in macaques. However in the present study we focused on differential gene expression of morphologic advanced, but stable human atherosclerotic lesions and ruptured human atherosclerotic lesions. Suppression subtractive hybridization $(\mathrm{SSH})^{13}$ on whole mount specimens was used to make an inventory of genes differentially expressed in both lesion types. The advantage of SSH is the isolation of low abundant sequences that might not be isolated using the micro-array technology. We identified several genes that were differentially expressed in a larger panel of individual ruptured and stable human atherosclerotic plaques. Our results show that it is possible to identify genes that are specifically and reproducibly associated with specific stages of atherosclerosis using whole mount human atherosclerotic specimens.

\section{Materials and Methods}

\section{Experimental Procedures}

SSH was performed on RNA pools of three ruptured and three stable human atherosclerotic plaques. Two libraries were constructed, one containing clones upregulated in ruptured plaques and the other containing clones downregulated in ruptured plaques. Differential expression was confirmed by macro-array analysis. Clones showing an at least 2 -fold difference in expression were sequenced. To validate the reproducibility of expression of these clones, reverse transcriptase (RT) PCR analysis was performed on a larger series of ruptured $(n=10)$ and stable $(n=10)$ plaques. Cellular distribution of the two clones with the most reproducible expression pattern was assessed by RNA in situ hybridisation, whereas expression and localization of the 


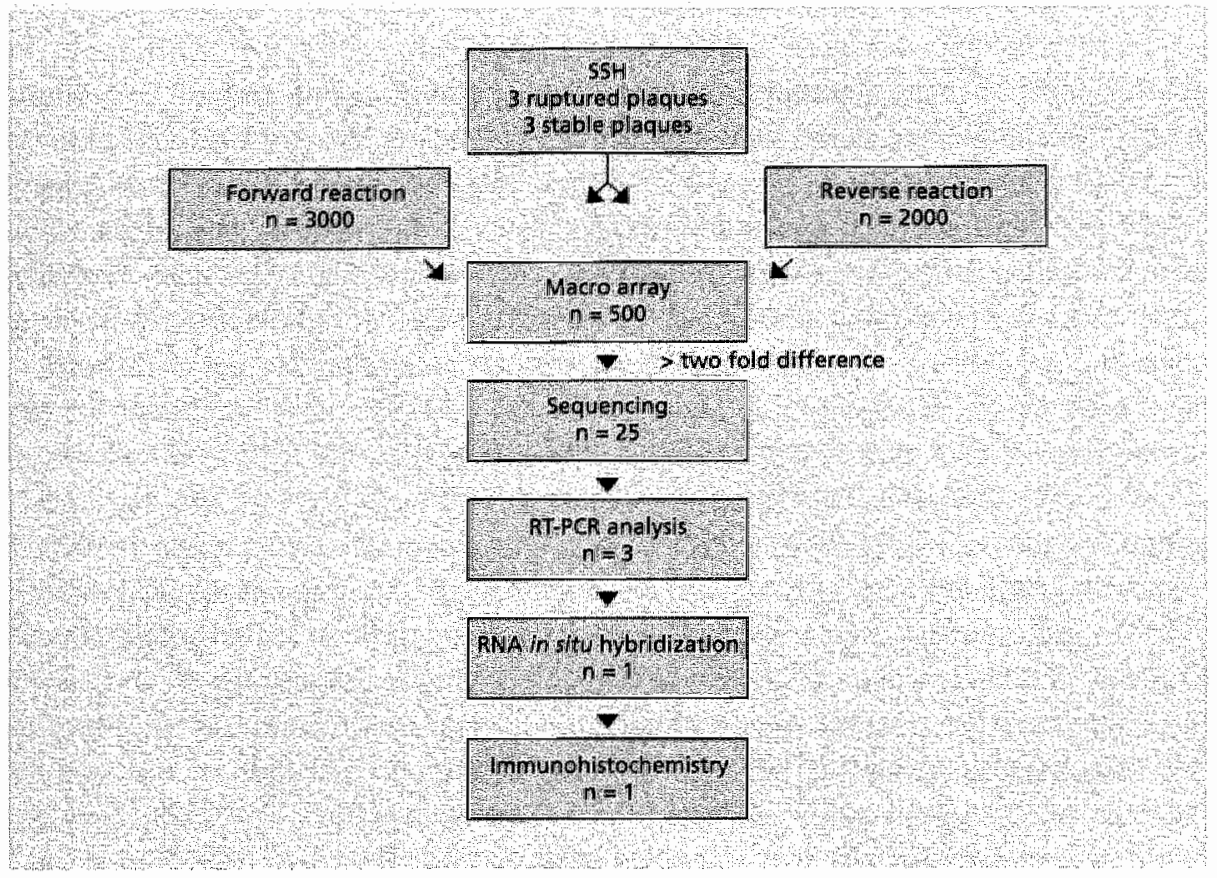

Figure 1. Flow chart of the reduction of the number of candidate genes by the various screening steps.

protein of one of the two clones was determined by immunohistochemistry. Figure 1 schematically depicts the experimental design and the reduction of the number of candidate genes by the various screening steps.

\section{Tissue Sampling and RNA Isolation}

Plaques were obtained from patients undergoing vascular surgery (Department of General Surgery, Academic Hospital Maastricht). Patient characteristics are summarized in table 1. Immediately after resection, the atheroscleratic specimen was divided into parallel parts of $5 \mathrm{~mm}$ for RNA isolation and histological analysis. Tissue destined for RNA isolation was immediately frozen in liquid nitrogen and stored at $-80^{\circ} \mathrm{C}$. Total RNA was isolated using the guanidine isothiocyanate / CsCl method 14 . Specimens for histological analysis were fixed in $10 \%$ phosphate buffered formalin ( $\mathrm{pH} 7.4$ ), routinely processed and embedded in paraffin. Sections were cut, stained with hematoxylin and eosin and classified according to the morphological criteria of the American Heart Association 4 . Stable lesions (type $\mathrm{V}$ and $\mathrm{V}$ ) are characterized by an intact fibrous cap that contains smooth muscle cells, fibroblasts and connective tissue. These plaques contain either a large lipid core (type Va), calcification (type Vb) or fibrous tissue (type Vc). A disrupted fibrous cap and presence of a thrombus characterize the ruptured lesion (type VI). 


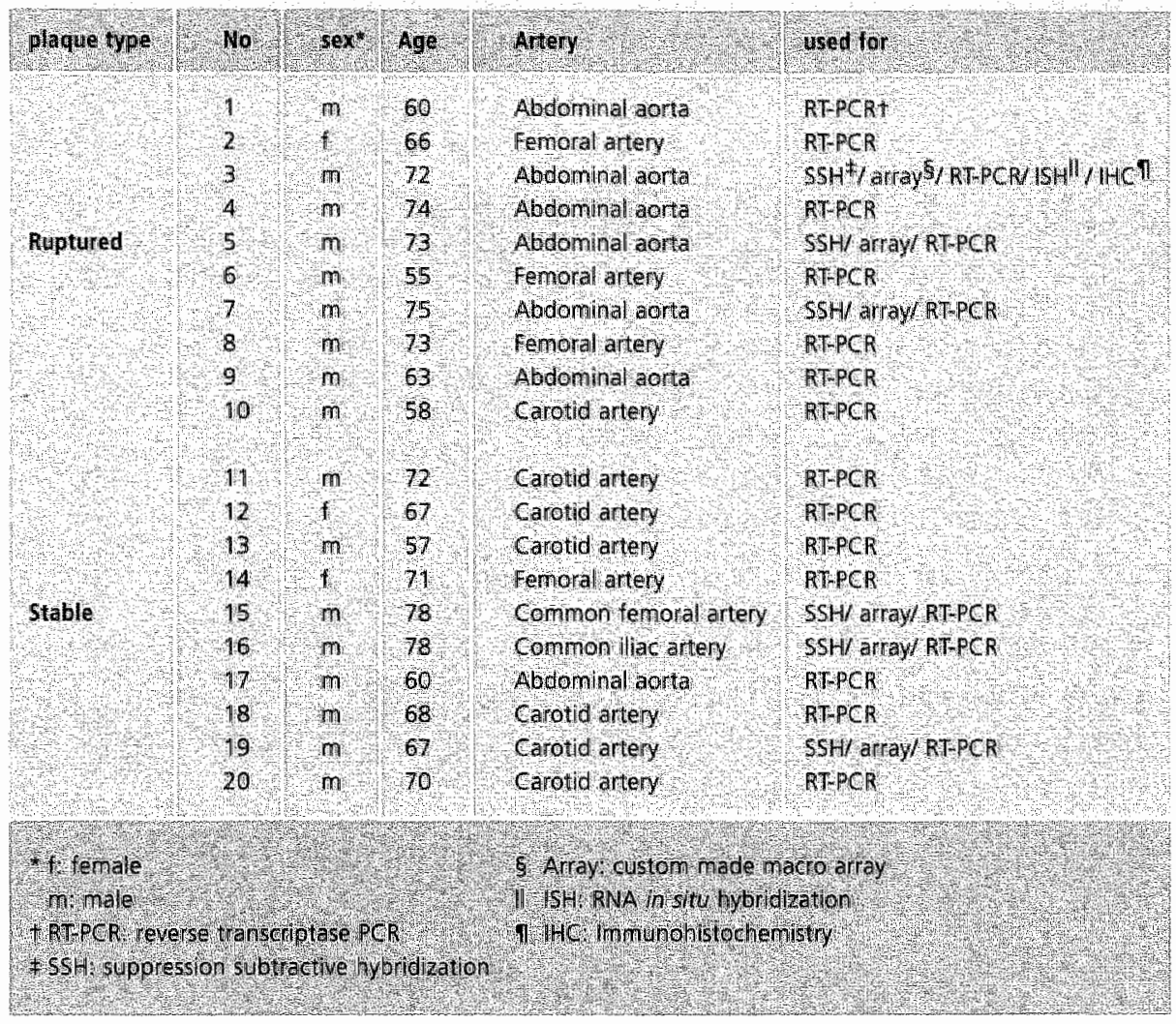

\section{Suppression Subtractive Hybridization}

The SSH procedure was performed using the PCR-Select CDNA Subtraction Kit (Clontech) essentially according to the protocol of the manufacturer, with minor adjustments. Briefly, total RNA was isolated from whole mount plaques of 6 , age matched, male patients undergoing vascullar surgery (table 1). To correct for patient based differences in gene expression, we generated two pools of total RNA. Pool one contained $1 \mu \mathrm{g}$ of total RNA derived from three ruptured plaques of the abdominal artery of three individual patients. Pool two contained $1 \mu \mathrm{g}$ of total RNA derived from three stable plaques of respectively the iliac artery, femoral artery and carotid artery of three individual patients. The SMART ${ }^{\text {TM }}$ PCR CDNA Synthesis Kit (Clontech) was used for the preparation and amplification of double stranded CDNA. In the forward reaction, genes upregulated in ruptured plaques were isolated, while the reverse reaction resulted in the isolation of genes downregulated in ruptured plaques. Rsal digested tester CDNA was ligated to two different adaptors and hybridized twice to a 4 -fold excess of driver CDNA to enrich for differentially expressed genes. Differentially expressed 
genes were amplified by two rounds of PCR. The resulting fragments were gel purified, cloned into the pGEMT-easy vector (Promega) and subsequently transformed to highly competent E.coli M109 cells (Promega).

\section{$>$ Analysis of Subtracted CDNA Libraries}

\section{Macro-array analysis}

Clones derived by $5 \mathrm{SH}$ were tested by macro-array analysis. Inserts were amplified by PCR using the T7 (5' TAATACGACTCACTATAGGG 3') and SPG (5' ATTTAGGTGACA CTATA $3^{\prime}$ ) primers under standard conditions. Briefly, $10 \mu$ of PCR product was diluted in $190 \mu \mathrm{l} 6 \times 5 S C$, heated to $95^{\circ} \mathrm{C}$ and quenched on ice. Two identical macro-arrays were made by transferring $100 \mu \mathrm{l}$ of the sample to a nylon membrane (Nytran; Schleicher \& Schuell) using a 96-wells BioRad Dot Blot apparatus and the DNA was subsequently crosslinked by UV irradiation. The filters were hybridized at high stringency with ${ }^{32}$ P-labeled (High Prime, Boehringer Mannheim) SMART'M CDNA of either stable or ruptured plaques using standard procedures. Hybridization signals were normalized using RNA-polymerase II and genomic DNA signals. Quantitative analysis was performed by phosphor image analysis (Quantity One, BioRad).

\section{Sequencing}

Differentially expressed clones were sequenced using the Thermo Sequenase fluorescent labelled primer (M13 reverse 5' IIICACACAGGAAACAGGAAACAGCTATGAC 3" M13 forward $5^{\prime}$ CGCCAGGGITTTCCCAGTCACGAC 3') eycle sequencing kit (Amersham Pharmacia Biotech) and analyzed on an ALF-express automatic sequencer. Homology searches were performed using the advanced Blast Program on the combined GenBank/EMBL nonredundant ( $\mathrm{nr}$ ), Expressed Sequence Tag (dEST), mouse EST, human EST, rat EST, Swissprotein and human tagged genomic sequence (htgs) databases (National Centre for Biotechnology Information: www.ncbi.nlm.nih.gow/).

\section{RT-PCR}

Isolation of total RNA was carried out as described above. The SMART PIA PCR CDNA Synthesis Kit (Clontech) was used for the preparation of double stranded CDNA from $0.5 \mu \mathrm{g}$ template RNA. CDNA was diluted to a total volume of $50 \mu \mathrm{l}$. PCR amplification of 5 SHG (reverse: $5^{\prime}$-GGCTAATTCGGGA GATAGCC-3' + forward: $5^{\prime}$-CAACACCTCATGGCAAG TCC-3') perilipin (SSH1/SSH11) (forward: 5'-CTTTAACCAAACTTGTGGCC-3' + antisense: 5'-TACTCAGAAAGTGACACTAG-3'), SSH42 (reverse: 5'-TTAGGGCTACACATGTT GCC-3' + forward: 5'-AAAGTGGCACTGTTGTGAC- 3') and GAPDH (reverse: 5'-GGGAAGCTTGTCATCAATGG-3'+ forward:5' CATGGTTCACACCCATGACG-3') was performed on $1 \mu$ of first strand CDNA using standard conditions ( 30 cycles of 
denaturation for 1 min at $94^{\circ} \mathrm{C}$, annealing for $1 \mathrm{~min}$ at $55^{\circ} \mathrm{C}$ and extension for $1 \mathrm{~min}$ at $72^{\circ} \mathrm{C}$, reaction volume $25 \mu \mathrm{l}$ ). Resulting PCR products of approximately $\sim 300 \mathrm{bp}$ were analyzed on a $1 \%$ agarose gel.

\section{RNA In Situ Hybridization}

Sense and antisense digoxygenin (DIG) labelled RNA probes of perilipin (S5H1) and SSH6 were generated on the ECORI-ECoRI CDNA fragments which were first re-cloned in pTZ18 (Pharmacia, Uppsala, Sweden) in both orientations. After linearization with BamH1, DIG labeled RNA was transcribed from the $T 7$ promoter. Hybridization of $4-\mu \mathrm{m}$ paraffin embedded sections, and visualization with alkaline phosphatase coupled anti-DIG antibodies and indoxil-nitroblue tetrazolium (NBT/BCIP) substrate was done essentially as described previously ${ }^{15}$. Sections were counterstained with nuclear red.

\section{IImmunohistochemistry}

Rabbit polyclonal antibody, raised against human perilipin, was a kind gift of Dr. A.5. Greenberg (Jean Mayer Human Nutrition Research Center at the Tufts University, Boston). Paraffin sections ( $4 \mu \mathrm{m}$ ) were deparaffinized, hydrated and pre-treated by boiling in $0.01 \mathrm{M}$ citrate buffer ( $\mathrm{pH} 6.0$ ) for $10 \mathrm{~min}$ in a microwave oven (750 Watt). Sections were incubated with the polyclonal perilipin antibody (1:1000) for $30 \mathrm{~min}$. Subsequently, the sections were incubated with a biotinylated swine anti-rabbit antibody (1:1000, Dako) for 30 min followed by a 30 min incubation with an alkaline phosphatase coupled $A B C$ reagent $(1: 200$, Dako). Alkaline phosphatase activity was visualized using the Alkaline Phosphatase Kit I (Vector), resulting in a red precipitate. The sections were counterstained with hematoxylin. Combined immunohistochemical staining was performed to identify the cell types expressing perilipin. Perilipin was first localized using the above described protocol, with minor adjustments. The $A B C$ reagent was coupled to horseradish peroxidase (1.500, DAKO) and the peroxidase activity was visualized using diamine benzidine, resulting in a brown precipitate. Subsequently, the sections were treated with $0.1 \%$ pepsin (Boehringer) in $0.1 \mathrm{~N} \mathrm{HCl}$ for 30 min and incubated with either monoclonal anti-CD68 (1:100, DAKO) or polyclonal anti-Factor VIII (1:2000, Biomakor) for $30 \mathrm{~min}$. The sections were incubated with respectively a biotinylated swine anti mouse antibody (1:250, Amersham Life Science) or biotinylated swine anti rabbit antibody (1:1000, Dako) for $30 \mathrm{~min}$ followed by a 30 min incubation with an alkaline phosphatase coupled $A B C$ reagent (1:200. Dako). Alkaline phosphatase activity was visualized using the Alkaline Phosphatase Kit Ill (Vector), resulting in a blue precipitate. 


\section{$>$ Results}

\section{Macro-array and Sequencing Analysis}

SSH resulted in a forward library, containing 3000 clones upregulated in ruptured atherosclerotic plaques and the reverse library containing 2000 clones downregulated in ruptured plaques. Differential expression of the clones of both SSH libraries was verified by a second independent method, the macro-array analysis. Ten percent of the clones of both libraries, 300 of the forward subtracted library and 200 of the reverse library, were randomly chosen and screened for expression in ruptured and stable plaques. The macra-arrays were performed in triplicate and the variation was approximately $\sim 10 \%$. Figure 2 shows a representative macro array of clones selected by $S S H$, hybridized to the pool of stable plaque CDNA (fig. 2a), and to the pool of ruptured plaque CDNA (fig. 26 ). Hybridization signals were normalized for the signals of RNA-polymerase II and human genomic DNA. Forty-five of the 500 clones tested, showed a differential expression pattern by macro-array analysis. Three clones were uniquely expressed in ruptured plaques and four clones were uniquely expressed in stable plaques. In addition, 18 of the 45 clones showed an at least 2-fold difference in expression between ruptured and stable plaques. These 25 clones were sequenced and compared to available data in the Genbank. All 11 clones upregulated in ruptured plaques had different sequences, two of these clones were homologous to distinct parts of the gene encoding perilipin (SSH1 and SSH11). Furthermore, one clone was homologous to a SRProtein. Additional searches in the EST (human, mouse and rat) and htgs databases revealed homology to human ESTs for four clones and two clones showed homology to distinct parts of the human chromosome 5. One clone (SSH6) shared high homology to a sequence encoding a putative protein; however, no information regarding its expression is available. Finally, one clone contained a previously

A 123 H 5,789101112

123456789101112
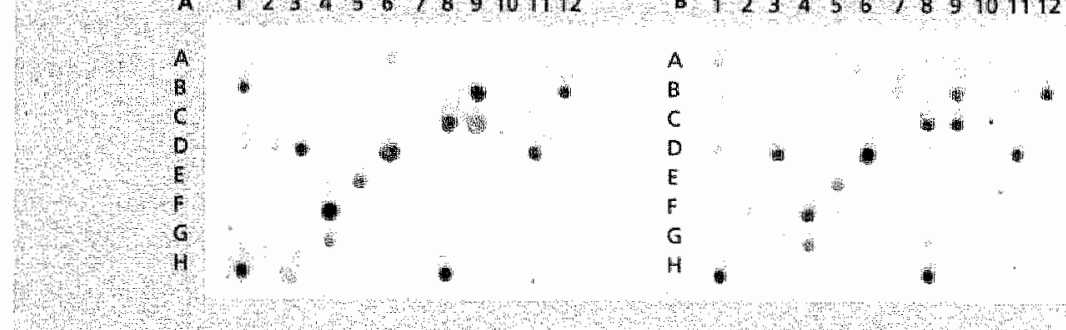

Figure 2. Macro-array analysis of CDNA clones generated by $55 \mathrm{H}$. Two identical macro-arrays were made by transfer of PCR products to nylon membranes. The Dot Blots were hybridized to (a) a iz-labeled CDNA pool of three different stable plaques and (b) a sp-labeled cDNA pool of three different ruptured plaques as described in Materials and Methods. Position Al represents a clone upregulated in ruptured plaques and position $B 1$ represents a clone downegulated in ruptured plaques. Position BVZ contains RNA polymerase $\|_{1}$ and positions D6 and H4 contain genomic DNA and empty vector, respectively. 
Table 2. Summary of characteristics of genes upregulated in ruptured plaques

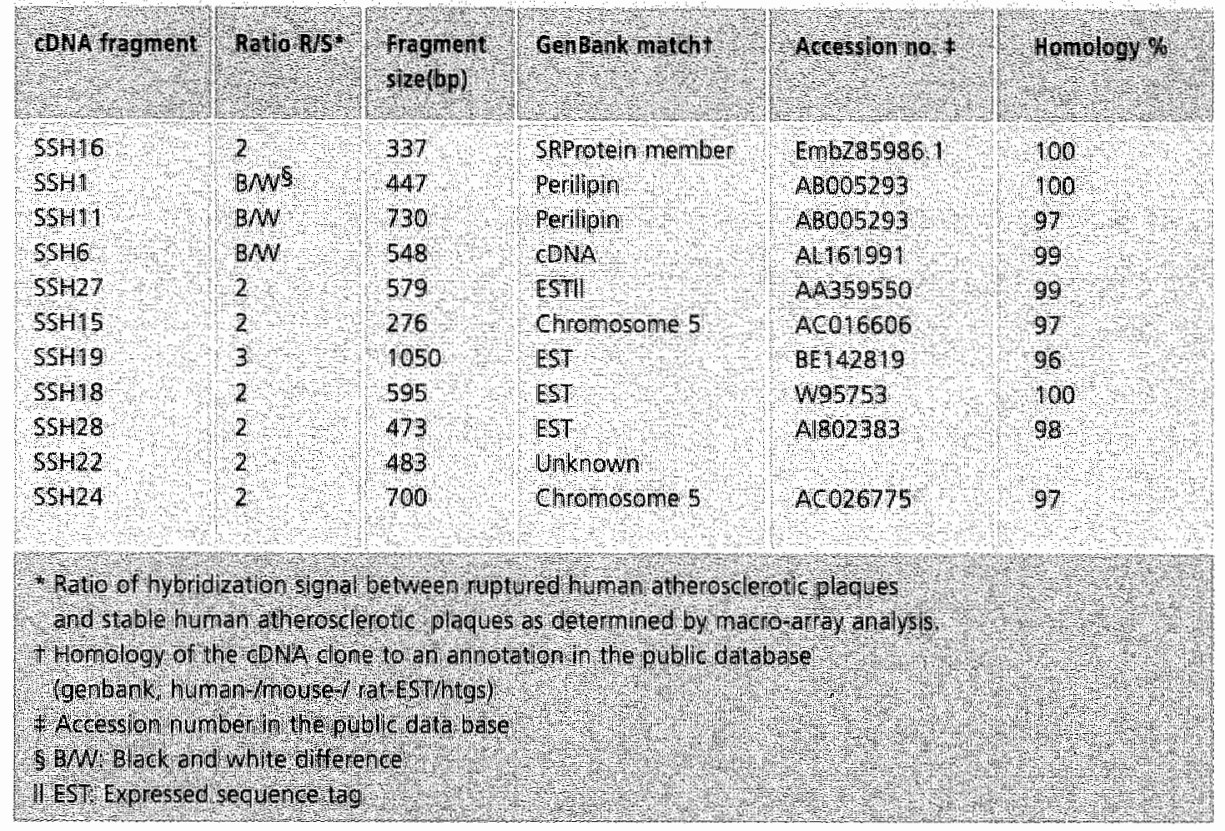

unknown sequence. Homology data of the clones upregulated in ruptured plaques are shown in table 2 .

Alignment of the 14 clones downregulated in ruptured plaques revealed high homology of three clones to the known genes of $\beta$-actin, fibronectin and an immunoglobulin $\lambda$ light chain. Additional searches in the EST (human, mouse and rat) and htgs database showed homology to human ESTS for 8 clones and 2 clones were homologous to parts of chromosome 5 and 17 . Finally, one clone was homologous to a human genomic clone of a thus far unknown chromosomal localization. The results of the homology searches are shown in table 3 .

\section{RT-PCR Anallysis}

To further validate the expression profile found in the macro-array, RT-PCR analysis on 10 ruptured and 10 stable plaques was performed. Since we were mostly interested in genes that were upregulated in ruptured plaques we focused our further analysis on those genes that showed unique expression in ruptured plaques (SSH1/11 and SSH6) and on one ( $55 \mathrm{H} 42)$ out of four clones that were uniquely expressed in stable plaques. To exclude patient- and artery-biased expression, plaques originated from different arteries of different patients (table 1). Expression was normalized to the expression level of GAPDH, which expression level was comparable between the samples (fig. 3). 
Table 3. Summiany af characteristic of genes downregulated in ruptured phaues

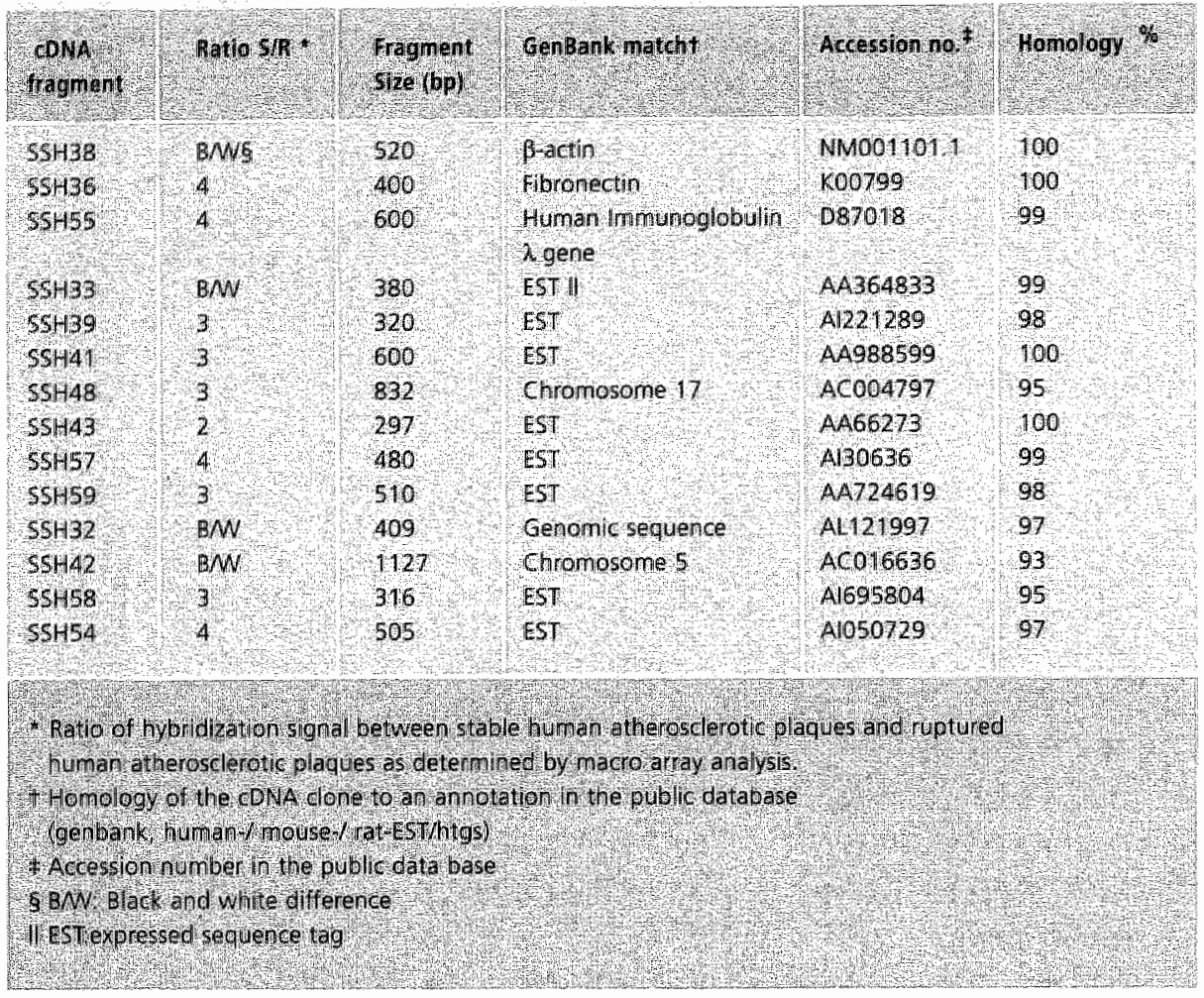

Expression of clone 5546 was found in 8 out of 10 ruptured plaques, while only 2 out of 10 stable piaques tested positive. Perilipin (clones SSH1 and SSH11) was expressed in 8 out of 10 ruptured plaques, whereas expression was completely absent in all 10 stable plaques tested (fig. 3). Although macro-array analysis showed absence of clone SSH42 in puptured plaques, RT-PCR analysis showed no qualitative difference in expression between stable and ruptured plaques (fig. 3)

\section{RNA In Situ Hybridization}

Since perilipin (SSH1 and SSH11) showed a unique expression pattern in ruptured plaques, RNA in situ hybridization was performed to localize expression of the perilipin gene within different lesion types. Specific expression of perilipin within ruptured plaques $(n=2)$ was observed in the cytoplasm of several cells surrounding the cholesterol clefts (indicated with an arrow) and in cells (indicated with an arrowhead) most likely resembling foam cells (fig. $4 a$, b). Furthermore, positive staining was observed in endothelial cells of newly formed vessels (data not shown). However, no detectable signal was observed in non diseased arteries $(n=2)$ and stable plaques $(n=2)$ (fig. $4 e, f)$. 


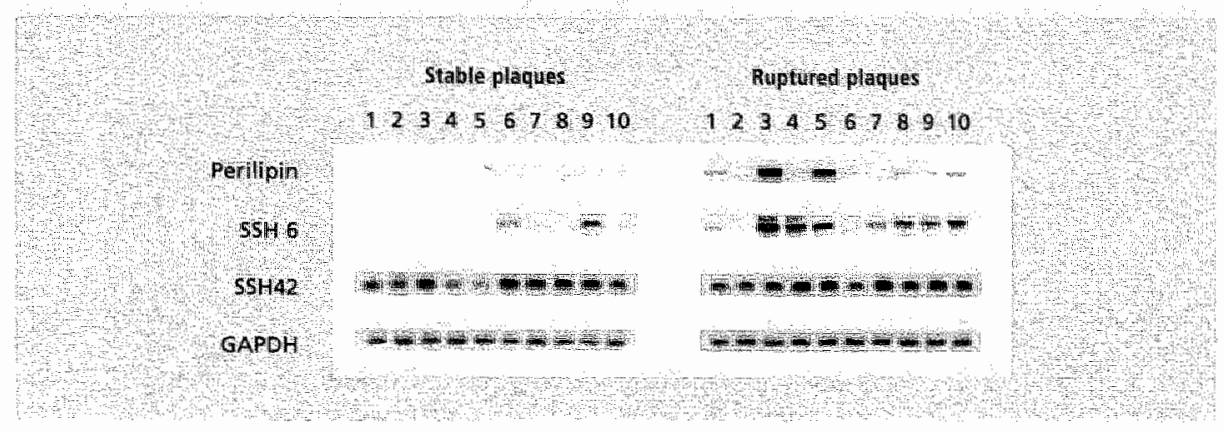

Figure 3. RT-PCR analysis of three genes differentialy axpressed in ruptured or stable humar atherostherotic plaques. The figure shows the expression pattern of perilpin (5SH1/11). 5416 and 55442 in 10 different stable piaques (left parvel) and 10 different ruptured plaques right pand. Expression of the housekeeping gene GAPDH is shown in the lower panel.

The sense perilipin riboprobe did not show any hybridization signal (fig. 4C). Unfortunately, thus far we were not able to obtain a specific $15 \mathrm{H}$ signal for clone 5 SH6.

\section{Immunohistochemistry}

To further substantiate the perilipin mRNA expression data, immunohistochemistry was performed. Perilipin immunoreactivity in ruptured human atherosclerotic plaques $(n=6)$ was observed in several cells. surrounding cholesterol clefts (indicated with an arrow), foam cells (indicated with an arrowhead, fig. 5a) and endothelial cells of newly formed small vessels (indicated with an arrow, fig. $5 b$ ). Combined staining for perilipin and antibodies directed towards CD68 or factor VIII confirmed that perilipin was expressed in foam cells (fig. 50) and endothelial cells (fig. $5 d$ ) of ruptured plaques. No staining was observed in non diseased arteries $(n=3)$ (fig. 5 e) whereas only few cells in the shoulder region of stable plaques (indicated with an arrow) $(n=6)$ tested positive for perilipin (fig 5f). 


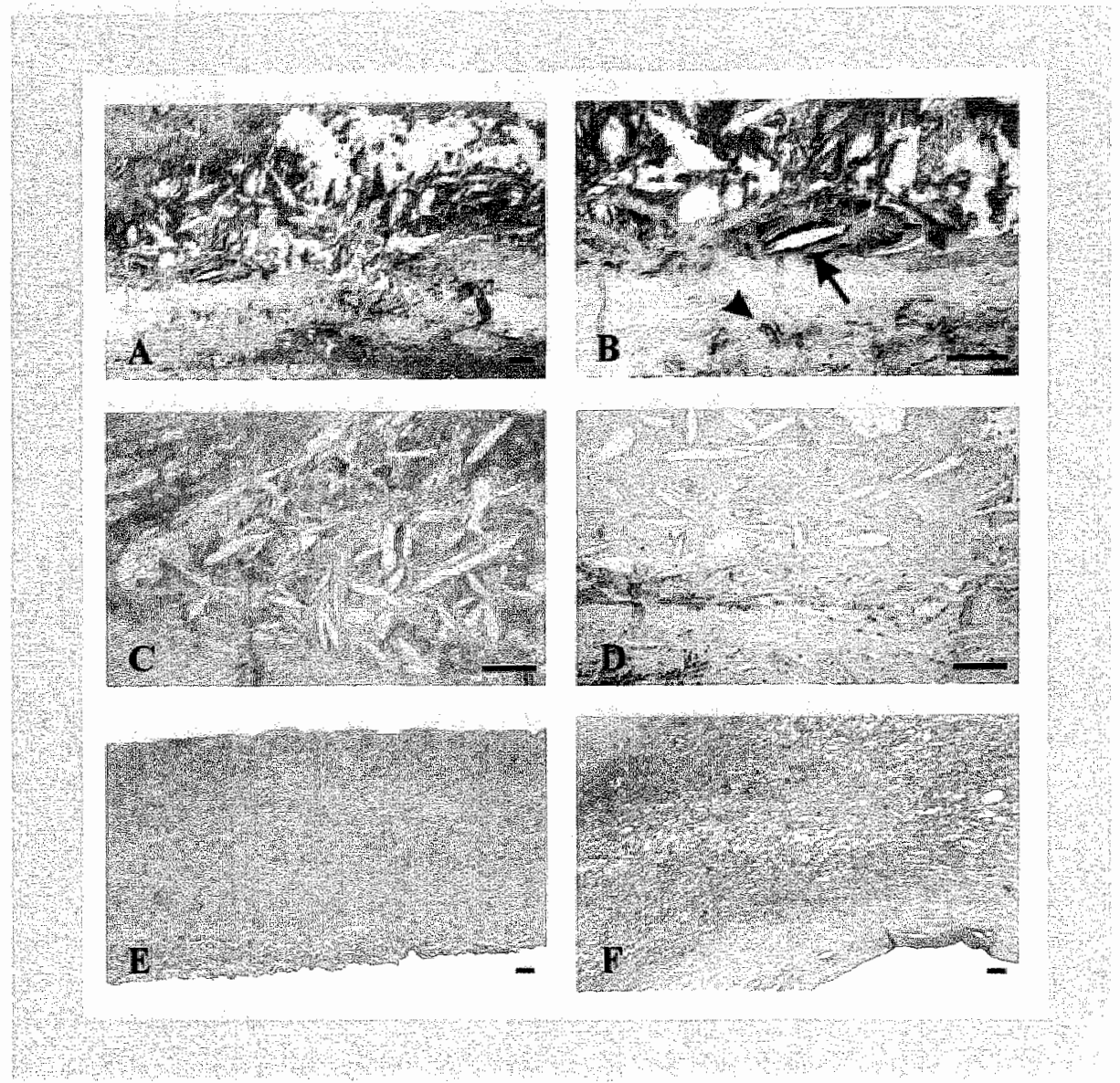

Figure 4. Localization of perifipin mRNA expression within the different plaque types by RNA in situ hybridisation. (a) Representative ruptured plaque hybridized with an anti-sense DIG-labelled perilipin RNA probe. (b): Section of the same ruptured plaque at a higher magnification. (c): Serial section of the ruptured plaque hybridized with the sense RNA probe. (d): Hematoxylin and eosin staining of a serial section. (e): Representative non diseased artery (f) and a representative stable plaque hybridized with an anti-sense DG -labelled RNA prabe. Dark purple staining indicates expression of perition mRNA. Bar = 100um. 

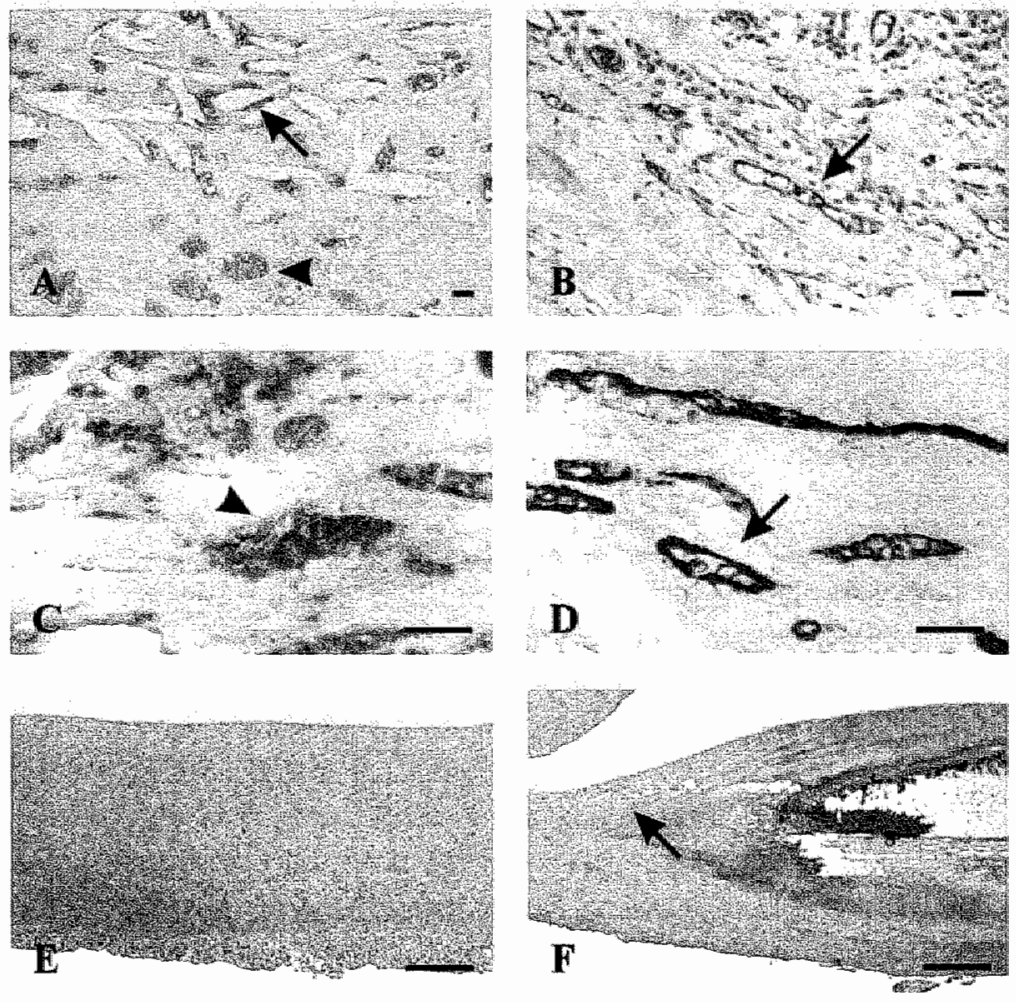

Figure 5. Localization of perilipin protein expression in different buman atheroscierotic plaque typers. Perilipin immunoreactivity tred staining) in ruptured plaques was observed in (a) cells surrounding some cholesterol defts (arrow) and foam cells (arrowhead), (b) endothelial cells in newly formed wessels (arrow) Combinad immunohistochemical staining in ruptured plaques for perilipin (in brown) and both in biwel c068 (nacrophage specific) (c) and factor Will lendothelium specific) (d) indicating that perifipm is expressed in foam calls farrowhead, of and endothelial cells (arrow, d). Perilipin was not expressed in non diseased arteries fel white few

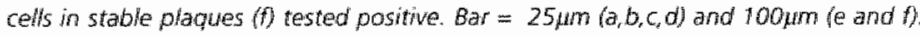


In the present study we show that it is possible to identify genes that are differentially and reproducibly expressed in whole mount human atherosclerotic plaques using the SSH procedure. In the present study, we discribe the identification of several genes differentially expressed between stable and ruptured atherosclerotic plaques. Our stable plaques are classified according to the morphological criteria of the AHA and are characterized by a thick fibrous cap, high smooth muscle cell/collagen content, and a small lipid core. Furthermore, these stable lesions also comprise rupture-prone lesions, with a thin fibrous cap and a large lipid core, but with no signs of intraplaque haemorhage or a healed fibrous cap. According to the classification scheme described by Virmani et al. "our group of stable atherosclerotic plaques includes thin and thick fibrous cap atheromas and fibrocalcified plaques. Our group of ruptured plaques (type $\mathrm{V}$ lesions according to the AHA dassification) is defined by the presence of a ruptured fibrous cap and a luminal thrombus, and the plaques correspond to the fibrous cap atheromas with a thrombus according to the Virmani classification.

Recently, several groups published data on differential gene expression between activated and non-activated human umbilical vein cells and vascular smooth muscle cells ${ }^{7.8}$. Although cell lines do provide a reproducible source of RNA, it remains to be determined whether gene expression in vitro mimics gene expression in vivo. Hiltunen et al. " also used whole mount human atherosclerotic plaques to study differences in gene expression between fatty streaks and advanced lesions. They however, did not validate their findings on a large panel of individual patients and did not study the localization of differentially expressed genes. Two other groups used the whole mount approach, McCaffrey et al. " studied differences in gene expression between the intima to the media of an atherosclerotic plaque and Adams et al. "studied differential gene expression of veins and arteries in macaques. However, until now data regarding differential gene expression profiles in human plaque rupture were lacking. Because of differences in cellularcomposition between the different lesion types. A challenge of the whole mount approach, as applied in our study, is the isolation of plaque type specific genes, rather than the isolation of cell type specific genes ${ }^{2}$. To obtain plaque type rather than cell type specific gerves, both pools contained comparable sets of morphologically diverse plaques regarding the presence of a lipid core, calcium deposition and the amounts of inflammatory cells. To circumvent patient based differences the initial $55 \mathrm{H}$ was performed on two pools each containing three lesions. Our data indicate that we indeed did select for differences in gene expression rather than differences in cellular composition. We selected only one inflammatory cell related gene (human immunoglobulin $\lambda$ chain) which was even downregulated in ruptured plaques. Additionally, the RT-PCR analysis did show differential expression of 2 genes (SSHE and perilipin [SSH1/SSH11]) in 10 different ruptured plaques compared to 10 different stable plaques, including some stable plaques that contained many inflammatory cells. Although heterogeneity in the types of arteries used for the initial $55 \mathrm{H}$ procedure does 
exist, the RT-PCR analysis illustrated that we did select for plaque type specific genes rather than artery specific genes. This is illustrated by the expression profile of perilipin and SSH6, that was present in ruptured plaques derived from abdominal aorta femoral artery and carotid artery. Additionally, SSH6 was expressed in stable plaques of peripheral and carotid artery and $5 \mathrm{SH} 42$ was expressed at comparable levels in all specimens tested.

Forty-five ( $9 \%$ ) out of 500 randomly chosen clones showed differential expression between ruptured- and stable plaques in macro array analysis. The number of differentially expressed genes might even be higher, because most likely we may have missed differential expression of some low abundant genes, which expression level was below the detection level of the macro-array. However, differential expression of $9 \%$ of the clones recovered during the SSH procedure is however in close agreement with previous studies investigating differential gene expression by this technique 16. 17.

Sequence analysis of the 25 clones, that showedl an at least 2-fold difference in expression, revealed homology of 6 clones $(24 \%)$ to known genes, 12 clones were homologous to ESTs ( $48 \%$ ) while 6 clones (24\%) were homologous to parts of genomic sequences but did not have any functional annotation and one clone contained a complete novel sequence. The distribution of known genes/EST fragments and novel sequences among the selected clones is comparable to the data derived from the human genome project 18.21 .

A very interesting finding of this study is that differences in gene expression found in small pools $(n=3)$ of stable or ruptured plaques could be reproduced in a larger panel $(n=10$ for both stable and ruptured plaques) of plaques derived from individual patients. RT-PCR analysis revealed mRNA expression of SSH6 in $80 \%$ of the ruptured plaques and in $20 \%$ of the stable plaques. Expression of $55 \mathrm{H} 6$ in stable plaque number 6 might be explained by the presence of a very thin fibrous cap, a known risk factor for plaque rupture. Plaque morphology could however not explain the expression of SSH6 within stable plaque number 9. Differential expression of perilipin ( $S \mathrm{SH} 1 / 5 \mathrm{SH} 11$ ) was even more striking, since expression was completely absent in all 10 stable plaques, while $80 \%$ of the ruptured plaques tested positive. Although perilipin is known to be associated with lipid droplets ${ }^{22.24}$, MRNA expression could not be explained by the presence of a lipid core or large amounts of foam cells, as several stable plaques also shared these features. In addition, plaques 3 and 5 that showed high expression of perilipin contained a very 5 mall lipid core. In contrast to perilipin and $55 \mathrm{H6}$, expression of SSH42 showed no gross differences between stable and ruptured plaques in RT-PCR analysis.

The differential expression pattern of SSH6 and perilipin (SSH1/11) suggests a possible role for these genes in plaque rupture. $\mathrm{SSH} 6$ is highly homologous to clone AL161991, present in the public domain and expressed in amygdala. However our clone contains an insertion of 120 nucleotides at position 1116 of the previously 
identified clone. Although clone AL161991 encodes a putative protein of 493 amino acids, nothing is known about the function of this protein.

The perilipin gene turned out to be exclusively expressed in ruptured atherosclerotic lesions. Our study is the first to link perilipin expression with atherosclerosis. Although human perilipin has recently been cloned ${ }^{22}$ most studies to unravel its possible function are performed using rat adipocytes. Perilipin is a phosphoprotein present on the surface layer of intracellular lipid droplets in adipocytes and sterogenic cells ${ }^{23.24}$. Upon lipolytic stimulation perilipin is phosphorylated ${ }^{23}$. Phosphorylation of perilipin causes an alteration in the lipid droplet surface that in turn may facilitate the actions of hormone sensitive lipase (HSL) in catalyzing the process of lipolysis ${ }^{25}$. Furthermore, overexpression of perilipin in 3T3-L1 pre-adipocytes increases triacylglycerol storage by a reduction of triacylglycerol hydrolysis ${ }^{26}$. 27 suggesting that the non-phosphorylated form of perilipin provides a barrier for the enzymes involved in lipolysis ${ }^{28}$. This idea is supported by the data obtained in mice carrying a defective perilipin gene ${ }^{20,30}$. These mice have smaller white adipocytes and show elevated basal lipolysis due to an increased activity of HSL. Our finding of specific expression of perilipin in ruptured plaques together with the localization of perilipin mRNA and protein in cells surrounding cholesterol crystals and in foam cells, might indicate a reduced lipolysis in these plaques. It is attractive to speculate that this will result in increased lipid retention and plaque destabilization.

In conclusion, our results show that it is possible to identify genes that are differentially expressed in a larger panel of whole mount stable or ruptured human atherosclerotic plaques. A first analysis of differentially expressed clones revealed several interesting candidates that may be involved in destabilization of atherosclerotic plaques. This approach may thus lead to a better understanding of the molecular processes involved in plaque destabilization.

\section{$>$ Acknowledgements}

This work was supported by the grant PF1197 from the Academic Hospital Maastricht and N.V. Organon, Oss, The Netherlands. K. Cleutjens was supported by a NWO 902-26-223 grant. A Greenberg was supported by research grants from DK 50647 (ASG), from the National Institutes of Health, Research Awards from the American Diabetes Association (ASG), and by the USDA Agriculture Research Service under contract 3KO6510 (ASG). 


\section{References}

1. Ross R: Atherosclerosis-an inflammatory disease. N Engl J Med 1999,340:115-26.

2. Libby $P$ : Changing concepts of atherogenesis. I Intern Med 2000,247:349-58.

3. Zaman $A G$, Helft $G$, Worthley SG, Badimon Jl: The role of plaque rupture and thrombosis in coronary artery disease. Atherosclerosis 2000, 149:251-66.

4. Stary $H C$, Chandler $A B$, Dinsmore RE, Fuster $V_{\text {a }}$ Glagov $S_{\text {; }}$ insull $W$, Ji., Rosenfeld ME, Schwartz Cl, Wagner WD, Wissler RW: A definition of advanced types of atherosclerotic lesions and a histological classification of atherosclerosis. A report from the Committee on Vascular Lesions of the Council on Arteriosclerosis, American Heart Association. Arterioscler Thromb Vasc Biol 1995, 15:11512-31.

5. Virmani $R$, Kolodgie FD, Burke AP, Farb A, Schwartz SM: Lessons from sudden coronary death: a comprehensive morphological classification scheme for atherosclerotic lesions. Arterioscler Thromb Vasc Biol 2000; 20:1262-75.

6. Kullo IJ, Edwards WD, Schwartz RS: Vulnerable plaque: pathobiology and clinical implications. Ann Intern Med 1998,129:1050-60.

7. LU KP. Ramos KS: Identification of genes differentially expressed in vascular smooth muscle cells following benzolalpyrene challenge: implications for chenical atherogenesis. Biochem Biophys Res Commun 1998,253:828-33.

8. de Vries $C J$, wan Achterberg TA, Horrevoets AJ, ten Cate JW, Pannekaek H: Differential display identification of 40 genes with altered expression in activated human smooth muscle cells. Local expression in atherosclerotic lesions of smags, smooth muscle activation-specific genes, I Biol Chem 2000,275:23939-47.

9. Shiffman D, Mikita T, Tai JT, Wade DP, Porter JG, Seilhamer JJ, Somogyi R, Liang S, Lawn RM: Large scale gene expression analysis of cholesterol-loaded macrophages. I Biol Chem $2000,275: 37324-32$

10. Hiltunen MO, Niemi M, Yla-Herttuala S: Functional genomics and DNA array techniques in atherosclerosis research. Curr Opin Lipidol 1999, 10:515-9.

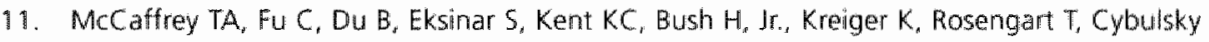
M. Silverman $\mathbb{E S}$, Collins $\mathrm{T}$ : High-level expression of Egr-1 and Egr-1-inducible genes in mouse and human atherosclerosis. J Clin Invest 2000, 105:653-62.

12. Adams LD, Geary RL, MCManus B, Schwartz SM: A comparison of aorta and vena cava medial message expression by CDNA array analysis identifies a set of 68 consistently differentially expressed genes, all in aortic media. Circ Res 2000,87:623-31.

13. Diatchenko L, Lau YF, Campbell AP, Chenchik A, Moqadam F, Huang B, Lukyanov 5 , Lukyanov $K$, Gurskaya N, Sverdlow ED, Siebert PD: Suppression subtractive hybridization: a method for generating differentially regulated or tissue-specific cDNA probes and libraries. Proc Natl Acad Sci U S A 1996,93:6025-30.

14. Chomczynski $P$, Sacchi $N$ : Single-step method of RNA isolation by acid guanidinium thiocyanate-phenol-chloroform extraction. Anal Biochem 1987,162:156-9. 
15. De Block M, Debrouwer D: RNA-RNA in situ hybridization using digoxigenin-labeled probes: the use of highmolecular-weight polywinyl alcohol in the alkaline phosphatase indoxyl-nitroblue tetrazolium reaction. Anal Biochem 1993,215:86-9.

16. von Stein OD. Thies WG, Hofmann M: A high throughput screening for rarely transcribed differentially expressed genes. Nucleic Acids Res 1997,25:2598-602.

17. Hufton SE, Moerkerk PT, Brandwijk R, de Bruine AP, Arends JW, Hoogenboom HR: A profile of differentially expressed genes in primary colorectal cancer using suppression subtractiwe hybridization. FEBS Lett 1999,463:77-82.

18. Hattori M, Fujiyama A, Taylor TD, Watanabe H, Yada T, Park HS, Toyoda A, Ishii K, Totoki $Y$, Choi DK, Soeda E, Ohki M, Takagi T, Sakaki Y, Taudien S, et al.: The DNA sequence of human chromosome 21. The chromosome 21 mapping and sequencing consortium. Nature $2000,405: 311-9$.

19. Dunham I, Shimizu N, Roe BA, Chissoe 5, Hunt AR, Collins IE, Bruskiewiich R, Beare DM, Clamp M, smink $U$. Ainscough $R$, Almeida JP, Babbage A, Bagguley C, Bailey $J_{*}$ et al: The DNA sequence of human chromosome 22. Nature 1999,402:489-95.

20. Venter IC, Adams MD. Myers EW, Li PW, Mural RJ, Sutton GIG, Smith HO, Yandell M. Evans CA, Holt RA, Gocayne JD, Amanatides P, Ballew RM, Huson DH, Wortman JR, et al: The Sequence of the Human Genome. Science 2001,291:1304-1351.

21. Lander ES BB, Nusbaum, C, Zody M, Bialdwin J, Devon K, Dewar K, Doyle M, Fitzhugh W, Funke, $R$, Gage D, Harris $K$, Heaford $A$. Howland $H$ et al. , Centre: TS et al.. Initial sequencing and analysis of the hurnan genome. Nature 2001, 409:860 - 921 .

22. Nishiu J, Tanaka T, Nakamura $Y$ is Isolation and chromasomal mapping of the human homolog of perilipin (PLIN), a rat adipose tissue-specific gene, by differential display method. Genomics $1998,48: 254-7$.

23. Greenbera AS. Eaan J). Wek SA. Gartv NB Blanchotto-Markis FI Inndne $r$. Poritinin a major hormonally regulated adipocytewspecific phosphoprotein associated with the periphery of lipid storage droplets. I Biol Chem 1991,266:11341-6.

24. Blanchette-Mackie EJ, Dwyer NK, Barber T, Coxey RA, Takeda T, Rondinone CM, Theodorakis JL. Greenberg AS, Londos C: Perilipin is located on the surface layer of intracellular lipid droplets in adipocytes. J Lipid Res 1995,36:1211-26

25. Clifford $\mathrm{GM}_{8}$ Londos $\mathrm{C}$, Kraemer $\mathrm{FB}$, Vernon $\mathrm{RG}$, Yeaman SJ: Translocation of hormone-sensitive lipase and perilipin upon lipolytic stimulation of rat adipocytes. J Biol Chem 2000,275:5011-5.

26. Souza SC, de Vargas LM, Yamamoto MT, Lien P. Franciosa MD, Moss LG, Greenberg AS: Overexpression of perilipin $A$ and $B$ blocks the ability of tumor necrosis factor alpha to increase lipolysis in 3T3-LI adipocytes. J Biol Chem 1998,273:24665-9.

27. Braseamie DL, Rubin B, Harten IA, Gruia-Gray J, Kimmel, AR, Londos, C. Perilipin A increases triacylglycerol storage by decreasing the rate of triacylglycerol hydrolysis. J.Biol. chem. 1998; 273:24665-24669.

28. Clifford GM, MCCormick DK, Londos C, Vernon RG, Yeaman S.: Dephosphorylation of perilipin by protein phosphatases present in rat adipocytes. FEBS Lett 1998,435:125-9. 
29. Martinez-Botas J. Anderson IB, Tessier D, Lapillonne A, Chang BH, Quast MJ, Gorenstein D, Chen $\mathrm{KH}$, Chan L: Absence of perilipin results in leanness and reverses obesity in Leprdb/db mice. Nat Genet $2000_{s} 26: 474-9$

30. Tansey JT, Sztaliryd C, Gruia-Gray J, Roush DL, Zee JV, Gavrilova O, Reitman ML, Deng CX. Li C. Kimmel AR, Londos C. Perilipin ablation results in a lean mouse with aberrant adipocyte lipolysis, enhanced leptin production, and resistance to diet-induced obesity. Proc Natl Acad Sci U 5 A 2001,98:6494-9. 



\section{CHAPTER 4}

\section{LARGE SCALE GENE EXPRESSION PROFILING OF HUMAN ATHEROGENESIS}

Birgit C.G. Faber, Donald Dunbar*, Darcey Black*, Chris Evelo, Mat JAP Daemen, Kitty BJM Cleutjens

Department of Pathology, Cardiovascular Research Institute Maastricht (CARIM), University of Maastricht, The Netherlands. * Organon NV, Newhouse, United Kingdom. 


\section{$>$ Abstract}

Over the past few years gene expression profiling methods like DNA micro-array, SSH (suppression subtractive hybridization), differential display and serval analysis of gene expression ( $S A G E$ ) enabled us to study the molecular mechanisms involved in atherogenesis. Although many genes potentially involved in atherogenesis have already been isolated, the complete molecular picture is still far from established. In this study we describe the identification of genes that are differentially expressed between whole mount human early lesions, stable lesions and lesions containing a thrombus using two independent methods, SSH and DNA micro-array analysils. Both techniques resulted in the identification of many genes that were differentially expressed during human atherogenesis. The majority of the SSH derived clones encoded for EST fragments or novel sequences $(60 \%)$, in contrast to the results obtained by DNA micro-array analysis in which only $11 \%$ coded for EST fragments. Sequence comparison between the two methods showed that only 2 genes (fibronectin and TGFB binding protein 1) were identified as differentially modulated above threshold levels by both methods, which is indicative for the isolation of two almost completely different gene sets. Functional clustering of the differentially expressed genes resulted in 8 major clusters 1) genes involved in lipid metabolism, 2) genes encoding growth factors and their receptors, 3) cytoskeletal genes, 4) genes involved in extra cellular matrix (ECM) turn-over, 5) immune system associated genes, 6) genes coding for cytokines and their receptors, 7$)$ cell adhesion associated genes and 8) genes encoding phosphatases, kinases and esterases. Differential mRNA and protein expression of two genes derived from DNA micro-array analysis, MMP-12 and the leukaemia inhibitory factor receptor (lif receptor) (clusters 4 and 6) were verified in individual patients. MMP-12 mRNA expression was enhanced in stable lesions compared to early lesions. This increased gene expression was reflected by a significant increase of MMP-12 activity in stable compaired to early lesions. Gene expression of the lif receptor was increased in stable lesions compared to early lesions and expression was further enhanced in lesions containing a thrombus. In conclusion, we identified several genes that were differentially regulated during human atherosclerosis using the SSH and DNA micro-array technology. Comparison of the results abtained by both techniques revealed that two distinct sets of genes were isolated. 


\section{Introduction}

Atherosclerosis is a chronic disease of the arteries and is the major cause of death in western society : Already early in life macrophages and lipids accumulate in the arterial wall to form fatty streaks. These fatty streaks can progress to advanced lesions containing a lipid core, calcium depositions or fibrotic material ${ }^{2}$. Most complications like stroke and myocardial infarction do occur after rupture of a lesion. Atherosclerotic lesions contain a variety of cell types like endothelial cells, vascular smooth muscle cells, macrophages and T-cells. While several research groups studied the gene expression profiles of individual cell types given an atherogenic stimulus ${ }^{3.5}$, few research groups studied gene expression profiles on whole mount human vascular tissue. These latter studies focussed on differences in gene expression between normal and atherosclerotic arteries ${ }^{6.8}$, fatty streaks and advanced lesions ${ }^{\circ}$ or differences between fibrous cap and media ${ }^{10}$. Using suppression subtractive hybridisation $(\mathrm{SSH})$ we recently showed that the transition from advanced but stable lesions to lesions containing a thrombus is accompanied by differential gene expression ". By detailed screening of a small part of these $\mathrm{SSH}$ libraries we identified the gene encoding perilipin to be exclusively expressed in lesions containing a thrombus. In addition many EST fragments or unassigned genes were isolated. Since this rather small scale screening already yielded several new candidates, we decided to expand the analysis of the SSH libraries. In addition we also used another high throughput gene expression methodology, the DNA micro-array technique. In contrast to the time consuming SSH technology, DNA micro-array technology is a fast procedure, which allows detection of differences in expression of thousands of annotated genes between numerous biological specimens. DNA micro-array analysis was performed on early lesions, stable lesions and lesions containing a thrombus. We show that the SSH and the DNA micro-array procedures result in the identification of an unique set of genes that are clifferentially regulated during the progression of human atherogenesis. 


\section{$>$ Materials and Methods}

\section{Tissue sampling}

Atherosclerotic plaques were collected from patients undergoing wascular surgery (Department of General Surgery. Academic Hospital Maastricht) or at autopsy (Department of Pathology, Academic Hospital Maastricht) and were collected in compliance with institutional guidelines. Vascular specimens were processed as described previously ", classified according to Virmani et al. 2 and grouped. Early lesions comprised intimal thickening and intimal xanthoma's. Stable lesions included fibrous cap atheromats, thin fibrous cap atheroma's and fibrocalcific lesions. Lesions with thromb included ruptured plaques, intraplaque hemorrhage and plaque erosion.

\section{Suppression Subtractive hybridisation}

The SSH procedure was performed using the PCR-Select CDNA Subtraction Kit (Clontech) as described previously" ". Briefly, SSH was performed on two pools of mRNA, the first pool contained total RNA derived from three stable lesions and the second pool contained RNA derived from three lesions containing a thrombus. Two libraries were generated. The first library contained clones upregulated in stable lesions, while the second library contained clones upregulated in lesions containing a thrombus.

\section{Analysis of the SSH libraries}

Sequence analysis was performed on 1250 clones. Inserts were first amplified by PCR using the M13 forward (5' CGCCAGGGTTITCCCAGTCACGA 3') and M13 reverse (5' TTTCACACAGGAAACAGCTATGA 3') primers under standard conditions. Subsequently, the inserts were sequenced using the $M 13$ forward and reverse primers. Homology searches were performed using the advanced Blast Program on the combined GenBankJEMBL nonredundant ( $\mathrm{nr}$ ), Expressed Sequence Tag (dEST), mouse EST, human EST, rat EST, Swissprotein and the human tagged genomic sequence (htgs) databases (National Centre for Biotechnology Information: Www ncbinim.nihgown and the incyte database.

Differential expression of clones derived by the $55 \mathrm{H}$ procedure was verified by macro-array analysis. Inserts were amplified by PCR using the M13 forward and M13 reverse primers under standard conditions. Identical nitrocellulose fitters were generated by the Biomek 2000 robot (Beckman Coulter) using standard procedures. Each clone was spotted in duplicate. The filters were hybridized at high stringency with ${ }^{3 a}$-labeled (High Prime, Boehringer Mannheim) SMART ${ }^{\text {M }}$ CDNA (pools derived from three individual lesions) of early lesions, stable lesions and lesions containing a thrombus using standard procedures. Quantitative analysis was performed by phosphorimage analysis (Storm molecular Dynamics). Hybridization signals between the different blots were normalized for the house keeping gene ubiquitin and genomic DNA signals. 
Clones were included in the analysis when both spots were expressed above an arbitrary threshold of 300 counts per $\mathrm{mm}^{2}$, which is over 2 times background, in at least one of the three blots. As before " the threshold for differential expression was set at 2 -fold.

\section{DNA micro-array}

Using Oligotex polystyrene resin (Quiagen), poly(A)* RNA was purified from $50 \mu \mathrm{g}$ total RNA derived from a pool of 4 different stable lesions and 3 early lesions for one hybridisation and a pool of 6 stable lesions and 5 lesions containing a thrombus for the other hybridisation respectively. Subsequently, the poly(A)+ RNA was labelled with Cy3 and Cy5 fluorescent dye for DNA micro-array hybridisations to the UniGEM-V (>9000 genes, Incyte Genomics) as described elsewhere 12. A gene was selected for further analysis when the signal to background ratio was at least 2.5. a signal intensity above 250 units for one of the dyes, and a spot area of at least $40 \%$ of the spotted area. Data were analyzed using Gemtools ${ }^{\mathrm{m} M}$ and $a 1.7$ fold change in expression was considered to be relevant.

\section{Validation of candidate genes}

\section{RT-PCR analysis}

Total RNA isolation, CDNA synthesis an RT-PCR were performed as decribed before ". RT-PCR was performed on MRNA isolated from individual samples of normal artery $(n=3)$, early lesions $(n=4)$, stable lesions $(n=7)$ and lesions containing a thrombus $(n=10)$. To exclude patient- and artery-based expression, samples originated from several arteries from different patients. Phospholipase A2 (pla2), the leukaemia inhibitory factor receptor (lif-receptor). MMP-12 and GAPDH specific DNA fragments were amplified on first strand CDNA using the following primers: plaz, forward: 5' GCAGTGATCATGATCTIGG 3' reverse: 5' CTAGCAAAACAGGTGGCAGC 3'. lif receptor, forward: 5" AGTGATACTTG TAGGCTCAG 3' reverse: 5' TGAATGAAGTAGGAGTATGG 3". MMP-12, forward: 5' AAGAGAACCGCTTGCC 3' reverse: 5" CTCCTTCATCATACCTCC $3^{\prime}$.

\section{Immunohistochemistry}

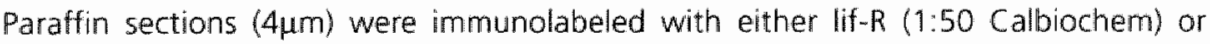
MMP-12 (1:250; Triple Point Biologics) polyclonal antibodies. To determine the cell type expressing lif receptor or MMP-112, serial sections were labelled for either CD68 (macrophages 1:100, Dako) or a smooth muscle cell actin (smooth muscle cells 1:500, Dako). Staining was visualized using the Alkaline Phosphatase Kit I (Vector). Sections 
were counterstained with hematoxylin. All stainings were performed essentially as described previously "n. Negative controls, sections incubated without the primary antibody, did not show any staining.

\section{Zymography and Western blot analysis of MMP-12}

Proteins were extracted from vascular specimens as described previously ${ }^{13}$. In brief, vascular tissue was homogenized in ice-cold lysis buffer $(10 \mathrm{mM}$ Tris. $\mathrm{HCl} \mathrm{pH} 8.0$, $2.5 \mathrm{mM} \mathrm{KCl}, 150 \mathrm{mM} \mathrm{NaCl}, 0.5 \%$ Nonidet $\mathrm{P} 40,0.5 \%$ Triton- $\times 100,20 \mathrm{mM}$ B-glycerolphosphate, $50 \mathrm{mM} \mathrm{NaF}, 1 \mathrm{mM}$ dithiothreitol, $10 \mu \mathrm{g} / \mathrm{ml}$ soytrypsin inhibitor, $10 \mu \mathrm{g} / \mathrm{ml}$ leupeptin, $2 \mathrm{mM} \mathrm{NaVO}_{3}, 200 \mathrm{mM}$ benzamidin) and incubated for $30 \mathrm{~min}$ on ice. After centrifugation (20 $\mathrm{min}, 4500 \mathrm{xg}$ ) the supernatant was stored at $-20^{\circ} \mathrm{C}$. Proteins (20 $\mu \mathrm{g} / \mathrm{sample)}$ and recombinant MMP-12 (Triple Point Biologics) were separated on a $10 \%$ SDS-PAGE containing $0.4 \%$ casein under non-reducing conditions. After migration the gel was divided into two parts one part for zymography and one part for Western blot analysis. The part for zymography was soaked twice in $2.5 \%$ Triton $\times 100$ and incubated overnight in substrate buffer $\left(50 \mathrm{mM}\right.$ Tris- $\mathrm{HCl}, 5 \mathrm{mM} \mathrm{CaCl}, 0.02 \% \mathrm{NaN}_{3}$; pH5.0) at $37^{\circ} \mathrm{C}$ to allow substrate cleavage. Subsequently, gels were stained in $0.2 \%$ Commassie Brilliant bilue solution (10\% HAC, 40\% methanol) and destained in $10 \%$ acetic acid and 30\% methanol. MMP-12 activity was detected as unstained bands. The part of the gel for Western blot analysis was transferred to a nitro-cellulose membrane (Protran, 5chleicher \& Schuell). After blocking overnight with 2\% non-fat milk and $0.1 \%$ Tween 20 in $10 \mathrm{mM}$ Tris buffered saline pH7.5 (TBS) blots were incubated with a polyclonal antibody directed towards MMP-12 (1:2000. Triple Point Biologics). Biotin labelled swine anti-rabbit antibody (1:2000, Dako) was used as the secondary antibody and the blots were subsequently incubated with Strep-AB-complex (1:200, Dako). Specific antibody binding was visualized with enhanced chemiluminiscence (ECL) western blotting detection reagent according to the suppliers instruction (Amersham Pharmacia Biotech). The MMP-12 signal was quantified using Quantity One software (Biorad).

\section{Statistical analysis}

Data are expressed as mean \pm SEM. Protein expression between lesion types was compared using a non-parametric Mann-Whitney $U$ test. The level of statistical significance was set at $p<0.05$. 


\section{Initial screening of genes differentially expressed during lesion progression}

\section{$S S H$}

The two SSH libraries contained 5000 clones enriched for genes upregulated in stable lesions and genes upregulated in lesions containing a thrombus. Apart from the 500 clones that were analysed previously, 1860 clones were further analyzed. Of these clones, 1250 randomly chosen were sequenced. Sequence comparisons of the two libraries revealed a minimal overlap of only 12 sequences, which was indicative for a successful subtraction procedure. Since analysis of these 1250 sequences showed that $36 \%$ of the clones was represented more than once, further analysis was confined to these sequences.

The majority of the clones present in the SSH libraries encoded EST fragments $(51 \%)$. In addition, $5 \%$ of the clones was homologous to genomic sequences, while $21 \%$ of the clones did not show any homology to any sequence present in the currently available public databases. Only $23 \%$ of the clones represented known genes.

Since previous data showed that approximately $10 \%$ of the $\mathrm{SSH}$ clones represent truly differentially expressed genes $" 1415$, the expression profile of individual clomes was verified by macro-array analysis. Because of the significant redundancy of the SSH libraries, macro-array analysis was confined to 1860 clones. These 1860 dones did not include the 500 clones previously analysed. Macro-arrays were hybridised to pools of CDNA derived from early lesions, stable lesions and lesions containing a thrombus. Twenty percent of the clones showed expression above threshold value in at least one hybricisation. Differential expression between early lesions, stable lesions and lesions containing a thrombus was observed for $11 \%$ of the 1860 clones. As shown in table 1. 95 clones showed enhanced expression in early lesions when compared to stable lesions, whereas 47 clones were downregulated in early lesions. In addition, 22 clones were upregulated and 104 clones were downregulated in lesions containing a thrombus when compared to stable lesions. Differential expression in both comparisons (early vs stable and stable vs thrombus) was observed for 60 clones.

Combined sequencing and expression analysis revealed that $58(40 \%)$ of the differentially expressed clones encoded known genes, 62 clones coded for EST fragments, 6 clones were homologous to genomic sequences and 19 clones were not homologous to any known gene in the public and Incyte database. No sequence information was yet obtained from 63 clones (table 2).

\section{DNA Microwarray}

Since the SSH procedure yielded a high percentage of EST fragments and unknown genes, a second independent method, the DNA micro-array, was used to identify additional known genes that are differentially expressed during human atherogenesis. 
Table t: Genes differantially expressed between early fesions, stable lesions and lesions containing a thrombus.

\begin{tabular}{|c|c|c|c|}
\hline Expression & Cluster & DNA miero array & SSH \\
\hline Early > stable & A & 99 & 95 \\
\hline Early $<$ stable & $\mathrm{B}$ & 85 & 47 \\
\hline Thrombus > stable & c & 96 & 22 \\
\hline Thrombus $<$ stable & D & 90 & 104 \\
\hline Modulated in both & $A C, A D$ & 41 & 60 \\
\hline inn & $\mathrm{BC}, \mathrm{BD}$ & & \\
\hline
\end{tabular}

Gene expression profiles of early lesions and lesions containing a thrombus were both compared to gene expression profiles of stable lesions by two independent hybridisations to the Unigem $V$ micro-array. Differential regulation during lesion progression was observed for 329 genes (3.6\%). As shown in table 1, 99 genes were upregulated and 85 genes. were downregulated in early lesions. In addition, 96 genes were upregulated and 90 genes were downregulated in lesions containing a thrombus. Differential expression in both comparisons was observed for 41 out of 329 genes.

Of the 329 differentially regulated genes, 293 encoded known genes (89\%), 35 genes were EST fragments $(10.6 \%)$ and 1 gene was homologous to a genomic fragment $(0.4 \%$ ) (table 2 ). Thus in contrast to the data obtained by the SSH procedure in which $40 \%$ represented known sequences, the majority (89\%) of the DNA micro-array derived clones coded for known sequences.

Comparison of the initial SSH libraries with the DNA micro-array revealed that 64 CDNA's of the SSH libraries were also represented on the DNA micro-array. Only 4 of these 64 sequences were differentially modulated above threshold on the DNA micro-array. These sequences included protein phosphatase $1(E>5,2.5)$, glycerol kinase $(T<S, 1.7)$, fibronectin $(T<S, 2.5)$ and $T G F \beta$ binding protein $1(T<S, 2.1)$. Fibronectin and TGF $\beta$ binding protein 1 were both expressed above threshold levels in the macro-array analysis of the SSH libraries. Fibronectin $(S>E, 17$ and $S>T, 9)$ and TGF $\beta$ binding protein 1 ( $S>E, 6$ and $S>T, 10$ ) were both upregulated in stable lesions when compared to early lesions and lesions containing a thrombus. The minimal overlap in differentially expressed clones shows that both techniques identify different sets of candidate genes.

\section{Cluster analysis of atherosclerosis responsive genes}

To enhance the insight in the complex data set obtained by both SSH and DNA micro-array analysis, genes were clustered according to two different criteria. The first clustering was based on gene function (functional clustering), while the 
second clustering was based on expression profiles (expression clustering) (table 2). Known genes that were differentially expressed during plaque progression were clustered according to their function. Eight major groups could be identified that contained 1) genes involved in lipid metabolism, 2) genes encoding growth factors and their receptors, 3) cytoskeletal genes, 4) genes involved in extra cellular matrix (ECM) turnover, 5) immune system associated genes, 6) genes coding for cytokines and their receptors, 7) cell adhesion associated genes and 8) genes encoding phosphatases. kinases and esterases. This is in close agreement with the literature study described in chapter $2{ }^{16}$, in which we already stressed the importance of genes involved in lipid metabolism and ECM turnover. Additionally, each gene was clustered based on their expression profile. Cluster A contained genes upregulated in early lesions "cluster $B$ represented genes downregulated in early lesions, cluster $C$ contained genes upregulated in lesions containing a thrombus and cluster $D$ represented genes downregulated in lesions containing a thrombus (tablle 1). As mentioned before all expression profiles were compared to expression profiles in stable lesions. EST fragments, novel sequences and sequences homologous to genomic sequences were clustered according to their expression profiles. Table 2 summarizes the results of the functional and expression clustering of genes differentially expressed during lesion progression.

Genes involved in lipid metabolism showed heterogeneous expression profiles. For example, expression of phospholipase A2 group IIA (pla2) was enhanced in the onset of atherosclerosis, decreased in stable lesions and expression peaked again in lesions containing a thrombus. In contrast, expression of ApoE was maximal in stable lesions. Enhanced expression of many growth factors (e.g. endothelin-1, cluster A: E S S: 2.3) and cytoskeleton related genes (e.g. laminin $\alpha-2$, clustel A E/5: 2.4) was observed during lesion initiation, indicative for the dynamic state of the early lesion. Genes involved in ECM turmover showed interesting profiles. Genes involved in ECM synthesis showed heterogeneous expression profiles throughout lesion progression, while ECM degrading enzymes showed peak levels of expression in stable lesions (e.g. MMP-12, cluster B: E<S: 8 and cluster D: T<S: 3). Expression of proteinase inhibitors, such as the serine proteinase inhibitors, was enhanced during lesion initiation. Increased expression in the stable lesions of immunoglobulin, major histocompatibility complex (MHC) and cytokines genes may reflect the influx of inflammatory cells during the progression of atherogenesis (e.g. leukaemia inhibitory factor (iif) receptor, cluster $B$ : E<S: 3.0 and cluster $C: T>S: 1.7$ ). Complement related genes showed an interesting expression profile. Expression was upregulated during lesion initiation, dropped during lesion progression and increased again in lesions containing a thrombus. One of the key features of plaque rupture is the loss of integrity of the fibrous cap. This phenomenon is reflected by a decreased expression of genes involved in cell adhesion in lesions containing a thrombus. 
Table 2: Functiond custering and gene expression profies of genes derved from 554 and nicro-array anahsis

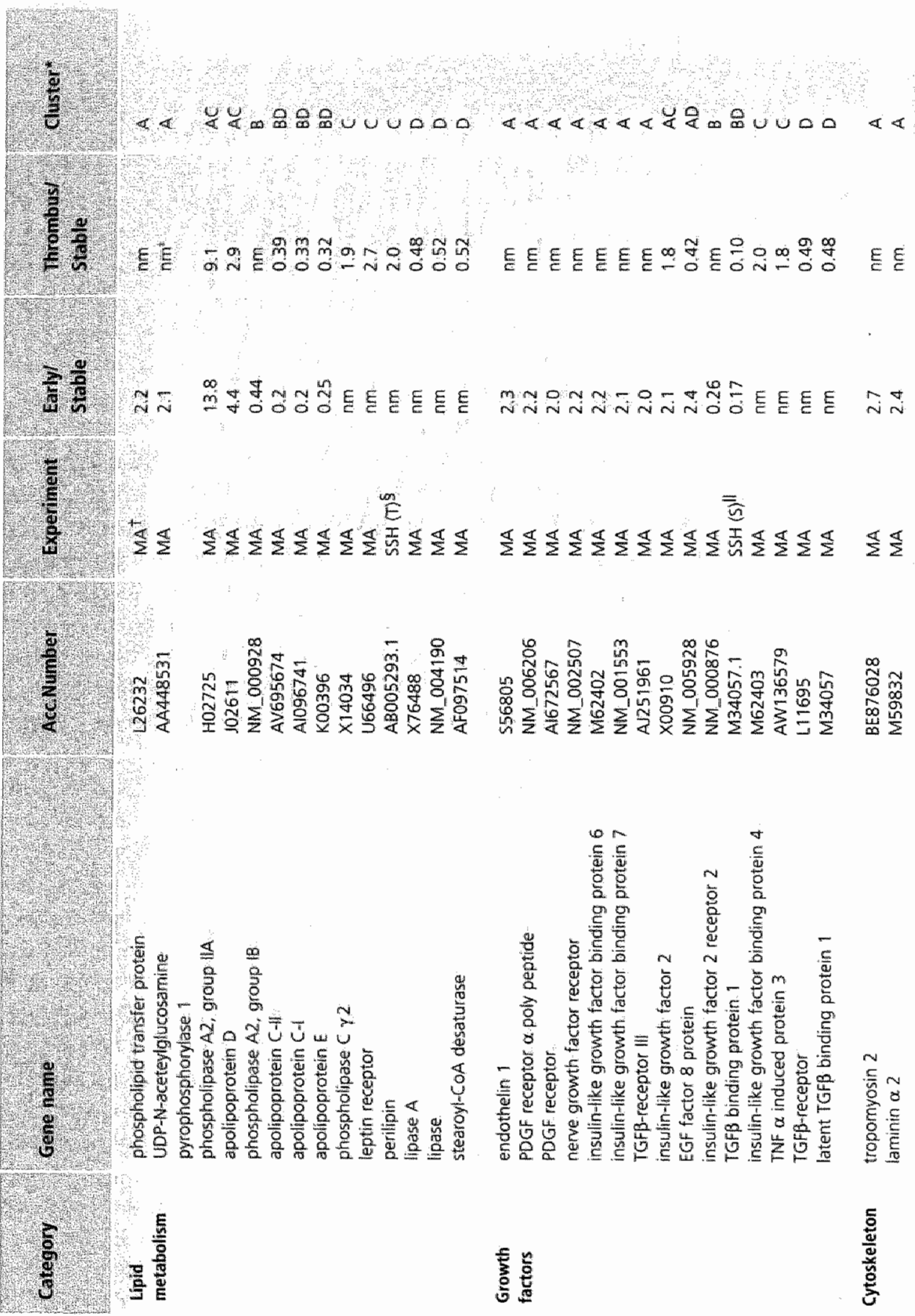




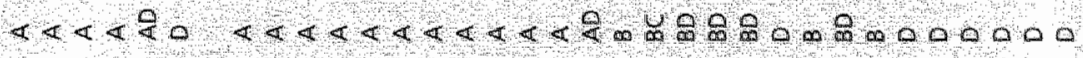

है.

EEEEO O

$\frac{5}{6} \frac{0}{6}$

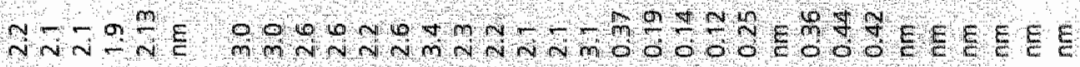

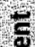

E

8.

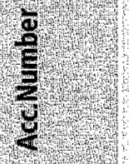

I. $N$.

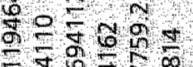

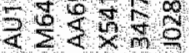

a)

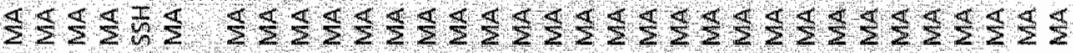

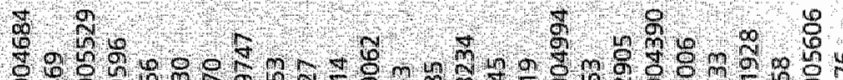
ㅇㅇㅇㅢ

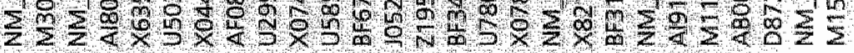
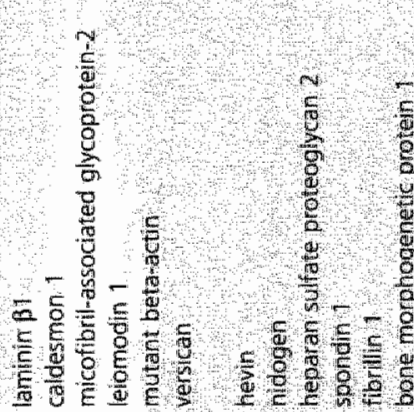

18

< 10

C $\mathrm{g} g \mathrm{~g}$

$=9$

की

to

$\mathrm{c}=1$

a $5: 5$

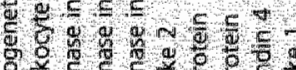

$\frac{5}{4} 5=25 \%$

d)

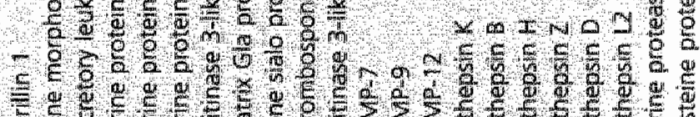

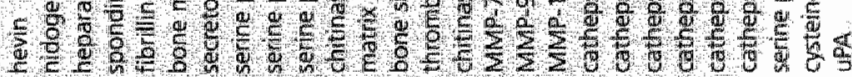

\section{$\frac{8}{9}$}

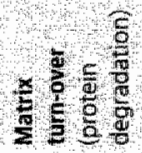




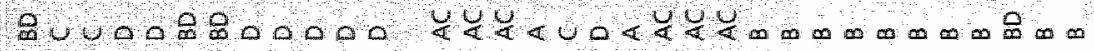

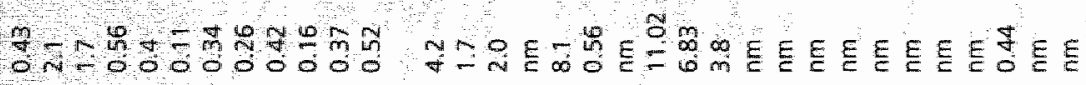

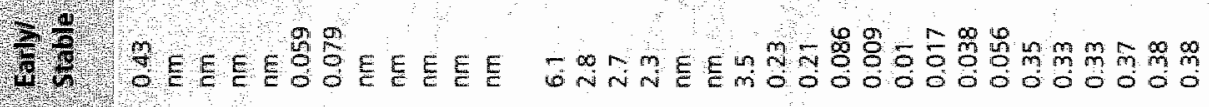

E.

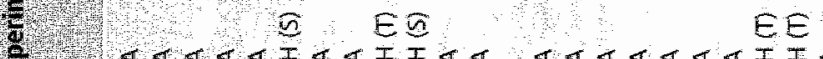

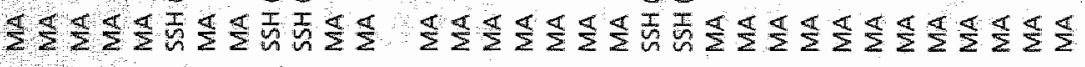

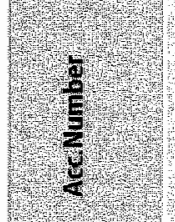

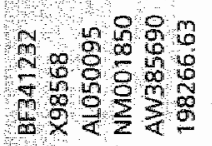

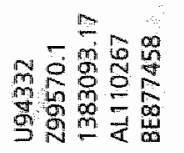

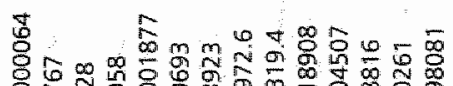

$\stackrel{\infty}{\sim}$

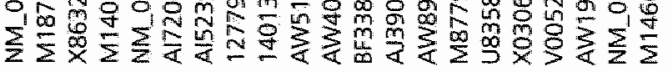
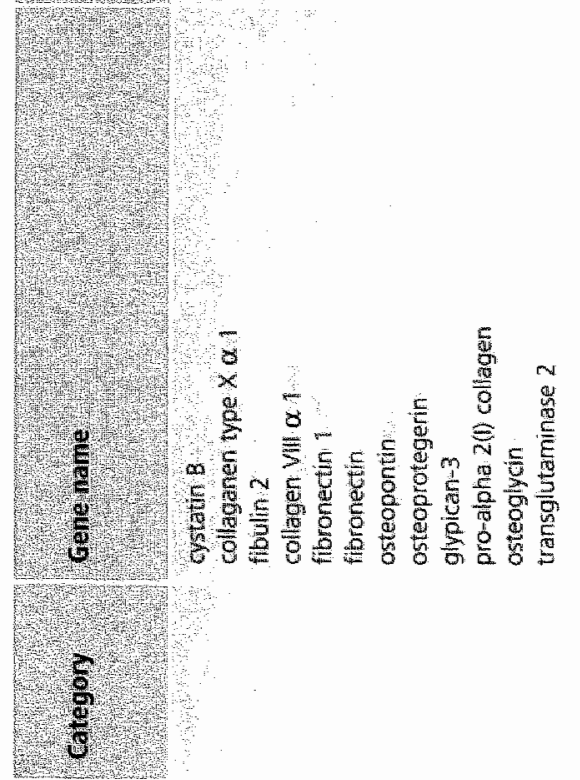

4n.

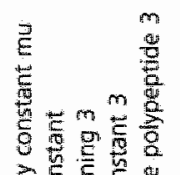

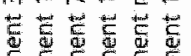

绎

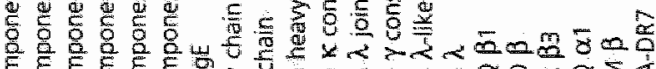

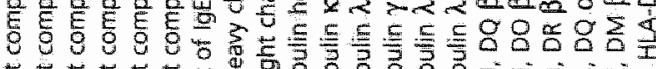

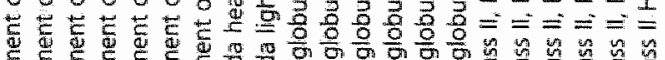

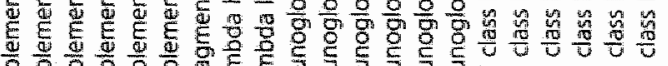

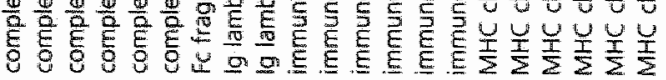
त. 


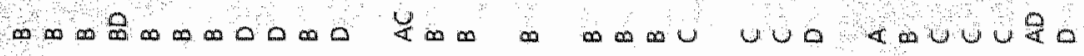

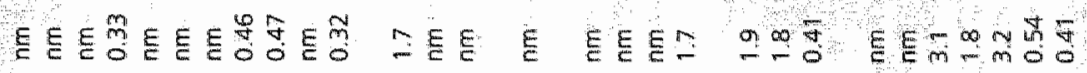

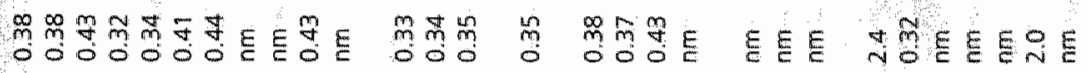

तथ

할.

74-

$\frac{5}{4}$

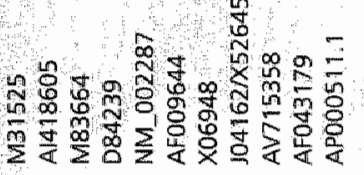

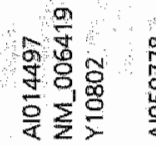

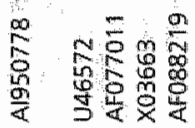

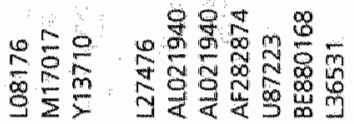

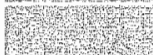

(2)
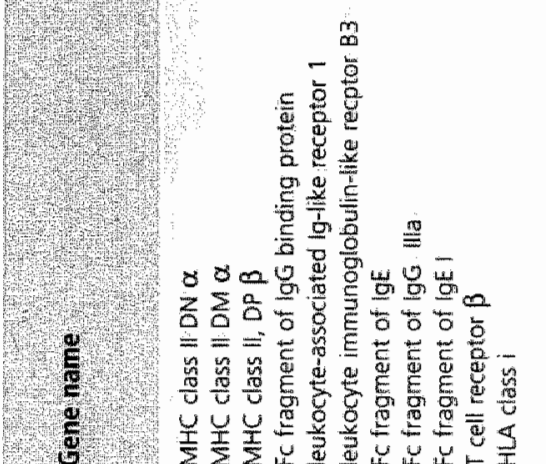

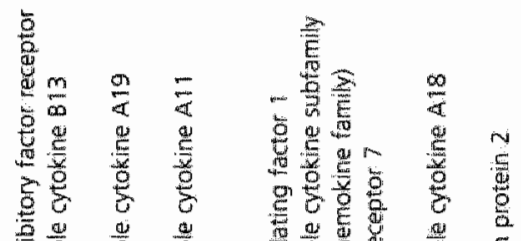

$\frac{\mathrm{g}}{\mathrm{g}} \mathrm{g}$.

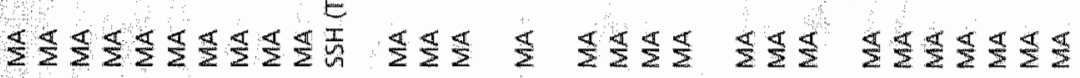

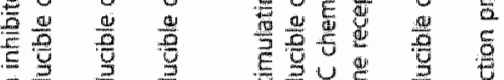

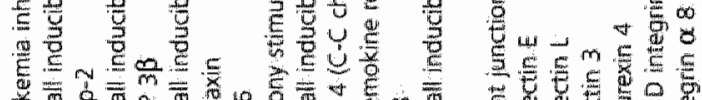

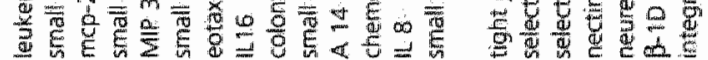




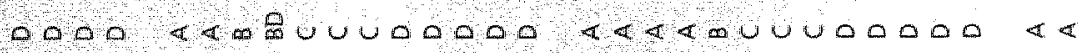

भI

혼

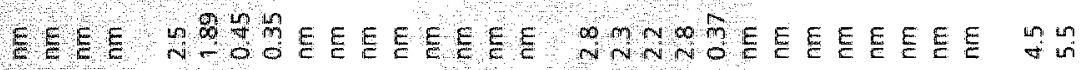

$\frac{\mathrm{E}}{\mathrm{E}}$

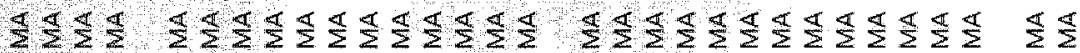

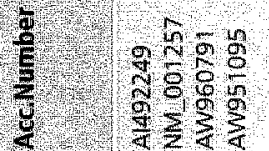
\%

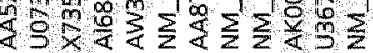

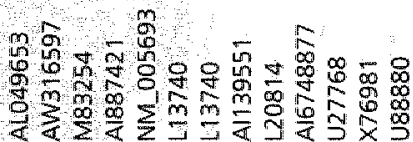

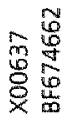
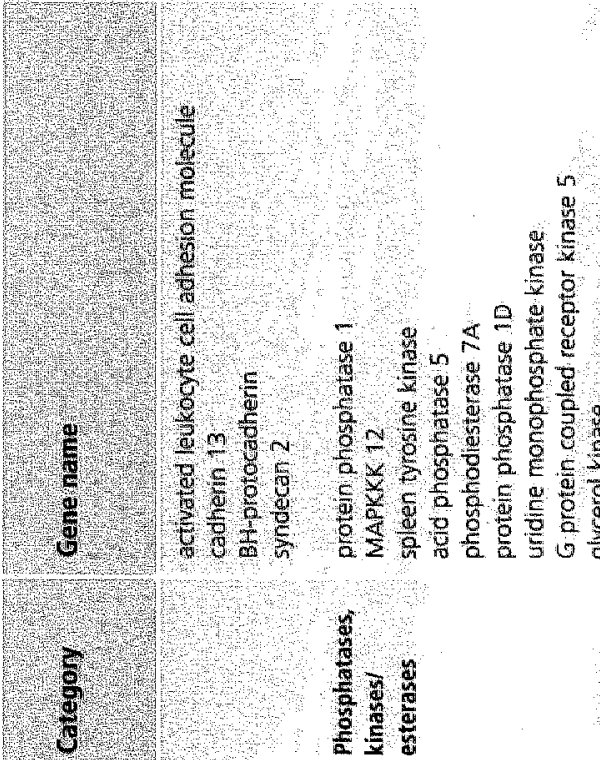

$\frac{5}{5}$

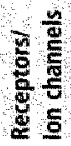




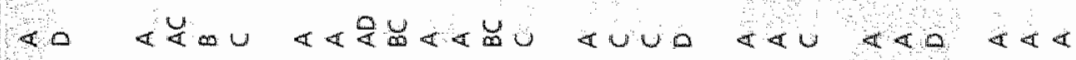

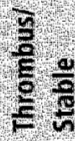

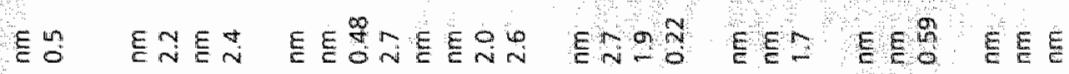

部

E

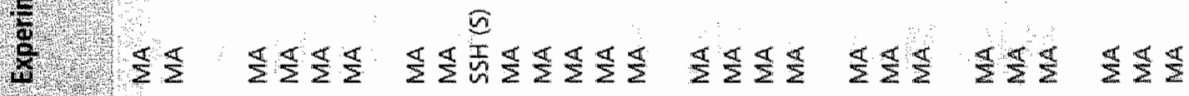

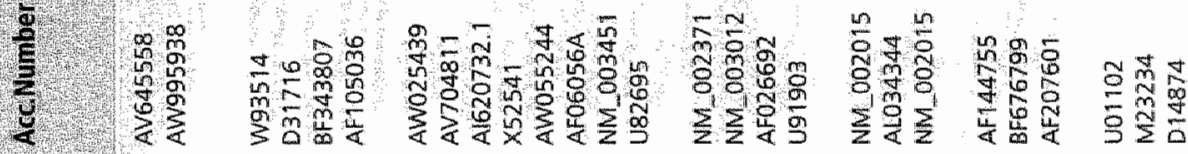
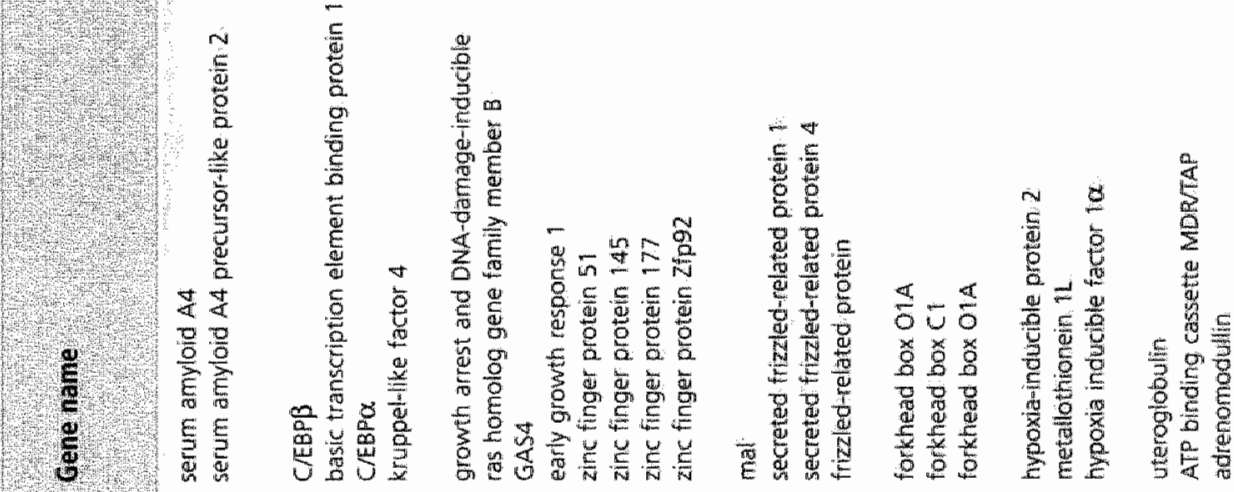

ह⿱艹

尊

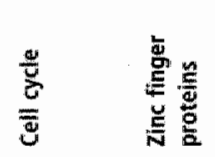

墨
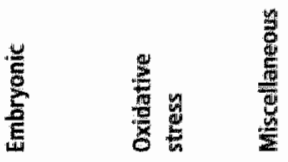


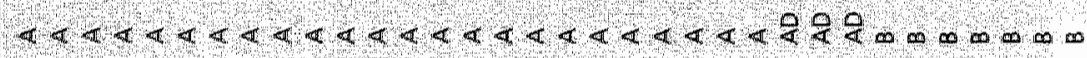

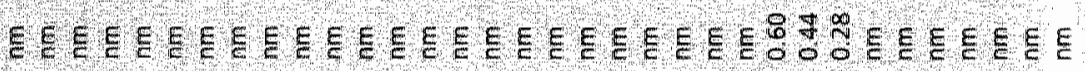

\section{क.}

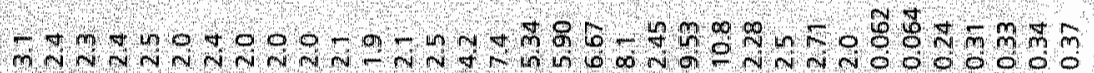

है

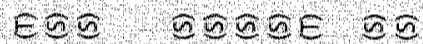

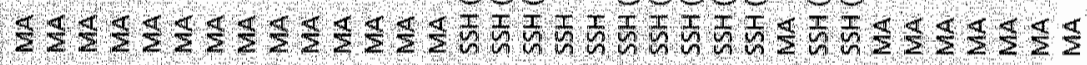

$\frac{2}{5}$

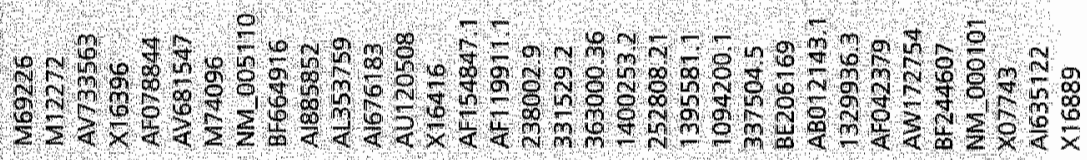
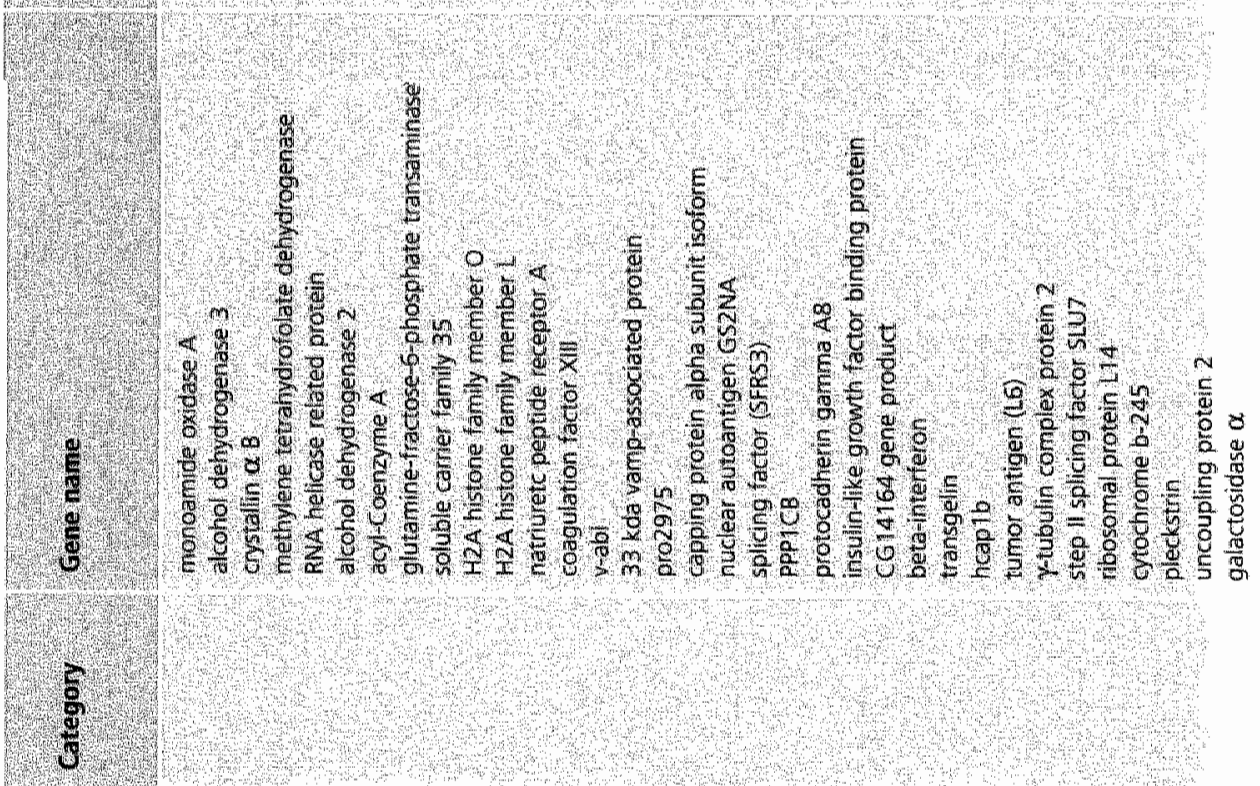


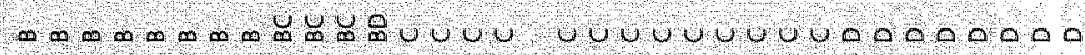

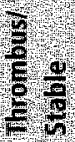

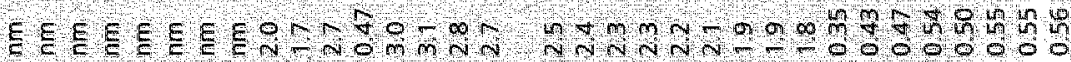

정

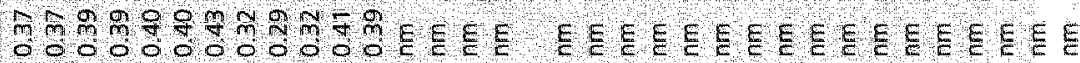

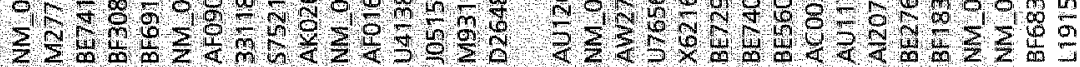

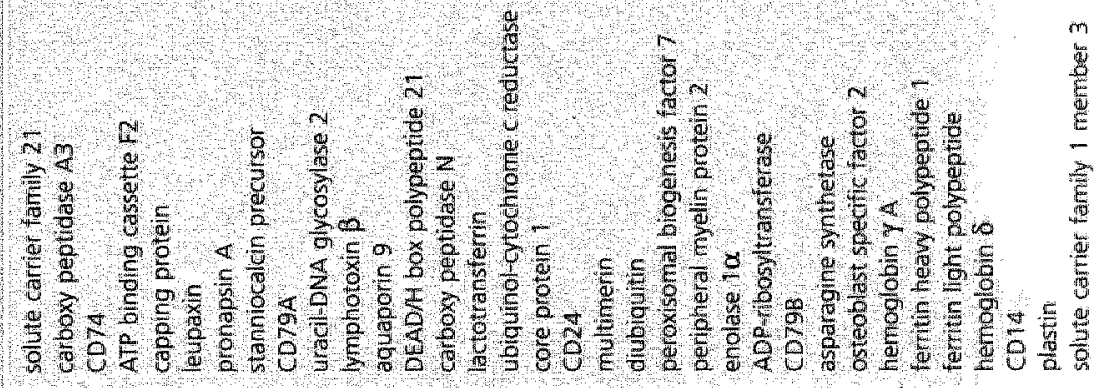




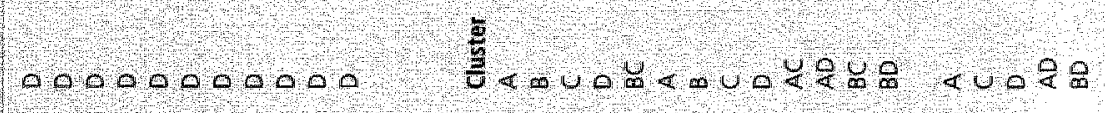

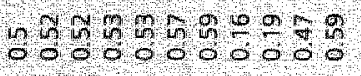
EEEEEEEEEEEE

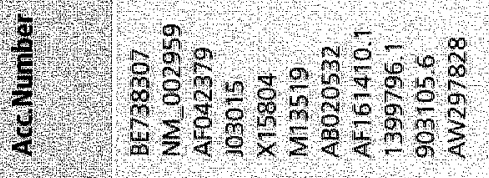




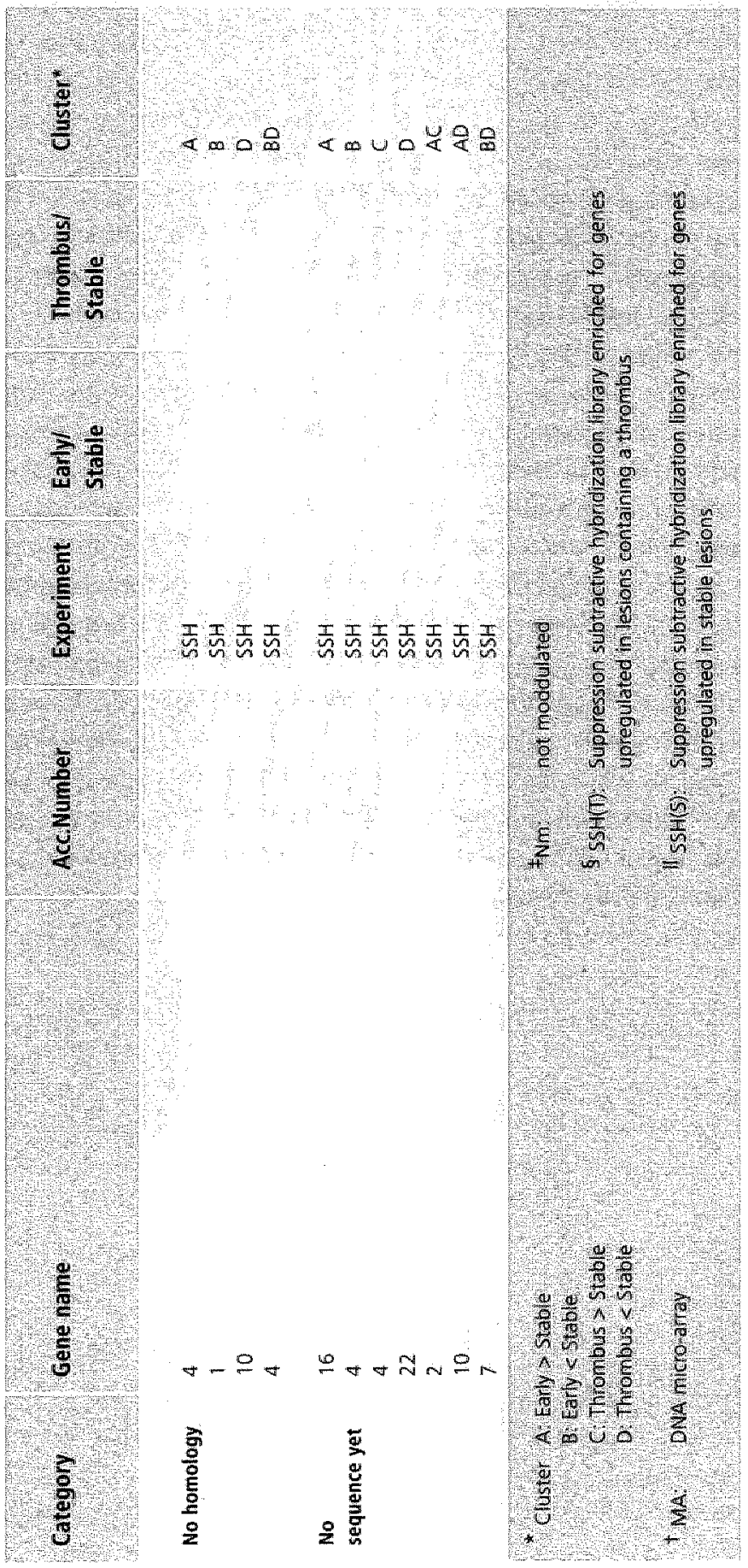




\section{Validation of candidate genes}

\section{RT-PCR analysis}

Validation of two 55H derived candidates, perilipin and 5SH6 is described in chapters 7 and 8. Expression profiles of three candidate genes derived from DNA micro-array analysis were further substantiated on individual vascular specimens, using standard RT-PCR analysis in which the prevalence of expression was determined (fig. 1). Representative genes for three functional clusters were chosen for further validation. Pla2 was chosen as a representative for functional cluster one (lipid metabolism), the lif receptor represent functional cluster 6 (cytokines and cytokine receptors) and MMP-12 represents functional cluster two (ECM turnover). RT-PCR analysis confirmed the previously observed expression profile of plaz since all early lesions tested showed pla2 expression. Incidence of expression dropped in stable lesions (4 out of 7) and pla2 was again enhanced in ruptured lesions. Expression profiles of the lif receptor obtained by RT-PCR analysis mimicked the DNA micro-array data that is an increased expression during lesion progression. Interestingly, the lif receptor ligand, leukaemia inhibitory factor (lif) was present in the SSH library containing genes upregulated in lesions containing a thrombus. Unfortunately expression of lif did not exceed the threshold value of the macro-array analysis (data not shown). Therefore differential expression of lif could not be verified. MMP-12 expression was enhanced during plaque progression. However, expression prevalence did not decrease in lesions containing a thrombus as observed during the DNA micro-array analysis.

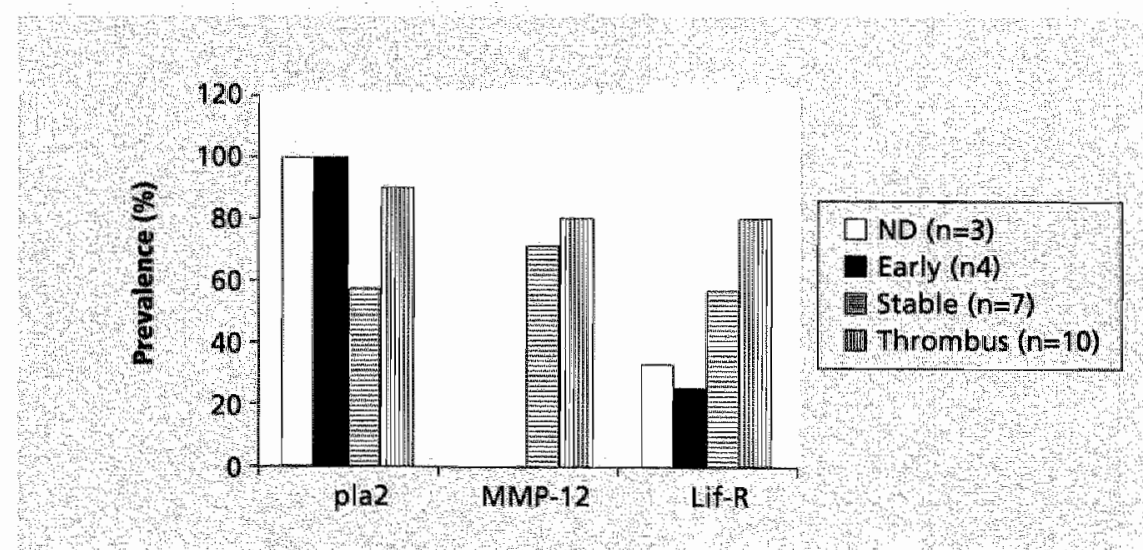

Figure 1: RTFCR analysis of phospholipase A2, lif receptor and MMP.12 during human atherogenesis. Expression in non-diseased artery (ND), early fesions, stable lesions and lesions containing a thrombus is depicted as incidence of expression. 


\section{Immunohistochemistry}

To further substantiate the differential expression profiles of lif receptor and MMP-12. protein expression and cellular lacalization were determined by immunohistochemistry. Lif receptor protein was completely absent in all early lesions tested ( $n=3$ ) (fig. 2 ). In stable lesions, expression of the lif receptor was associated with lipid accumulation $(n=4)$. in these lesions, small clusters of macrophages (as determined by CD68 staining of serial slides) in the shoulider area and the fibrous cap overlying the lipid core expressed lif receptor protein (fig. 2). In contrast, lif receptor protein expression was not associated with fibrotic or calcified areas in the lesions $(n=4)$. In lesions containing a thrombus the lif receptor was expressed by macrophages nearby the site of rupture and macrophages present within the thrombus $(n=3)$. Remarkably, endothelial cells of small vessels within an organized thrombus also showed lif receptor expression (fig. 2).

MMP-12 protein could not be detected in the early lesions tested $(n=3)$ (fig. 3). In stable lesions and lesions containing a thrombus MMP-12 expression was observed at the rim of the lipid core and within the lipid core (fig. 3). As determined by CD68 staining of serial slides (data not shown), expression of MMP-12 was predominantly observed in macrophages. MMP-12 protein was also present extracellulary. In calcified lesions ( $n=2$ ) MMP-12 expression was found at the edges of calcification (fig. 3 ).

\section{Zymography}

Since MMP-12 is a potent elastase we examined MMP-12 activity in early lesions, stable lesions and lesions containing a thrombus by casein zymography. Human is expressed as a pro-enzyme of $54 \mathrm{kDa}$, a $45 \mathrm{kDa}$ intermediate form and an active form of $22 \mathrm{kDa}$. Caseinolytic activity in atherosclerotic lesions corresponded to the caseinolytic activity of recombinant MMP-12 (fig. 4A). Western blot analysis of the zymogram confirmed that the caseinolytic protein was indeed MMP-12 (fig. 4B). Subsequent quantification of the zymogram showed a significant upregulation of MMP-12 activity

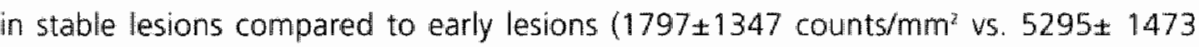
counts/mm $\mathrm{m}^{2} \mathrm{p}=0.046$ ) (fig $4 \mathrm{C}$. MMP-12 activity was not significantly modulated between stable lesions and lesions containing a thrombus. 


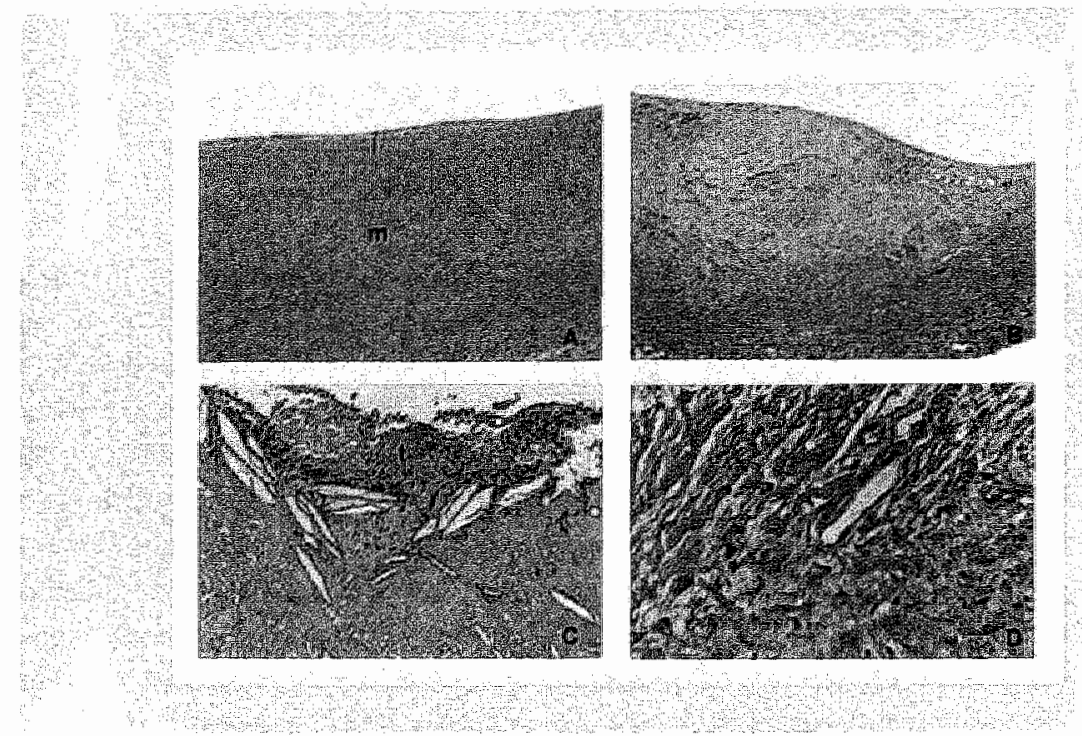

Figure 2: Immunohistochemical staining of the If receptor in different stages of human atherogenesis. Immunoreactivity is depicted in red. No protein expression was abserved in early lesions (A). lif receptor expression was obserwed in a subset of macriophages in stable lesions (B). inmumoreactivity for the lif receptor was found in macrophages near a thrombus $(C)$, and in endothelial cells of small vessels in an organized thrombus 10 ). $i=$ intima: $m=$ media; $t=$ thrombus

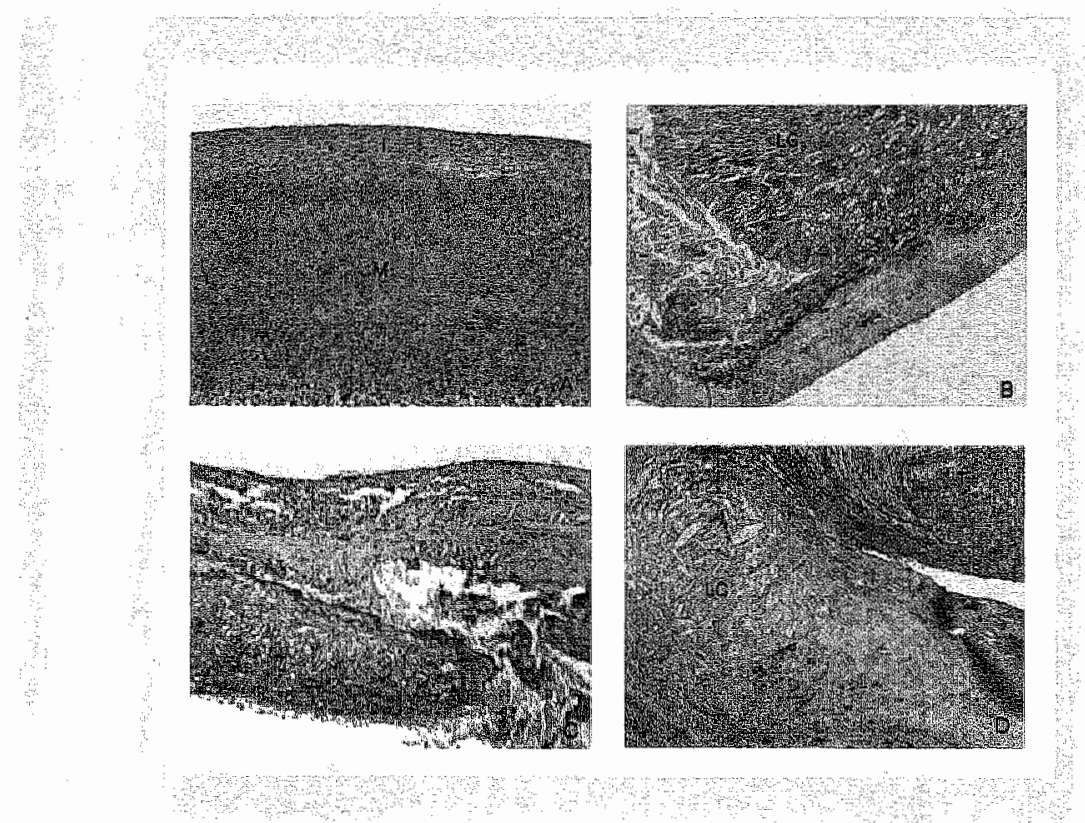

Figure 3: Immunohistochemical staning of MMP-12 in different stages of human atherogenesis. Immunoreactivity is depicted in red. No protein expression was observed in early hesions (A) MMP-12 expression was obserwed in a subset of macrophages at the rim of the lipid core in stable lesions (B) and lesions containing a thrombus. MAP.12 expression was atso associated with areas of calcification (b). $f$ intima; $m=$ madia, ic a lipid core; $t=$ thrombus 

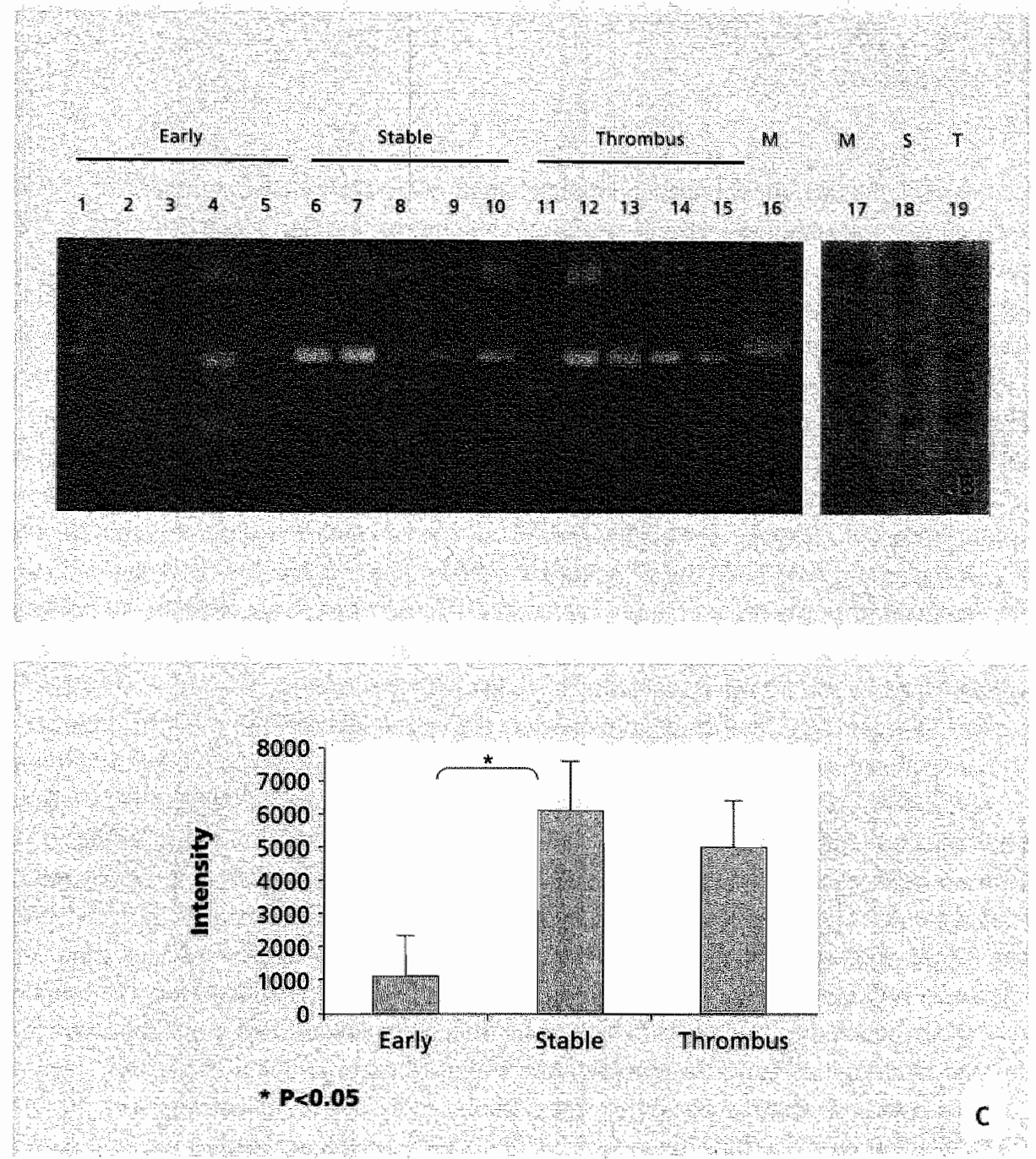

Figure 4a) Casein zymography demonstrating casemolytic activity in early lesions (lanes 1-5). stable lesions (lanes 6-10), lesions containing a thrombus (hanes 11-15) and recombinant MMp-12 (lane 16 ).

4b) Western blot analysis of the casein zymography of recombinant MMP-12 (NA: lane 17), a stable kesion (5: lane 18j and a lesion containing a thrombus (T) lane 19) dernonstrating that the caseinolytic activity in the stable leston, the lesion containing a thombus and recombinant MMP-12 is MMP-12 derived.

4c) Quantification of the scanned major casemolytic band. 


\section{$>$ Discussion}

The current study describes the identification of genes that are differentially expressed between morphologically characterized whole mount human early lesions, stable lesions and lesions containing a thrombus. We used two independent techniques. SSH and DNA micro-array, to identify genes potentially involved in lesion initiation, lesion progression and rupture of atherosclerotic lesions. $5 \mathrm{SH}$ resulted in the isolation of 208 genes, while DNA micro-array resulted in the identification of 329 genes differentially expressed between the described lesions.

Comparison of the SSH and DNA micro-array results showed that almost entirely different gene sets were isolated. This is stressed by the finding that only 4 sequences (protein phosphatase 1, glycerol kinase, fibronectin 1 and TGFP binding protein 1) present in the $5 \mathrm{SH}$ libraries showed differential expression on the DNA micro-array. Of these clones, only fibronectin 1 and TGFB binding protein 1 were expressed above threshold value of our macro-array anallysis. Fibronectin expression was consistently upregulated in stable lesions in both SSH and DNA micro-array analysis, which is in close agreement with the results obtained by the initial SSH screening ". This indicates that the fibronectin gene showed sustained differential expression between three independent pools of CDNAA derived from stable lesions and lesions containing a thrombus. Expression of fibronectin has already been identified in early and stable lesions ${ }^{6,17}$. Fibronectin is involved in cell adhesion, SMC migration and proliferation, processes that are characteristic for stable lesions ${ }^{10,19}$. In advanced lesions, disruption of the fibronectin fibrils was observed which might be indicative for containing a thromby decreased cell adhesion and weakening of the fibrous cap ${ }^{17}$. Our finding of decreased fibronectin expression in lesions containing a thrombus also hints towards an important role for fibronectin in maintaining the integrity of the fibrous cap.

An important finding of the current study is the different distribution of EST fragments obtained by both techniques. The majority (60\%) of the $55 \mathrm{H}$ derived clones represented EST fragments and novel sequences, whereas the majority $(89 \%)$ of the genes selected by DNA micro-array coded for known genes. An explanation for this apparent discrepancy is that the DNA micro-array uses a fixed set of known genes and EST fragments of which the majority were derived from non-atherosclerotic tissue and cell lines. The SSH-technology identifies all genes, known and unknown, that are differentially expressed between two specimens. An interesting aspect of EST fragments and novel genes is the possibility to identify new proteins that are important in atherogenesis. However, revealing the function of these sequences is very laborious, since tools to study these novel proteins need to be developed.

Two different clustering criteria based on function and expression pattern were used to gain more insight in the complex data set obtained by both SSH and DNA micro-array analysis. Functional dustering resulted in the identification of 8 major clusters. One functional cluster contained genes involved in lipid metabolism. since lipid uptake and lipid metabolism is a continuous process in atherogenesis it 
is not surprising that genes in this cluster were modulated between all stages of atherogenesis. DNA micro-array analysis revealed Pla2 to be upregulated in early lesions and in lesions containing a thrombus. This pattern was confirmed by RT-PCR analysis on individual lesions. $\mathrm{Pla}$ is is an enzyme capable of modification of circulating lipoproteins and lipoproteins in the arterial wall ${ }^{20}$. Pla2 is clearly linked to atherogenesis since expression was observed in early and adwanced atherosclerotic lesions 34,22 . Furthermore, plaz transgenic mice show an increased susceptibility for atherosclerosis ${ }^{23}$. Pla2 is considered to be an acute phase reactant ${ }^{24}$ and expression levels are correlated with unstable angina ${ }^{25,26}$. Our observations of enhanced pla2 expression in lesions containing a thrombus could well reflect this acute phase reaction.

The increased influx of inflammatory cells during atherogenesis was reflected by the expression profiles of genes involved in the immune system and the cytokines. For example, several complement factors ( $C 3, \mathrm{CRR2}, \mathrm{C} 1 \mathrm{~s}, \mathrm{C} 7$ and $\mathrm{C} 1 \mathrm{q})$ were enhanced during the initiation of atherosclerosis and expression was even more upregulated in lesions containing a thrombus. Expression of $\mathrm{C} 1 \mathrm{r}, \mathrm{C} 1 \mathrm{~s}, \mathrm{C3a}, \mathrm{C} 4, \mathrm{C} 5 \mathrm{a}, \mathrm{C} 7, \mathrm{C} 8$ was already observed in atherosclerotic lesions ${ }^{27,28}$. Furthermore, increased expression of iC $3 \mathrm{~b}$ was observed in macrophages at the site of actual plaque rupture ${ }^{28}$.

The leukaemia inhibitory factor receptor was studied as a representative of the cytokine cluster. Lif receptor expression increased during atherogenesis, as shown by both DNA micro-array and RT-PCR analysis. Lif receptor protein expression was observed in a subset of macrophages in stable lesions and lesions containing a thrombus. Expression was localized near the lipid core, the shoulder regions of a lesion, near sites of rupture and in endothelial cells of small vessels in an organized thrombus. It was shown that the lif receptor ligand, leukaemia inhibitory factor, inhibits angiogenesis in vitro ${ }^{2}$. Furthermore, lif infusion decreased fatty streak formation in rabbits ${ }^{\text {*o }}$. Therefore, we might speculate that the lif-lif receptor interaction acts as a negative feedback mechanism on lesion development?.

Genes involved in matrix synthesis showed a heterogeneous modulation pattern, while the extracellular matrix degrading genes showed peak expression levels in stable lesions. As an example of these ECM degrading genes, differential expression of MMP-12 was further substantiated. RT-PCR analysis confirmed the upregulation in stable lesions compared to early lesions. However, no modulation between stable and lesions containing a thrombus was observed. This discrepancy might be due to biological diversity of the vascular specimens used. In addition, we have to bare in mind that the RT-PCR used in this study is not quantitative. MMP-12 protein expression was predominantly observed in macrophages at the rim of the lipid core, which is in close agreement with the observation of Halpert et al ${ }^{34}$. MMP-12 is a potent proteinase capable of digesting elastin, type IV collagen and fibronectin ${ }^{32}$. In this study we show a pronounced increase of MMP-12 activity in stable lesions compared to early lesions. 
Besides direct ECM degradation. MMP-12 can allso influence ECM degradation indirectly, since it is capable to actwate other MMP's as MMP-2 and MMP-3 ${ }^{32}$. It is interesting to speculate that MMP-12 activity is involved in weakening of the fibrous cap, which is a risk factor for plaque rupture ${ }^{33}$ 34. However, we did not observe MMP-12 expression at sites of potential rupture such as the shoulder area or the fibrous cap. Furthermore, MMP-12 expression and activity was not elevated in lesions containing a thrombus. The observation of enhanced MMP-12 MRNA expression by acetylated LDL ${ }^{32}$ together with the presence of MMP 12 at the rim of the lipid core suggests a role in migration of macrophages towards pools of lipid accumulation.

Using SSH and DNA micro-array analysis on early lesions, stable lesions and lesions containing a thrombus we identified genes that were alleady linked to atherogenesis, like fibronectin and pla2, which is a validation of the techniques used. We also isolated many EST-fragments and novel genes, that might encode novel proteins possibly involved in atherogenesis. Interestingly, we also found genes that were previously not linked to atherogenesis, such as insulin-like growth factor binding protein 6 , an inhibitor of cell proliferation ${ }^{35}$, cathepsin $Z$ and cathepsin $\mathrm{L} 2$ both members the cathepsin family of which among others cathepsin $S$ and cathepsin $\mathbb{K}$ are expressed in human atheroma ${ }^{36}$. Extensive analysis of the lif receptor and MMP-12 on the mRNA and protein levels further substantiated our gene expression results. Both proteins were absent in early lesions, while expression was increased after plaque progression. Furthermore, MMP-12 activity was also increased during plaque progression. These data suggest a role for the lif receptor and MMP-12 in lesion progression. In conclusion, in this study we identified several genes that show differential expression during human atherogenesis. This study therefore provides an enhanced insight in the molecular mechanisms involved in human atherogenesis. 
1. Zaman $A G$. Helft $G$, Worthley $S G$, Badimon JJ: The roie of plaque pupture and thrombosis in coronary artery disease. Atherosclerosis 2000, 149:251-66.

2. Virmani R, Kolodgie FD. Burke AP, Farb A, Schwartz SM: Lessons from sudden coronary death: a comprehensive morphological classification scheme for atherosclerotic lesions. Arterioscler Thromb Vasc Biol 2000, 20:1262-75.

3. de Vries $C J$, van Achterberg TA, Horrevoets AJ, ten Cate JW, Pannekoek H: Differential display identification of 40 genes with altered expression in activated human smooth muscle cells. Local expression in atherosclerotic lesions of smags, smooth muscle activation-specific genes. J Biol Chem 2000,275:23939-47.

4. Horrevoets AJ, Fontijn IRD, van Zonneveld AJ, de Wries Cl, ten Cate JW. Pannekoek H: Vascular endothelial genes that are responsive to tumor necrosis factor-alpha in vitro are expressed in atherosclerotic lesions, including inhibitor of apoptosis protein-1, stannin, and two novel genes. Blood 1999,93:3418-31.

5. Mikita $T$, Porter $G$, Lawn RM, Shiffman D: Oxidized low density lipoprotein exposure alters the transcriptional response of macrophages to inflammatory stimulus. I Biol chem $2001.276: 45729-39$.

6. Hiltunen M, Tuomisto T, Niemi M, Brasen J, Rissanen T, Toronen P, Vajanto I, Yla-Herttuala S: Changes in gene expression in atherosclerotic plaques analyzed using DNA array. Atherosclerosis 2002,165:23.

7. Martinet W, Schrijwers DM, De Meyer GRY, Thielemans 1; Knaapen MWM, Herman AG, Kockx MM: Gene expression profing of apoptosis-related genes in human atherosclerosis. Upregulation of death- associated protein kinase. Arteriosclerosis Thrombosis and Vascular Biology 2002,22.

8. Tyson $\mathrm{KL}$, Weissberg PL, Shanahan CM: Heterogeneity of gene expression in human atheroma unmasked using CDNA representational difference analysis. Physiol Genomics 2002,91:121-30.

9. Hiltunen MO, Niemi M, Yla-Herttuala S: Functional genomics and DNA array techniques in atherosclerosis research. Curr Opin Lipidol 1999, 10:515-9.

10. McCaffrey TA, Fu C, Du B, Eksinar S, Kent KC, Bush H, Jr, Kreiger K, Rosengart T, Cybulsky MI, Silverman ES, Collins T: High-level expression of Egr-1 and Egr-1-inducible genes in mouse and human atherosclerosis. I Clin Invest 2000, 105:653-62.

11. Faber BC, Cleutjens KB, Niessen RL, Aarts PL, Boon W. Greenberg AS, Kitslaar PJ, Tordoif JH, Daemen MI: Identification of genes potentially inwolved in rupture of human atherosclerotic plaques. Circ Res 2001,89:547:54.

12. DeRisi JL, lyer VR, Brown PO: Exploring the metabolic and genetic control of gene expression on a genomic scale. Science 1997,278:6801-6.

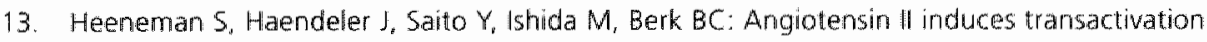
of two different populations of the platelet-derived growth factor beta receptor. Key role for the p65 adaptor protein Shc. J Biol Chem 2000,275:15926-32. 
14. Hufton SE, Moerkerk PT, Brandwijk R, de Bruine AP, Arends JW, Hoogenboom HR: A profile of differentially expressed genes in primary colorectal cancer using suppression subtractive hybridization. FEBS Lett 1999,463:77-82.

15. won Stein OD. Thies WG. Hofmann M: A high throughput screening for rarely transcribed differentially expressed genes. Nucieic Acids Res 1997,25:2598-602.

16. Faber BC, Heeneman S. Daemen M. Cleutjens KB: Genes potentially involved in plaque rupture. Curr Opin Lipidal 2002,13:545-52.

17. Kakolyris S, Karakitsos P. Tzardi M, Agapitos E: Immunohistochemical detection of fibronectin in early and advanced atherosclerosis. In Vivo 1995,9:35-40.

18. Pearlstein E: Plasma membrane glycoprotein which mediates adhesion of fibroblasts to collagen. Nature 1976,262:497-500.

19. Nelson PR, Yamamura $S$, Kent $K C$ : Extracellular matrix proteins are potent agonists of human smooth muscle cell migration. I Vase Surg 1996,24:25-32.

20. Hurt-Camejo $E$, Camejo $G$, Peilot H, Oorni K, Kowanen P: Phospholipase A(2) in vascular disease. Circ Res 2001,89:298-304.

21. Hurt-Camejo $\mathbb{E}$. Andersen 5 , Standal $R$, Rosengren B, Sartipy $P$, Stadberg $E$, Johansen $B$ Localization of nonpancreatic secretory phospholipase A2 in normal and atherosclerotic arteries. Activity of the isolated enzyme on low-density lipoproteins. Arterioscler Thromb Vasc Biol 1997. 17:300-9.

22. Romano M, Romano E, Bjorkerud S, Hurt-Camejo E: Ultrastructural localization of secretory type II phospholipase $A 2$ in atherosclerotic and nonatherosclerotic regions of human arteries. Arterioscler Thromb Vasc Biol 1998,18:519-25.

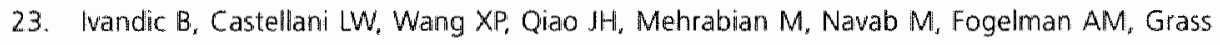
DS, Swanson ME, de Beer MC, de Beer F, Lusis AJ: Role of group II secretory phospholipase A2 in atherosclerosis: 1. Increased atherogenesis and altered lipoproteins in transgenic mice expressing group lla phospholipase A2. Arterioscler Thromb Vasc Biol 1999,19:1284-90.

24. Crowl RM, Stoller HI. Conroy RR, Stoner CR: Induction of phospholipase A2 gene expression in human hepatoma cells by mediators of the acute phase response. I Biol Chem $1991,266: 2647-51$

25. Kughyama $K$, Ota $Y$, Sugiyama S, Kawano $H$, Doi H, Soejima $H$, Miyamoto S, Ogawa $H$, Takazoe K, Yasue $H$ : Prognostic value of plasma levels of secretory type II phospholipase A2 in patients with unstable angina pectoris. Am I Cardiol 2000,86:718-22.

26. Kugiyama $K$, Ota $Y$, Takazoe $K$, Moriyama $Y$, Kawano $H$, Myyo $Y$, Sakamoto T, Soejima $H_{\text {, }}$ Ogawa $H$, Doi $H$. Sugiyama $S$, Yasue $H$ : Circulating levels of secretory type It phospholipase A(2) predict coronary events in patients with coronary artery disease. Circulation 1999, 100:1280-4.

27. Yasojima K. Schwab C. McGeer EG, McGeer PL: Complement components, but not complement inhibitors, are upregulated in atherosclerotic plaques. Arteriouscler Thromb Vasc Biol 2001.21:1214.9. 
28. Laine $\mathbb{P}$, Pentikainen MO, Wurzner $R$, Penttila A, Pazwonen T, Meri S. Kovanen PT: Evidence for complement activation in ruptured coronary plaques in acute myocardial infarction. Am \Cardiol 2002,90:404-8.

29. Pepper MS, Ferrara N. Orci L, Montesiano R: Leukemia inhibitory factor (LIF) inhibits angiogenesis in vitro. I Cell Sci 1995, 108:73-83.

30. Moran CS, Campbell JH, Campbell GR: Human leukemia inhibitory factor upregulates LDL receptors on liver cells and decreases serum cholesterol in the cholesterolfed rabibit. Arteriosiler Thromb Vasc Biol 1997, 17:1267-73.

31. Halpert I, Sires UI, Roby JD, Potter-Perigo 5, Wight TN, Shapiro SD, Welgus HG, Wickline SA Parks WC: Matrilysin is expressed by lipid-laden macrophages at sites of potential rupture in atherosclerotic lesions and localizes to areas of versican deposition, a proteoglycan substrate for the enzyme. Proc Natl Acaid Sci U S A 1996,93:9748-53.

32. Matsumoto $S$, Kobayashi $T$, Katoh $M$, Saito $S$, Ikeda $Y$, Kobori M, Masuho $Y$, Watanabe $T$ : Expression and localization of matrix metalloproteinase-12 in the aorta of cholesterolwed rabbits: relationship to lesion development. Am J Pathol 1998, 153:109 19 .

33. Sukhova GK, Schonbeck U, Rabkin E, Schoen FI, Poole AR, Billinghurst RC, Libby P: Evidence for increased collagenolysis by interstitial collagenases- 1 and -3 in vulnerable human atheromatous plaques. Circulation 1999,99:2503-9.

34. Young $U$, Libby $P_{v}$ Schombeck $U$ : Cytokines in the pathogenesis of atherosclerosis. Thromb Haemost 2002,88:55,4-67.

35. Seurin D, Lassarre C. Bienvenu G, Babajko S: Insulin-like growth factor binding protein-6 inhibits neuroblastoma cell proliferation and tumour development. Eur I Cancer 2002,38:2058.

36. Sukhova GK, Shi GP, Simon DI, Chapman HA, Libby P. Expression of the elastolytic cathepsins $S$ and $K$ in human atheroma and regulation of their production in 5 mooth muscle cells. 1 Clin invest 1998, 102:576-83. 



\title{
CHAPTER 5
}

\section{UNIQUE GENE EXPRESSION PROFILES CHARACTERIZE CHOLESTEROL CHALLENGE AND ATHEROSCLEROTIC PLAQUE PROGRESSION IN APOE DEFICIENT MICE}

\author{
Birgit Faber'* ,Esther Lutgens'*, Chris TA Evelo", Gordon J Porter", Mat JAP Daemen' \\ and Kitty B.IM Cleutjens'. \\ *Both authors have contributed equally \\ ' Dept of Pathology, Cardiovascular Research Institute (CARIM), University \\ of Maastricht, Maastricht, the Netherlands \\ "Dept of Bioinformatics, CARIM, University of Maastricht, Maastricht, \\ The Netherlands \\ ${ }^{3}$ Incyte Genomics Inc., Palo Alto, CA, USA
}




\section{$>$ Abstract}

We conducted a large scale gene expression analysis on aortic arches of ApoE-/- and C57Bl6 mice fed a normal chow (NC) or a Western type (WT) diet for 3,4.5 and 6 months (m). MRNA was amplified and hybridized in duplicate to a DNA micromarray $(>9000$ genes, Incyte Genomics $(n c$ ) and compared to the co-hybridized reference (ApoE-/-mice fed a NC diet for $3 \mathrm{~m}$ ). To identify genes affected by cholesterol withdrawal, an additional group of ApoE- mice, in which the WT diet was replaced after $4.5 \mathrm{~m}$ by a NC diet $(1.5 \mathrm{~m})$, was added. 498 genes were differentially ( $>2$ fold) expressed in at least one group compared to the reference. During atherogenesis, the number of differentially expressed genes increased exponentially, especially in the diet group. In the NC diet group high correlations were observed between the number of differentially expressed genes and plaque area $\left(r^{2}=0.95\right)$, the number of plaque cells $\left(r^{2}=0.99\right)$. plaque macrophages $\left(r^{2}=0.95\right)$, plaque Twcells $\left(r^{2}=0.99\right)$. While no significant correlations in serum lipid levels were observed (LDL $r^{2}=0.47, \mathrm{HDL} r^{2}=0.00$, cholesterol $r^{2}=0.23$, triglycerides $r^{2}=0.03$ ). In contrast, no significant correlations were observed in the WT diet group. Time related expression-pattern clustering and functional clustering suggested an important role in atherogenesis for genes involved in inflammation and the immune system (such as MIP $1 \alpha$, small inducible cytokine A6 and fractalkine), and genes involved in protein/matrix degradation (such as cathepsin 5, MMP-2 and MMP-12). After cholesterol-withdrawal, lipid levels decreased significantly, while plaque morphology did not change. The number of differentially expressed genes (vs relerence) decreased by $26 \%$. Twenty-two genes showed a $>2$ fold decrease after cholesterol withdrawal compared to the $6 \mathrm{~m}$ WT diet group. In conclusion, atherosclerosis induces a gene expression profile that is related to plaque characteristics and that disappears after a WT diet intervention. Clustering suggested an important role for genes involved in inflammation and proteolysis. Cholesterol withdrawal decreased the number of differentially expressed genes. This detailed DNA micro-array study will help to understand the pathogenesis of atherosclerosis and might establish new targets for therapeutic intervention. 
Atherosclerosis is a complex, multifactorial disease that is responsible for the highest morbidity and mortality in the Western world ". Although the clinical consequences and pathological aspects of atherosclerosis are well known and described, understanding of the precise molecular mechanisms of atherosclerotic plaque initiation and progression has already been a daunting task for years.

Until now, the effects of many individual candidate genes on atherosclerosis have been investigated, and have revealed an important role for mediators of inflammation, extracellular matrix regulation, lipid metabolism and oxidative stress in the progression of atherosclerosis 1. . However, rather than to result from a monogenetic cause, many genes seem to be involved in atherosclerosis.

During the last decade, techniques such as differential display (DD), sequential analysis of gene expression (SAGE), suppression subtraction hybridization (SSH) and DNA micro-array analysis have been developed to monitor differential gene expression profiles in a high throughput fashion in complex disease systems. All these techniques have now been successfully used to identify disease related gene expression profiles in cancer " CNS disease ${ }^{5}$ and cardiovascular disease 5.

In atherosclerosis, the majority of high throughput gene expression studies has been performed in atherosclerosis-related cell lines ${ }^{\prime 9}$. These studies revealed an increased expression of mediators of inflammation, lipid metabolism, signaling molecules and extracellular matrix related genes, but also differential expression of many unknown genes. Although cell lines do provide a reproducible source of RNA, the gene expression profile may not accurately reflect the molecular events that take place in the atherosclerotic lesion. Although the use of whole mount tissue also has its drawbacks (cell heterogeneity, differences in tissue composition), its use is often preferred as it reflects the invivo situation. Recently, we were able to identify genes that were differentially expressed between stable and ruptured atherosclerotic plaques using the SSH technique ${ }^{10}$. This study suggested an important role of perilipin and SSH6 in plaque rupture. A similar study has been conducted comparing human non-diseased and atherosclerotic vessel walls ". Another study compared gene expression of aorta versus vena cava tissue of macaques, using DNA micro-array hybridizations. That study revealed specific expression of RGS5 in aortic tissue ".

Recently, DNA array analysis, in which the expression profiles of 588 genes in vascular trees of $\mathrm{ApOE}-1$ - mice and wild type (C57B|6) were compared, revealed a dynamic gene expression pattern of numerous genes ${ }^{1}$. However, the number of genes and timepcints investigated in this study was limited.

The aim of the present study was to obtain a detailed portrait of gene expression in the different stages of atherosclerosis. For this purpose we choose for DNA micro-array analysis (mouse unigene 1, >9000 genes, Incyte genomics Inc), the technique that is suited best for comparisons of gene expression profiles between multiple samples. 
To limit the effects of genetic heterogeneity and environmental influences, the experiment was performed in a well established mouse model of atherosclerosis, the ApoE deficient mouse. Gene expression patterns were determined on (atherosclerotic) aartic arches of ApoE- and wild type (C57B16) mice that were fed normal chow (NC) or a Western type (WT) diet $(0.21 \%$ cholesterol) for $3,4.5$ and 6 months. In addition, a cholesterol withdrawal study in which the western type diet was replaced after 4.5 months by a normal chow diet (1.5 months) was performed. Only 498 of the 9000 genes investigated were differentially expressed at one or more timepoints. The number of differentially expressed genes increased exponentially with the progression of atherosclerosis. Gene expression profiles were related to plaque composition, but only in the non-diet subgroup. Both time related expression clustering and functional clustering suggested an important role of genes involved in inflammation and the immune-system (such as MIP $1 \alpha$ (macrophage inflammatory protein), small inducible cytokine $A 6$ and fractalkine) and genes inwolved in protein/matrix degradation (such as cathepsin S, MMP-2 and MMP12). With this study, we have created a detailled gene-expression database containing the expression profiles of many genes during different stages and conditions of mouse atherosclerosis. One may assume that further analysis and (functional) validation of this DNA micro-array data will yield new insights into relevant pathways and might result in new therapeutic targets in atherosclerosis.

\section{$>$ Materials and Methods}

\section{Mice and experimental protocols}

Male ApoE- $/$ - mice and C57Bit6 mice were purchased from iffa Credo. Mice were fed a normal mouse chow diet (NC), or a Western type diet (WT) $10.21 \%$ cholesterol, Hope Farms) starting at 5 of weeks of age. Mice were sacrificed at the age of 3 months (m) (ApoE-/ - NC $n=35$, ApoE-/ WT $n=13$, C57Bl6 NC $n=17$, C57Bl6 WT $n=17), 4.5 \mathrm{~m}$ (ApoE $/-$ NC $n=14$, ApoE $/ \%$ WT $n=14), 6 \mathrm{~m}$ (APoE- $/-N C n=16$, ApoE- $/-$ WT $n=16$, C57Bi6 NC $n=18, C 57 \mathrm{Bl}$ WT $n=18$ ), $9 \mathrm{~m}$ (ApoE- $/ \mathrm{NC} n=14$ ) and $12 \mathrm{~m}$ (ApoE- $/ \mathrm{NC}$ $n=15)$ in addition. an extra group of mice (cholesterol withdrawal) was fed a WT diet until the age of $4.5 \mathrm{~m}$, followed by a normal chow diet for $1.5 \mathrm{~m}$ (ApoE- $/-n=16$, C $57816 n=18$ ).

After the experimental period, mice were euthanized and blood $( \pm 1 \mathrm{ml})$ was taken from the caval vein for lipoprotein analysis. Mice were used for either RNA extraction or histological anallysis. For RNA-extraction, the aortic arches including their main branchpoints were cleaned from fatty tissue, excised, rinsed in ice-cold PBS, snap frozen in liquid nitrogen and stored at $-70^{\circ} \mathrm{C}$ until further use. For histological analysis, five mice were used per group. Mice were perfused with PBS containing $1 \%$ nitroprusside followed by perfusion with $1 \%$ paraformaldehyde as described before ${ }^{1 \%}$. 
The entire aortic arch including its main branch points (brachiocephalic artery, left carotid artery and left subclavian artery) was cleaned free for fatty tissue, fixed overnight in $1 \%$ paraformaldehyde and the tissue was processed as described earlier ${ }^{44}$. After processing, aortic arches were embedded longitudinally and twenty $4 \mu \mathrm{m}$ sections that represented the central portion of the aortic arch were cut.

\section{RNA isolation and DNA micro-array analysis}

Total RNA was isolated using either the RNeasy kit (Qiagen) (DNA micro-array) or the isothiocyanianate/CsCl method (RT-PCR). Per isolation, three aortic arches of ApoE $\%$ - mice or 4 aortic arches of C $57 \mathrm{Bl} 6$ mice were pooled. The mean yield per isolation was $2 \mu \mathrm{g}$. For DNA micro-array analysis, mRNA was amplified using a 17 based technique "t: and labeled with Cy3 and Cy5 fluorescent dyes. CDNA of the 3,4.5 and 6 months NC and WT groups as well as CDNA of the cholesterol withdrawal group was hybridized to a DNA micro-array (22 micro-arrays in total) (Mouse Unigene 1, >9000 genes, Incyte Genomics Inc.) and always compared to the co-hybridized reference (20 aortic arches of ApoE-/- mice fed a normal chow diet for 3 months, the time-point at which the first small initial lesions appear). All hybridizations were performed in duplicate. mRNA of the aortic arches of the 9 and 12 months ApoE-/ mice was used for additional validation of the differentially expressed genes. Genes were included in the subsequent analysis if both readings had a signal to background ratio of 2.5 or more, a signal intensity of above 250 units for one or both dyes, and a spot size of at least $40 \%$ of the spotted area. Data were analyzed using Gemtools ${ }^{\mathrm{rm}}$, and the threshold of differential expression was set at $>2$-fold. Subsequently, time related expression pattern clustering was performed using a developed computer-based algorithm. Functional clustering of differentially expressed genes was performed using the mouseGOmapps (biological process. 3.40 clusters) from Genmapp (www.genmapp.org) and by manual clustering. Since all data reflect hybridization signals that are normalized to the co-hybridized reference, (ApoE-/-, $3 \mathrm{~m}$ NC) the expression data of the ApoE-/-cholesterol withdrawal group were also compared to the expression data of the 6 months WT diet group.

\section{Plaque morphology and gene expression}

To relate changes in atherosclerotic plaque composition to changes in gene expression, aortic arches were analyzed histo-morphologically. Plaque area per aortic arch wais measured on 4 hematoxylin and eosin stained aortic arch sections ( $20 \mu \mathrm{m}$ apart) per mouse, using the Leica 570 Quantimet morphometry system. Furthermore, the total number of plaque cells, plaque macrophages and plaque T-lymhocytes per aortic arch was counted on HE, anti-Mac-3 (rat monoclonal, Pharmingen, 1:30) and anti-CD45 (rat monoclonal Pharmingen, 1:50) stained sections. 


\section{Lipid profille}

For the assessment of lipid profiles standard enzymatic techniques were used, automated on the Cobas Fara centrifugal analyzer (Hoffmann-La Roche). Total plasma cholesterol and HDL were measured using kit no. 0736635 and no. 543004 (Hoffmann-la Roche); total glycerol using kit no 337-40A/337-10B (Sigma) and free glycerol was measured using kit no. 0148270 (Hoffmann-La Roche). Precipath (standardized serum) was used as an internal standard. LDL was calculated as total cholesterol - ((total glycerol-free glycerol $/ 2.2)$-HDL)).

\section{Validation procedures}

\section{Reverse Transcriptase PCR}

The SMART PCR CDNA synthesis kit (BD sciences) was used for the preparation of double stranded CDNA from 0.5 . Hg template RNA. CDNA was diluted to a total volume of $50 \mathrm{ml}$. PCR-amplification of MIP $1 \alpha$ (macrophage inflammatory protein): sense 5"-GACTAAGAGAAACCGGCAG-3' plus anti-sense 5'-TCGATGTGGCTACTTGGCA G-3", small inducible cytokine A6 sense 5'-GATCGICGCTATAACCCTC-3' plus anti-sense 5'-TGCTIAGGCACCTCTGAAC-3' and fractalkine sense 5'-GATCATGCTCCACAGAACC-3' plus anti-sense 5"-GGCACAGACATTGGTAAG-3' and GAPDH was performed according to standard procedures.

\section{Statistics}

All DNA micro-arrays were analyzed and validated using Gemtools ${ }^{\text {st }}$. To calculate the correllation coefficient of the number of differentially expressed genes and histological plaque characteristics or lipid profiles, a log-linear regression analysis was performed. In the cholesterol withdrawal study, a Mann-Whitney $U$ test was used to compare plaque characteristics and cholesterol lipid values between ApoE-/-mice fed a WT diet for 6 months and ApoE-/- mice of the cholesterol withdrawal group. 


\section{DNA Micro-array analysis}

Datamanalysis was performed as depicted in figure 1. In total, 498 genes were differentially expressed $>2$ fold (compared to the co-hybridized reference: ApoE- $/$ - mice, 3 months NC diet) in one or more of the experimental groups analyzed. Genes that were upregulated/downregulated in aortic arches of $\geq 3$ ApoE-/-groups and at the same time upregulated/downregulated in aortic arches of $\geq 3$ C57Bif groups were excluded from further analysis $(n=40)$. These genes might reflect an age related effect. Of the remaining 458 genes, 104 genes coded for EST fragments and 354 represented known genes.

The majority of the genes $(n=406)$ was differentially regulated in aortic arches of ApoE-/-mice (273 upregulated, 130 downregulated, 3 up and down), while only 109 genes were differentially expressed in C57Bl6 mice (52 upregulated, 55 downregulated, 2 up and down) (fig. 1). The number of differentially expressed genes increased exponentially during atherosclerotic plaque progression, especially in ApoE- - mice between the age of 4.5 and 6 months (fig. 2). For example, the inumber of genes in ApoE- $/$ - fed a normal chow diet ( 4.5 months - 6 months) increased $244 \%$, and fed a Western type diet (3-6 months) increased $243 \%$ (fig. 2).

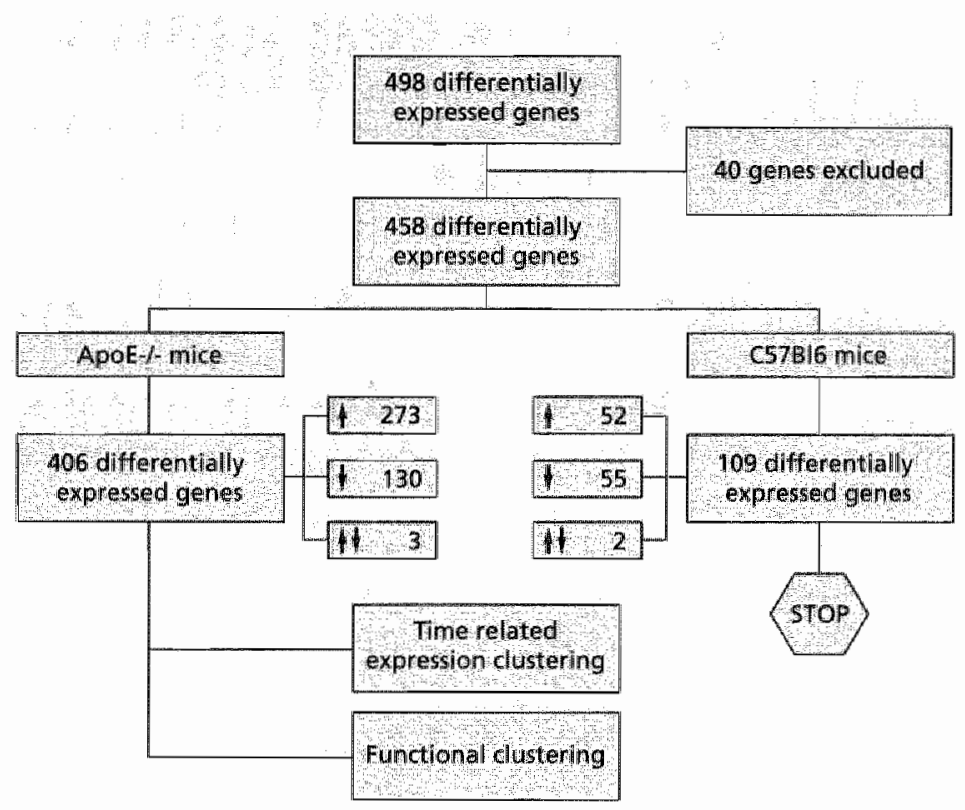

Figure 1: Fom-chant of the analysis of genes that are differentialy expressed during atherogenesis in Apo Edefient mice and $C 57 B / 6$ mice. 


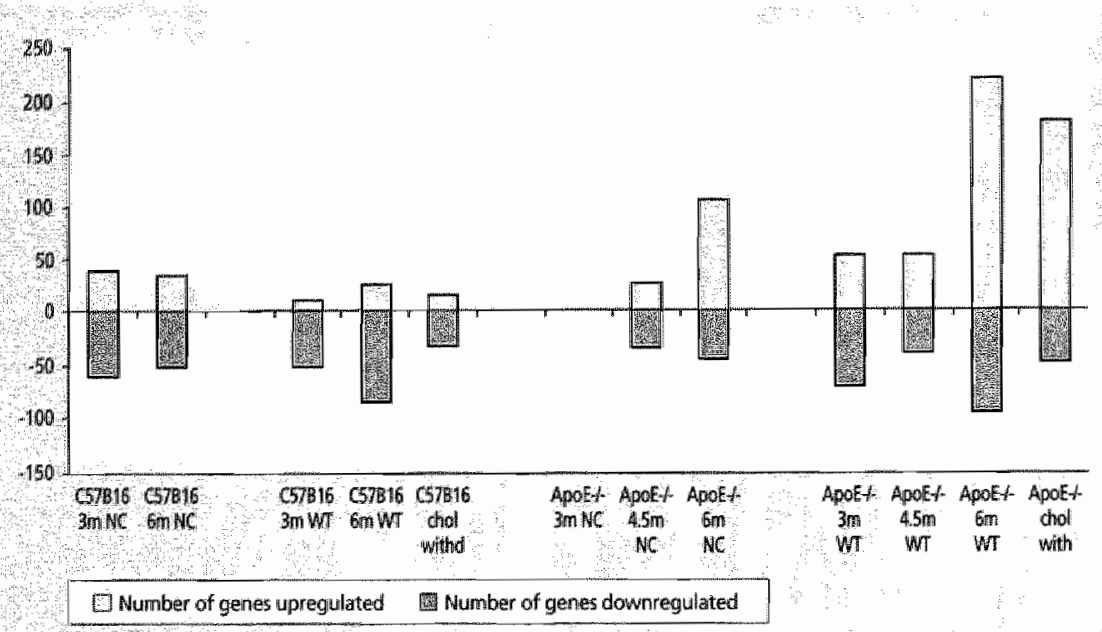

Figure 2: Number of genes that are differentially expressed (S2-fold) in the aortic arches of Apot deficient and (57B:6 mice that were given a normal chow (NO) diet a western type diet (MT) for 3 months (m), $4,5 \mathrm{~m}$ or $6 \mathrm{~m}$. or a NC diet for $4.5 \mathrm{~m}$ which was replaced by a NC diet for an additiona $1.5 \mathrm{~m}$ fcholesterol withdrawal groupl.

\section{Correlation of the number of differentially expressed genes with histological and lipid profile changes in atherosclerosis}

To investigate whether the increase in the number of differentially expressed genes was correlated with changes in plaque size and composition, or plasma lipid levels, correlation studies comparing plaque morphology or serum lipids with the number of differentially expressed genes were performed.

Within the group of normal chow fed mice, the correlations between the number of differentially expressed genes and plaque area and plaque composition were significant. Correlation co-efficients in the normal chow fed mice were: plaque area $\left(r^{2}=0.95\right)$. number of plaque cells $\left(r^{2}=0.99\right)$, plaque macrophages $\left(r^{2}=0.95\right)$, plaque T-cells $\left(r^{2}=0.99\right)$ while serum lipid levels (LDL $r^{2}=0.47, H D L r^{2}=0.00$, cholesteroll $r^{2}=0.23$, triglycerides $r^{2}=0.03$ ) showed no correlation. In contrast, no correlation was observed between the number of differentially expressed genes and plaque characteristics in the ApoE $/$ - groups fed Western type diet (plaque area $\left(r^{2}=0.6\right)$, number of plaque cells $\left(r^{2}=0.4\right)$, plaque macrophages $\left(r^{2}=0.5\right)$, plaque T-cells $\left(r^{2}=0.7\right)$ and serum lipids (LDL $r^{2}=0.05, \mathrm{HDL} r^{2}=0.3$, cholesterol $r^{2}=0.04$, triglycerides $\left.r^{2}=0.2\right)$ ).

\section{Expression levels}

Differential expression levels, pelative to the co-hybridized reference, ranged from 2 to 36.7 fold and from -2 to -11.1 fold. In the ApoE-/-groups, 5 genes showed al more then 10 -fold increase, 15 genes were increased between 5 and 10 -fold, and 256 genes 
showed an increase between 2 -fold and 5-fold. For the downregulated genes, these numbers were 3,18 and 112 genes respectively.

Genes that showed the highest relative expression levels were serine protease inhibitor 2-2 (10.5-fold), CD.68 (11.0-fold), cathepsin S(12.6-fold), lectin galactose binding soluble 3 (12.4-fold) and apoptosis inhibitory $6(17.5$-fold). Genes with the lowest relative expression levels were 3 EST fragments (all-10. 11 -fold).

In C57Bl6 mice, less genes showed a high level of differential expression. Only one gene, the apolipoprotein E gene, which is a perfect positive control, showed a $>10$ fold increase. Three genes (two EST fragments and a serum albumin variant) were increased between 5 and 10 -fold and the remaining 50 genes showed an increased expression level between 2 and 5-fold. Differential expression levels of downregulated genes ranged between 2 and 5 -fold.

\section{Time related expression clustering}

For the detection of time related expression clustering, we developed a new algorithm. In short, the different groups representing the different stages of atherosclerosis were ordered sequentially based on plaque area as measured by the morphometry system: 3 months WT diet, 4.5 months NC, $4.5 \mathrm{~m}$ WT, $6 \mathrm{~m} \mathrm{NC}, 6 \mathrm{~m}$ WT. Subsequently every gene was given a number representing upregulation (1), no change (0) or downregulation (-1) when compared to the co-hybridized reference. The different groups were sorted according to the different patterns. In theory, $3^{i}=243$ clusters could be formed. However, only 34 different clusters were observed. Within these 34 clusters, the major clusters that were identified represented genes involved in plaque initiation, plaque progression and a cluster of genes that were highly expressed throughout both plaque initiation and plaque progression. The number of genes per cluster, its expression pattern and examples of the genes present in the respective clusters are indicated in table 1 and table 2. The cluster of genes involved in plaque initiation contained for example small inducible cytokine A5 (RANTES), small inducible cytokine A7 (MCP-3), and protein tyrosine phosphatase. The cluster of genes involved in plaque progression included MMP-2, small inducible cytokine A4 (MIP-1B), and osteoprotegerin. Genes that were upregulated throughout atherogenesis were cathepsin $S$, ATP-binding cassette subfamily $\mathrm{G}$ and lysosomal associated protein transmembrane 5 . Although the genes in each duster belonged to different families, it was remarkable that many genes were linked to inflammation and proteolysis.

\section{Functional clustering}

Functional clustering was performed using 340 mouse GO Mapps (biological processes) of Genmapp (www.genmapp.org). In adidion a manual functional clustering was performed (table 2). Clusters that contained most of the differentially expressed genes were those inwolved in inflammation (acute phase response, chemotaxis, 
Table 1: Cuerwisw of the different the retated expression chusters

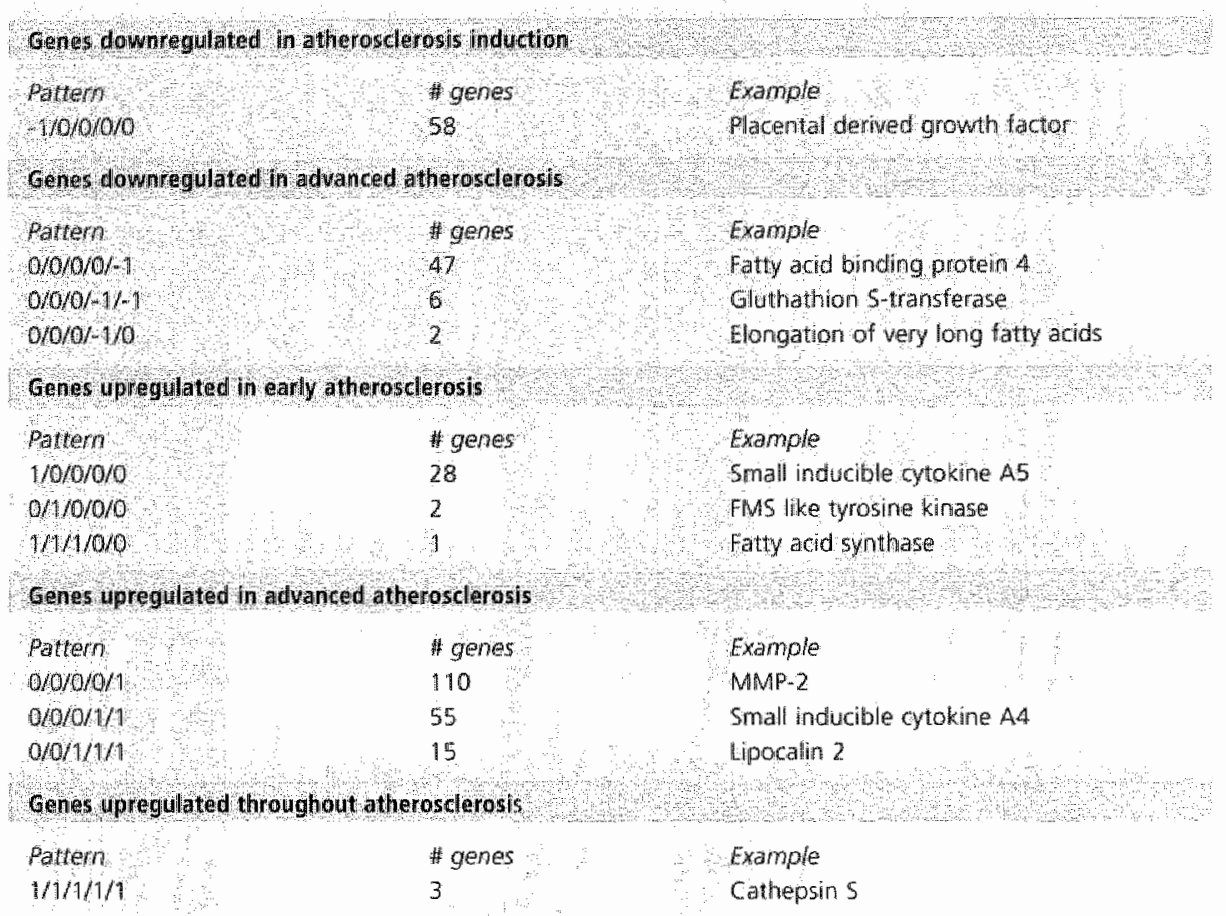

cytokines, inflammatory responses) and protein/matrix degradation (protein degradation, proteolysis and peptidolysis, catabolism). Of special interest was the family of small inducible cytokines (SIC) of which 10 members showed differential expression. Expression clustering showed a heterogeneous pattern. Some SIC's were upregulated during plaque initiation (RANTES and MCP-3) while others were upregulated in advanced lesions (MIP-1 $\alpha, M C P-3$ and SIC-21a). To further validate the expression profiles of MIP $1 \alpha$, SIC A6 and fractalkine, RT-PCR performed. As shown in table 3, MIP $1 \alpha$ was absent in C57BI6 mice and in the early phase of atherosclerosis in ApoE deficient mice, whereas expression was observed during the advanced phase of atherogenesis. This is in close agreement with the DNA-micro-array data (table 2). SIC-A6 was expressed in all aortic trees. As already obseved by DNA micro-array analysis expression of fractalkine was merely observed in advanced lesions.

Interestingly, many members (6) of the cathepsin gene family were modulated during atherogenesis. Most cathepsins were upregulated in advanced lesions. Besides the two most abundant functional clusters, many genes involved in lipid/cholesterol metabolism were moduloated during atherogenesis (e.g. fatty acid binding protein). 
Table 3: RT-PCR analysis of small inducible cytokines (SIC) A6, MP ia and fractalkine in artic anches of $\mathrm{C} 7 \mathrm{C} 6 \mathrm{6}$ wice and ApoE deficient mice.

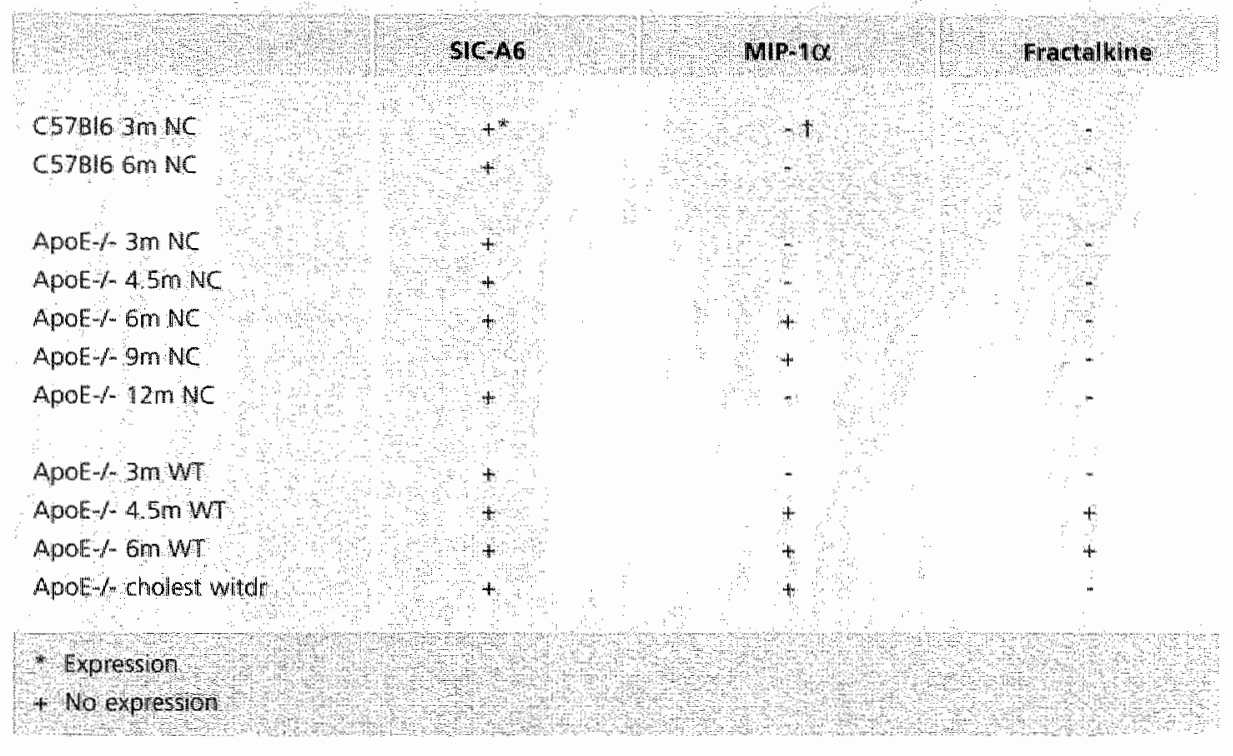

The clustering according to the GO Mapps revealed the presence of gene clusters involved in embryogenesis and morphogenesis (homeobox genes, dickkopf homolog 3).

\section{Cholesterol withdrawal study}

In ApoE- / mice in which the western type diet was replaced after 4.5 months by a normal chow (for 1.5 months) a drop of $26 \%$ in the number of differentially expressed genes was observed. In ApoE-\% mice fed the Western type diet for 6 months, the number of differentially expressed genes was 311 , while this number was only 230 in the cholesterol withdrawal group.

Although the gene expression profile altered after cholesterol withdrawal, plaque histology (plaque area, number of plaque cells, number of macrophages, number of T-lymphocytes) did not change significantly. Only lipid levels had significantly decreased (ApoE-1- $6 \mathrm{~m}$ WT vs cholesterol withdrawal: cholesterol:2.48 $\pm 0.24 \mathrm{mmol} / \mathrm{L}$ vs $1.3 \pm 0.21$ $\mathrm{mmol} / \mathrm{L}, \mathrm{p}<0.05 ; \mathrm{LDL} 0.86 \pm 0.22 \mathrm{mmol} / \mathrm{L}$ vs $0.22 \pm 0.11 \mathrm{mmol} / \mathrm{L}, \mathrm{p}<0.05)$. Since the WT diet was only replaced by a NC diet for a very short period of time $(1.5 \mathrm{~m})$ and might be insufficient for alterations in plaque morphology. There fore it might be possible that the change in gene expression precedes histological changes of cholesterol withdrawal. An other explanation for the reduction in gene expression might involve the decreased lipid levels in the blood. 


\section{Genes specifically expressed after cholesterol withdrawal}

To identify genes that were affected by cholesterol withdrawal time related expression clustering was performed including the $3 \mathrm{~m}$ ApoE- $/$ WT, the $4.5 \mathrm{~m}$ ApoE- $/$ WT, the $6 \mathrm{~m}$ ApoE-/ WT and the ApoE-/-cholesterol withdrawal groups. The expression of these groups was compared to the co-hybridized reference (ApoE-/ $3 \mathrm{~m} \mathrm{NC}$ ) in total, 61 genes showed an increase ( 0 or -1 in $6 \mathrm{~m}$ A.poE WT diet to 1 or 0 in the ApoE cholesterol withdrawal group) while 57 genes showed a decrease ( 1 or 0 in $6 \mathrm{~m}$ ApoE WT to 0 or -1 in the ApoE cholesterol withdrawal group.

To identify candidates that were more than 2-fold differentially expressed after cholesterol withdrawal, the ratio of the expression data of the ApoE-/- cholesterol withdrawal groups and the $6 \mathrm{~m}$ ApoE-\% western type diet group was calculated (see materials and methods). In ApoE-1-mice, 22 genes showed differential expression. Two interesting clusters of cholesterol withdrawal responsive genes were observed. The first cluster consisted of 13 genes that were highly expressed in advanced stagers of atherosclerosis, but whose expression went back to baseline (lewel of ApoE-1-mice, 3 months NC) after cholesterol withdrawal. Six genes of this group were EST fragments and 7 genes were known (ephrin E4, serum amyloid A3, chitinase 3, rad and gem related GTP.binding protein, nuclear receptor subfamily 2, group $\mathrm{H}$, member 2 , FK506 binding protein 6 and stearoyl-Coenzyme $A$ desaturase). The second cluster contained 4 genes that were highly expressed in advanced atherosclerosis and showed a significant decrease after cholesterol withdrawal. However, expression levels did not decrease to baseline. These genes were: inter-alpha trypsin inhibitor, serine protease inhibitor $2-2$, lipocalin-2 and complement component 1. 
Table 2: Functional chstering and gene expression profites of genes differentathy expressed in the aortic arches of C5TBl6 or ApoE deficient mice

\begin{tabular}{|c|c|c|c|}
\hline Categror & Gene name & Clone 10 & \\
\hline Lipuid tmetabollism & $\begin{array}{l}\text { apolipoprotein A-I } \\
\text { apolipoprotein C-IV } \\
\text { apolipoprotein } \mathrm{E} \\
\text { apolipoprotein H } \\
\text { apolipoprotein B editing complex } 1 \\
\text { apolipoprotein B editing complex } 2 \\
\text { fatty acid synthase } \\
\text { solute carrer family } 27 \\
\text { fatty acid transporter), member } 2 \\
\text { fatty acid binding protein } 1 \\
\text { fatty acid binding orotein } 4 \\
\text { fatty acid binding protein } 5 \\
\text { fatty acid synthase } \\
\text { LOL receptor related protein } 1 \\
\text { phospholipid transfer protein } \\
\text { phospholipase } 03 \\
\text { glycosylphosphatidyinosytol } \\
\text { specific phospholipase DI }\end{array}$ & $\begin{array}{l}107774 \\
404046 \\
521479 \\
1350386 \\
618120 \\
482571 \\
1227828 \\
521620 \\
1277312 \\
523460 \\
990152 \\
1227828 \\
407600 \\
1001588 \\
933757 \\
333314\end{array}$ & $\begin{array}{l}0,0,1,0,0 \\
0,0,0,0,0 \\
0,0,0,0,0 \\
0,0,0,0,0 \\
0,0,0,0,1 \\
0,-1,-1,-1,-1 \\
1,1,1,0,0 \\
-1,0,0,-1,-1 \\
0,0,1,01 \\
0,0,0,0, * 1 \\
0,0,0,0,0 \\
1,1,1,0,0 \\
0,0,0,0,1 \\
0,1,1,1,1 \\
0,0,0,1,1 \\
0,0,0,0,0\end{array}$ \\
\hline $\begin{array}{l}\text { Matrix turn-over } \\
\text { (protein degradation) }\end{array}$ & 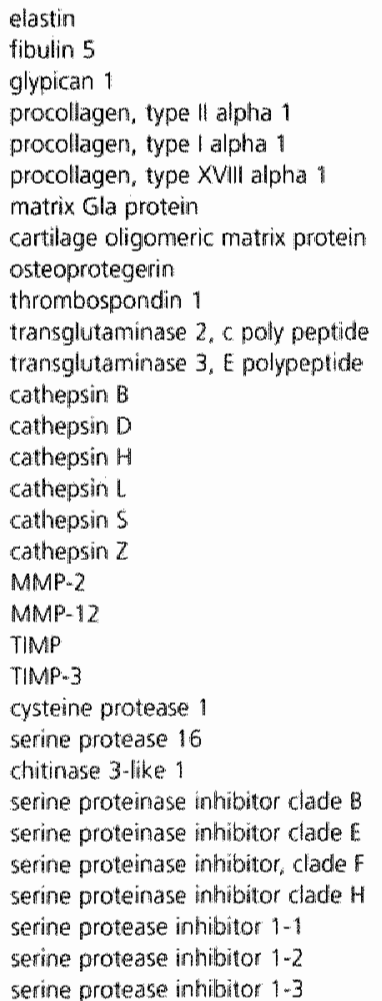 & 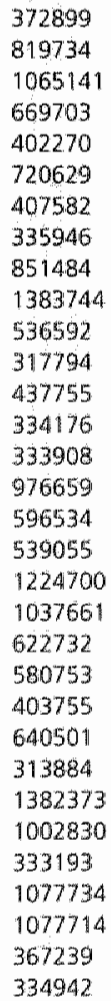 & $\begin{array}{l}0,0,0,0,1 \\
0,0,0,0,1 \\
-1,0,0,0,0 \\
0,0,0,0,1 \\
0,0,1,1,1 \\
0,0,0,0,1 \\
0,0,1,1,1 \\
0,0,0,1,1 \\
0,0,0,1,1 \\
0,0,0,0,1 \\
0,0,0,0,1 \\
-1,0,0,0,0 \\
0,0,0,1,1 \\
0,1,0,1,1 \\
0,0,0,0,1 \\
0,1,1,1,1 \\
1,1,1,1,1 \\
0,0,0,0,1 \\
0,0,0,0,1 \\
0,0,0,1,1 \\
0,0,0,1,0 \\
0,0,0,0,1 \\
0,0,1,1,1 \\
-1,0,-1,-1,1 \\
0,0,0,0,1 \\
-1,0,0,-1,0 \\
0,0,0,0,1 \\
0,0,0,0,0 \\
0,0,0,0,0 \\
0,0,1,0,1 \\
0,0,0,0,0 \\
0,0,1,1,1\end{array}$ \\
\hline
\end{tabular}




\section{Category}

cytoskvelleton

Growth factors

Inmunesystem

Cytokines

\section{Gene name}

serine protease inthibitor 1-5

serine protease inhibitor 2 related sequence 1

senine protease inhibitor 22

secretory leukocyte protease inhibitor

extracellubar proteinase inhibitor

myosin $\mathrm{V}$

mielanoma $X$-actin

actin, gamma, cytoplasmic

alpha actin cardiac

larrinin $\gamma 2$

endothelin !

insulin-like growth factor 1

insulin-like growth factor binding protein 2

insulin-like growth factor binding protein 4

pitacental growth factor

latent TGF $\beta$ binding protein 2

complement component $1 \mathrm{q}$ alpha polypeptide complement component $1 \mathrm{q}$ beta polypeptide complement component $1 \mathrm{q}$ c polypeptide complement component 4 complement factor H-related protein

Fc receptor, IgGs high affirity

FC receptor, igG low affinity lit

Fo receptor, lgE high affinily

Fe receptor, $\operatorname{lgE}$ lowalfinity II

inmunoglobulin heawy chain 6

immunoglobulin heawy chain 1

immunoglobulin heawy chain 3

immunoglobulin gamma constant

immunoglobuli in kappa chair wariable 28

immunoglobulin kappa chain variable 20

imrnunoglobulin joining thain

IG alpha chain C region

immunoglobulin-associated beta

delta-immunoglobulin

histocompatibility 2, Q region locus 7

small inducible cytokine D/ (fractalkine)

small inducible cytokine $A_{2}$

small inducible cytokine $A 3$ (MP $1 \alpha$ )

small inducible gytokine A 4 (MP 1 B)

small inducible cytokine A5 (RANTES)

small inducibla cytokina $A 6$

smell inducible cytokine A7 (MCP 3)

small inducible cytokine $A \&$ (MCP 2)

small inducible cytokine $A 21$.

small indurible cytokine $\mathrm{A2} 1 \mathrm{~b}$

h.t heceptor alpho chain 1

It 19 receptor alpha chain 2

II $12 \mathrm{~b}$

It. 1 receptor accessony protein

L2. receptor gamma chain 2

TNF superfamily member 11

\section{Cllone ID}

331065

1077424

1077628

1367229

1195775

872172

1005837

1005899

536543

335886

1040154

1001007

1277469

597004

1617488

1396864

597157

1430527

426010

1227418

681810

576062

516594

316763

717625

1179412

636695

1448206

635556

597591

2749406

1277614

875830

720992

831907

596447

333711

$5 \% 3898$

751833

621095

832342

1077529

1181707

620243

335077

316441

366999

1349690

750641

678770

721711

618692
$0,0,1,0,1$

$0,0,0,0,0$

$0,1,1,1,1$

$-1,-1,-1,-1,-1$

$0,0,0,1,1$

$-1,0,0,0,0$

$0,0,0,0,1$

$0,0,0,0,1$

$0,0,0,0,0$

$-1,0,0,0,0$

$0,0,0,0,1$

$0,0,0,1,1$

$0,0,0,0,1$

$0,0,0,1,1$

$-1,0,0,0,0$

$0,0,0,0,1$

$0,0,0,1,1$

$0,0,0,1,1$

$0,0,0,1_{i} 1$

$0,0,1,1,1$

$0,0,0,0,1$

$0,0,0,1,1$

$0,0,0,1,1$

$0,0,0,1,1$

$1,0,0,0,0$

$1,-1,-1,0_{4}-1$

$1,-1,-1,1,0$

$1,-1,-1,1,-1$

$1,-1,-1,1,0$

$1,-1,-1,0,-1$

$1,-1,-1,0,-1$

$0,0,0,0,0$

$-1,-1,-1,-1,-1$

$1,0,0,0,0$

$1,0,0,0,0$

$0,0,0,0,1$

$0,0,0,1,1$

$1,0,0,0,1$

$0,0,0,1,1$

$0,0,0,1,1$

$1,0,0,0,0$

$0,0,1,0,1$

$1,0,0,0,0$

$1,0,0.1,1$

$1,0,0,0,0$

$-1,-1,0,0,0$

$0,0,0,0,1$

$0,0,0,0,1$

$-1,0,0,0,0$

$-1,0,0,0,0$

$-1,0,0,0,0$

$0,0,0,1,1$ 


\begin{tabular}{|c|c|c|c|}
\hline Categary & Gene name & Clone & Clustrer : \\
\hline \multirow[t]{3}{*}{ Acute phase } & serim anyloid $\mathrm{A}_{3}$ & 126951 & $0,0,0,0,1$ \\
\hline & heat shock protein $70 \mathrm{kDa}$ & 779196 & $1,0,1,0,1$ \\
\hline & theat shock protein $70 \mathrm{kDa} 3$ & 582093 & $1,0,1,0,1$ \\
\hline \multirow[t]{5}{*}{ Cell adhesion } & VCAM 1 & 635211 & $0,0,0,0,1$ \\
\hline & syndecan 1 & 1077399 & $0,0,0,0,1$ \\
\hline & p-selectin & 876033 & $0,0,0,0,1$ \\
\hline & cadherin 13 & 482972 & $0,0,0,0,1$ \\
\hline & glycosylation dependent cell adhesion moleculle 1 & 749605 & $1,0,0,0,0$ \\
\hline $\begin{array}{l}\text { Phosphatases, } \\
\text { kinases }\end{array}$ & $\begin{array}{l}\text { 6-phosphotructo-2-kinase/fructose-2,6- } \\
\text { biphosphatase }\end{array}$ & 1511542 & $0,0,-1,0,+1$ \\
\hline \multirow[t]{9}{*}{ Esterases. } & $\begin{array}{l}\text { proline-serine-threonine phosphatase-interacting } \\
\text { protein } 1\end{array}$ & 1349888 & $0,0,0,0,1$ \\
\hline & MAPKKKK 1 & 318867 & $0,0,0,1,1$ \\
\hline & spleen tyrosine kinase & 642318 & $1,0,0,1,1$ \\
\hline & serum/glucocorticoid regulated kinase & 1383570 & $-1,0,0,0,0$ \\
\hline & esterase 31 & 747188 & $0,0,0,0,0$ \\
\hline & protein tyrosine phosphatase, non-receptor type 11 & 332650 & $0,0,0,1,0$ \\
\hline & lymphocyte protein tyrosine kinase & 1148872 & $0,0,0,0,0$ \\
\hline & creatine kinase & 520908 & $0,0,0,0,-1$ \\
\hline & $\begin{array}{l}\text { protein tyrosine phosphatase, receptor type, v } \\
\text { polypeptide-associated }\end{array}$ & 642720 & $1,0,0,0,0$ \\
\hline \multirow[t]{2}{*}{ Apoptosis } & apoptosis inhibitory 6 & 764624 & $0,1,1,1,1$ \\
\hline & cell death-inducing DNA fragmentation factor & 333124 & $0,0,0,0,-1$ \\
\hline Differentiation & growth differentiation factor 15 & 8204034 & $0,0,0,0,1$ \\
\hline Transcription factors & paired-like homeodomain transcription factor 3 & 482871 & $1,0,0,0,0$ \\
\hline \multirow[t]{2}{*}{ Cell cycle } & growth arrest and DNAminducible 45 alpha & 961868 & $0,1,0,1,1$ \\
\hline & cyclin dependent kinase intibitor $1 \mathrm{C}$ & 1038618 & $0,0,0,1,0$ \\
\hline \multirow[t]{4}{*}{ lon channels/receptors } & $\begin{array}{l}\text { potassium intermediate/smail conductance } \\
\text { calcium activated channel }\end{array}$ & 642677 & $0,0,0,0.1$ \\
\hline & ruclear receptor subfamily 2 group $\mathrm{H}$ member 2 & 1092732 & $0,0,0,0,1$ \\
\hline & nuclear receptor subfamily 4 group A member 1 & 641865 & $0,0,0,1,0$ \\
\hline & colony stimulating factor 2 receptor & 1148775 & $0,0,0,1,1$ \\
\hline oxidative stress & metallothionein 2 & 394351 & $0,0,0,0,1$ \\
\hline \multirow[t]{2}{*}{ Coagulätilian } & GAS 6 & 537284 & $0,0,0,0,9$ \\
\hline & coatgulation factor xll & 318749 & $0,0,0,0,0$ \\
\hline
\end{tabular}

* Gene expression in artic arches of ApoE deficient mice fed a western type diet (Wr) for 3 months (no) normal chow diet (NC) for $4.5 \mathrm{~m}$, WT for $45 \mathrm{~m}$. NC for $6 \mathrm{~m}$ or WT for $6 \mathrm{~m}$

1 trepresents downregulation, 0 no modulation and 1 upregulation when gene expresston was conparec to ApoE deficient mice fed a NC diet for 3 months. 
In the present study, we obtained a detailed gene expression profile of murine atherosclerosis, and show that each stage of atherosclerosis is characterized by a unique expression pattern of genes. Although the gene expression patterns in the different stages of atherosclerosis are unique, they are quite complex and dynamic. Therefore, we performed both time related expression clustering and functional clustering. The first clustering strategy revealed several genes imvolved in early stages and late stages of atherosclerosis or during the whole process of atherogenesis. Combined expression and functional clustering showed that many genes were part of the gene family of inflammatory genes or proteolytic genes, but also genes involved in lipid metabolism, signal transduction and embryogenesis were isolated. The importance of these gene clusters has been shown before for many individual genes such as gm-CSF ${ }^{13}$, MCP-1 ${ }^{13}$, IFN $\gamma^{15}, C D 40 L{ }^{15}, 30$, MMP-1 ${ }^{21}$ and TGF ${ }^{14}$. Jormsjo et al. ${ }^{22}$ showed mRNA and protein expression of a whole range of genes involved in protein degradation (MMP-9, TIMP -1, cathepsins) in atherosclerotic lesions of ApoE $\%$ mice that were 10 or 20 weeks of age. However, here we show the dynamic expression pattern of and within entire gene clusters at multiple stages and conditions of atherosclerosis.

Our DNA micro-array data show that especially the subfamilies of small inducible cytokines and cathepsins were modulated during atherogenesis. Broad range inhibitors of both families may therefore be considered as valuable targets. for the treatment of atherosclerosis, especially since inhibition of individual genes showed promising results. Atherosclerotic mice that lack MCP-1 ${ }^{18}, \mathrm{CCR}-2{ }^{23}$ or CXCR2 ${ }^{24}$ show a decrease in plaque area and the number of plaques. Furthermore, cathepsin B, D, L and $S$ and $K$ are expressed in atherosclerotic plaques ${ }^{22,25}$. In this thesis (chapter 6 ) we observed that ApoE deficient mice lacking the cathepsin $K$ gene, show reduced progression of atherosclerosis, a reduced macrophage content and a increase in fibrous cap thickness. Mice deficient in cathepsin 5 and the LDL-receptor showed a decrease in plaque area, plaque macrophage, smooth muscle cell and T-lymphocyte content ${ }^{26}$.

We confirmed the importance of previously known regulators of atherosclerosis, such as infiammatory and extracellular matrix related genes, but we also showed the importance of other gene clusters such as apoptosis, angiogenesis, embryonic genes and genes inwolved in catabolism. For example, 'apoptosis inhibitory $\sigma^{\prime}$ was highly modulated throughout atherosclerosis. Placental derived growth factor, an important stimulator of angiogenesis ${ }^{2 k, 28}$ was modulated in early atherosclerotic lesions.

Rupture of atherosclerotic plaques is the predominant underlying cause of many acute clinical symptoms (such as acute coronary syndromes, cerebro-vascular accidents, acute limb ischemia etc) of atherosclerosis in humans $1,2,29$. Rupture-prone atherosclerotic lesions are characterized by large lipid cores, thin fibrous caps and inflammatory infiltrates ${ }^{20}$. Treatment of these 'vulnerable' plaques is aimed at stabilization of these lesions, mostly by using cholesterol lowering diet regimens or drugs like statins ${ }^{30}$. 
Of special interest is therefore our gene expression analysis of plaques after cholesterol withdrawal. Although the cholesterol withdrawal period was relatively shont, and histological changes did not yet occur, the gene expression profile already showed remarkable changes. DNA micro-array analysis revealed 2 unique dusters of cholesterol withdrawal responsive genes. Both clusters are characterized by a downregulation of genes after cholesterol withdrawal. These cholesterol withdrawal responsive genes are very promising therapeutic targets to stabilize atherosclerotic plaques. Unfortunately the majority of the genes in these clusters were unknown EST fragments. We are currently investigating the characteristics of some of these EST fragments in order to identify new plaque stabilizing agents.

DNA micro-array analysis is a very powerful technique, but caution must be paid to the experimental design and interpretation of its results. For example when multiple array analysis is performed, a good reference that is co-hybridized must be used to allow comparisons across arrays ${ }^{3}$. In our study we used a pool of cDNA derived from the ApoE-\% mice fed a NC for 3 months as a reference that was used for all micro-arrays. Furthermore, when a difference of more than 0.2 -fold was observed between duplicate hybridisations, we always used the lowest modulation factor and only if this factor was $>2$-fold the gene was used for further analysis. Validation experiments using RT-PCR mostly confirmed the DNA micro-array data. A drawback of our study is that the entire mouse aortic arch was used instead of specific mouse atherosclerotic plaque tissue. This is due to the large amount of mRNA that is needed per hybridization. However, future developments, such as hybridizations with nanograms of RNA and RINA-amplification will enable us to study more detailed regions of the atherosclerotic plaque. An approach that will enable us to identify gene expression patterns in mouse plaques, plaque specific areas and plaque specific cell types is laser capture microdissection ${ }^{32}$.

Besides DNA micro-array analysis genomic analyses, techniques like 2D-gel electrophoresis, protein arrays and phage display techniques are rising. For example, 2D-gel electrophoresis was used to identify differentially expressed proteins in a breast cancer cell line ${ }^{33}$. In vivo screening of phage display peptide libraries in a patient and in a mouse model of atherosclerosis ${ }^{35}$ were performed successfully and revealed new interesting peptides that home in the vasculature. However, most of these proteomics tools are still under development and cannot yet be used as a standard, easy applicable tool. This is in contrast to DNA micro-array analysis which has become a standard lab tool. Here we show that the use of such a DNA micro-array analysis yielded a detailed database that will improve the insight into the pathogenesis of atherosclerosis and might be helpful to identify new diagnostic markers of atherosclerotic plaque progression. 


\section{$>$ References}

1. Ross $\mathbb{R}:$ Atherosclerosis--an inflammatory disease. N Engl I Med 1999,340:115-26.

2. Glass CK, Witztum d: Atherosclerosis, the road ahead. Cell 2001, 104:503-16.

3. Libby $\mathrm{P}$ : Inflammation in atherosclerosis. Nature 2002,420/868-74.

4. Rhodes DR, Barrette TR, Rubin MA, Ghosh D. Chinnaiyan AM: Meta-analysis of microarrays: interstudy validation of gene expression profiles reveals pathway dysregulation in prostate cancer. Cancer Res 2002,62:4427-33.

5. Lock $C$, Hermans $G$, Pedotti $R$, Brendolan A, Schadt E, Garren $H$, Langer-Gould A, Strober S, Cannella B, Allard J, Klonowski P, Austin A, Lad N, Kaminski N, Galli SJ, Oksenberg JR, Raanine CS. Heller R, Steinman L: Gene-micraarray analysis of multiple sclerosis lesions yields new Largets walidated in autoimmune encephalomyelitis. Nat Med 2002,8:500-8.

6. Hwang JJ, Allen PD, Tseng GC, Lam CW, Fanamapazir L, Dzau VI, Liew CC: Microarray gene expression profiles in dilated and hypertrophic cardiomyopathic end-stage heart falure. Physial Genomics 2002,10:31-44.

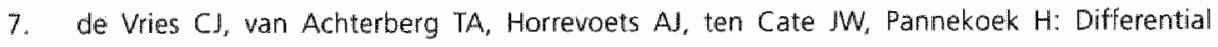
display identification of 40 genes with altered expression in activated human smooth muscle cells. Local expression in atherosclerotic lesions of smags, smooth muscle activation-specific genes. I Biol Chem 2000,275:23939-47.

8. Shiffman D, Mikita T, Täi JT, Wade DP, Porter JG, Seilhamer JJ, Somogyi R, Liang S, Lawn RM: Large scale gene expression analysis of cholesterol-loaded macrophages. I Biol Chem 2000,275:37324-32.

9. Chen BP, Li YS, Zhao Y, Chen KD, Li S, Lao J, Yuan S, Shyy JY, Chien S: DNA microarray analysis of gene expression in endothelial celts in response to 24 -h shear stres5. Physiol Genomics 2001,7:55-63.

10. Faber BC, Cleutjens KB, Niessen RL, Aarts PL, Boon W, Greenberg AS, Kitsllaar PJ, Tordoir JH, Daemen MJ: Identification of genes potentially inwolved in rupture of human atherosclerotic plaques. Circ Res 2001,89:547-54.

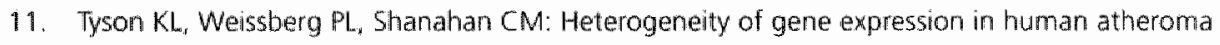
urmasked using CDNA representational difference analysis. Physiol Genomics 2002,9:121-30.

12. Adams LD, Geary RL, MCManus B. Sctwartz SM: A comparison of acrta and vena cava medial message expression by cDNA array analysis identifies a set of 68 consistently differentially expressed genes, all in aortic media. Circ Res 2000,87:623-31.

13. Wuttge $D M$, Sirsjo $A$, Eriksson $P$, Stemme 5: Gene expression in atherosclerotic lesion of ApoE deficient mice. Mol Med 2001,7:383-92.

14. Lutgens $E$, Gijbels $M$. Smook $M$, Heeringa $P$. Gotwals $P$. Koteliansky $V$, Daemen J: Transforming growth factor-beta mediates balance between inflammation and fibrosis during plaque progression. Arterioscler Thromb Vase Biol. 2002,22:975-982.

15. Lutgens E, Gorelik L, Daemen MI, de Muinck ED, Grewal IS, Koteliansky VE, Flavell RA: Requirement for CD154 in the progression of atherosclerosis. Nat Med 1999,5:1313-6.

16. Pabon C. Modrusan 2, Ruvolo MV Coleman IMM, Daniel S, Yue H, Arnold L, Jr: Optimized $T 7$ amplification system for microarray analysis. Biotechniques 2001,31:874-9. 
17. Smith JD, Trogan E, Ginsberg M, Grigaux C. Tian I, Miyata M: Decreased atherosclerosis in mice deficient in both macrophage colony-stimulating factor (op) and apolipoprotein E. Proc Niail Acad Sci U 5 A 1995,92:8264-8.

18. Gu L. Okada Y. Clinton SK, Gerard C, Sukhova GK, Libby $P_{r}$ Rollins Bl: Absence of monocyte chemoattractant protein-1 reduces atherosclerosis in low density lipoprotein receptor-deficient? mice. Mol Cell 1998,2:275-81.

19. Gupta 5 , Pablo AM, jiang $X$, Wang $N$, Tall AR, Schindler $C$ : IFN-gamma potentiates atherosclerosis in ApoE knock-out mice. J Clin Invest 1997.99:2752-61.

20. Lutgens E, Cleutjens KB, Heeneman S, Koteliansky VE, Burkly LC, Daemen MJ: Both early and deliayed anti-CD4OL antibody treatment induces a stable plaque phenotype [see comments]. Proc Natl Acad Sci U S A 2000,97:7464-9.

21. Lemaitre $V$, $O^{\prime}$ Byrne TK, Borczuk AC, Okada Y, Tall AR, D'Armiento I: ApoE knockout mice expressing human matrix metalloproteinase-1 in macrophages have less advanced atherosclerosis. J Clin Invest 2001,107:1227-34.

22. Jormsjo 5 , Wuttge DM, Sirsjo A, Whatling C. Hamsten A, Stemme S, Eriksson P: Differentiall expression of cysteine and aspartic proteases during progression of atherosclerosis in apolipoprotein E-deficient mice. Am J Pathol 2002, 161:939-45.

23. Boring $L_{s}$ Gosling $J$, Cleary $M$, Charo IF: Decreased lesion formation in CCR2 $\%$ mice reveals a role for chemokines in the initiation of atherosclerosis. Nature 1998,394:894-7.

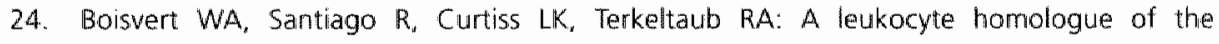
$\| L-8$ receptor $C X C R-2$ mediates the accumulation of macrophages in atherosclerotic lesions of LDL receptor-deficient mice. J Clin linvest 1998, 101:353-63.

25. Sukhova GK, Shi GP, Simon DI, Chapman HA, Libby P: Expression of the elastolytic cathepsins $S$ and $K$ in human atheroma and regulation of their production in smooth muscle cells. $\mathrm{J} C$ lin Invest 1998, 102:576-83.

26. Sukhova GK, Zhang Y, Pan J "Libby P, Shi G: Targeted disruption of Cathepsin 5 reduces. atherosclerosis in low-density lipoprotein receptor deficient mice. (Abstract). Cire. $2001,104: 11 \cdot 328$.

27. Carmeliet $P$, Moons $L$, Luttun A, Vincenti $V$, Compernole $V_{*}$ De Mol $M, W u$, Bono $F$, Devy L. Beck. $H_{x}$ Scholz D. Acker T, DiPalma T, Dewerchin M, Noel A, et al.: Synergism between vascular endothelial growth factor and placental growth factor contributes to angiogenesis and plasma extravasation in pathological conditions. Nat Med 2001,7,575-83.

28. Luttun A, Tjwa M, Moons L. Wu Y, Angelillo-Scherrer A, Liao F, Nagy JA, Hooper A, Priller J, De Klerck B, Compernolle $V$. Daci E, Bohlen P, Dewerchin M. Herbert JM, et al.: Revascularization of ischemic tissues by PIGF treatment, and inhibition of tumor angiagenesis. arthritis and atherosclerosis by anti-Fit.1. Nat Med 2002,8:831-40.

29. Virmani $R$, Kolodgie $F D$, Burke AP, Farb A, Schwartz $S M$ : Lessons from sudden coronary death: a comprehensive morphological classification scheme for atherosclerotic lesions. Arterioscler Thromb Vasc Biol 2000,20:1262-75. 
30. Brown BG, Zhao XQ. Chait A, Fisher LD. Cheung MC, Morse J5, Dowdy AA, Marino EK. Bolson E1, Alaupovic P, Frohlich J, Albers Jf: Simvastatin and niacin, antioxidant vitamins, or the combination for the prevention of coronary disease. N Engl J Med 2001,345:1583-92.

31. Lee ML, Kuo FC, Whitmore GA, Sklar J: Importance of replication in microarray gene expression studies: statistical methods and evidence from repetitive CDNA hybridizations. Proc Matl Acad Sci US A 2000,97:9834-9.

32. Trogan E, Choudhury RP, Dansky HM, Rong IX, Breslow لlL, Fisher EA: Laser capture microdissection analysis of gene expression in macrophages from atherosclerotic lesions of apolipoprotein Emdeficient mice. Proc Natl Acad Sci U S. A. 2002,99:2234m9.

33. Vercoutter-Edouart AS, Czeszak X, Crepin M, Lemoine 1, Boilly $B$, Le Bourhis X, Peyrat $I \mathbb{P}$, Hondermarck $\mathrm{H}$ : Proteomic detection of changes in protein synthesis induced by fibroblast growth factor- 2 in MCF-7 human breast cancer cells. Exp Cell Res 2001,262:59*68.

34. Arap $W$, Kolonin MG, Trepel M, Lahdenranta $\Downarrow$, Cardo-Vila M, Giordano RJ, Mintz PJ. Ardelt

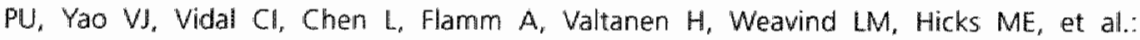
Steps toward mapping the human vasculature by phage display. Nat Med 2002,8:121-7.

35. Houston $P_{n}$ Goodman J, Lewis A, Campbell CJ, Braddock M: Homing markers for atherosclerosis: applications for drug delivery, gene delivery and vascular imaiging. FEBS Lett 2001,492:73-7. 


\title{
CHAPTER 6
}

\section{DISRUPTION OF THE CATHEPSIN K GENE REDUCES THE PROGRESSION OF ATHEROSCLEROSIS}

\author{
K.B.J.M. Cleutjens', PhD; B.C.G. Faber1, MSc; E. Lutgens', MD PhD; B. Jutten', BSc; S. \\ Heeneman', PhD; M. Gijbels', PhD; A.M. Sijbers², PhD; A. Fisher², PhD; C.J. Long?' \\ PhD; P. Saftigi. PhD; D. Black², PhD; and M. J.A.P. Daemen", MD PhD. \\ 'Department of Pathology, Cardiovascular Research Institute Maastricht (CARIM), \\ University of Maastricht, ${ }^{2} \mathrm{~N} . \mathrm{V}$. Organon, Research and Development, The Netherlands, \\ UK. 'Biachemical Institute, University of Kiel,
}




\section{$>$ Abstract}

Several proteases, including matrix metalloproteases and cathepsins are considered to be important in the various stages of atherosderotic lesion progression. Using macro-array analysis, RT-PCR, Western blotting and immuno-histochemistry we showed that the expression of cathepsin K, a lysosomal cysteine protease, was highly upregulated in endothelial cells, vascular smooth muscle cells and macrophages in advanced but stable human atherosclerotic plaques when compared to early lesions and lesions containing a thrombus. To assess the function of cathepsin $K$ in atherogenesis, we crossed cathepsin $\mathrm{K}$-deficient mice with ApoE-deficient mice. At 26 weeks of age, we compared lesion development along the arterial tree of cathepsin $\mathrm{K}-1 / \mathrm{f} / \mathrm{ApoE}-/$ mice to ApoE- $/$ - mice. The most profound effects were observed on lesions in the aortic arch. cathepsin $\mathrm{K}-/-/ / \mathrm{ApoE}-/$ - mice showed a $45 \%$ reduction in plaque burden and a remarkable shift in lesion type. In cathepsin K-1-//ApoE-\% mice, the majority of plaques were classified as initial lesions (58.3\%), while in ApoE- mice the majority of plaques $(73.7 \%)$ had progressed to advanced lesions. In addition, although cathepsin $K$ deficiency has no apparent effect on plaque initiation, disruption of the cathepsin $K$ gene resulted in a reduction of macrophage content of initial lesions. Moreover, advanced lesions of cathepsin K-1-1/ApoE- $/$ mice showed an increase of fibrous cap thickness and collagen content compared to ApoE-/- mice.

Our data indicate an important role of cathepsin $K$ in the progression of atherosclerosis since cathepsin $K$ is upregulated in advanced human plaques and disruption of the cathepsin $K$ gene in mice results in a reduction of both lesion size and plaque progression and in an induction of plaque fibrosis. 


\section{Introduction}

Atherosclerosis is characterized by the accumulation of lipoproteins, the infiltration of macrophages and T-cells into the intima, local expansion of vascular smooth muscle cells and extracellular matrix (ECM) remodelling ${ }^{14}$. Early in plaque development, the migration of smooth muscle cells and macrophages needs extensive ECM remodelling. In addition, the ECM constituent's elastin, collagen and proteoglycan are indispensable for maintenance of fibrous cap strength and integrity $3,5,6$. As a result, erosion and plaque rupture, the underlying causes of the majority of acute cardiovascular events, primarily take place at sites of matrix remodellings. Proteases are key regulators of matrix remodeling and several proteases have been linked to the cascade of pathological alterations involved in atherogenesis. Functional in vivo studies to study their role in primary atherosclerosis are however sparse. Most extensively studied in this respect are the matrix metalloproteases (MMPs). Several MMP family members (MMP-1, $-2,-3,-7$, $-8,-9,-12,-13$ and -14 ) are expressed in atherosclerotic lesions, while expression of MMP-1, -3 and -9 is increased in the vulnerable shoulder region ${ }^{5}$. In vivo MMP intervention studies showed diverse effects, and even suggest that MMP inhibition may lead to progression of atherosclerosis 5,6 .

In contrast to the relative large amount of data on metalloproteinases in atherosclerosis, data regarding the effects of cathepsins, a family of lysosomal cysteine proteases ${ }^{8}$ on the initiation and progression of atherosclerosis are limited. Large scale gene expression studies recently indicated differential expression of cathepsin B, L, S and $\mathrm{H}$ in diseased human and mouse arteries ${ }^{912}$. Previously, Sukhova et al. ${ }^{13}$ reported that cysteine proteases account for $40 \%$ of the total elastase activity of human atheroma extracts and showed cathepsin 5 and $K$ overexpression in macrophages and smoath cells in the shoulder region of advanced human atherosclerotic lesions. Cultured vascular SMCs showed increased secretion of active cathepsin $S$ in response to proinflammatory cytokines. Furthermore, genetic disruption of the cathepsin 5 gene reduced plaque progression in $L D L$ receptor deficient mice ${ }^{14}$, In addition, a decrease in cystatin C levels. the most abundant extracellular inhibitor of cysteine proteases ${ }^{15}$, was frequently observed in patients with severe vascular disease "

Recently, our group performed Suppressive Subtractive Hybridisation (SSH) analysis on whole-mount human atherosclerotic plaques to establish a library of CDNA fragments preferentially expressed in stable atheroscleratic plaques versus lesions containing a thrombus ". Sequence analysis of these differentially expressed CDNA5 showed the upregulation of cathepsin $K$ in stable lesions. Cathepsin $K$ protein is composed of a 15 residue $\mathbb{N}$-terminal signal peptide, a 99-residue propeptide and a mature protein of 215 amino acids showing strong collagenase, elastase and gelatinase activity ${ }^{* 49}$. cathepsin $\mathrm{K}$ was initially isolated from an osteoclast CDNA library and expression was first considered 
to be confined to osteodlasts. Over the years cathepsin $K$ expression was also observed in many other tissues ${ }^{2, z, z}$. In the present study, we show that cathepsin K MRNA and protein expression is highly upregulated in advanced human atherosclerotic lesions. Based upon its proteolytic potential and the observed differential expression during human plaque progression, we investigated the functional role of cathepsin $K$ by studying atherogenesis in mice lacking both ApoE and cathepsin $K$.

\section{$>$ Materials and methods}

\section{Tissue Sampling}

Atherosclerotic plaques were obtained from patients undergoing vascular surgery (Department of General Surgery, Academic Hospital Maastricht) or at autopsy (Department of Pathology, Academic Hospital Maastricht) and were collected in compliance with institutional guidelines. Plaques originated from several arteries including the abdominal aorta, femoral, iliac and carotid artery. Non-diseased artery specimens originated from the subclavian and brachial artery. Saphenous vein samples were waste material obtained after coronary by-pass grafting. Vascular specimens were processed as described "and classified according to Virmani et all.".

\section{Macro-array analysis}

Two independent sets of 5 macro-arrays containing cathepsin K CDNA ( $20 \mathrm{ng} /$ spot) were hybridized at high stringency with ${ }^{32}$ pmlabeled (High Prime, Boehringer Mannheim) SMART'M CDNA derived from pooled ( $n=3$ per group) whole mount human vascular specimens, essentially as described previously " Hybridization signals from non-diseased arteries, early atherosclerotic lesions, advanced but stable plaques, lesions containing a thrombus and veins were quantified by phosphor image analysis (Quantity One, BioRad) and normalized for the signals of RNA-polymerase II and human genomic DNA.

\section{RT-PCR}

Total RNA, CDNA synthesis and RT-PCR were performed as described before 13. RT-PCR was performed on MRNA isolated from individual samples of veins $(n=5)$, non-diseased arteries $(n=4)$, eariy atherosclerotic plaques $(n=5)$, advanced lesions $(n=10)$ and lesions with thrombi $(n=10)$. To exclude patient-and artery-biased expression, samples originated from several arteries and veins from different patients. cathepsin $K$ and GADPH specific DNA fragments were amplified on first strand CDNA using the following primers; cathepsin $K$ sense: 5'GGATATATCCTCATGGCTCG 3', antisense: 5'TAGGAAGGATCATTTGAAGCAC 3', GAPDH sense: 5'GGGAAGCTTGTCATCAATGG $3^{\prime \prime}$ and antisense: $5^{\circ}$ CATGGTTCACACCCATGACG 3'. 


\section{Western blot analysis}

For Western blot analysis, $25 \mu \mathrm{g}$ of total protein, extracted as described before ${ }^{23}$, was separated by SDS-PAGE followed by transfer onto nitrocellulose (Protran, Schleicher \& Schuell). After blocking in PBS containing $2 \%(w / v)$ skimmed milk powder, blots were subsequently incubated with mouse monocional anti cathepsin $K$ antibody ( $5 \mu \mathrm{g} / \mathrm{ml}$, Calbiochem) and horseradish peroxidase coupled rabbit anti-mouse antibody (RAM-HRP, 1:1000 Dako). Specific antibody binding was visualized using enhanced chemiluminiscence (Amersham Pharmacia Biotech).

\section{Immunohistochemistry}

Four $\mu \mathrm{m}$ paraffin embedded tissue sections were deparaffinized, hydrated and pre-treated with $0.1 \mathrm{M}$ pepsin, blocked with $10 \%$ fetal calf serum and subsequently incubated with one of the following antibodies: anti-cathepsin $\mathrm{K}$ antibody (mouse monodonal, $50 \mathrm{mg} / \mathrm{ml}$, Calbiochem), $\alpha$-smooth muscle actin (ASMA) monoclonal antibody (1:500. Sigma) as a marker for vascular smooth muscle cells and myo-fibroblasts; MAC3 rat monoclonal antibody, (1:30, Pharmingen) to detect macrophages; and CD3 polyclonal antibody (A0452, 1:200; Dako) to detect T lymphocytes. Subsequently, sections were incubated with either biotinylated swine-anti-mouse antibody (1:1000, Amersham Life Science), Amersham Life Science), biotinylated rabbit-anti-rat (1:1000, Amersham Life Science) or biatinylated swine-anti-rabbit antibody (1:1000, Dako), by incubation with peroxidase-coupled-ABC-reagent (1:500, Dako) or alkaline phosphatase-coupled-ABC-reagent (1:200, Dako), Immunolabeling was visualised using either diaminobenzidine tetrahydrochloride and imidazole or the Alkaline Phosphatase Kit I (Vector) supplemented with $0.1 \mathrm{M}$ levamisole to suppress background staining. Sections were counterstained with hematoxylin. The relative amounts of cells were determined as described previously ${ }^{{ }^{4}}$.

\section{Animals}

ApoE- - - mice on a C57Bl6 background were obtained from Iffa Credo (Lyon, France) and were crossed to cathepsin $\mathrm{K} \%$ mice ${ }^{25}$. All animal work was approved by the regulatory authority of the University of Maastricht and was performed in compliance with the Dutch government guidelines. Normal chow diet and water were provided ad libitum. At the age of 26 weeks, male cathepsin $\mathrm{K}-/ / / \mathrm{ApoE}-/-(\mathrm{n}=9)$, ApoE- $/(\mathrm{n}=9)$ and cathepsin $K-f-(n=9)$ mice were sacrificed after a 24 -hour fast. Blood $(0.5$ to $1 \mathrm{ml})$ was obtained from the right cardiac ventricle, mixed with $50 \mu \mathrm{l} 0.5 \mathrm{M}$ EDTA, centrifuged at $1500 \mathrm{rpm}$ for $10 \mathrm{~min}$ and plasma was stored at $-80^{\circ} \mathrm{C}$ untill lipoprotein analysis. After in situ perfusion fixation, the complete arterial tree was excised and fixed as described previously ${ }^{26}$. The aortic arch including its main branch points (brachiocephalic trunk, left common carotid artery, and left subclavian artery) was embedded longitudinally 


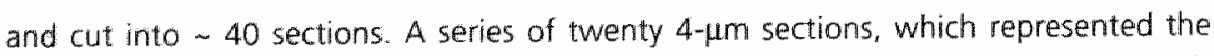
central area of the arch with an intact morphology of the complete arch and branch points was analyzed as described previously ${ }^{2 * 2627}$

\section{Lipid Profile}

For assessment of lipid profiles, standard enzymatic techniques, automated on the Cobas Fara centrifugal analyzer (Hoffmann-La Roche), were used. Total plasma cholesterol and HDL were measured using kit No. 0736635 and kit No. 543004 (HoffmannLa Roche) respectively; total glycerol was measured using kit No. 337-40A/337-10B (Sigma Chemical Co) and free glycerol was measured using kit No. 0148270 (Hoffmann-La Roche). Standardized serum (Precipath) was used as internal standard. LDL was calculated by the equation: total cholesterol- ((total glycerol-free glycerol)/2.2)-HDL.

\section{Evaluatilon of Possible Systemic Effects}

Twenty organs (brain, lung, heart, thymus, liver, spleen, kidney, stomach, intestine, pancreas, bone (skull, femur) adrenal gland, bladder, skin, prostate, seminal vesicle, salivary gland, lymph node, tonsil) were excised from $n=4$ mice per group and analysed on $4 \mu \mathrm{m}$ sections stained with hematoxylin and eosin.

\section{Histology and Morphometry of mouse plaques}

For gross histological analysis and morphometry, 4 sections (20 $\mu \mathrm{m}$ apart) were stained with hematoxylin and eosin, while 4 consecutive sections (also $20 \mathrm{~mm}$ apart) were stained with Lawson solution. Sirius red staining was performed to detect collagen. Perl's iron staining was used to detect iron and von Kossa staining was used to detect calcification. Morphometric parameters were determined as described previously ${ }^{2:}$. Atherosclerotic lesions were analyzed and classified according to Virmami et al. ${ }^{22}$. Because the data between the separate initial plaque stages (intimal thickening and intimal xanthomas) as well as between the separate advanced atherosclerotic lesions (thin and thick fibrous cap atheromas and fibrocalcified plaques) were comparable. data are presented in 2 groups: initial lesions and advanced lesions.

\section{Bone density measurements}

Various parameters were assessed in cross section using peripheral quantitative computed tomography (pQCT, model XCT-960A Norland Stratec, Birkenfeld, Germany). The measurement in the left femur was started at the metaphysis $3 \mathrm{~mm}$ below the articular surface. Cross sections were made at a distance of $1 \mathrm{~mm}$ and sections selected for analysis contained a complete cortical ring. Using a voxel size of $0.08 \mathrm{~mm}$ and a threshold of 0.464 , the following parameters were measured: trabecular mineral density $\left(\mathrm{mg} / \mathrm{cm}^{3}\right)$, total bone area $\left(\mathrm{mm}^{2}\right)$, cortical mineral density $\left(\mathrm{mg} / \mathrm{cm}^{\mathrm{s}}\right)$ and cortical thickness $(\mathrm{mm})$. 


\section{Statistical analysis}

All data are expressed as mean \pm SEM. Means between groups were compared by the use of the nonparametric Mann-Whitney $U$ test. Data were considered statistically significant at $P<0.05$. 


\section{Cathepsin $\mathrm{K}$ mRNA expression during human atherogenesis}

Macro-array analysis showed that cathepsin K mRNA is expressed at a low level in human veins, non-diseased arteries and early atherosclerotic lesions (fig. 1). Expression is upregulated 28 -fold in advanced but stable lesions when compared to early lesions and 11 -fold when compared to lesions containing a thrombus. In addition, RT-PCR analysis on individual samples revealed no detectable cathepsin $\mathrm{K}$ expression in any of the veins and non-diseased arteries, while $20 \%$ of early lesions, $70 \%$ of the advanced lesions and $30 \%$ of lesions with a thrombus tested positive (fig. 2).

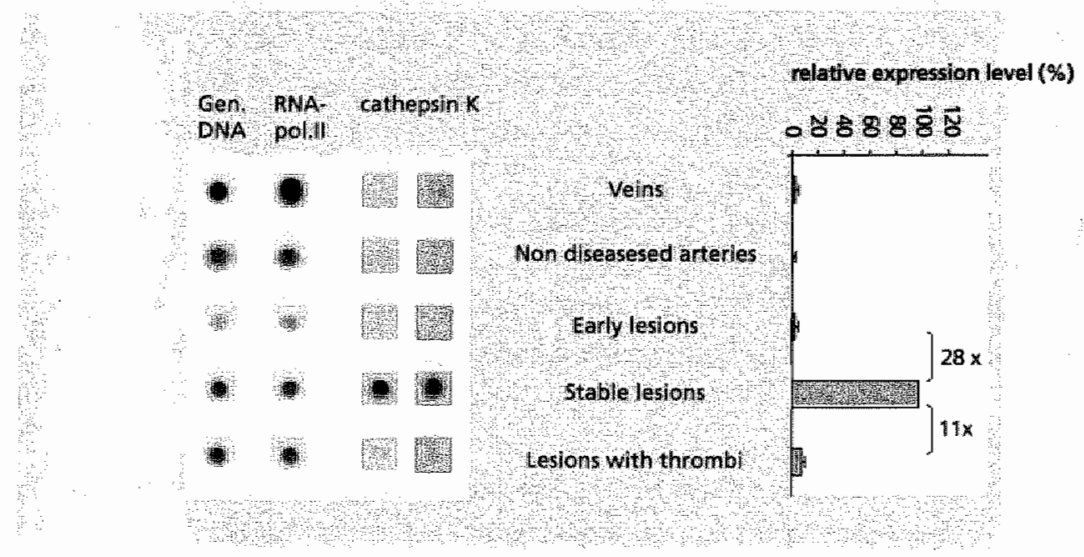

Figure 1. Macro array analysis of cathepsin $K$ mRNA expression.

Two sets of five identical macro arrays containing cathepsin K CDNA were hybridized to poals of a-labeled CONA derived from human veins, non diseased anteries, early lesions, stable lesions and lesions with a thrombus. Expression levels were nomalized to the hybridization signals for Genomic DNA and RNA polymerase It The cathepsin $k$ expression level in stable lestons was set at $100 \%$.

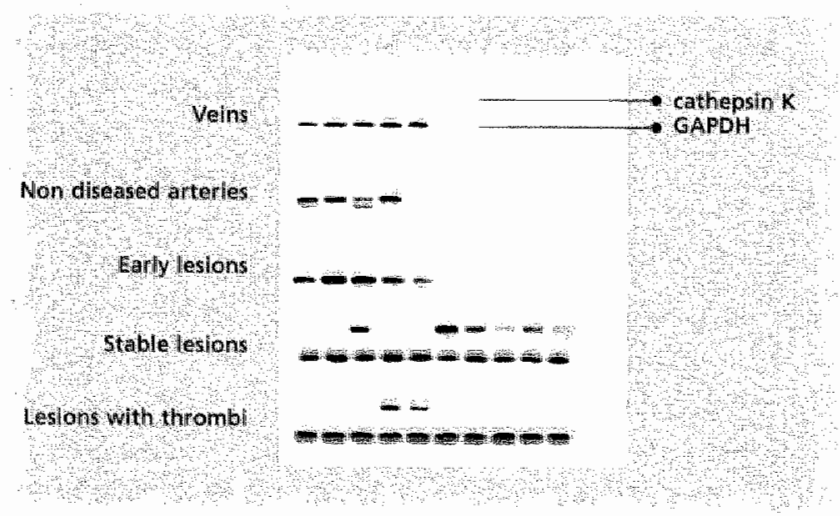

Figure 2. cathepsin $K$ MRNA expression in individual plaque samples.

RTPCR andysis on MRNA isolated from veins, non-diseased arteries, early lesions, stable fesions and lesions containing a thrombus. Expression of cathepsin $k$ and the housekeeping gene GAPDW is shown in each upper and bottom paned, respectively. 


\section{Cathepsin $\mathrm{K}$ protein expression}

To evaluate whether the observed differential mRNA expression pattern also resulted in differential cathepsin $K$ protein expression, we performed Western blot analysis on lysates derived from individual early lesions, stable lesions and atherosclerotic plaques with a thrombus ( $n=3$ per group). The monoclonall anti cathepsin $K$ antibody used, can distinguish at least three cathepsin $K$ protein products: the pre-pro-enzyme of $40 \mathrm{kDa}$, a pro-enzyme of $37 \mathrm{kDa}$, and the mature and active enzyme, with a molecular weight of $27 \mathrm{kDa}$. As shown in fig. $3 \mathrm{~A}$, low levels of the pre-pro-en pro-enzyme could be detected in all samples. However, expression of active cathepsin $K$ was upregulated more than 50-fold in stable lesions when compared to early lesions and 6.5-fold when compared to lesions containing a thrombus (fig. 3B). In addition, we observed an over 50 fold increase in the expression level of a $\sim 20 \mathrm{kDa}$ immunoreactive band, presumably representing a cathepsin $\mathrm{K}$ degradation product, in stable lesions when compared to early lesions and a 4.5-fold increase when compared to lesions with a thrombus.

To localize cathepsin $K$ protein in the vascular wall, immunohistochemical analysis was performed (fig. 4A-F). Incidentally, a single smooth muscle cell (SMC) or macrophage showed positive staining in human veins, non-diseased arteries and early atherosclerotic lesions (fig. 4A). Strong immuno-reactivity was present in stable lesions, especially in vascular endothelial cells, neointimal and medial SMCs and macrophages (fig. 4B). In particular, SMCs and macrophages in the fibrous cap, the shoulder region and at the rim of the lipid core showed high levels of cathepsin $K$ expression. Lesions with a thrombus revealed intermediate levels of immuno-reactivity, while the pattern was comparable to that observed in stable lesions (fig. $4 \mathrm{C}$ ). Interestingly, cathepsin $\mathrm{K}$ protein was also expressed at the actual site of plaque rupture (fig. $4 D$ ). As shown in figure $4 E$, also advanced mouse lesions show high levels of cathepsin K expression in the cytoplasm of vascular endothelial cells, neointimal and medial SMC and macrophages. No cathepsin $K$ immunoreactivity was observed in lesions of cathepsin $K-/-/ /$ Apoe-/- mice.
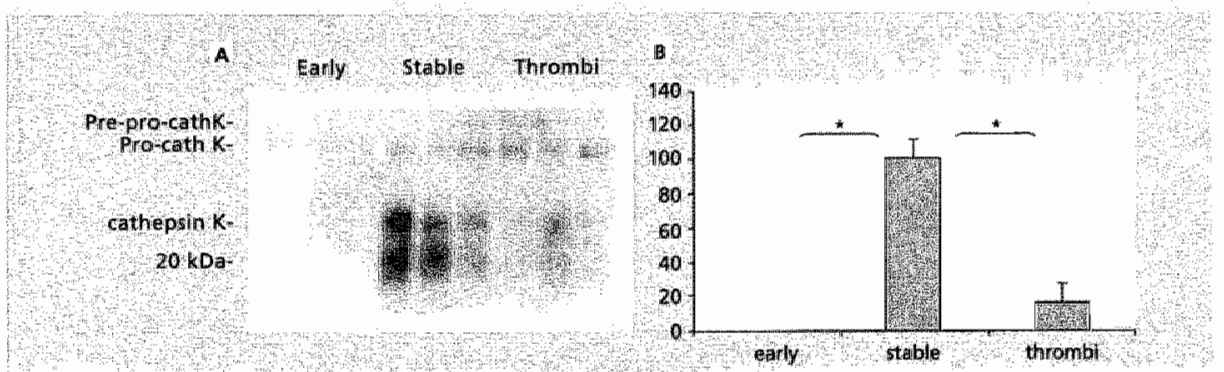

Figure 3. Western blot analysis of cathepsin K expression in human atherosclerotic lesions.

4: Lanes 1-3, early lesions, lanes 4-6 stable atheroscleratic lesions, lanes 7-9: kesions containing a thrombus. For each sample, amounts equivalent to $25 \mathrm{mg}$ protein were applied. B: Quantification of the active cathepsin $\mathrm{K}$ content, as judged by densitometric scanning. 


\section{In vivo validation}

Survival rates of cathepsin $\mathrm{K}-\mathrm{f}-\mathrm{f} / \mathrm{ApoE}-\mathrm{H}-$ mice, ApoE-deficient mice and cathepsin $\mathrm{K}-\%$ - mice were $100 \%$ in all three groups. Body weights were also comparable. LDL and total cholesterol levels were elevated in cathepsin $\mathrm{K}-\mathrm{f}-/ / \mathrm{ApoE}-\mathrm{f}-$ and ApoE- $/$ - mice when compared to cathepsin $K-1$ - mice (see table 1). No differences were found between cathepsin $\mathrm{K}-/ / / \mathrm{ApoE}-/$ - and ApoE-/- mice.

Histology performed on 20 argans revealed no macroscopic or microscopic abnormalities on sections stained with hematoxylin and eosin, except for the increased trabecularization of long bones in cathepsin $\mathrm{K} \%$ and cathepsin $\mathrm{K} / / / / \mathrm{ApoE}-\%$ mice (see fig. 5A, B) when compared to ApoE-- mice, as previously described by Saftig et al. ${ }^{25}$. The observed increase in bone trabecularization was further substantiated by bone density measurements, showing a 2-fold increase in trabecular bone density in cathepsin $\mathrm{K}-\mathrm{f}$ - and cathepsin $\mathrm{K}-/-/ / \mathrm{ApoE}-/ /$ mice when compared to ApoE-/- mice. No difference in bone density was observed between cathepsin $\mathrm{K}-\mathrm{-} / / \mathrm{AppE}-/$ - and cathepsin $\mathrm{K}-\mathrm{H}$ - mice (table 2 ).

Livers of cathepsin $\mathrm{K}-1 / \mathrm{H} / \mathrm{ApDE}-/$ - and ApoE- $/$ - mice contained a limited amount of fatty degeneration (fig. 5C, D). Furthermore, no signs of bone marrow, lymph node and spleen abnormalities (fig. 5E, F), or end-organ damage were observed.

Table 1. Plasma Cholesterol and Trighcericle levels. Values are represented as mean \pm SEM.

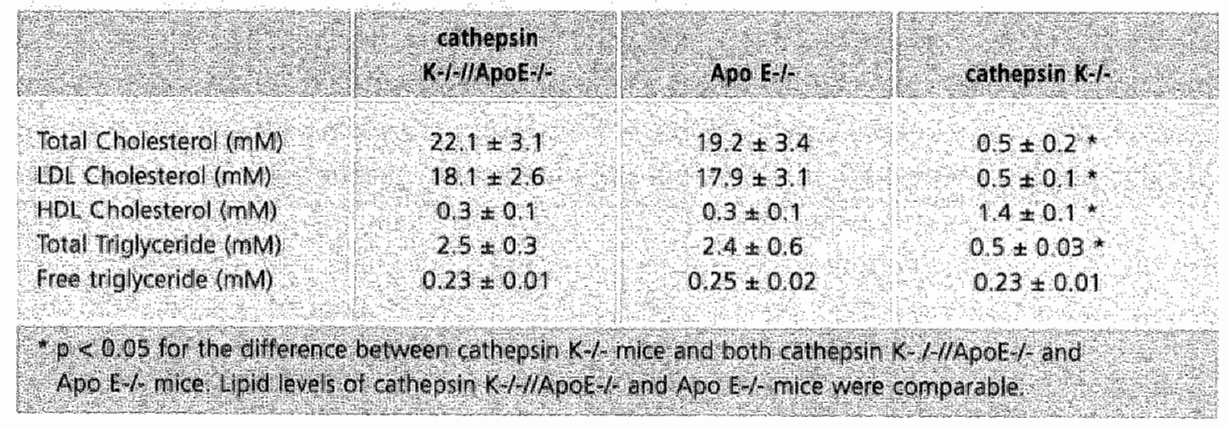

Table 2. Bane density. Vaves are represented as mean t. SEM.

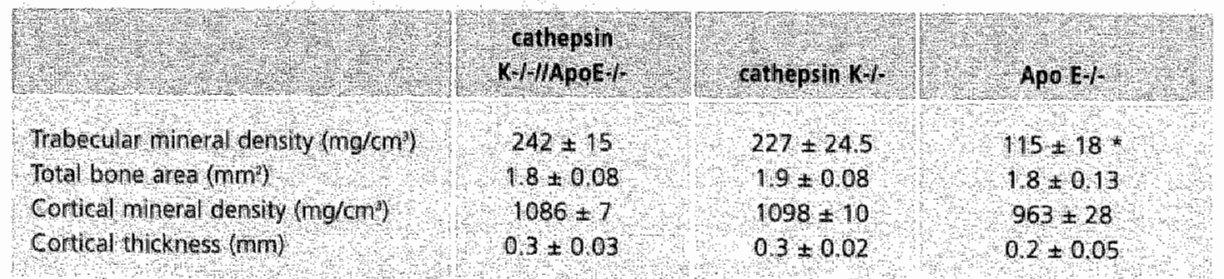

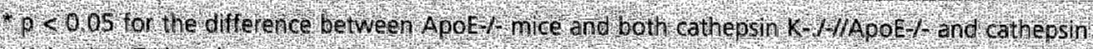

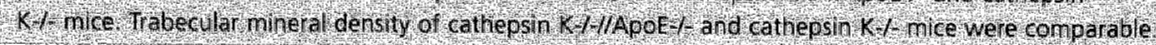




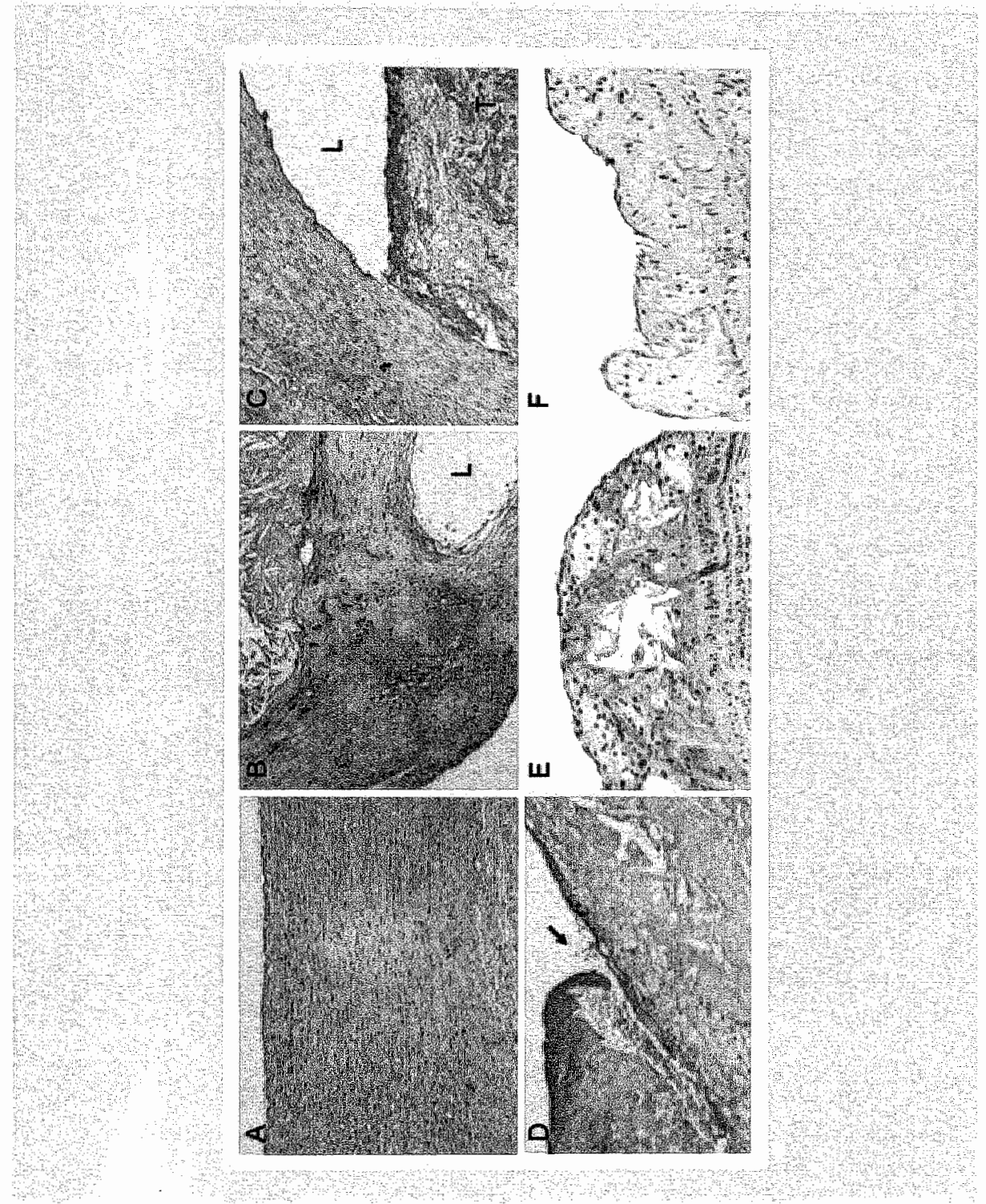

Frgure 4. Localization of cathepsin K expression.

This figure shows cathepsin $K$ expression in warious stages of human atherogenesis. (A) early lesion, (B) a stable fesion, $(C)$ a lesion containing a thrombus and $(D)$ at the actual site of plaque rupture. Pand $E$ shows cathepsin $K$ expression in an adwanced Apo E-/ mouse lesion, white panel $F$ shows the absence of cathepsin $k$ staining in a cathepsin $K-1-1 / A p o E-$ derved advanced murine plaque cathepsin $K$ immunoreactivity is depicted in red (A - D) or in brown (E,F) $L=$ lumen, T=thrombus, the arrow points towards the actual site of plaque rupture. 


\section{Plaque burden}

We analyzed 58 atherosclerotic lesions in the aortic arches of cathepsin $\mathrm{K}-/-/ / a p o E-/-$ mice $(n=9)$ and 54 aortic arch lesions of ApoE- $/$ - mice $(n=9)$. cathepsin $K-/$ mice showed no vascular abnormalities. cathepsin $K-/ / / A p o E-/-$ mice showed a $45 \%$ reduction of plaque area $\left(603370 \pm 94306 \mathrm{~mm}^{2}\right.$ in cathepsin $\mathrm{K} / 1 /$ ApoE-/- mice vs. $1060986 \pm$ $132648 \mathrm{~mm} 2$ in ApoE $/$ - mice, $P<0.05$ ) (fig. 6A). Interestingly, although the number of plaques per aortic arch was comparable in both groups, a remarkable shift in lesion type was observed. In cathepsin $\mathrm{K}-/-/ / \mathrm{ApoE}-/$ - mice, the majority of plaques were classified as initial lesions (58.3\%), while in ApoE-/ mice the majority of plaques $(73.7 \%)$ had progressed to advanced lesions (fig. 6B). The number of advanced plaques had not only decreased, but these lesions were also smaller (fig. 6C). This indicates an important role for cathepsin $K$ in atherosclerotic plaque progression.

\section{Plaque composition}

In addition to the decrease in plaque progression and plaque area, significant differences im plaque composition between cathepsin $\mathrm{K}-/-/ /$ ApoE-/- and ApoE-/ mice were observed (fig. 7A-D). Analysis of initial lesions revealed that the amount of MAC3-positive cells (macrophages) decreased with 23\% after disruption of the cathepsin $K$ gene $(52.1 \pm 5.9 \%$ in cathepsin $\mathrm{K}-1 /$ / ApoE- $/$ - mice versus $67.8 \pm 3.6 \%$ in ApoE-/- mice, $P<0.05$, fig. 6D). In advanced lesions however, no significant difference in macrophage content was observed. Furthermore, advanced lesions of cathepsin K-/-//ApoE- $/$ mice showed a $90 \%$ increase in collagen content $(31.2 \pm 3.8 \%$ vs 16.4 $\pm 2.9 \%$, fig. $6 \mathrm{E})$ and a $164 \%$ increase in fibrous cap thickness $(4.48 \pm 0.37 \mu \mathrm{m}$ vs 1.70 $\pm 0.33 \mu \mathrm{m}$, fig. $6 \mathrm{~F} /$ when compared to ApoE $/-$ mice. In addition, in plaques containing calcification, cathepsin K-/-1/ApoE-/- mice showed a remarkable over 2 -fold decrease in calcification content per advanced plaque (5.5 $\pm 1.4 \%$ in cathepsin $\mathrm{K}-1-/ / \mathrm{ApoE}-/$ - mice vs $12.3 \pm 3.6 \%$ in ApoE- mice, $p=0.08$, fig. $6 G)$. Smooth muscle cell content, T-lymphocyte content and lipid core area showed no significant differences in both initial and advanced lesions between cathepsin $\mathrm{K}-1-/ / \mathrm{ApoE}-/ \mathrm{-}$ and ApoE- $/$ - mice (see Table 3).

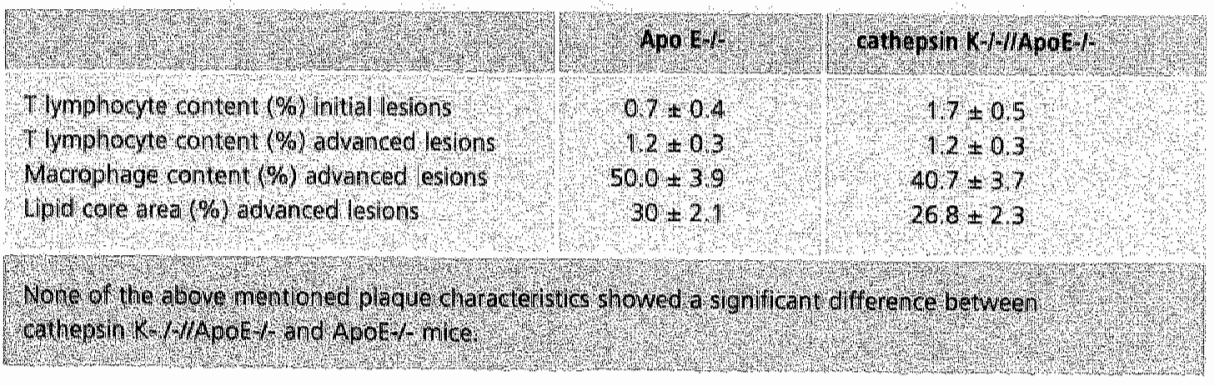

Table 3. Additional quantification of plaque characteristics of cathepsin K-/ //ApoE-l- and ApoE-/- mice. Walues are represented as mean $\pm 5 E M$. 


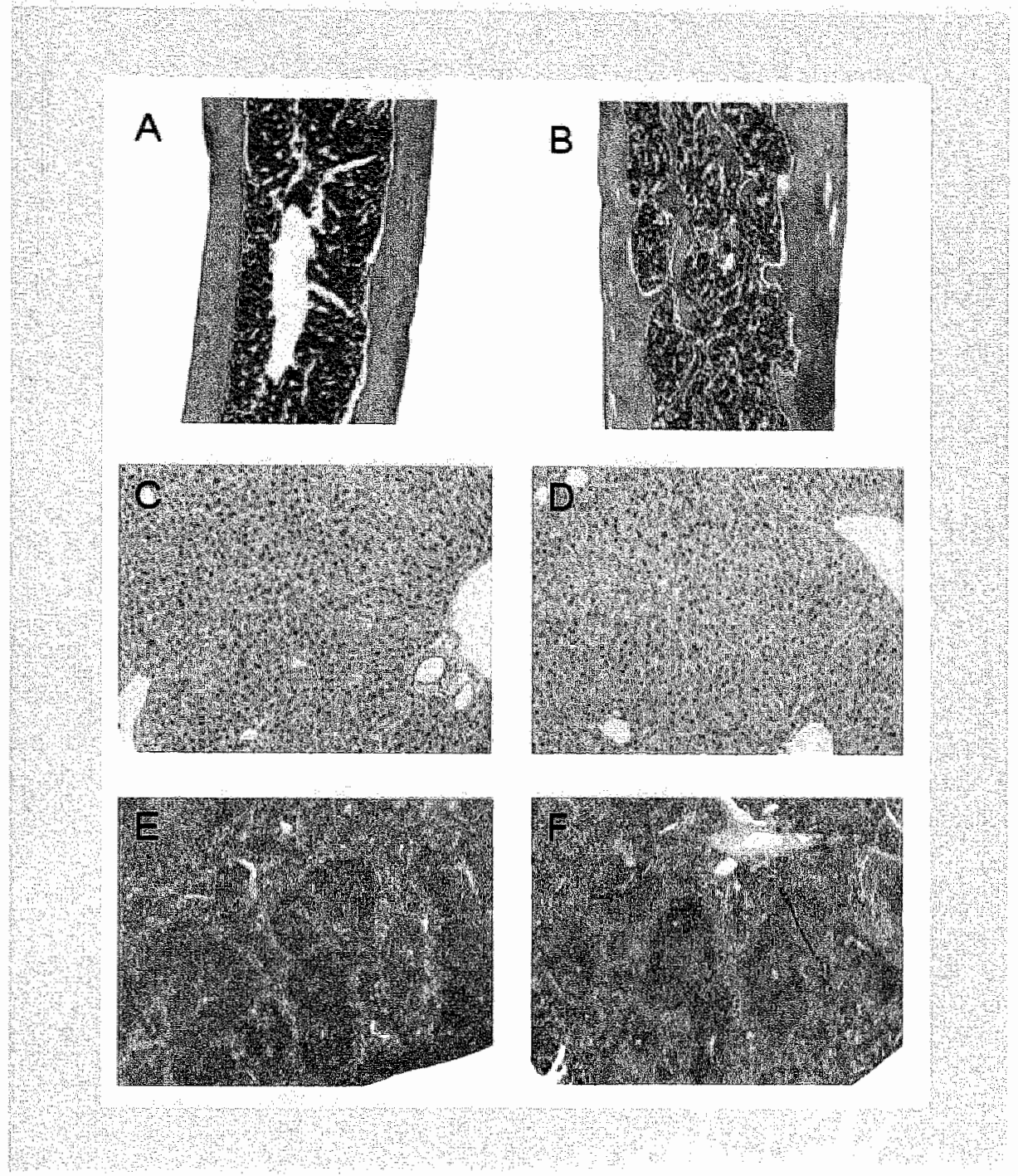

Figure 5. Histological analysis of the femur, liver and' spleen.

Hematoxylin and eosin staining of the left fernur (A, B), liver (C,D) and spleen $(E, F)$ of ApoE. mice $, A, C, E)$ and cathepsin K-HApoE-H $(B, D, F)$. 

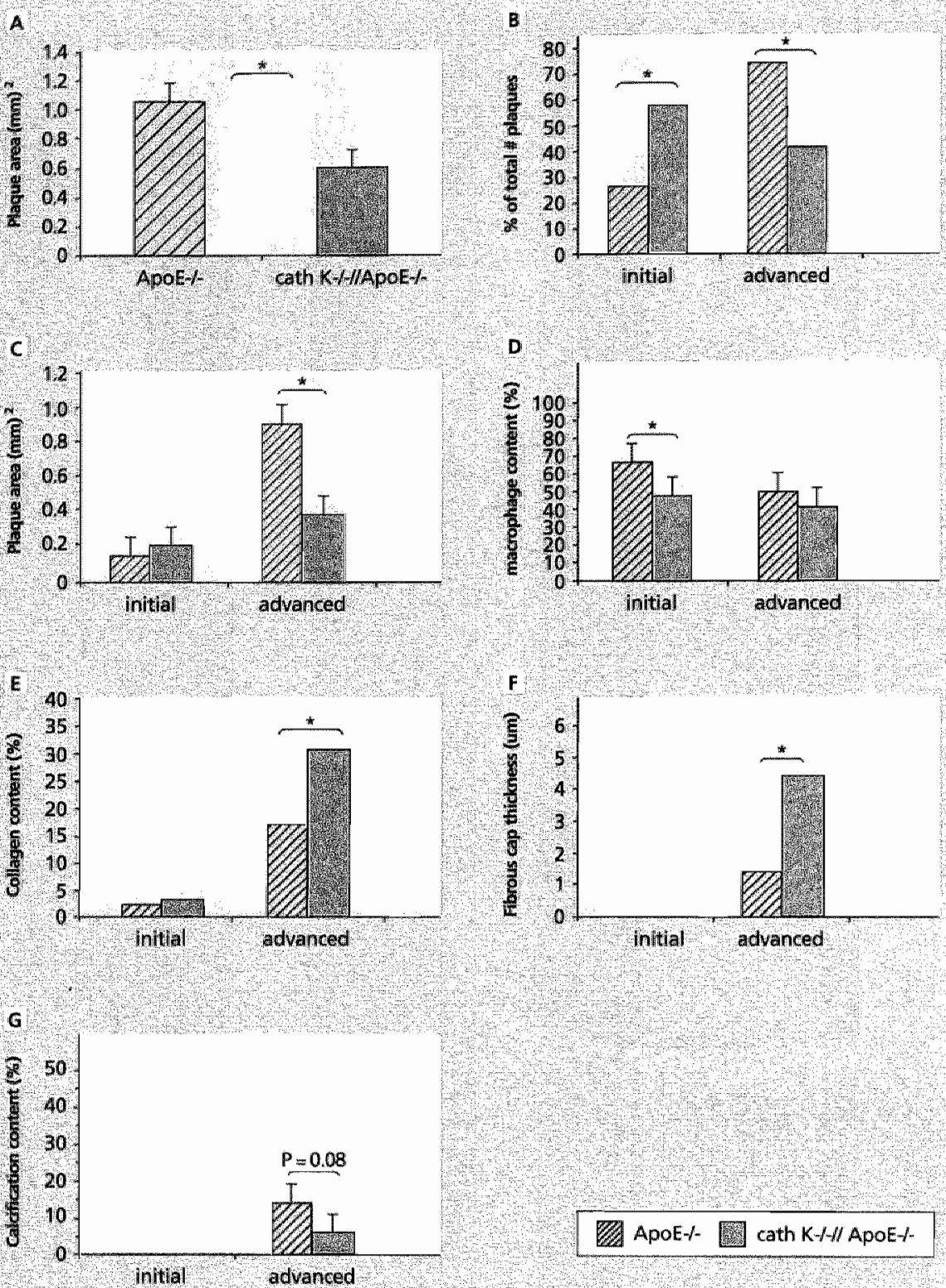

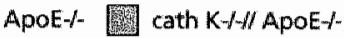

Figure 5. Quantification of plaque characteristics of cathepsin $K-/-/ / A p o E-/-$ and ApoE-l- mice.

Total plaque area (A), kesion type (B), lesion type specific plaque area (C), macrophage content (O), collagen content $(E)$ f fbrous cap thickness ( $F$ ) and calcification conrent $(G$ ) of intial and advanced lesions of cathepsin K-HApoE-H and A Aoot- mice. 


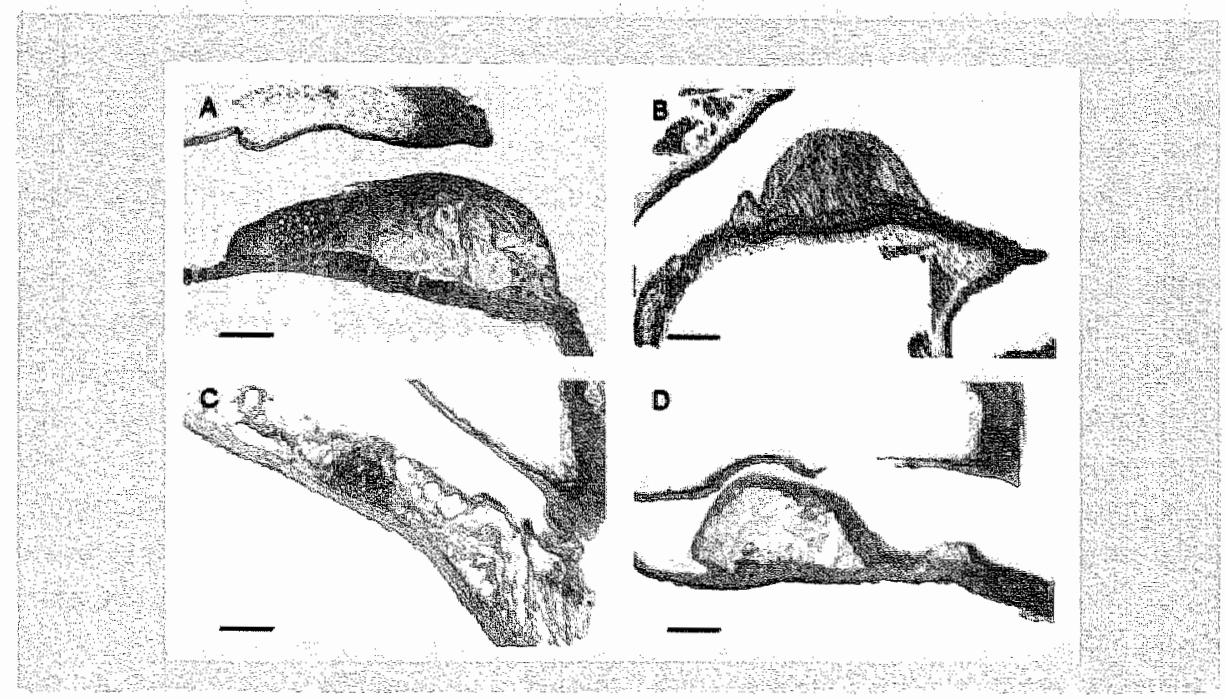

Figure 7. Histological characteristics of Cathepsin K//LApoE/ and ApoE-f derived atherosclerotic lesions.

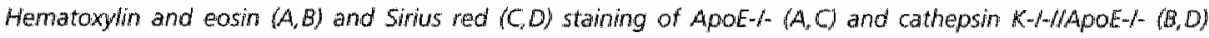
atherosclerotic lesions. 
The present study investigated the cathepsin $K$ mRNA and protein expression profile during human atherogenesis and is the first to describe the in vivo role of cathepsin $K$ in atherosclerotic lesion progression in ApoE-/ mice. The elevated levels of cathepsin $K$ MRNA and protein in stable human lesions is in close agreement with the observation of Sukhova et al. "who reported high levels of cathepsin $K$ and the closely related cathepsin $S$ protein in human atherosclerotic lesions. cathepsin $K$ is the most potent mammalian elastase yet described ${ }^{18}$. ${ }^{2}$. Furthermore it contains a unique collagenolytic activity; since it is the only human protease capable of cleaving interstitial collagens in their triple helical domains ${ }^{19,20,30}$. Although cathepsin $K$ and the closely related family members generally reside in and function optimally within acidic lysosomes, they may also function extracellularly at or near the cell surface "3. In view of the proteolytic potential of cathepsins $K$ and the observed increase in cathepsin $K$ expression in stable human lesions, it was tempting to speculate that cathepsin $K$ is involved in atherosclerotic lesion progression.

Indeed, cathepsin K-/-//ApoE-/ mice showed a remarkable decrease in plaque progression illustrated by the remarkable shift in lesion type (fig. 6B). In addition, initial lesions showed a decrease in macrophage content. Although our in wivo experiments indicated an important role for cathepsin $K$ in lesion progression and lesion composition, disruption of the cathepsin $K$ gene has no apparent effect on plaque initiation, illustrated by the development of a comparable total number of plaques in the aortic arch and the abdominal aorta (data not shown) of cathepsin K-/-//ApoE-/- mice and ApoE $\%$ mice. The extremely low expression levels of cathepsin $K$ in initial human lesions also support a minor role of cathepsin $K$ in the very first phase of atherogenesis.

Our data did, however, point to an important role of cathepsin $\mathrm{K}$ in plaque progression. cathepsin $\mathrm{K}-/-/ / \mathrm{A}$ poE-/ mice not only showed a decrease in the amount of advanced lesions, but also several phenotypic alterations were observed. When compared to ApoE / mice, advanced lesions from cathepsin $\mathrm{K}-/ \mathrm{-} / \mathrm{A} / \mathrm{ApoE}-/$ - mice showed induced plaque fibrosis, illustrated by an increase in collagen content and fibrous cap thickness, and decreased calcification (fig. $6 E_{*} F_{2}$ G). At first sight, the finding of decreased plaque progression, and the observed phenotypic alterations in cathepsin K-I//ApoE-\%-mice seem contradictory to the marked upregulated of cathepsin $K$ in human stable atherosclerotic lesions when compared to early lesions. However, early human lesions, in contrast to cathepsin K-/-//ApoE-/- mice, contain trace amounts of cathepsin $\mathrm{K}$, which might be sufficient for the initial degradation of collagens. while other cathepsins and/or metalloproteinases exert most of the proteolytic activity needed in the initial stage of atherogenesis. Recently, expression of the closely related family members cathepsin S, L, B and $H$ in human and mouse atherosclerotic lesions has been reported ${ }^{9.3}$. Although these family members also show elastolytic and some collagenolytic activity, they lack the unique proteolytic capacity of cathepsin $\mathrm{K}$ which is 
needed for maximal collagenolytic activity. This unique role of cathepsin $K$ in collagen degradation when compared to other cathepsins might explain the observed difference on collagen content as described in this study and the reported effect of genetic disruption of the cathepsin $\mathrm{S}$ gene in LDL. Receptor knockout mice ${ }^{14}$. cathepsin $5-\% / / L D L$ R. $\%$ mice showed a decrease in collagen content when compared to LDL $R$ - - mice, while in our study cathepsin $K-/ / / A$ ApoE- $/$ - mice showed an increase in collagen content when compared to ApoE- $/$ - mice.

Expression profiling in human atherosclerotic lesions not only revealed a marked increase in cathepsin K mRNA and protein expression in stable versus early atherosclerotic lesions, but also when compared to lesions containing a thrombus. The apparent paradox between the high levels of cathepsin $\mathrm{K}$ in advanced but stable lesions and the observed effects of cathepsin $K$ deficiency on plaque progression and plaque phenotype may be explained by the fact that the net proteolytic activity of cathepsin $\mathrm{K}$ is not only dependent of the levels of active cathepsin $K$, but is the result of the balance of active cathepsin $\mathrm{K}$ protein and its natural inhibitors e.g. cystatin $C$. Shi et al. recently showed that cystatin $C$ is expressed at high levels in non-diseased arteries and is severely reduced in both advanced atherosclerotic lesions and aortic aneurysms ${ }^{16}$. Furthermore, abdominal aortic diameter was shown to correlate inversely with serum cystatin $C$ levels.

The present study clearly indicates an important role for cathepsin $\mathbb{K}$ in atherogenesis. At present however, the molecular mechanism(s) underlying the profound effects on plaque progression and plaque phenotype is largely unknown. However, based upon in vitro experiments and the structural homology between cathepsin family members some mechanisms/pathways can be postulated.

In in vitro experiments, the cathepsin derived elastolytic activity of vascular SMCS could be blocked by TGF- $\beta 1$ induced cystatin $C{ }^{16}$. These findings not only indicate a potential important role for imbalance between cysteine proteases and cystatin $C$ in severe atherosclerosis but also link cathepsin activity to the TGF- $\beta$ pathway (an increase in TGFB results in increased levels of cystatin C. As a result hereof the net cathepsin activity is decreased). Recently, we and others showed the importance of TGF- $\beta$ for plaque fibrosis ${ }^{32-34}$. Inhibition of TGF- $\beta$ signalling by a neutralizing antibody against TGF- $\beta 1,-\beta 2$, and $-\beta 3$ or via injection of recombinant soluble TGF- $\beta$ receptor II, resulted in the development of atherosclerotic lesions containing a high inflammatory cell content and a decreased amount of collagen ${ }^{32 .}{ }^{33}$. In addition, intraplaque hemorrhage and iron and fibrin deposition were frequently observed ${ }^{34}$.

Besides its well-recognized function in extracellular matrix remodelling, cathepsin $\mathrm{K}$ might exert its effect on plaque progression and plaque phenotype via other mechanisms. First, in plaques containing calcified areas, disruption of the cathepsin $K$ gene resulted in a remarkable decrease (over 2 -fold, $p=0.08$ ) in the calcification content. Possibly, the observed decrease in calcification is mediated via osteonectin. Osteonectin is one 
of the major activators of atherosclerotic calcification and its expression is highly upregulated in advanced, but especially in calcified advanced atherosclerotic lesions ${ }^{35.35}$. Although intact osteonectin has basal calcification activating properties, partial degradation of osteonectin by cathepsins (including cathepsin K) and metalloproteinases results in an over 10-fold increase of its collagen binding capacities which is a major initial step in the process of atherosclerotic calcification ${ }^{37-39}$. Besides the profound effects on atherosclerotic plaque progression and morphology, disruption of the cathepsin $\mathrm{K}-\mathrm{l}$ - gene resulted in induced trabecularization and trabecular bone density. This finding is in full agreement with previous findings in cathepsin $\mathrm{K}-1-$ mice ${ }^{25,42}$. However, both our group and the Saftig group did not observe the abnormalities in the hematopoietic compartments, including decreased bone marrow cellularity and splenomegaly as previously described by Gowen et $a /{ }^{42}$. Most likely this discrepancy in hematopoietic phenotype between the two currently available strains of cathepsin $K$ deficient mice is due to differences in the gene targeting construct. With respect to the observed changes in trabecular bone density it is important to note that disruption of the ApoE- $/$ gene has no apparent effect on the phenotypic changes induced by disruption of the cathepsin K, since cathepsin K-f-//ApoE-/- and cathepsin K-/- mice show comparable bone morphology and bone density. Vice versa, cathepsin $K$ has no apparent effect on plasma lipid levels, since the lipid profile of cathepsin $\mathrm{K}-\mathrm{H} / \mathrm{/} / \mathrm{ApoE}-\mathrm{f}$ - mice is comparable to the profile in ApoE -/- mice.

Our findings on the in vivo function of cathepsin $\mathrm{K}$ in ApoE $/$ - and its expression profile in human atherosclerotic lesions identify cathepsin $K$ function as a potential therapeutic target. Inhibition of cathepsin $K$ activity could lead to decreased plaque progression and increased plaque stability. In addition, inhibition of cathepsin K activity might be beneficial in the treatment of osteoporosis, since cathepsin $\mathrm{K}$ deficiency, both in humans and in mice, resulted in a significant increase in trabecular bone density 25.42 .43 .

In conclusion, we have shown that cathepsin K mRNA and protein is differentially expressed during human atherogenesis and that genetic disruption of the cathepsin $K$ gene in a mouse model for atherosclerosis results in reduced plaque progression, and the development of a collagen-rich stable plaque phenotype. Assuming comparable effects in humans, treatment with cathepsin $\mathrm{K}$ inhibitors might be beneficial, inhibition of lesion progression, and lesion size and by increased plaque fibrosis. 


\section{Acknowledgement}

The authors want to thank Wendy Boon, ine Middeldorp and Kitty Schapira for excellent technical assistance. They further acknowledge Dr J. Peters, Organon , Oss for bone density measurements. 


\section{$>$ References}

1. Ross R: Atherosclerosis--an inflammatory disease. N Engl J Med 1999, 340:115-26.

2. Libby P: Changing concepts of atherogenesis. I Intern Med 2000,247:349-58.

3. Glass CK, Witztum Jil: Atherosclerosis the road ahead. Cell 2001, 104:503-16.

4. Lusis At: Atherosclerosis. Nature 2000,407:233-41.

5. Galis 25 , Khatri JJ: Matrix metalloproteinases in vascular remodeling and atherogenesis: the good, the bad, and the ugly. Circ Res 2002,90:251-62.

6. Faber BC. Heeneman 5, Daemen MJ. Cleutjens KB: Genes potentially inwolved in plaque rupture. Curr Opin Lipidal 2002,13:545-52.

7. Herman MP, Sukhova GK, Libby $P$, Gerdes $N$, Tang $N$, Horton DB, Kilbride $M$, Breitbart RE* Chun M, Schonbeck U: Expression of neutrophil collagenase (matrix metalloproteinase-8) in human atheroma: a novel collagenolytic pathway suggested by transcriptional profiling. Circulation 2001, 104:1899-904.

8. Turk V, Turk B, Turk D. Lysosomal cysteine proteases: facts and opportunities. Embo J 2001, 20:4629-33

9. Jormsjo S, Wuttge DM. Sirsjo A, Whatling C, Hamsten A, Stemme 5, Eriksson P. Differential expression of cysteine and aspartic proteases during progression of atherosclerosis in apolipoprotein E-deficient mice. Am J Pathol 2002,161939-45.

10. Tung WS, Lee JK, Thompson RW: Simultaneous analysis of 1176 gene products in normal human aorta and abdominal aortic aneurysms using a membrane-based complementary DNA expression array. I Vasc Surg 2001,34:143-50.

11. Hiltunen M, Tuomisto T, Niemi M, Brasen J, Rissanen T, Toronen P, Vajanto I, Yla-Herttuala S: Changes in gene expression in atherosclerotic plaques analyzed using DNA array. Atherosclerosis 2002, 165:23.

12. Chen J, Tung $\mathrm{CH}$, Mahmood U, Ntziachristos $V$, Gyurko R, Fishman MC, Huang PL, Weissleder $R$ : In vivo imaging of proteolytic activity in atherosclerosis. Circulation 2002,105:2766-71

13. Sukhova GK, Shi GP. Simon Di, Chapman HA, Libby P: Expression of the elastolytic cathepsins $S$ and $K$ in human atheroma and regulation of their production in smooth muscle cells. J Cinn Invest 1998, 102:576-83.

14. Sukhova GK, Zhang $Y$, Pan J, Libby $P$, Shi G: Targeted disruption of cathepsin S reduces atherosclerosis in low-density lipoprotein receptor deficient mice. (Abstract). Circ. 2001,104:11-328.

15. Barrett Al, Davies ME, Grubb A: The place of human gamma-trace (cystatin C) amongst the cysteine proteinase inhibitors. Biochem Biophys Res Commun 1984, 120:631-6.

16. Shi GP. Sukhova GK, Grubb A, Ducharme A, Rhode LH, Lee RT, Ridker PMx Libby P, Chapman HA: Cystatin $C$ deficiency in human atherosclerosis and aortic aneurysms. I Clin Invest 1999, 104:1191-7.

17. Faber BC. Cleutjens KB, Niessen RL, Aaris PL, Boon W, Greenberg AS, Kitslaar PJ, Tordoir $\mathrm{HH}$, Daemen MJ: Identification of genes potentially involved in rupture of human atherosclerotic plaques. Circ Res 2001,89:547-54. 
18. Bromme D, Okamoto $K$, Wang BB, Biroc S: Human cathepsin O2, a matrix protein-degrading cysteine protease expressed in osteoclasts. Functional expression of human cathepsin 02 in Spodoptera frugiperda and characterization of the enzyme. I Biol Chem 1996,271:2126-32.

19. Lecallle $F$, Choe $Y$, Brandt $W, L i Z$, Craik CS, Bromme D: Selective inhibition of the collagenolytic activity of human cathepsin $\mathrm{K}$ by altering its 5.2 subsite specificity. Biochemistry 2002,41:8447-54.

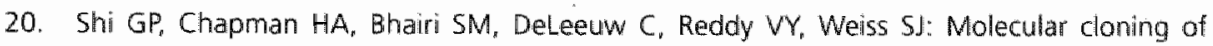
human cathepsin $O_{s}$ a novel endoproteinase and homologue of rabbit OC2. FEBS Lett 1995,357:129-34.

21. Littlewood-Evans AJ, Bilbe G, Bowler WB, farley D, Wlodarski B, Kokubo T, Inaoka T, Sloane J, Evans DB, Gallagher IA: The osteoclast-associated protease cathepsin $K$ is expressed in human breast carcinoma. Cancer Res 1997,57:5386-90.

22. Virmani R, Koladgie FD, Burke AP, Farb A, Schwartz SM: Lessons from sudden coronary death: a comprehensive morphological classification scheme for atherosclerotic lesions. Arterioscler Thromb Vasc Biol 2000,20:1262-75.

23. Heeneman S, Haendeler J, Saito $Y$, Ishida M, Berk BC: Angiotensin II induces transactivaltion of two different populations of the platelet-derived growth factor beta receptor. Key role for the p66 adaptor protein Shc. J Biol Chem 2000,275:15926-32.

24. Lutgens E, Gorelik L, Daemen MJ, de Muinck ED, Grewal IS, Koteliansky VE, Flavell RA: Requirement for CD154 in the progression of atherosclerosis. Nat Med 1999,5:1313-6.

25. Saftig $P$, Hunziker $E_{\text {n }}$ Wehmeyer $O$, Jones $S$, Boyde $A$, Rommerskirch $W$, Moritz JD, Schu $P_{\text {n }}$ von Figura K: Impaired osteoclastic bone resorption leads to osteopetrosis in cathepsin-K-deficient mice. Proc Natl Acad Sci U S A 1998,95:13453-8.

26. Lutgens $E$, Daemen $M$, Kockx $M$, Daevendams, $P$, Hotker $M$, Havekes $L$, Wellens $H$, de Muinck ED: Atherosclerosis in APOE*3-Leiden transgenic mice: from proliferative to atheromatous stage. Circulation 1999,99:276-83.

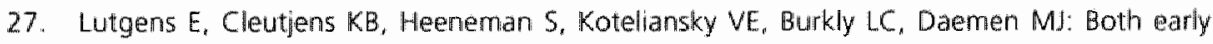
and delayed anti-CD $40 \mathrm{~L}$ antibady treatment induces a stable plaque phenotype [see commentsi. Proc Nat Acad Sci U S A 2000,97:7464-9.

28. Bossard MJ, Tomaszek TA, Thompson SK, Amegadzie BY, Hanning CR, Jones C, Kurdyla Ji. MCNulty DE, Drake FH, Gowen M, Lewy MA: Proteolytic activity of human osteoclast cathepsin K. Expression, purification, activation, and substrate identification. I Biol Chem $1996.271: 12517-24$.

29. Kafienah W, Bromme D, Buttle DJ, Croucher LS, Hollander AP: Human cathepsin K deaves native type I and II collagens at the N-terminal end of the triple helix. Biochem J 1998, $331: 727-32$.

30. Garnero P, Borel $O$, Byrjalsen I, Ferreras M, Drake FH, McQueney MS, Foged NT, Delmas PD, Delaisse $M$ : The collagenolytic activity of cathepsin $K$ is unique among mammalian proteinases. I Biol Chem 1998,273:32347-52. 
31. Reddy WY, Zhang QY, Weiss S: Pericellular mobilization of the tissue-destructive cysteine proteinases, cathepsins $B, L$, and $S$, by human monocyte-derived macrophages. Proc Natl Acad Sci U S A 1995,92:3849-53.

32. Mallat Z, Gojova A, Marchiol-Fournigault C. Esposito B, Kamate C, Merval R, Fradelizi D, Tedgui A: Imhibition of transforming growth factor-beta signaling accelerates atherasclerasis and induces an unstable plaque phenotype in mice. Circ Res 2001,89:930-4.

33. Lutgens $\mathbb{E}$, Daemen MJ: Transforming growth factor-beta: a local or systemic mediator of plaque stability? Circ Res 2001,89:853-5.

34. Lutgens $E$, Gijbels $M$. Smook $M$, Heeringa $P$, Gotwals $P$, Koteliansky $V$, Daemen J: Transforming growth factor-beta mediates balance between inflammation and fibrosis during plaque progression. Arterioscler Thromb Vasc Biol. 2002,22: 975-982.

35. Bini A, Mann KG, Kudryk BJ, Schoen Fl: Noncollagenous bone matrix proteins, calcification, and thrombosis in carotid artery atherosclerosis. Arterioscler Thromb Vasc Biol $1999,19: 1852-61$

36. Dhore CR, Cleutjens IP, Lutgens E, Cleutjens KB, Geusens PP, Kitslaar P』, Tordoir IH, Spronk $H M$, Vermeer $C$. Daemen MJ: Differential expression of bone matrix regulatory proteins in human atherosclerotic plaques. Arterioscler Thromb Vasc Biol 2001,21:1998-2003.

37. Tyree $B$ : The partial degradation of osteonectin by a bone-derived metalloprotease enhances binding to type I collagen. J Bone Miner Res 1989,4:877-83.

38. Page $A E$, Hayman AR, Andersson LM, Chambers TJ, Warburton MJ: Degradation of bone matrix proteins by osteoclast cathepsins. Int I Biochem 1993,25:545-50.

39. Sasaki $T$, Miosge $\mathrm{N}$, Timpl R: Immunochemical and tissue analysis of protease generated neoepitopes of BM-40 (osteonectin, SPARC) which are correlated to a higher affinity binding to collagens. Matrix Biol 1999, 18:499.508.

40. Leake DS, Peters TI: Proteolytic degradation of low density lipoproteins by arterial smooth muscle cels; the role of individual cathepsins. Biochim Biophys Acta 1981,664:108-16.

41. Tertov WV, Orekhov AN: Metabolism of native and naturally occurring multiple modified low density lipoprotein in smooth muscle cells of human aortic intima. Exp Mol Pathol $1997,64: 127-45$

42. Gowen M, Lazner F, Dodds R, Kapadia R, Fell J, Tavaria M, Bertoncello I. Drake $F_{x}$ Zavarselk S. Tellis I. Hertzog P, Debouck $C_{n}$ Kola I. cathepsin $K$ knockout mice develop osteopetrosis due to a deficit in matrix degradation but not demineralization. J Bone Miner Res 1999, $14: 1654-63$.

43. Gelb BD, Shi GP, Chapman HA, Desnick RJ: Pycnodysostosis, a lysosomal disease caused by cathepsin K deficiency. Science 1996,273:1236-8. 




\section{CHAPTER 7}

\section{SPATIO-TEMPORAL EXPRESSION OF PERILIPIN, ADIPOCYTE DIFFERENTIATION RELATED PROTEIN AND HORMONE SENSITIVE LIPASE IN HUMAN ATHEROSLEROSIS}

Birgit CG Faber, Andrew S Greenberg", Sylvia Heeneman, Peter JEHM Kitslaar* , Jan HM Tordoir*, Mat JAP Daemen, Kitty B.IM Cleutjens.

Departments of Pathology and General Surgery* , Cardiovascular Research Institute Maastricht (CARIM), University of Maastricht, The Netherlands. Jean Mayer USDA Human Nutrition Research Center on Aging at Tufts University, Boston, USA t 


\section{- Abstract}

Since excessive accumulation of lipids and cholesterol within atherosclerotic plaques. is a risk factor for plaque rupture, we made an inventory of mRNA and protein expression of perilipin, hormone sensitive lipase (HSL) and adipocyte differentiation related protein (ADPP), all inwolved in neutrall lipid metabolism, during human atherogenesis. Perilipin MRNA was predominantly detected in plaques containing a thrombus, while perilipin protein expression was observed in foam cells of early lesions, the shoulder area of stable lesions and near the site of cap rupture in lesions containing a thrombus. Expression levels of HSL MRNA and protein increased during plaque progression and co-lacalized with perilipin. ADRP MRNA and protein were abundantly present in all stages of human atherosclerosis. We hypothesize that ADRP is important during the initial phases of lipid uptake. Once macrophage derived foam cells become more lipid-laden, perilipin expression increases. As a result, perilipin replaces ADRP on the surface of the lipid droplet and regulates accessibility of the lipolytic enzyme HSL. Our data are the first to describe perilipin, HSL and ADRP expression patterns during lesion progression and suggest a role for these regulators of neutral fat metabolism during atherogenesis. 
One of the most important characteristics of atherosclerosis is the presence of lipids and cholesterol in the vessel wall: Excessive accumulation of lipids and cholesterol is considered to be a risk factor for plaque rupture . In a previous study from our laboratory ${ }^{3}$ the gene coding for perilipin, a protein involved in lipid metabolism, was found to be exclusively expressed in lesions containing a thrombus. Perilipin protein expression was observed in foam cells and in microvascular endothelial cells of lesions containing a thrombus, while only few foam cells in the shoulder region of stable lesions expressed perilipin. Perlipin is a phosphoprotein present on the surface layer of

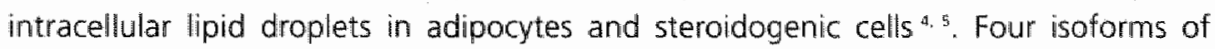
perilipin arise by alternative splicing from a single copy gene ". Perilipin $A$ is the predominant form in adipocytes and steroidogenic cells. Perilipin $B$ is found primarily in adipocytes, while isoforms $C$ and $D$ are restricted to steroidogenic cells 5.7 . In adipocytes, perilipin is hyperphosphorylated by CAMP dependent protein kinase A (PKA) upon lipolytic stimulation ${ }^{4.8}$. As a consequence, the surface of the lipid droplet is altered, resulting in an increased accessibility for the lipolytic enzyme hormone sensitive lipase (HSL), an enzyme, if phosphorylated by PKA, capable of hydrolyzing triacylglycerol and cholesteryl

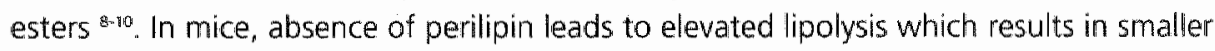
white adipocytes 11. : . In adipacytes, overexpression of perilipin decreases triacylglycerol hydrolysis ${ }^{8.13 .}$.4. These data suggest that perilipin, if not hyperphosphorylated, provides. a barrier for enzymes involved in lipolysis.

In human atherosclerotic plaques, the macrophage derived foam cells express a low level of HSL MRNA (approximately two percent of the level found in human adipocytes) 15. 15 . Involvement of HSL in atherosclerosis was suggested in al transgenic mouse model, showing macrophage specific HSL overexpression. Surprisingly, these mice developed more advanced lesions, probably due to an increase in free cholesterol within the lesion resulting in a pro-atherogenic inflammatory response $"$.

A third factor involved in intracellular neutral lipid storage is adipocyte differentiation related protein (ADRP), also known as adipophilin. ADRP shares sequence homology with the $\mathrm{N}$-terminal region of perilipin $\$$. ADRP MRNA was detected in foam cells of human atherosclerotic plaques and expression is upregulated in oxLDL laaded macrophages ${ }^{19}$. 20 . In early stages of adipocyte differentiation, lipid droplets are coated with ADRP, which is thought to facilitate the uptake of fatty acids and/or stabilize the lipid droplet 2123 . In mature adipocytes, the ADRP protein is replaced by perilipin either by competition or exclusion ${ }^{22}$. Despite the apparent homology between ADRP and perilipin, ADRP cannot take over the 'barrier role' of perillipin, since basal lipolysis is enhanced in the perilipin null mice while ADRP protein is increased "2. In summary. current data suggest a role for ADRP to facilitate the uptake and storage of neutral lipids and perilipin as a regulator of HSL dependent lipolysis. 
Recent literature provides additional evidence for an important role of neutral lipid metabolism in atherogenesis. Targeted disruption of Acyl-COA:Cholesterol Acyltransferase (ACAT), the enzyme involved in esterification of free cholesterol within foam cells, resulted in increased atherosclerotic lesion progression in LDL deficient mice ${ }^{2 A}$. Increasing evidence suggest HSL as an important neutral cholesterol ester hydrolase in macrophages ${ }^{15,25}$.

Accumulation of lipids in atherosclerotic lesions is a risk factor for plaque rupture? and the observation of increased perilipin expression in lesions containing a thrombus ${ }^{3}$ combined with the presence of other cholesterol/lipid regulatory genes like HSL and ADRP in the vessel wall suggests a role for proteins involved in cholesterol hydrolysis. during plaque destabilization ${ }^{15.16 .19}$. To further substantiate this hypothesis we made an inventory of perilipin, ADRP and HSL MRNA and protein in all stages of human atherosclerosis.

\section{$>$ Materials and Methods}

\section{Tissue Sampling and RNA Isolation}

Atherosclerotic plaques were collected from patients undergoing vascular surgery or at autopsy (Departments of Surgery and Pathology, Academic Hospital Maastricht). Characteristics of each vascular sample used in this study are described in table 1. Vascular specimens were processed as described previously ${ }^{3}$ and classified according to Virmani et al. ${ }^{26}$. Early lesions comprised intimal thickening and intimal xanthoma's. Stable lesions included fibrous cap atheroma's, thin fibrous cap atheroma's and fibrocalcific lesions. Lesions with thrombi included ruptured plaques, intraplaque haemorrhage and plaque erosion. Expression profiles of MRNA and protein did not differ between arteries and between plaques originating from either surgery or autopsy (data not shown).

\section{RT-PCR}

First strand CDNA was prepared using the SMART'M PCR CDNA Synthesis Kit (Clontech). Subsequently, $10 \mathrm{ng}$ CDNA was used for RT-PCR analysis using standard conditions ( 30 cycles: 1 min $94^{\circ} \mathrm{C}, 1$ min $55^{\circ} \mathrm{C}$ and 1 min $72^{\circ} \mathrm{C}$. The following primer sets were used: perilipin: sense (s) 5'-CTTTAACCAAACTTGTGGCC-3' + antisense (as) 5'-TACTCAGAAAGTGACACTAG-3', HSL: s 5'-GCTGGTGCGGCGGGACAC-3' + as 5'-GAAGGCGGCACGGACGCC-3', ADRP: s 5'-TGTGAGATGGCAGAGAACGG-3' + as 5'-CTCAGTGAGAGGGAGGTAC-3' and for normalization GAPDH: 5 5'-GGGAAGCTTGTCATCAATGG-3' + as 5'CATGGTTCACACCCATGACG-3'. 


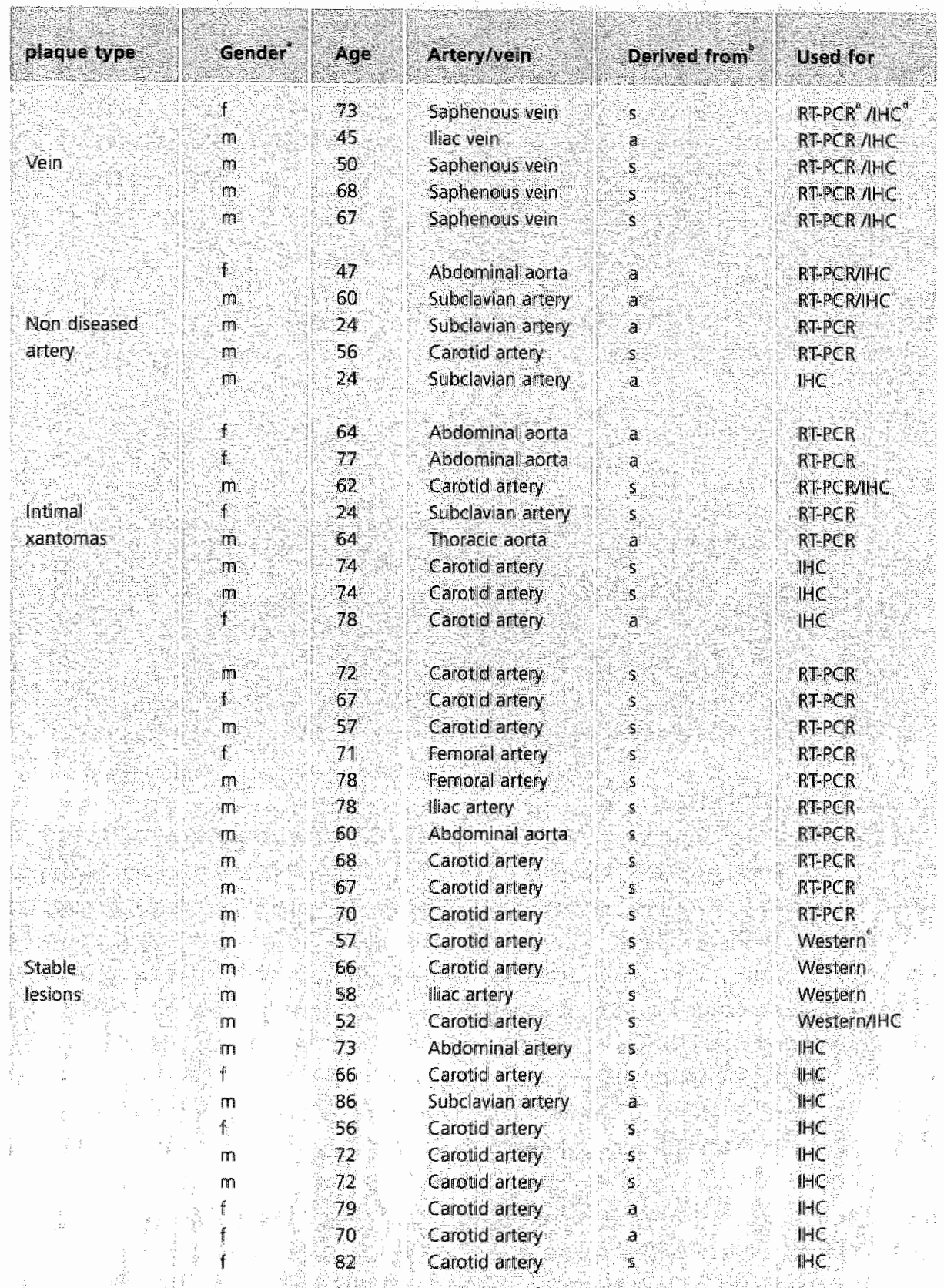




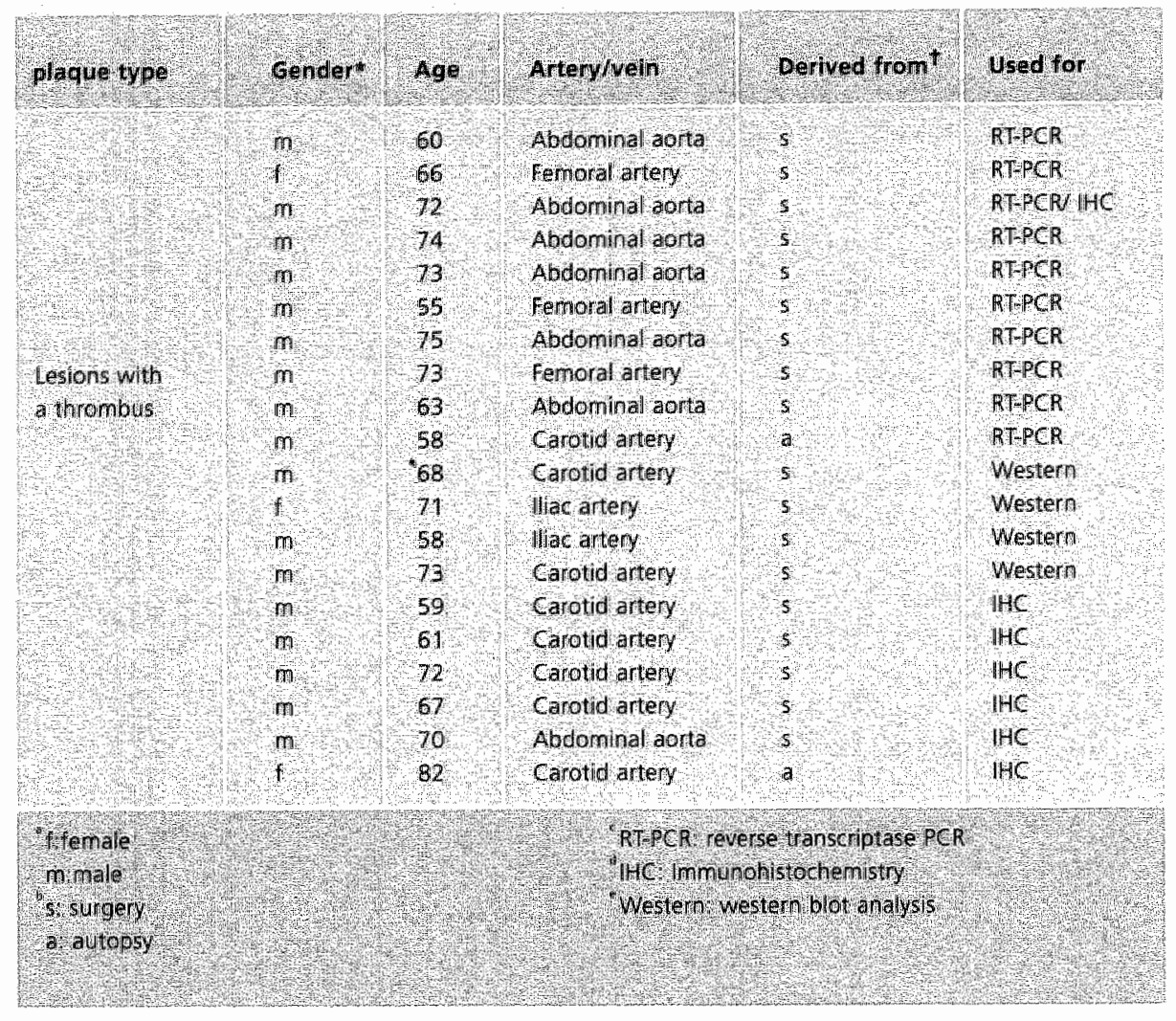

\section{Immunohistochemistry}

Paraffin sections ( $4 \mu \mathrm{m}$ ) were immunolabeled with either perilipin (1:1000; raised against the peptide MSMNKGPTLLDGDLPEQENVC; recognizing all perilipin isotypes), HSL " (1:500; a kind gift of A. Green) or ADRP (1:1000; raised against the peptide (AQDQGAEMDKSSQETQR) polyclonal antibodies. Serial sections were used to assess co-localization of perilipin, ADRP and HSL. To determine cell types expressing perilipin, HSL. and ADRP double immunohistochemical staining was performed. Sections labeled for either perilipin. HSL or ADRP were subsequently labeled for either CD68 (1:100, Dako; staining macrophages) or Factor Vill (1:2000, Biomakor; staining endothelial cells). All stainings were performed as described previously". Negative controls, that is sections incubated without the primary antibody, did not show any staining (data not shown).

\section{Western blot analysis}

Proteins were extracted essentially according to Greenberg et al ". Briefly, the vascular tissue was homogenized at $4^{\circ} \mathrm{C}$ in $1 \mathrm{ml} 20 \mathrm{mM}$ Tris HCl $(\mathrm{pH} 7.4), 255 \mathrm{mM}$ 
sucrose, $10 \mathrm{mM} \mathrm{NaF}, 200 \mu \mathrm{M}$ sodium orthovanadate, $1 \mathrm{mM}$ EDTA, $10 \mu \mathrm{l} / \mathrm{ml}$ leupeptin. $1 \mu \mathrm{M}$ benzamidine and $0.1 \mu \mathrm{M}$ phenylmethylsulfonyl fluoride and centrifuged for 5 minutes at $4000 \mathrm{rpm}$. The supernatant including floating fat, was mixed with $1 \mathrm{ml}$ of $1 \%$ SDS, $1 \mathrm{mM}$ EDTA, $20 \mu \mathrm{M}$ leupeptin $1 \mathrm{mM}$ benzamidine and $20 \mathrm{mM} \mathrm{NaF}$ at $4^{\circ} \mathrm{C}$. The mixture was sonified and stored at $-20^{\circ} \mathrm{C}$. Proteins ( $20 \mu \mathrm{g} / \mathrm{sample}$ ) were separated on a 10\% SDS-PAGE gel and transferred to a nitro-cellulose membrane (Protran. Schleicher \& Schuell). Blots were incubated with polyclonal antibodies directed towards either perilipin (1:1000; recognizing all perilipin isoforms). HSL (1:10000) or ADRP (1:750). Anti rabbit horseradish peroxidase (1:2000, Dako) was used as the secondary antibody. Specific antibody binding was visualized using enhanced chemiluminiscence (Amersham Pharmacia Biotech). Mouse adipocyte lysate, a source rich in perilipin and HSL, was used as a positive control.

\section{Results}

\section{Perilipin, ADRP and HSL mRNA and protein expression patterns}

Veins

Saphenous vein segments $(n=5)$ were included to assess whether perilipin, HSL and ADRP mRNA and protein expression was present in veins. Perilipin mRNA was detected in only 1 vein, while all veins expressed HSL MRNA and 4 out of 5 veins tested positive for ADRP MRNA in RT-PCR analysis (fig. 1).

In contrast none of the veins tested showed perilipin, HSL or ADRP protein expression using immunohistochemistry (data not shown).

\section{Non-diseased artery}

Perilipin mRNA was not detected in non-diseased artery $(n=4)$. Only 1 non-diseased artery expressed HSL MRNA, while 3 out of 4 specimens tested positive for ADRP mRNA (fig. 1).

HSL and ADRP protein expression were not observed in non-diseased artery $(n=3)$. The intima and media of the non-diseased artery did not express perilipin. In contrast, adipocytes and endothelial cells (as determined by double immunohistochemical staining using FVIII) of small vessels in the adventitial layer showed intense immunoreactivity for perilipin (data not shown).

\section{Early lesions}

Early lesions are characterized by the presence of foam cells in the intimal layer of the vessel wall. Both perilipin and HSL mRNAs were observed in only 1 out of 5 early lesions. In contrast, ADRP mRNA was present in the majority of the specimens tested (4 out of 5) (fig. 1). 
In early lesions ( $n=4$ ) lipid laaded macrophages (CD68 positive) just underneath the endothelial layer stained positive for ADRP, while these cells did not express perilipin nor HSL protein (fig. $2 A, B, O$. Macrophage derived foam cells deeper in the intima expressed either perilipin or ADRP (data not shown). Only a small subset of foam cells in the intima expressed both proteins. In general, protein expression of ADRP was more abundant than perilipin expression. HSL immunostaining was faint and only present in some intimal foam ceils (data not shown).

\section{Stable lesions}

Stable lesions include fibrous plaques, fibrocalcific plaques and fibrous cap atheromas. As described previously ${ }^{3}$ perilipin mRNA was completely absent in 10 individual stable plaques, representing all 3 subtypes. In contrast, HSL mRNA was detected in 4 out of 10 stable plaque, whereas ADRP MRNA was highly expressed in all stable plaque tested $(n=10)$ (fig. 1).

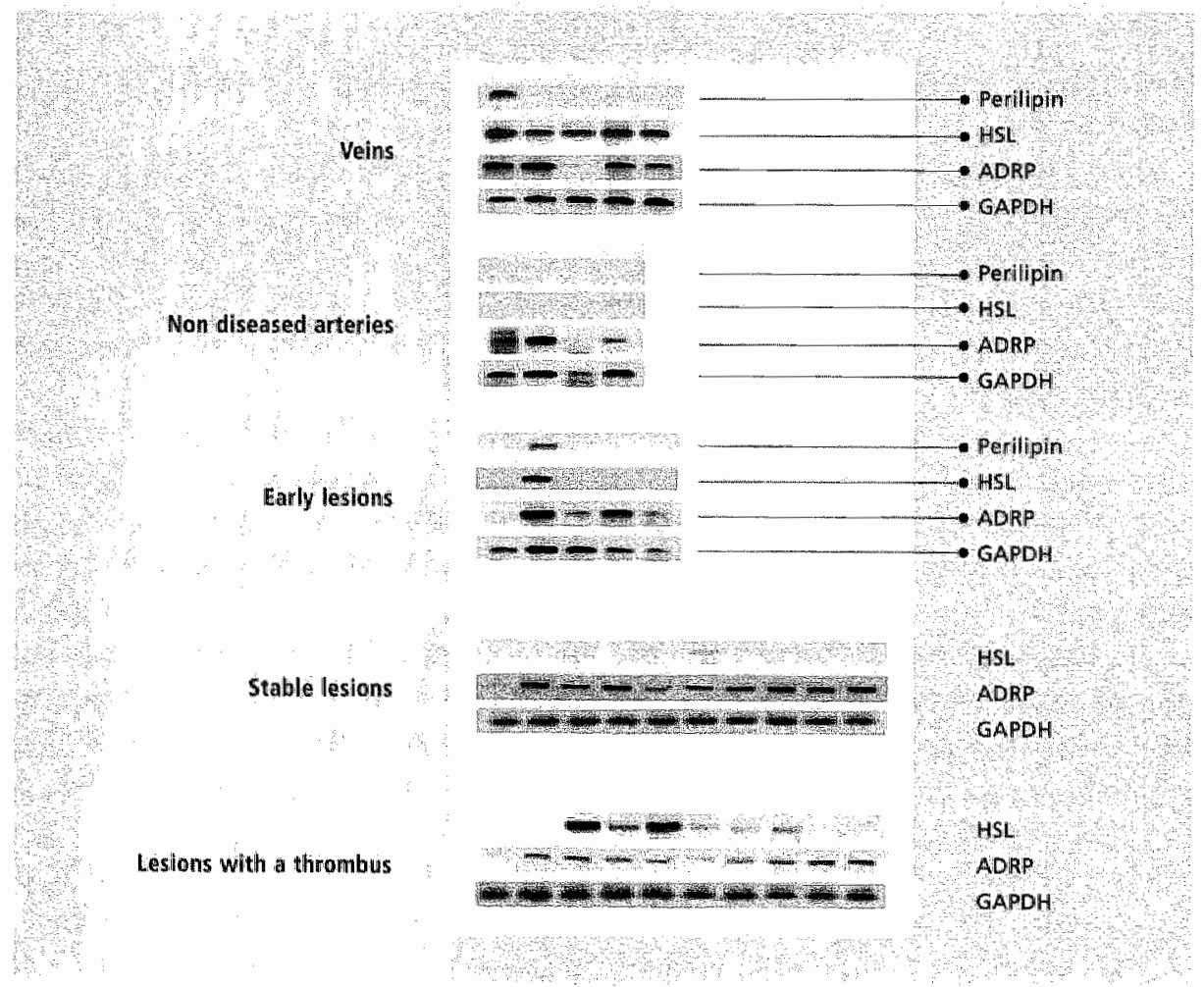

Figure I. ATPCR andysis of perilipin. HSL and ADRP during human atherogenesis. The figure shows perilipin, HSL and ADRP mRNA expression in veins, non-diseased arteries and early lesion. Furthermore, expression of MSL and ADRP MRNA in stable plaques and iesions with a thrombi is depicted. Expression of GAPDH is shown in the bottom panes. 
Fibrous plaques $(n=4)$ expressed low levels of perilipin protein mainly restricted to macrophages in the shoulder of the plaque (data not shown). Calcified areas did not show perilipin expression ( $n=3$ ). In fibrous cap atheromas $(n=3)$ perilipin was expressed in foam cells in the outer rim of the lipid core and in foam cells in the shoulder of the plaque. Remarkably, foam cells in areas of intense inflammatory infiltration showed high levels of perilipin protein expression (fig. 2 D). Perilipin immunoreactivity was also observed in endothelial cells of small vessels in advanced plaques (data not shown).

Fibrous cap atheromas showed low levels of HSL protein expression (fig. 2 E) which was mainly restricted to a small subset of perilipin expressing foam cells (fig. $3, A, B, D$ and $E$ ). Only a few foam cells demonstrated both HSL and ADRP protein expression (fig. 2 E F).

ADRP was found to be expressed in foam cells in the shoulder of fibrous plaques, whereas no expression was observed in areas of calcification (data not shown). In fibrous cap atheromas ADRP was abundantly expressed in foam cells in the shoulder (data not shown) and in the outer rim of the lipid core (fig. $2 \mathrm{~F}$ and fig. $3 \mathrm{~F}$ ). Foam cells expressing both ADRP and perilipin were scarce (fig. 3 A, C,D and F). Our series of fibrous cap atheromas encompassed two samples with lateral xanthomas. Macrophages just underneath the endothelial layer were mostly ADRP negative, whereas macrophages deeper into the lateral xanthomas showed abundant ADRP expression (fig. $2 \mathrm{~L}$ ). The lateral xanthomas showed a very low level of perilipin protein, while no HSL protein was expressed (fig. $2 J_{k} K$ ).

\section{Lesions containing a thrombus}

These lesions are characterized by either the presence of a ruptured fibrous cap and a related thrombus or an intraplaque heamorhage. Perilipin mRNA was found to be expressed in 8 out of 10 plaques containing a thrombus 3,7 out of 10 plaques expressed HSL MRNA and ADRP MRNA was observed in all 10 plaques (fig. 1).

In lesions with a ruptured cap $(n=4)$ perilipin protein expression was localized in foam cells at the actual site of cap rupture. Furthermore, foam cells surrounding the thrombus showed perilipin protein expression (fig. $2 \mathrm{G}$ ). In lesions containing intraplaque heamorthage $(n=3)$, foam cells near the luminal site of the plaque expressed perilipin. As described above, foam cells in highly infiamed regions showed extensive perilipin protein expression.

The majority of the ruptured plaques showed HSL protein expression, predominantly in foam cells in the ruptured cap (fig. $2 \mathrm{H}$ ). In lesions containing a thrombus, a low level of HSL expression was observed in a subset of perilipin positive cells.

ADRP protein was expressed at a low level in foam cells of the ruptured cap. In contrast, lipid loaded macrophages within the thrombus or foam cells adjacent to the thrombus showed thigh levels of ADRP expression (fig. 2 l). As described above, foam cells at the rim of the lipid core were ADRP positive. Foam cells deeper in the 


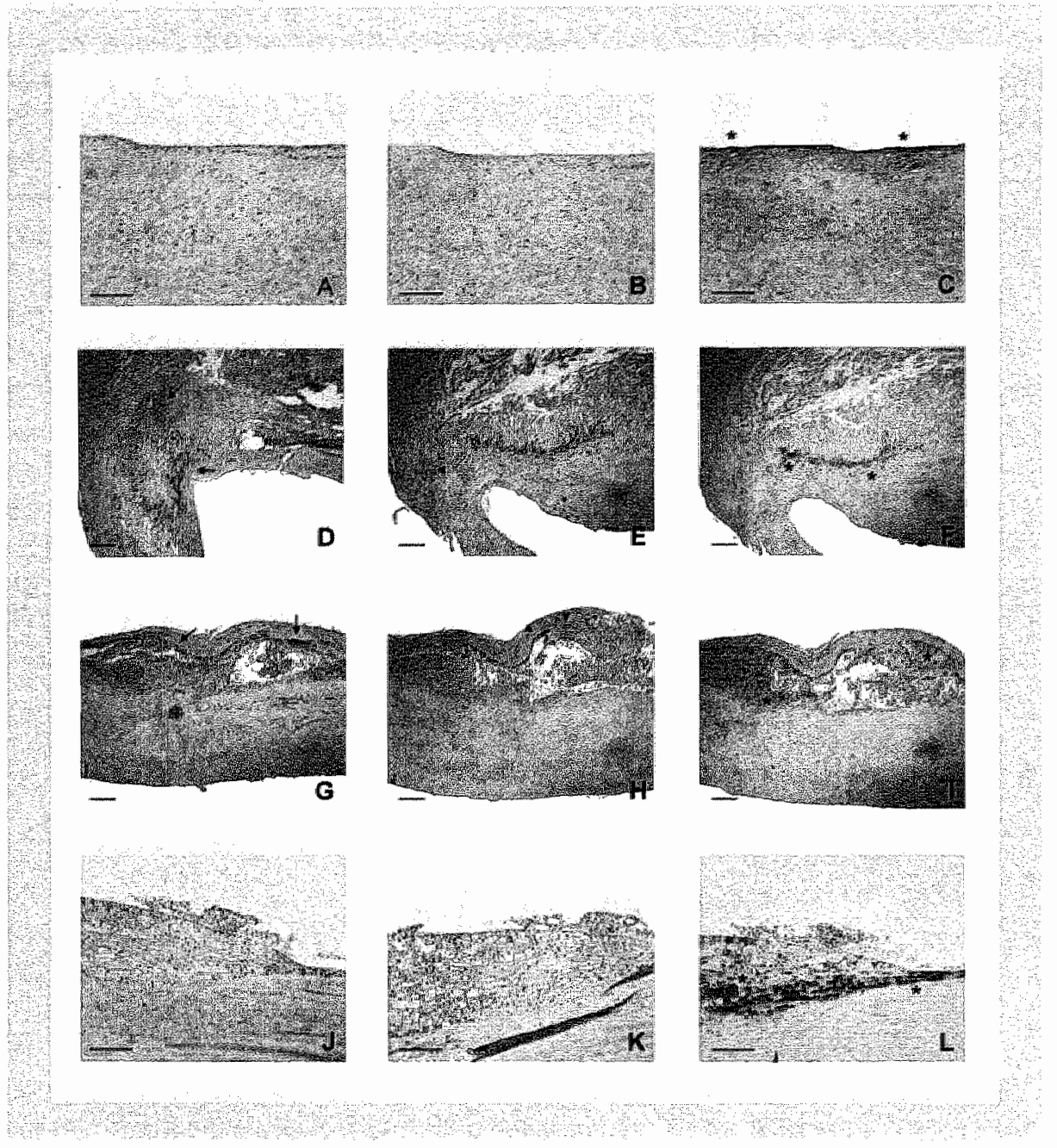

Figure 2. Immunohistochemical staining of perilipin (left panels, indicated by an arrow) HSL (middle panels. indicated by an arrowhead) and AORP (right panels, indicated by an asterix) during humam atherogenesis. Immunoreactiwity is depicted in red. The figure shows perilipin. HSL and ADRP protein expression in an early

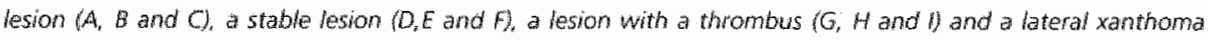

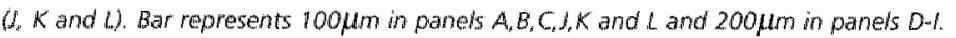




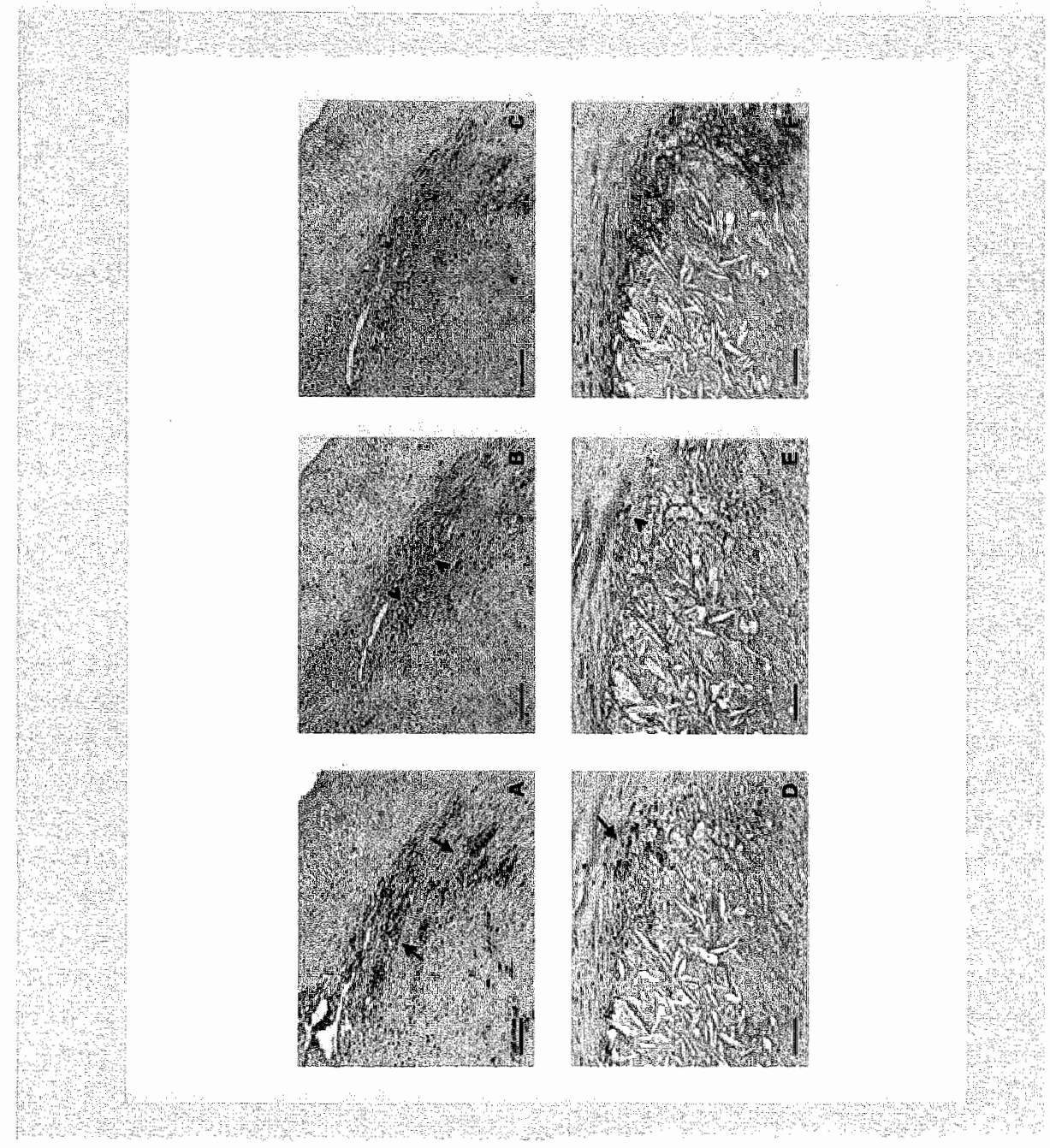

Figure 3. Immunohistochemical staining of perilhin (left panels), HSL (middle panels) and ADRP (right panels) during human atherogenesis. Immunoreactivity is depicted in red. The upper panel shows cowlocalizacion of perihpin ( $A$, indicated with an arrow) and HSL ( $B$, indicated with an arrowhead) in foam cells of a fibrous cap atheroma showing onty faint $A D R P$ expression ( $C$ indrated with an asterix). The lower panel shows faint perilipin $(D$. indicated with an arrow) and $M S L$ ( $E$, indicated with an arowhead) stairing in a fibrous cap athenoma that shows extensive ADRP (findicated with an asterix) protein expression in foam cells. Bar represents $100 \mathrm{Hm}$. 
intima of lesions containing an intraplaque haemorrhage expressed ADRP. ADRP expression near an intraplaque heamorrhage was comparable to expression near the thrombus after plaque rupture.

in summary, expression of perilipin MRNA was very low during the early phase of atherogenesis and was absent in stable plaques, while perilipin mRNA expression was upregulated in plaques containing a thrombus. Perilipin protein expression was observed in macrophage derived foam cells and expression increased during plaque progression. HSL MRNA expression increased during plaque progression. HSL protein, although expressed at a low level, was also increased during plaque progression and co-localized mainly with perilipin protein expression. Remarkably, ADRP MRNA was abundantly expressed during all stages of human atherogenesis. ADRP protein expression, observed in macrophage derived foam cells, increased during plaque progression in advanced but stable lesions. In lesions containing a thrombus ADRP protein was expressed by foam cells near the thrombus.

\section{Western blot analysis of perilipin, HSL and ADRP expression}

In order to assess perilipin isoform distribution during human atherogenesis, we performed western blotting of lysates of advanced stable lesions and plaques containing a thrombus. Perilipin $\mathrm{A}(65 \mathrm{kD}$ ) $)$ was the only perilipin isoform detected in human atherosclerotic lesions. Comparison of stable and lesions containing a thrombus revealed no significant differences in perilipin A expression levels * (fig. 4). Expression of the $84 \mathrm{kDa}$ HSL isoform was observed in all human plaque lysates (fig. 4). The doublet in 2 stable plaque lysates might be indicative of 2 separate HSL-isoforms or a post-translational modification such as phosphorylation. ADRP protein (53kDa) was expressed in 3 out of 4 stable plaque lysates and only in 1 lysate of a lesion containing a thrombus (fig. 4).

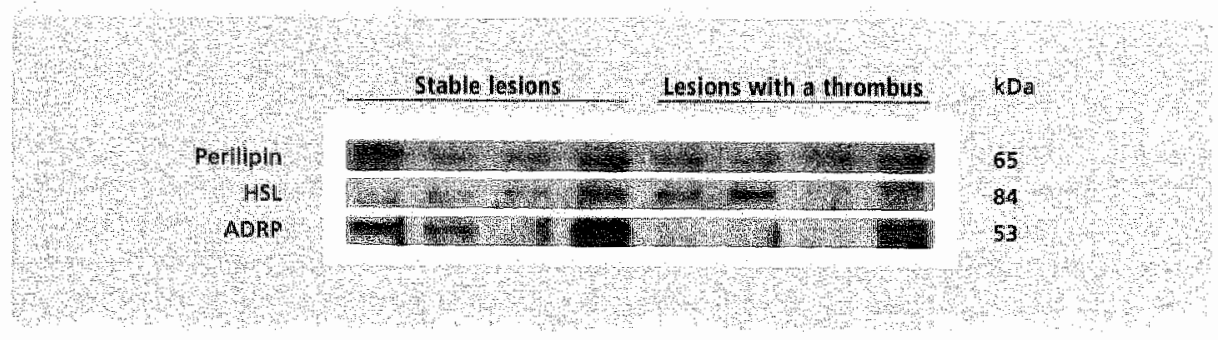

Figure 4. Westem blot analysis with antibodies directed towards perilipin, HSL and ADRP. Lanes 1-4 contain protein lysate of 4 stable plaques. Lanes 5 -8 represent protein lysate of 4 plaques containing a thrombus. The top panel represents perilipin protein expression $(65 \mathrm{kDa})$, the midde pane represents HSL protein expression (84KDa) and the bottom panel represents ADRP protein expression (53k0a). 
In the current study we investigated whether perilipin and the functionally closely rellated proteins HSL and ADRP are differentially expressed during the initiation and progression of human atherosclerosis. Perilipin. HSL, and ADRP protein expression was observed in macrophage derived foam cells in the intima. Low levels of perilipin protein expression were found in the early stages of atherosclerosis and in very fibrous plaques. In contrast, perilipin protein was expressed at high levels in foam cells of fibrous cap atheromas and in the ruptured caps of thrombus containing plaques. Furthermore, perilipin expression was often associated with areas of inflammation. since large lipid cores ${ }^{2}$, thin fibrous caps and areas of inflarmmation ${ }^{28}$ are considered to be risk factors for plaque stability, it is tempting to speculate that perilipin expression is associated with plaque vulnerability. In contrast to pepilipin protein, perilipin MRNA was not detectable in stable plaques ${ }^{3}$. Brasaemle et al. ${ }^{29}$ showed that lipid loading of adrenal cortical cells resulted in a 6-fold increase of perilipin MRNA while perilipin protein was enhanced up to 140-fold. In this respect, the apparent discrepancy between mRNA and protein expression may be explained by the high stability of perilipin protein in the presence of lipids ${ }^{5}$, whereas perilipin MRNA was below the detection limit of our RT-PCR. Thus far, no evidence for influx of the perilipin protein from distant locations is available.

Our finding of low levels of HSL MRNA and protein in foam cells of advanced lesions is in close agreement with the observation of Harte et al ${ }^{15}$ who found a low level of HSL MRNA in human arterial macrophage derived foam cells. Remarkably, expression of HSL protein was mainly restricted to perilipin positive foam cells, whereas co-localization of HSL and ADRP was only rarely observed.

Recent literature suggests a delicate interplay between HSL and perilipin in the regulation of neutral lipid hydrolysis ${ }^{8}$. Lipolytic stimuli result in the phosphorylation and activation of HSL and subsequent translocation to the lipid surface ${ }^{\text {xi }}$. Perilipin present on the surface of the lipid draplet is thought to act as barrier for HSL resulting in inhibition of lipolysis, whereas hyperphosphorylation of perilipin facilitates the accessibility of the lipid droplet for the lipolytic enzyme HSL *10. Co-expression of perilipin and HSL in the same foam cells suggests an interplay of the two proteins in human atherosclerotic plaques. Unfortunately, we were not able to assess perilipin phosphorylation status and thus the effect of perilipin on lipoiysis, in human atherogenesis. Theoretically, the presence of non-hyperphosphorylated perilipin may result in a reduction of lipolysis that leads to accumulation of lipids in the plaque and possibly increased plaque vulnerability. Perilipin in its hyperphosphorylated form however, increases accessibility of the lipid droplet for HSL and may result in increased lipolysis. On the other hand, increased lipolysis, does not necessarily result in smaller atherosclerotic lesions. Escary et al. "showed that HSL overexpression in macrophiages did increase lipolysis, but resulted in more advanced atherosclerotic lesions in mice. A possible explanation for this phenomenon is that a increase in free cholesterol leads to an 
induction of a pro-atherogenic inflammatory response. As perilipin protein expression is increased in areas of inflammation, one may speculate that perilipin acts ${ }_{i}$ by preventing lipolysis, as a negative feedback mechanism on the pro-atherogenic inflammatory response that results from the increase in local free cholesterol. Our study revealed expression of ADRP in infiltrating macrophages underneath the endothelial layer during the early onset of atherogenesis, in foam cells surrounding the lipid core of advanced lesions and in macrophages that infiltrated thrombi in lesions containing a thrombus. This expression pattern made us hypothesize that ADRP might either serve as a shuttling protein of the lipid substrate to the lipid droplet or as a protein that stabilizes the lipid droplet ${ }^{23}$. Furthermore, ADRP mRNA was highly upregulated in macrophages. soon after the onset of cholesterol loading ${ }^{20}$. These datas together with the localization of the ADRP positive foam cells in regions of possible lipid intake (infiltrating macrophages, foam cells at the rim of the lipid core and macrophages within the thrombus), suggest a role for ADRP in the formation or stabilization of lipid droplets in human atherosclerotic plaques. Remarkably, the prevalence of ADRP protein expression was decreased after plaque rupture. In anallogy to previous findings in adipocyte research ${ }^{8,22}$, this might imply replacement of ADRP by perilipin in plaques containing a thrombus.

Perilipin and ADRP were mainly expressed in separate sets of foam cells. Only a small subset of foam cells showed co-localization of both proteins. Intriguingly, in these cells only one of the two proteins was expressed abundantly. In addition, foam cells in lateral xanthomas showed a gradient (low levels at the luminal site) of ADRP protein while no perilipin was detected. Our data are in close agreement with previous observations in adipocytes. ADRP in these cells was expressed during the early phase of lipid uptake, while expression decreased after the onset of perilipin expression ${ }^{22}$. We found a discrepancy between abundant ADRP mRNA expression and absence of ADRP protein in non-diseased artery and vein. This also is in agreement with the observations of Braseamle et al. ${ }^{22}$, which showed a rapid degradation of ADRP protein in the absence of lipids, while ADRP mRNA remained abundantly expressed. The absence of lipid depositions in veins and normal arteries may thus explain the rapid degradation of ADRP protein in these vessels.

In summary, our data are the first to describe perilipin, HSL and ADRP expression patterns during progression of human atherosclerosis. The observed expression patterins of these proteins indicated ADRP expression in infiltrating macrophages, in developing lesions and macrophages that engulf debris at the border of the lipid core or within a thrombus. If the macrophage derived foam cells take up more lipids, perilipin is expressed, while expression of ADRP diminishes. Perilipin regulates the accessibility of the lipid droplet for HSL and might therefore influence lipolysis within an atherosclerotic lesion. The expression patterns of perilipin, HSL and ADRP during lesion progression suggest a role for these regulators of neutral lipid metabolism during human atherogenesis. 


\section{Acknowledgments}

The authors thank Wendy Boon for excellent technical support. This work was supported by grant PF1197 from the Academic Hospital Maastricht, The Netherlands. K. Cleutjens was supported by grant 902-26-223 of the Netherlands Organisation for Scientific Research (NWO). A. Greenberg was supported by the United States Department of Agriculture, under agreement No. 581950-9-001 and DK 50647. 


\section{$>$ References}

1. Lusis Al: Atherosclerosis. Nature 2000,407:233-41.

2. Davies MJ, Richardson PD, Woolf $N$, Katz DR, Mann J: Risk of thrombosis in human atherosclerotic plaques: role of extracellular lipid, macrophage, and smooth muscle cell content Br Heart/ 1993,69:377 -81.

3. Faber BC, Cleutiens KB, Niessen RL, Aarts PL, Boon W, Greenberg AS, Kitslaar Pl, Tordoir IH. Daemen $\mathrm{M}$ : Identification of genes potentially involved in rupture of human atherosclerotic plaques. Circ Res 2001,89:547\%54.

4. Greenberg AS, Egan JJ, Wek SA, Garty NB, Blanchette-Mackie EJ, Londos C: Perilipin, a major hormonally regulated adipocyte-specific phosphoprotein associated with the periphery of lipid storage droplets. J Biol Chem 1991,266:11341-6.

5. Servetnick DA, Brasaemle DL, Gruia-Gray 1, Kimmel AR, Wolff 1, Londos C: Perilipins are associated with cholesteryl ester droplets in steroidogenic adrenal cortical and Leydig cells. J Biol Chem 1995,270:16970*3.

6. Lu X, Gruia-Gray J, Copeland NG, Gilbert DJ, Jenkins NA, Londos C, Kimmel AR: The murine perillipin gene: the lipid droplet-associated perilipins deriwe from tissue-specific, mRNA splice variants and define a gene family of ancient origin. Mamm Genome 2001,12:741-9.

7. Greenberg AS, Egan JJ, Wek SA, Moos MC. Jr., Londos C. Kimmel AR: Isolation of CDNAs for perilipins $A$ and $B$ : sequence and expression of lipid droplet-assaciated proteins of adipocytes. Proc Natl Acad Sci U S A 1993,90:12035-9.

8. Souza SC, Muliro KV, Liscum L, Lien P, Vamamoto MT, Schaffer JE, Dallal GE, Wang $X$, Kraemer FB, Obin M, Greenberg AS: Modulation of hormone-sensitive lipase and protein kinase A-mediated lipolysis by perilipin $A$ in an adenowiral reconstituted system. I Biol Chem 2002,277:8267-72.

9. Clifford $G M$, Londos C. Kraemer $F B$, Vernon RG, Yearnan St: Translocation of hormone-sensitive lipase and perilipin upon lipolytic stimulation of rat adipocytes. J Biol Chem 2000,275:5011-5.

10. Belkner I, Stender H, Holzhutter HG, Holm C. Kuhn H: Macrophage cholesteryl ester hydrolases and hormone-sensitive lipase prefer specifically oxidized cholesteryl esters as subsitrates over their non-oxidized counterparts. Biochem J 2000,352 Pt 1:125-33.

11. Martinez-Botas. J, Anderson JB, Tessier D, Lapillonne A, Chang BH, Quast MJ, Gorenstein D. Chen $\mathrm{KH}$, Chan L: Absence of perilipin results in leanness and reverses obesity in Leprab/db mice. Nat Genet 2000,26:474-9.

12. Tansey JT" Sztalryd C. Gruia-Gray \&, Roush DL, Zee IV, Gavrilova $O$, Reitman ML, Deng CX, Li C, Kimmel AR, Londos C: Perilipin ablation results in a lean mouse with aberrant adipocyte lipolysis, enhanced leptin production, and resistance to diet-induced obesity. Proc Natl Acad Sci U 5 A 2001,98:6494-9

13. Souza SC, de Vargas LM, Yamamoto $M T_{\text {, Lien }} P_{n}$ Franciosa MD, Moss LG, Greenberg AS: Overexpression of perilipin $A$ and $B$ blocks the ability of tumor necrosis factor alpha to increase lipolysis in 3T3-L1 adipocytes. J Biol Chem 1998,273:24665-9. 
14. Brasaemle DL, Rubin $B$, Harten IA, Gruia-Gray J, Kimmel AR, Londos C: Perilipin A increases triacylglycerol storage by decreasing the rate of triacylglycerol hydrolysis. I Biol Chem 2000,275:38486-93.

15. Harte RA, Hulten LM, Lindmark H, Reue K, Schotz MC, Khoo H, Rosenfeld ME; Low level expression of hormone-sensitive lipase in arterial macrophage-derived foam cells; potential explanation for low rates of cholesteryl ester hydrolysis. Atherosclerosis 2000, 149:343-50.

16. Reve K, Cohen RD, Schotz MC: Evidence for hormone-sensitive lipase MRNA expression in human monocyte/macrophages. Arterioscler Thromb Vasc Biol 1997,17:3428-32.

17. Escary IL, Choy HA, Reue K, Wang XP, Castellani LW, Glass CK, Lusis A, Schotz MC: Paradoxical effect on atherosclerosis of hormone-sensitive lipase overexpression in macrophages. J Lipid Res 1999,40:397-404.

18. Londos C, Brasaemle DL, Schultz Cl, Segrest JP, Kimmel AR: Perilipins, ADRP, and other proteins that associate with intracellular neutral lipid droplets in animall cells. Semin Cell Dev Biol 1999,10:51-8.

19. Wang $X$, Reape $T$, Li $X$, Rayner $K$, Webb $C L$, Burnand KG. Lysko $P G$ : Induced expression of adipophilin MRNA in human macrophages stimulated with oxidized low-clensity lipoprotein and in atherosclerotic lesions. FEBS Lett 1999,462:145-50.

20. Shiffiman D, Mikita T, Tai JT, Wade DP, Porter JG, Seilhamer JJ, Somogyi R, Liang S, Lawn RM: Large scale gene expression analysis of cholesterol-loaded macrophages. I Biol Chem 2000,275:37324-32.

21. Jiang $H P$, Serrero $G$ : Isolation and characterization of a full-length $C D N A$ coding for an adipose differentiation-related protein. Proc Nati Acad Sci U S A 1992,89:7856-60.

22. Brasaemle DL, Barber T, Wolins NE, Serrero G. Blanchette-Mackie EJ, Londos C: Adipose differentiation-related protein is an ubiquitously expressed lipid storage droplet-associated protein. J Lipid Res 1997,38:2249-63.

23. Gao J Serrero G: Adipose differentiation related protein (ADRP) expressed in transfected COS-7 cells selectively stimulates long chain fatty acid uptake. J Biol Chem 1999,274:16825-30.

24. Fazio S, Major AS, Swift LL, Gleaves LA, Accad M, Linton MF, Farese RV, Ir: Increased atherosclerosis in LDL. receptor-null mice lacking ACATI in macrophages. I Clin Invest 2001, 107:163-71.

25. Small CA, Goodacre IA, Yeaman SJ: Hormone-sensitive lipase is responsible for the neutral cholesterol ester hydrolase activity in macrophages. FEBS Lett 1989,247:205-8.

26. Virmani R, Kolodgie FD. Burke AP, Farb A, 5chwartz SM: Lessons from sudden coronary death: a comprehensive morphological classification scheme for atherosclerotic lesions. Arterioscler Thromb Vasc Biol 2000,20:1262-75.

27. Green A, Dobias SB, Walters DJ, Brasier AR: Tumor necrosis factor increases the rate of lipolysis in primary cultures of adipocytes without altering levels of hormone-sensitive lipase. Endocrinology 1994,134:2581-8.

28. Libby $P$ : Coronary antery injury and the biology of atherosclerosis: inflammation, thrombosis, and stabilization. Am J Cardiol 2000,86:3J-8J; discussion 8J-9l. 
29. Brasaemle DL. Barber T. Kimmel AR, Londos C: Post-translational regulation of perilipin expression. Stabilization by stored intraceilular neutral lipids: I Biol Chem 1997,272:9378-87.

30. Egan J, Greenberg AS. Chang MK, Wek SA, Moos MC, Jr. Londos C: Mechanism of hormone-stimulated lipolysis in adipocytes: translocation of hormone-sensitive lipase to the lipid storage droplet. Proc Natt Acad Sci U S A 1992,89:8537-41. 



\title{
CHAPTER 8
}

\section{VASCULIN, A NOVEL VASCULAR PROTEIN DIFFERENTIALLY EXPRESSED IN HUMAN ATHEROGENESIS}

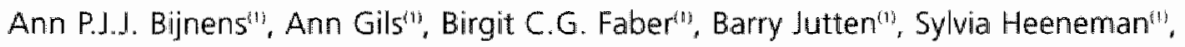 \\ Peter J.E.H.M. Kitslaar', Jan H.M. Tordoir', Carlie J.M. de Vries(3), Mat J.A.P. \\ Daemen ${ }^{\prime \prime 3}$ and Kitty B.J.M. Cleutjens ${ }^{(1)}$. \\ Department of Pathology" and General Surgery ${ }^{(2)}$, Cardiovascular Research Institute \\ Maastricht (CARIM), Maastricht, The Netherlands. Department of Biochemistrys) \\ Academical Medical Center, University of Amsterdam, The Netherlands.
}




\section{$>$ Abstract}

Recent Suppressive Subtractive Hybridization analysis on human atherosclerotic plaque-derived RNA, revealed genes upregulated in plaques with a thrombus versus stable plaques. Here, candidate clone $\$$ SHG, containing part of a putative open reading frame of an unknown protein, was further investigated. Full-length CDNA, coding for a 473 AA protein. was identified in a vascular Smooth Muscle Cell (SMC) CDNA library. Bio-informatics revealed that the $55 \mathrm{H} 6$ gene is localised on chromosome 5, p13 and suggested the presence of multiple SSH6 variants due to alternative splicing of exon 3. Multiple tissue Northern blot amalysis demonstrated a differential expression pattern of these variants, as a ubiquitously expressed SSH6 mRNA (SSH6- $\beta$ ), missing exon 3. was detected apart from a putative vascular SMC specific form (vascullin). Western blot analysis using a specific antibody fragment (5cFv) selected from a phage-displayed scFv library, indicate a ubiquitous $35 \mathrm{kDa}$ protein, that might be a transcriptional or translational CDNA variant of the SSH6 gene, besides a protein of thie expected size ( $45 \mathrm{kDa}$, vasculin), detected in the vascular wall and in plasma. Analysis of arteries displaying various stages of atherosclerosis, indicated that the ratio of vasculin versus $55 \mathrm{H6}-\beta$ increases throughout atherogenesis. Immunohistochemical anallysis demonstrated cytoplasmatic expression of vasculin and/or SSH6- $\beta$ in SMC. endothelial and secreting cells in various tissues. In summary, we identified a novel MRNAJprotein, vasculin, detected in the vascular wall and in plasma. The regulated expression of vasculin in atherosclerotic plaques suggests a role in atherogenesis. Moreover, its presence in plasma opens perspectives to develop vasculin as a marker for atherosclerosis. 


\section{Introduction}

In the past few years various large scale gene expression studies have been performed in order to identify genes that are involved in atherosclerosis ${ }^{\text {th }}$. In these studies a variety of techniques has been applied, including CDNA expression arrays $S_{*}$ differential display, RNA subtraction methods, serial analysis of gene expression (SAGE) and signature pyrosequencing, performed both on whole mount material and cell lines reported to be involved in atherosclerosis. The majority of these studies focussed on genes known to be involved in processes related to atherosclerosis, e.g. inflammation " apoptosis" matrix turnover ${ }^{12}$ and lipid metabolism " or on well-known genes whose relationship to atherosclerosis had not been reported before. However, the incidence of novel highly-up regulated genes in the outcome of these investigations indicated that a full understanding of the atherosclerotic process is far from established and studies elucidating presently unknown genes/proteins are indispensable to solve the 'missing links". Nevertheless, studies concentrating on these novel atherosclerosis-related genes are sparse. De Vries et al. "revealed thirty cytokine-responsive human genes of unknown function in cultured vascular smooth muscle cells. Moreover, Horrevoets et al. " and Yoshisue et al. 8 identified novel genes in human umbilical vein endothelial cells, whose expression was modulated by cytokines or shear stress, respectively.

The low abundance of reports describing novel genes can - at least partially - be explained by the lack of antigen-specific immmunological tools. Indeed, the availability of antibodies or antibody fragments is a prerequisite to study genes at the protein level, and whereas these tools are ample for well-established proteins, it is a laborious task to obtain high quality antibodies for novel proteins. In order to meet the need for antigen-specific tools, we selected in the present study single-chain variable fragments (scFvs) from a phage-displayed library ".4. These scFvs are demonstrated to serve as useful instruments to evaluate protein expression e.g. in Western blot and immunohistochemical analyses. Recently. Suppressive Subtractive Hybridisation (5SH) analysis has been performed on whole-mount human atherosclerotic plaques to establisth a library of CDNA fragments preferentially expressed in plaques with a thrombus versus stable atherosclerotic plaques ${ }^{15}$. Sequence analysis of clone S5H6 revealed that its CDNA shares partial overlap with a public database CDNA template coding for a putative protein with unknown function, but in addition contains a 120 bp insertion absent in the homologous sequence.

In this report, we describe the cloning and initial characterisation of this novel MRNA/protein, which was named tentatively vasculin, as an acronym for vascular wall linked protein. We isolated full-length CDNA from a vascular smooth muscle cell library and characterised its genomic organisation. Furthermore, we developed immunological tools to characterise the protein and to evaluate its presence in hurnan tissues. Our data indicate a regulated gene expression of vasculin in the vascular wall, suggesting an in vivo function for vasculin in normal vascular biology as well as in atherosclerosis. Moreover, the presence of wasculin in plasma opens perspectives for the development of vasculin as a marker for atherosclerosis. 


\section{Materials and methodes}

\section{Tissue sampling}

Atherosclerotic placues were collected from patients undergoing vascular surgery or at autopsy (Departments of Surgery and Pathology, Academic Hospital Maastricht). Vascular specimens were processed as described ts and classified according to Virmani et al. ${ }^{10}$. Non-diseased samples originated from abdominal aorta, subclavian, mammary or carotid artery; venous specimens were from the saphenous or liac veins; samples from early diseased arteries were from the abdominal or thoracic aorta, or the subclavian or carotid artery; advanced plaques were from the abdominal aorta, common iliac artery, or the (common) femoral or carotid artery; plaques with a thrombus originated from abdominal aorta, or the femoral, iliacal or carotid artery.

\section{Cell culture}

Human vascular smooth muscle cells were obtained from abdominal aortic lesions as described previously with minor modifications ${ }^{17}$. Cultures were maintained in DMEM (Life Technologies) complemented with $20 \%$ foetal calf serum, L-alanyl-L-glutamine (1 $x$ Glutamax 1 , Life Technologies), penicillin ( $100 \mathrm{lU} / \mathrm{ml})$ and streptomycin $(50 \mu \mathrm{g} / \mathrm{ml})$ and were used for further experiments between passage 2 and 5 .

\section{Screening of vascular smooth muscle cell cDNA library}

A 1490 bp probe including the unique 120 bp insertion of clone $55 H 6$ was PCR generated from first strand CDNA using the appropriate primers (see Table 1 ), "xp-labeled (High Prime, Roche Applied Science) and used to screen a human artery SMC CONA library". Positive clones were isolated, tested using PCR, and inserts were sequenced with the Thermo Sequenase cycle sequencing kit (Amersham Pharmacia Biotech). Bioinformatics were performed using the nucleotide Blast programs (National Center for Biotechnology, www.ncbi.nim.nih.gov, and EXPASy Molecular Biology Services (www.expasy.ch).

\section{Reverse Transcriptase Pollymerase Chain Reaction}

To reveal the expression profile of wasculin in the vascular wall, RT-PCR was performed on $\mathrm{MRNA}$ isolated from veins and arteries with atherosclerotic lesions in various stages. Total RNA, CDNA synthesis and RT-PCR were performed as described before "s, Vasculin and GAPDH specific DNA fragments were amplified on first strand CDNA using the in dicated primers (Table 1 ) and the resulting PCR products were analysed on a $1 \%$ agarose gel.

\section{Multi-tissue Northern blot analysis}

Multi-tissue Northerm blot was performed using the Multiple Tissue Expression Array MTE (Clontech) essentially according the protocol of the manufacturer. In brief, probes 
Table 1: Ongonudeotide sequences of primers used in $P C R$

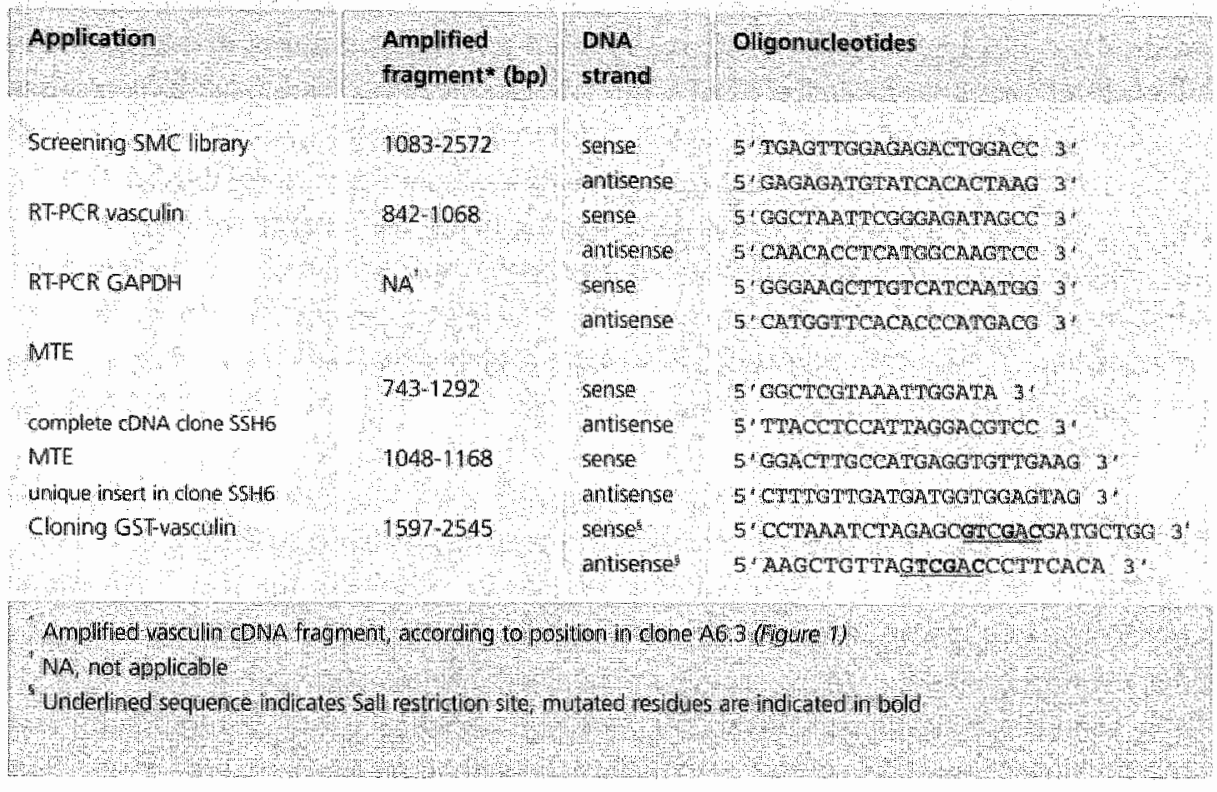

matching the complete CDNA fragment present in clone SSH6 or the unique 120 bp insert, respectively, were PCR amplified using the appropriate primers indicated in table 1. Subsequently, the MTE was hybridised with the denatured ${ }^{32}$ P-labeled probe at $65^{\circ} \mathrm{C}$ overnight and exposed to $x$-ray film at $-70^{\circ} \mathrm{C}$ during 48 hours. mRNA from a primary VSMC culture derived from an atherosclerotic plaque with a thrombus and plasmid DNA containing exon 3, were used as positive controls, respectively.

\section{Expression plasmid for Schistosoma japonicum glutathione S-transferase-vasculin fusion protein (GST-vasculin)}

A cDNA fragment corresponding to the 302 C-terminal amino acids of the open reading frame of vasculin was PCR amplified under standard conditions using the primers mentioned in Table $\%$, in order to introduce Sall restriction sites for the construction of the expression plasmid. As a result of the introduction of the desired restriction sites, a proline (CCA) and arginine (AGG) codon in the oper reading frame of vasculin was mutated into a serine (TCG) and threonine (ACG) codon, respectively. Subsequently, the PCR product was Sall digested and the 938 bp gel purified fragment was ligated into pGEX-4T-2 (Amersham Pharmacia Biotech). BL21 E.colii cells were transformed with the ligation product and the construct used for the expression of GST-wasculin (pGEX-GST-vasculin) was sequenced entirely in the GST-vasculin coding region. 


\section{Expression and purification of GST-vasculin and GST}

GST-vasculin was expressed basically as described before . Wild type GST protein, produced in BL21 E.coli cells transformed with a pGEX-4T-2 without insert, was used as a control. For the purification of GST and GST-vasculin, cells were lysed by sonication in buffer $20 \mathrm{mM}$ Tris $\mathrm{HCl}(\mathrm{pH} 8.0)$, containing $1 \%$ Triton $\mathrm{X}-100,100 \mathrm{mM} \mathrm{NaCl}, 1 \mathrm{mM}$ EDTA, $1 \mathrm{mM}$ dithiothreitol (DTT), $2 \mathrm{mM}$ phenylmethylsulfonyl fluoride (PMSF) and 0.1 mM benzamidine. The soluble fraction was purified with glutathione agarose by batch absorption (Amersham Pharmacia Biotech), essentially as described by the manufacturer. After dialysis against PBS, purity was checked using sodium dodecyl sulphate polyacrylamide gel electrophoresis (SDS-PAGE) and Coomassie Blue staining. Protein concentration was determined using a colorimetric assay (Bio-Rad Protein Assay. Bio-Rad Laboratories GmbH).

\section{Selection of vasculin-specific scFvs from a phage-display library}

The Griffin. 1 library, a human synthetic VH+VL sCFv library in the phagemid vector pHEN2 , was kindly provided by Dr. Heather Griffin (MRC Centre for Protein Engineering, Cambridge, UK).

Three rounds of selection of the library were performed by panning in immunotubes coated with $200 \mu \mathrm{g}$ GST-vasculin, essentially as described previously ${ }^{20}$. Prior to the final round of selection, the enriched library was depleted for GST-binders by panning on $200 \mu \mathrm{g}$ GST. After each round, single clones were characterized by size and BstNII fingerprinting of PCR amplified inserts. To identify vasculin-specific sCFvs resulting from the third round of selection, an ELISA was performed on purified vasculin-GST and GST, essentially as described before ${ }^{21}$. In short, individual bacterial clones were grown in 96-well microtiter tubes, soluble scFvs were expressed as described " and the bacterial supernatants were screened for antigen binding. Bound SCFvs were detected with horseradish peroxidase (HRP)-conjugated monodonal antibody 9E10 (9E10-HRP), directed against the human c-myc amino acid sequence, and visualised using trimethylbenzidine (TMB) and hydrogen peroxidase. The scFv-encoding region of phagemids coding for vasculin-specific scFvs were sequenced.

\section{Expression and purification of scFv-2A4 and scFv-1E5}

E.coli HB2151 cells were transformed with the phagemids pHEN2-sCFv-2A4 and pHEN2-SCFW-1E5, respectively. SCFvs were expressed as described ${ }^{20}$ and purified from the whole cell extract (B-per, Pierce Rockford) using Ni-NTA (Qiagen) according to the manufacturers instructions. Prior to further applications, scFvs were dialysed overnight at $4{ }^{\circ} \mathrm{C}$ against PBS and protein purity and concentration was determined as described above. 


\section{Affinity of scFvs}

Affinity constants for the binding of SCFvs with GST-vasculin was determined using the BIACore 2000 analytical system equipped with the CMI5 sensor chip (BIACore Amersham Pharmacia Biotech) as described previously ${ }^{22}$. in brief, purified GST-vasculin was coupled covalently up to 1100 RU to the sensor chip in $10 \mu \mathrm{M}$ acetate buffer. $\mathrm{pH}$ 4.0. ScFus diluted to a final concentration ranging from $50-800 \mathrm{nM}$ in $0.01 \mathrm{M}$ Hepes, 0.15 mM NaCl, 3 mM EDTA, 0,005\% Tween 20, pH 7.4, were injected at a flow rate $10 \mu \mathrm{l} / \mathrm{min}$ (injection volume $65 \mu \mathrm{l})$. After each cycle the chip was regenerated using $15 \mu \mathrm{l}$ of a $100 \mathrm{mM} \mathrm{H}_{3} \mathrm{PO}_{4}$ solution. The analyses of the association and dissociation phases were performed with the software of the BIAcore 2000 (Langmuir binding, local fit).

\section{Western blot and two-dimensionall (2D) analysis}

Proteins were extracted essentially as described ${ }^{23}$. In brief, cultured cells scraped in phosphate buffered saline (PBS) or vascular tissue, respectively, were homogenized in ice-cold lysis buffer $10 \mathrm{mM}$ Tris. $\mathrm{HCl}$ pH $8.0,2,5 \mathrm{mM} \mathrm{KCl}, 150 \mathrm{mM} \mathrm{NaCl}, 0,5 \%$ Nonidet $\mathrm{P} 40,0,5 \%$ Triton $X-100,20 \mathrm{mM}$ b-glycerolphosphate, $50 \mathrm{mM} \mathrm{NaF}, 1 \mathrm{mM}$ dithiothreitol, $10 \mu \mathrm{g} / \mathrm{m}$ l soytrypsin inhibitor, $10 \mu \mathrm{g} / \mathrm{ml}$ leupeptin, $2 \mathrm{mM}$ Nava3. $200 \mathrm{mM}$ benzamidin) and incubated for $30 \mathrm{~min}$ on ice. After centrifugation (20 min. $4500 \times g_{x}$ ) the protein concentration of the soluble fraction was determined as described above. Human aorta, muscle, testis, ovary and smooth muscle cell protein medleys were from Clontech.

For Western blot analysis, samples equivalent to $25 \mathrm{mg}$ of total protein were separated by SDS-PAGE $(9 \%)$, while for $2 \mathrm{D}$ gell electrophoresis, samples containing $50 \mu \mathrm{g}$ protein were separated using a $7 \mathrm{~cm}$ Immobiline $\mathrm{pH}$ gradient strip $(\mathrm{pH} \mathrm{4-7}$, Amersham Pharmacia Biotech), prior to separation by $12 \%$ SDS PAGE. After transfer onto nitrocellullose (Protran, Schleicher \& Schuel) and blocking (PBS containing $2 \%$ ( $w / v)$ skimmed milk powder (MPBS)), blots were incubated with scFv-2A4 (5 $\mu \mathrm{g} / \mathrm{ml})$. Bound scFv-2A4 was detected with anti-myc tag antibody $9 E 10$ (1:1000 dilution of the hybridoma supernatant), followed by incubation with a horseradish coupled rabbit anti-mouse antibody (RAM-HRP, 1:1000 Dako). Specific antibody binding was visualized using enhanced chemiluminiscence (Amersham Pharmacia Biotech). All antibodies were diluted in MPBS containing $0.5 \%$ gelatin. Between each incubation step the membrane was washed with PBS containing $0.1 \%$ (v/v) Tween 20.

\section{Immunohistochemical analysis}

After deparafination and rehydration, $4 \mathrm{~mm}$ tissue sections were pre-treated for $30 \mathrm{~min}$ with pepsin $(1 \mathrm{mg} / \mathrm{ml}$ in $0.1 \mathrm{~N} \mathrm{HCl}$ ) and blocked for $60 \mathrm{~min}$ with Tris buffered saline (TBS, Tris. $\mathrm{HCl} 0.1 \mathrm{M}, \mathrm{NaCl}, 2.7 \mathrm{M})$ containing $0.1 \%(w / w)$ Tween $20,1 \% \mathrm{BSA}$. Sections were incubated subsequently with scFv-2A4 $(120 \mu \mathrm{g} / \mathrm{m} / \mathrm{l})$, anti-myc $\mathrm{tag}$ 
antibody 9E10 (1:750 dilution of the hybridoma supernatant), biotinylated sheep anti-mouse antibody (1:250, Dako) and alkaline phosphatase coupled $A B C$ reagent (1:200, Dako). Each incubation step was performed for 30 minutes at room temperature. Alkaline phosphatase activity was visualized using the Alkalline Phosphatase Kit I (Vector) containing $1 \mathrm{mM}$ levamisole (Sigma), resulting in a red precipitate. Sections were counterstained with hematoxylin. To determine cell types expressing vasculin and/or $55 H 6-\beta$ (see further), double immunohistochemical stainings were performed. Sections labelled for vasculin and/or SSH6- $\beta$ were labelled subsequently for either ASMA (1:500, Dako; staining SMC), CD31 (1:2000, Biomakor; staining endothelial cells) or CD68 (1.100, Dako, staining macrophages) as described previously.

\section{Statistical analysis}

All data are expressed as mean $\pm S D$. Means between groups were compared by the use of the Mann-Whitney $U$ test. A value of $P<0.05$ was considered statisticailly significant.

\section{$>$ Results}

\section{SSH6 gene, vasculin mRNA and protein}

Bio-informatical analysis revealed that the CDNA of clone SSH6 differs from the homologous CDNA template (AL161991) due to the insertion of a unique 120 bp fragment 15. Further sequence analysis demonstrated that this insert includes the putative start codon of a previously unidentified open reading frame (ORF), suggesting that this ORF corresponds to a novel mRNA and protein.

In order to obtain the full-length ORF, a human artery SMC CDNA library "was screened with a probe that includes the unique 120 bp insert of clone 5SH6. Among more than 10 CDNA clones, all containing an insert over 2000 bp long, we isolated and characterized clone $A 6.3$, which contained the longest CDNA fragment (2858 bp fig. 1). Clone A6.3 comprises an 1105 bp $5^{\prime}$ untranslated region, an open reading frame of 1419 bp, and a 334 bp $3^{\prime}$ untranslated region.

Comparison of the sequence of done A6.3 with the human genome demonstrated that the gene was located on the short arm of chromosome 5 (5p 13). The gene comprises at least 12 exons and spans a region over 90.000 bp. Exon-intron boundaries and sizes of exons and introns are summarised in Table 2. Remarkably, exon 3, containing the start codon of the ORF identified in clone SSH6, exactly matches the unique 120 bp fragment, absent in most of clone SSH6 CDNA variants in the databases. These data strongly suggest that alternative splicing of exon 3 underlies the existence of various variants of the $\$ 5 H 6$ gene, and that the ORF cloned in the current study corresponds to a unique spllice variant containing exon 3. Because this ORF was identified 


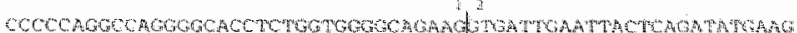
ATW

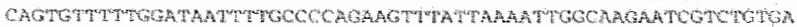

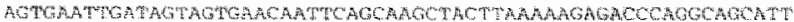

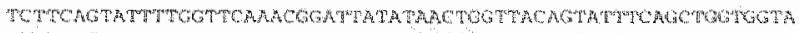

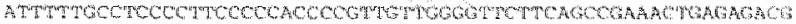
That

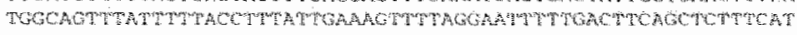

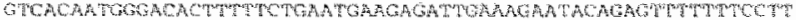
THATH

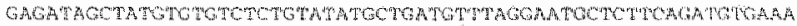

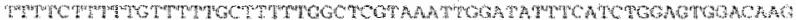

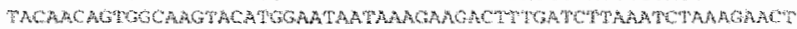

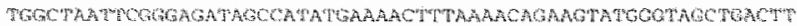

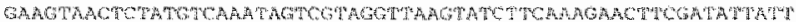

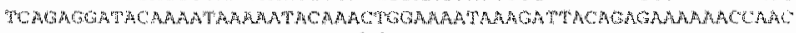
23

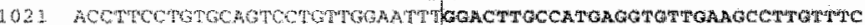

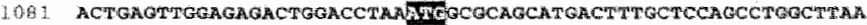

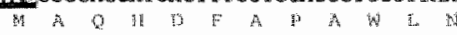
3 is

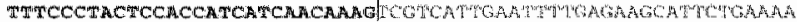

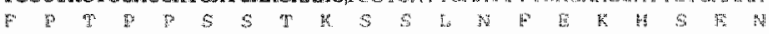

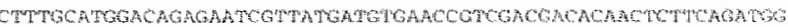

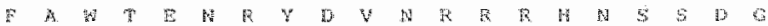
43

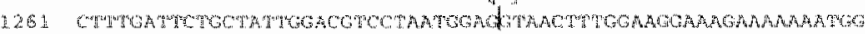

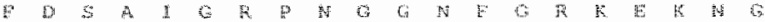

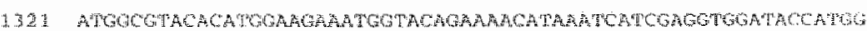

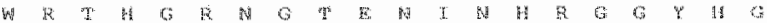

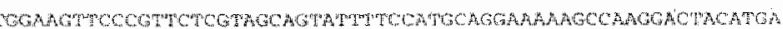

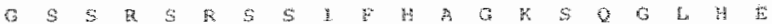

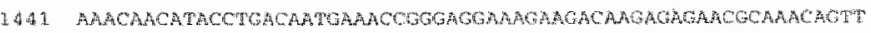

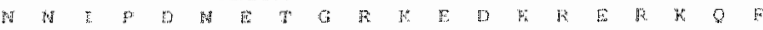
MA

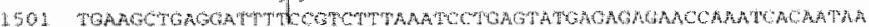

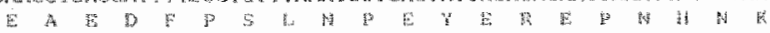
67

4561. Traw

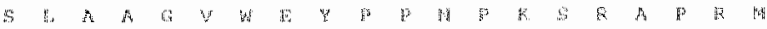

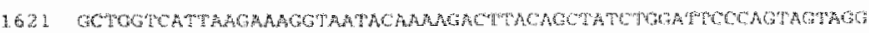

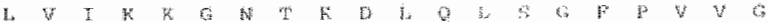

1681 AAATE

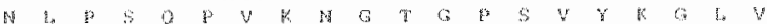

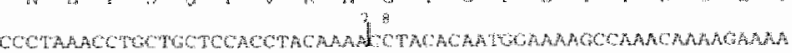

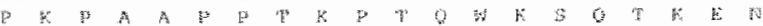

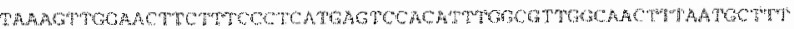

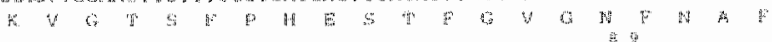

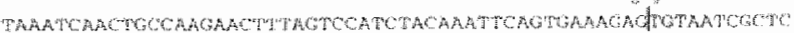

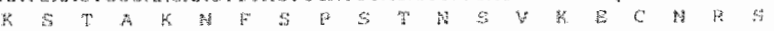




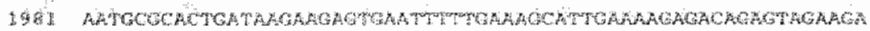
*

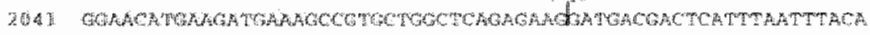

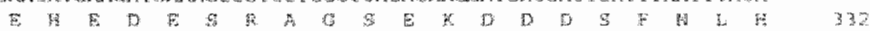

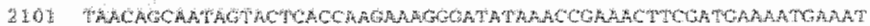

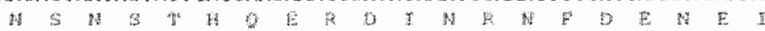

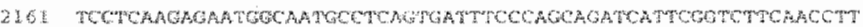

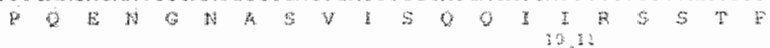

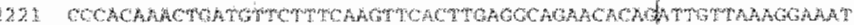

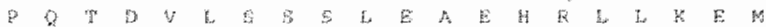

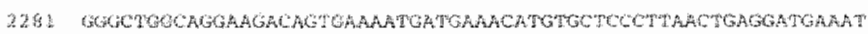

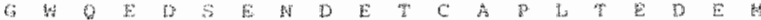
$1: \frac{1}{2}$

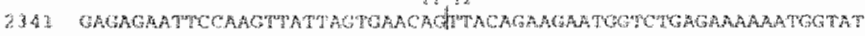

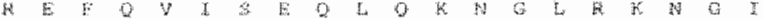

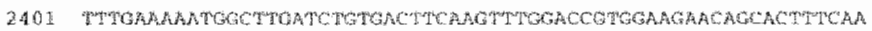

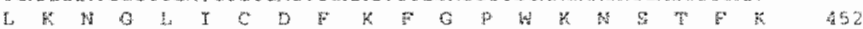

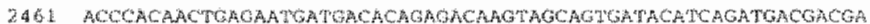

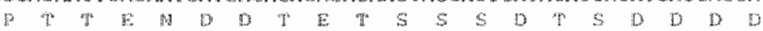

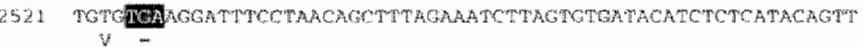

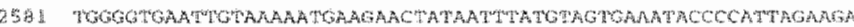

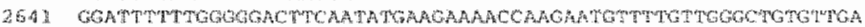

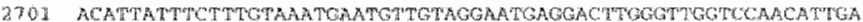

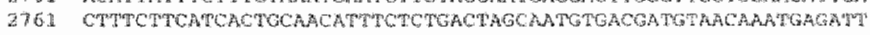

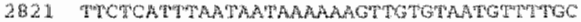

Figure 1: Nucleotide sequence of clone A6.3 and the deduced amino acid sequence for vasculin. The deduced amino acid sequence is shown below the DNA sequerce. The nucleotide sequence is numbered

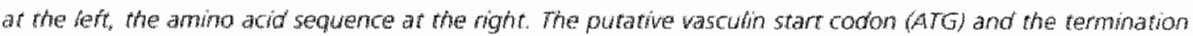
codon (TGA) are boxed. vertical bars indicate the exon limits and exons are numbered as indicated in table 2 Exon 3 is indicated in bold.

originally in a library of vascular wall derived CDNAs and subsequently isolated from a vascular smooth muscle CDNA library, we entitled the corresponding MRNA and protein

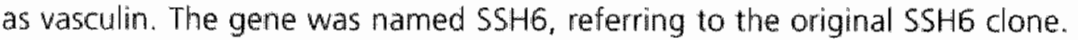

Analysis of the open reading frame of vasculin, spanning from the putative start codon in exon 3 to the stop codon in exon 12, revealed that it encodes a 473 AA protein (Fig 1). The presence of a TAA stop codon at position -3 to -1 from the putative start codon, ascertains that the ORF is identified completely at the $5^{\prime}$ end and codes for a full-length protein. The calculated mass of vasculin is $53 \mathrm{kDa}$ and its iso-electric point is 6.56, ignoring the potential contribution of posttranslational modifications. Extensive bio-informatical analysis did not result in the identification of any typical hydrophobic signal nor mitochondrial, peroxisomal or vacuolar targeting peptide. Moreover, no DNA I RNA binding motifs were detected, nor a model predicting nuclear or transmembrane localisation of vasculin. Furthermore, we were not able to identify a functional protein domain. Therefore, we are unable to assign a function to this protein. 
Table 2: Exon-intron junctions of the human 55H6 gene.

Exon/intron boundaries were determined by companing the wasculin CONA sequence (Figure 1) to humen genomic contigs laccession numbers ACO08435 and hCG4061\%, from public and CELEA databases, respectively. The rucleotide sequence of each exon (uppercase letters) and intron flowercase letters) at the wantimiton boundaries is shown. NA, not applicable

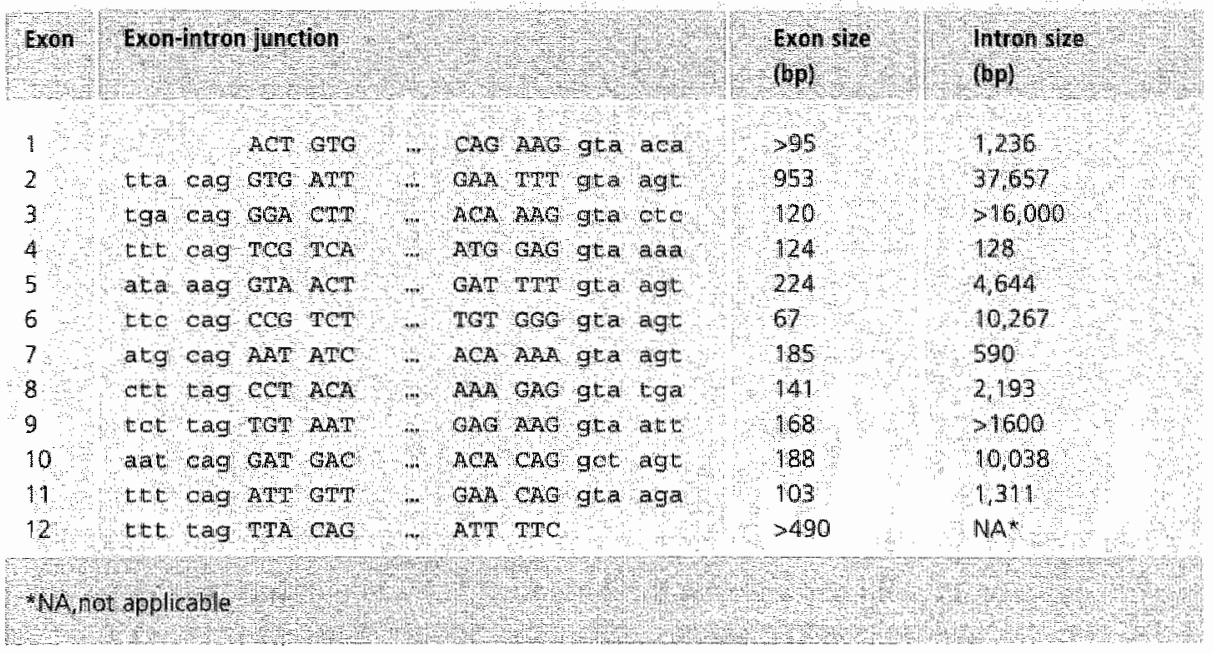

\section{Expression of vasculin mRNA in the vascular wall}

Because vascullin was identified in a subtraction library of cDNAs upregulated in " human atherosclerotic plaques with a thrombus versus human stable plaques, we extended RT-PCR analysis in order to evaluate the expression profile of vasculin in other vessels. Therefore RT-PCR analysis was carried out on individual samples of veins $(n=5)$. non-diseased arteries $(n=4)$ and early atherosclerotic plaques $(n=5)$. Potential interference of other variants from the $55 \mathrm{H} 6$ gene was circumvented by the use of one primer complementary to the 120 bp fragment. To exclude patient- and artery-biased expression, samples originated from several arteries and weins from different patients. Normalization to the housekeeping gene GAPDH, indicated the expression level was comparable between different samples (fig. 2). RT-PCR revealed vasculin expression in all veins, in $50 \%$ of non-diseased arteries, and in $40 \%$ of early lesions, respectively.

\section{Vascular smooth muscle cell specific expression pattern of vasculin}

To examine the tissue distribution of mRNA transcripts from the SSH6 gene, a multiple-tissue Northern blot anallysis was performed on 61 adult human tissues, 8 human cell limes, 7 foetal tissues and 6 controls. With the original insert of clone SSH6 as a probe, which covers 305 bp of exon 2. the entire exons 3 and 4 (120 bp and $124 \mathrm{bp}$, respectively) and 4 bp of exon 5, mRNA was detected in nearly all tested samples (fig. 3a). In contrast, multiple-tissue Northern blot analysis using an exon 3 specific 


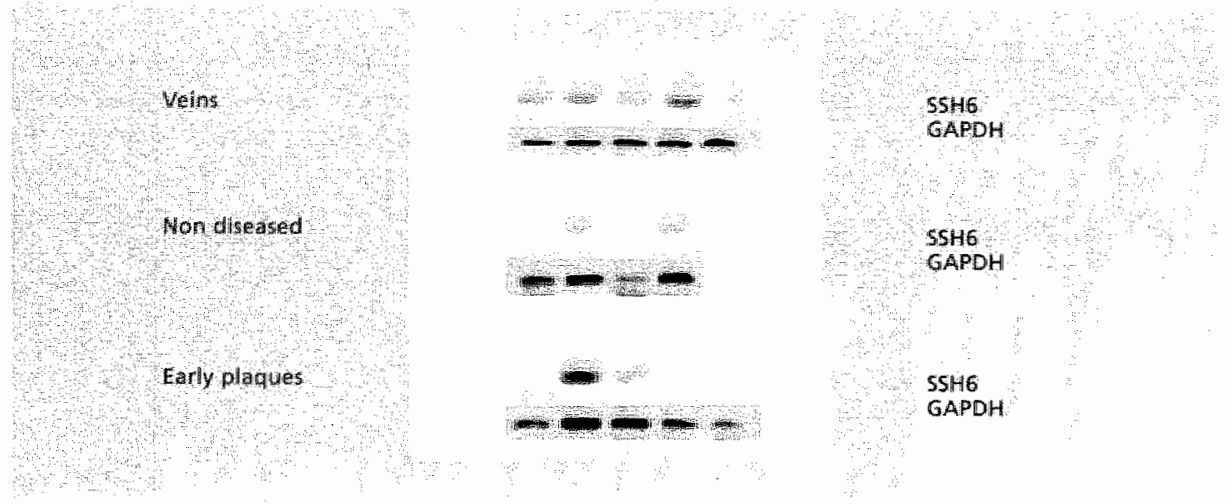

Figure 2: Expression of vasculin mRNA in the wascular wall.

AT-PCR analysis on MRNA isolated from weins, non-diseased arterias and arteries with atherosclerotic lesions in various stages. Expression of wasculin and the housekeeping gene GAPOH is shown in each wpper and bottom panel respectively.

probe (120 bp), resulted in the absence of any hybridisation signal in any tested tissue or cell line, except for human vascular smooth muscle cells and for our positive control, an exon 3 containing plasmid DNA (fig. 3b). These data strongly suggest a differential tissue distribution of various splice variants of the SSH6 gene, i.e. vasculin CDNA, containing a unique 120 bp fragment and detected exclusively in primary vascular smooth muscle cells, can be discriminated from other, ubiquitously expressed variant(s), lacking this $120 \mathrm{bp}$ insert.

figure 3: Expression of the S5H6 gene in a variery of human tisues and cell lines. Northem biot analysis of a

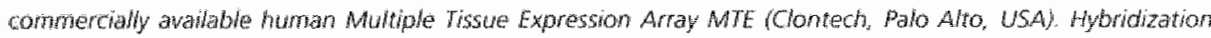
with a probe corresponding to (A) exon 2-344 and (B) exon 3. respectwely. Samples 1 to 61 correspond to poly

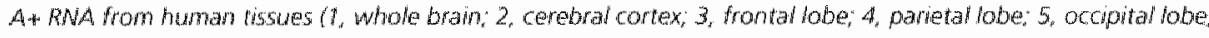

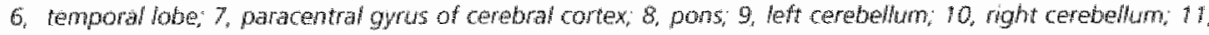

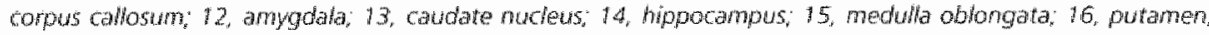
17. substantia nigra, 18 , accumbers nucleus; 19 , thalanus; 20 , piturary gland, 27, spinal cord, 22, heant; 23 .

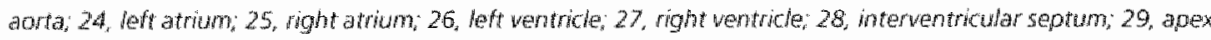
of the heart: 30 , esophagus: 31 , stomach, 32 , duodenum; 33 jejunum; 34 , ileum, 35 ilocectm, 36 , appendix. 37, ascending colon; 38 transuerse colon; 39 , descending colon; 40 rectum, 41 kidney, 42 . skeletal muscle; 43 .

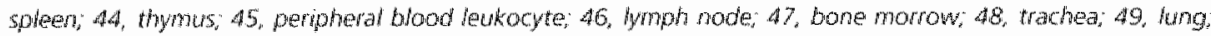

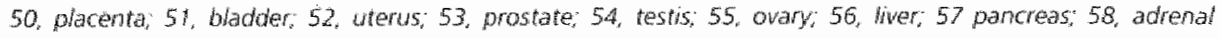

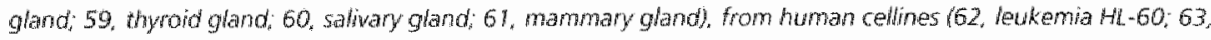
Mela S3; 64, leukdemia, K-562; 65, Jeukaema MOLT-4; 66, Burkitt's Jymphoma Raji; 67, Burkitis lymphoma Daudi, 68 , colorectad adenocarcinoma, 4549 ), from fetal tissues (69, fetal bram; 70 , fetal heart; 71 , fetal kidney. 72, fetal her: 73, fetal spleen; 74, fetal thymus; 75. fetal inng) and controls (76, yeast toial RNA: 77, yeast

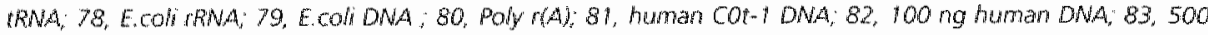
ng human DWA. Panels at the right show the hybridization signal of the exon 3 probe with VSMC derived RNA and exon 3 containing plasmid ONA, respectively. 
A

\begin{tabular}{|c|c|c|c|c|c|c|c|c|c|c|c|}
\hline y & 9 & 17 & 23 & 304 & 38 & $47 x$ & $P^{49}$ & 56 & 61 & 69 & 16 \\
\hline . & 10 & 18 & 3 & (1) & 30 & 42. & $50 /$ & S7 & 69 & (7) & 77 \\
\hline 3 & $\begin{array}{l}17 \\
4\end{array}$ & 19 & 24 & 32 & 40 & $4 y^{3}$ & 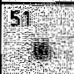 & 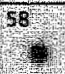 & ${ }^{6}{ }^{3}$ & $\begin{array}{ll}71 \\
4\end{array}$ & 78 \\
\hline 4 & (2) & 10 & 25 & W & & 44 & 52 & 59 & 4 & $\sqrt{72}$ & 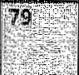 \\
\hline 5 & 13 & & 26 & 34 & & 45 & 5 & 604 & 65 & 78 & 80 \\
\hline 10. & 14 & & $\begin{array}{l}27 \\
7\end{array}$ & 3 & & 46 & $S^{4}$ & 615 & 66 & (6) & 81 \\
\hline 1) & 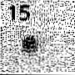 & & 28 & 36 & & 17 & 52 & & 67 & 75 & 82 \\
\hline 87 & (16. & & 19 & 8 & & 48 & & & 68 & & 83 \\
\hline
\end{tabular}

\begin{tabular}{l}
\hline \\
P
\end{tabular}

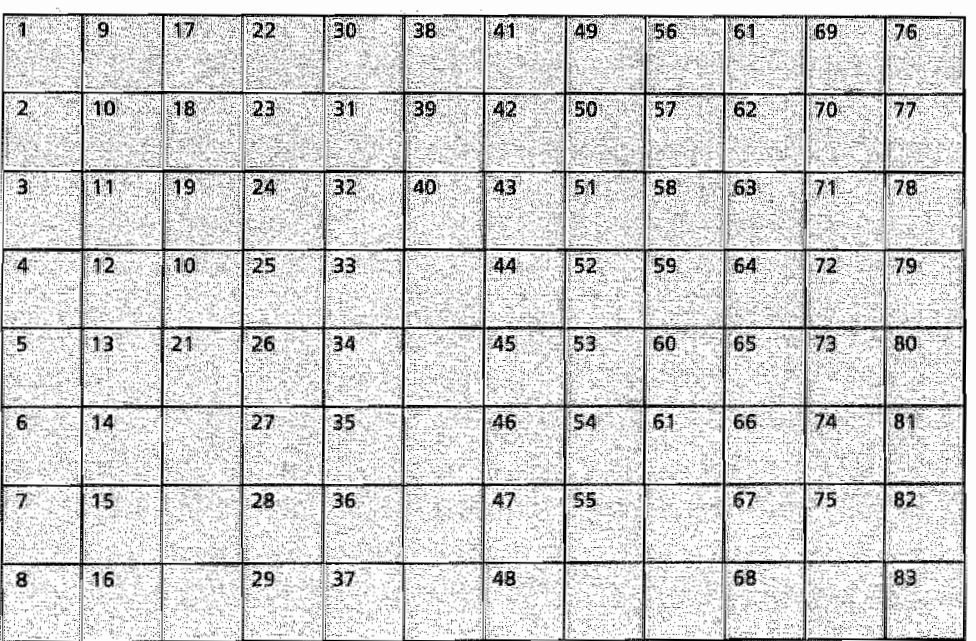

Exon 3 containing plasm d DNA

MSM deIVed RHA 


\section{Production of recombinant GST- vasculin protein, selection and characterisation of scFvs.}

In order to study vasculin at the protein level, high-affinity antibodies were selected to serve as immunological tools. Therefore a fusion protein (GST-vasculin, $535 \mathrm{AA}$ ) consisting of GST and the 302 C-terminal AA of vasculin, was expressed in Escherichia colli. For control experiments, recombinant wild-type GST protein was prepared. SDS-PAGE analysis and Coomassie Blue staining of purified proteins revealed a major band of the expected size for GST-vasculin ( $61 \mathrm{kDa})$ and GST ( $26 \mathrm{kDa})$, respectively.

Vasculin specific single-chain $\mathrm{Fv}$ fragments (scFvs) were selected from a combinatorial $V H+V L$ phage displayed library (MRC, Cambridge) by panning on purified GST-vasculin and GST. After the final round of selection, soluble sCFvs were screened for antigen binding by ELISA on plates coated either with GST-vasculin or GST. Thus it was demonstrated that all selected scFvs were directed against the vasculin segment of the fusion protein $(n=80)$. Fingerprinting and subsequent sequence analysis of the phagemids of positive clones demonstrated that at least two different scFvs could be discriminated. Clone $2 A 4$ and $1 E 5$, each coding for a different $5 \mathrm{CFV}$, were used in further experiments because the corresponding SCFvs (named SCFv-2A4 and SCFV-1E5, respectively) generated highest signals in ELISA.

Dot blot and ELISA analysis indicated that both SCFv reacted as well with denaturated as non-denaturated GST-vasculin, but lacked reactivity with non-related proteins (data not shown). BIAcore analysis demonstrated that SCFv-2A4 exhibits an affinity of $71 \pm$ $55 \mathrm{nM}(\mathrm{KD})$ for GST-vasculin, whereas the affinity of SCFv-1E5 was over two-fold lower $\left(K_{D} 163 \pm 118 \mathrm{nM}\right)$. Therefore, scFv-2A4 was used in further experiments.

\section{Analysis of vasculin protein in human tissues and cell lines}

To investigate the ability of SCFv-2A4 to bind to native, full-iength vasculin, we used scFv-2A4 to probe a Western blot of human atherosclerotic plaque lysates, in parallel with GST-vasculin, which was used as a positive control. As shown in figure 4 the predicted 61-KDa band was detected for GST-vasculin. In plaque lysates strongly immunoreactive bands were identified with an apparent molecular weight of 45 and

Figure 4: Vasculin and SSH6- $\beta$ in the vascular wall.

A. Representative Western blot analysis of lysates of complete segments of veins, non-diseased arteries and arteries displaying different stages of atherosclerosis $(n=2)$. Lanes $1-4$, weins; lanes 5- 8 , non-diseased arteries; lanes 10.14, early atherosclerotic plaques; lanes 15-18, advanced atherosclerotic plaques: lanes 20-23, ruptured atheroscleratic plaques; lane 24 GST-vasculio; lane 9 and 19. marker. For hysates and G5T-vasculin, samples equivalent to $25 \mu g$ and $1 / \mu g$ protein, respectively, were applied. $B$ and $C$, quantitative data of vasculin and SSH6- $\beta$ content, respectively as judged by densitometric scanning of two independent Western blot analyses (mean $\pm S D, n=4-5$ ). $N D$, ron-diseased. $D$, relative amount of vasculin versus the total amount of vasculin + SSH6- $B$ as determined in $B$ and $C$, in veins and arteries displaying various stages of atherosclerosis (mean \pm 50 . $n=4-5$ ). ND, non-diseased. 

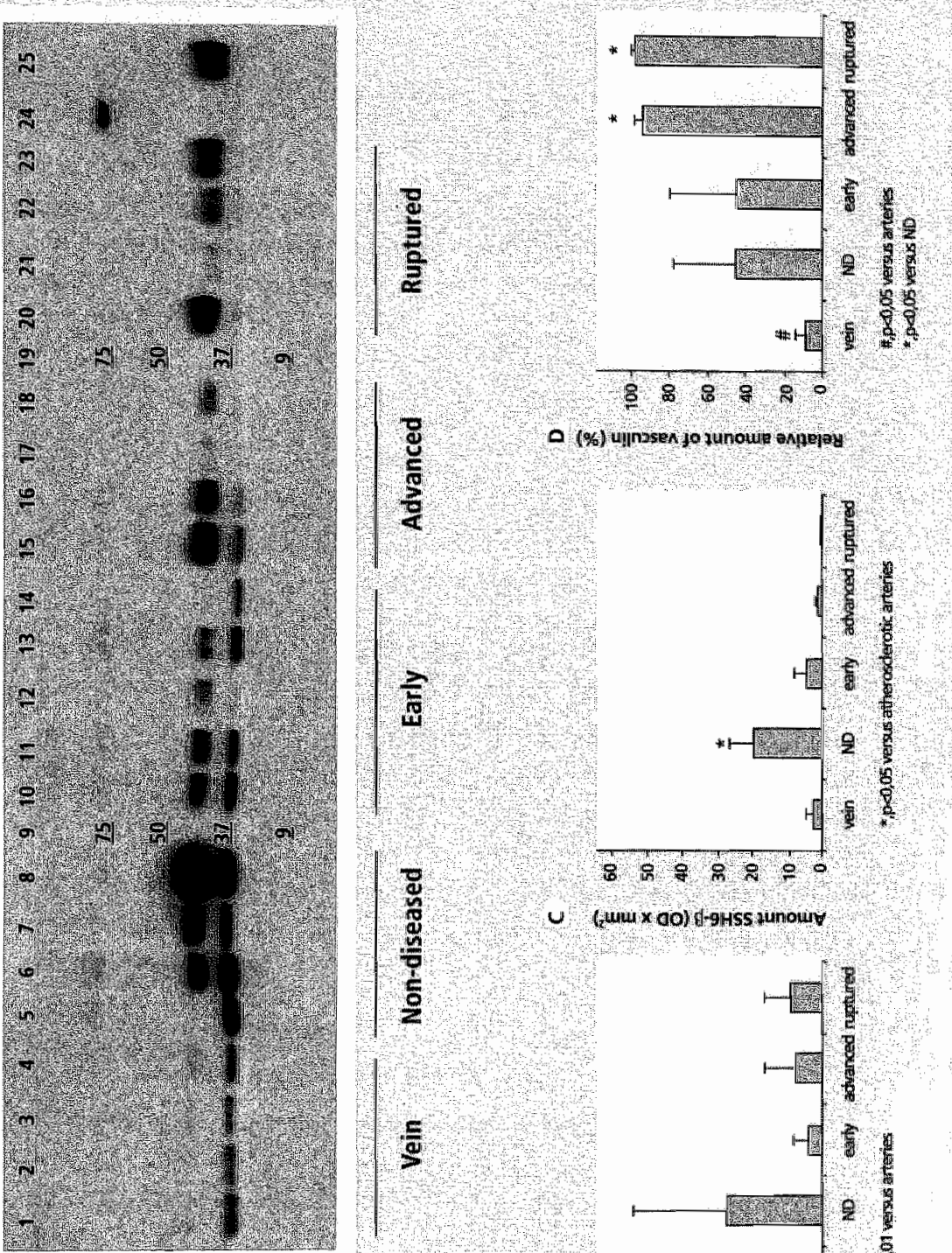

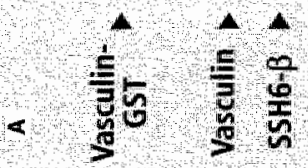

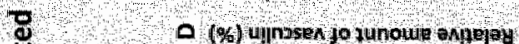

$\frac{2}{6}$

$\frac{7}{6}$
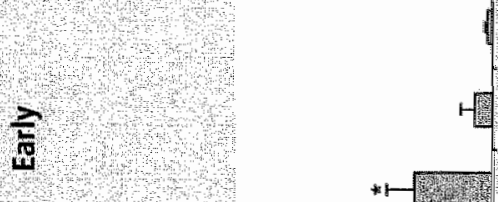

2

98

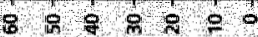

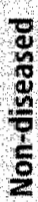

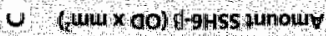

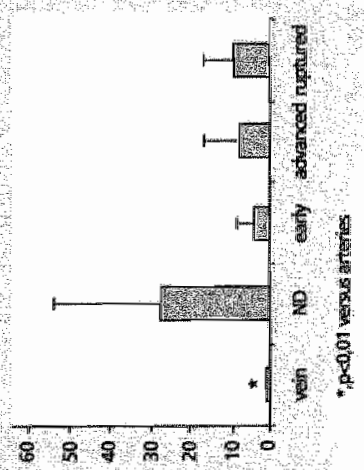

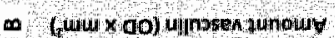




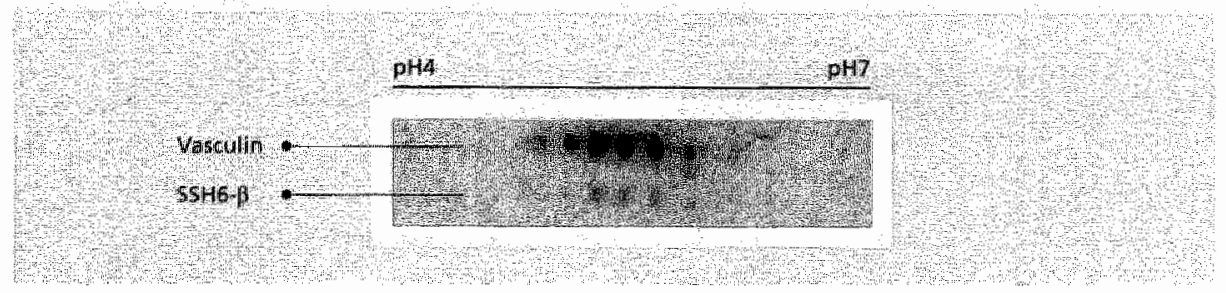

Figure 5: 20-gelelectrophoresis analysis of a human atheroscleratic plaque lysate

$50 \mu \mathrm{g}$ advanced plaque lysate was separated using a $7 \mathrm{~cm}$ oH gradient strip (pH 4-7), and a 12\% SDS-PAGE

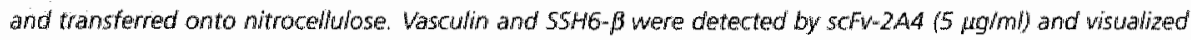
using enhanced themifuminiscence.

vasculin and 5 SH6- $\beta$ was detected in all samples, although to different extents and in different ratios. Most strikingly were the minimal amounts of vasculin in veins and SSH6- $\beta$ in plaques with a thrombus, respectively. Quantification of the intensity of the vasculin and SSH6- $\beta$ bands by densitometric scanning of the blots, demonstrated that vasculin content was significantly higher in arteries than in veins $(p<0,01$, fig. $4 b)$. However, no correlation was observed between the amount of vasculin and the stage of atherosclerosis. Analysis of the $55 \mathrm{H} 6-\beta$ content (fig. 4c) revealed no significant difference between veins and arteries. Remarkably, the amount of SSH6- $\beta$ was significantly higher in non-diseased arteries than in early, stable and plaques with a thrombus, respectively $(p<0,05)$. Comparison of the ratio vasculin / SSH6- $\beta$, demonstrates large differences between various vessels. Figure $4 \mathrm{~d}$ illustrates the ratio of vasculin versus $5 S H 6-\beta$ and shows that the relative amount of vasculin differs significantly between veins and arteries, between non-diseased arteries and stable atherosclerotic plaques and between non-diseased arteries and plaques with a thrombus, respectively $(p<0,05)$.

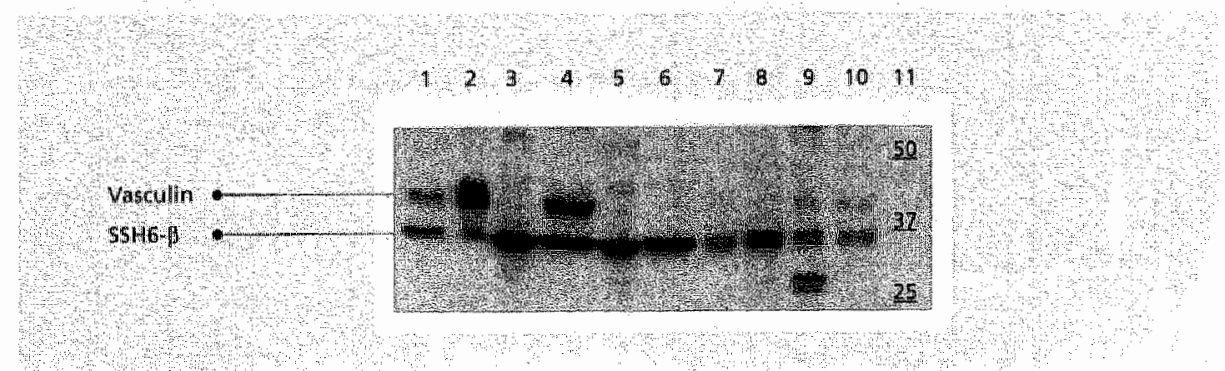

Figure 6: Western blot analysis of vasculin and $55 H 6-b$ in a varjety of human cell lines and tissues. Lane 1, atheruscherotic plaque, lane 2, human plasma, lanes 3-6. human cell imes (3. colon carcinoma; 4, human umbitical vein endothelwat celis; 5 , Lowis lung carcimoma, 6, vascular smooth muscle cell thel fanes 7 - 11 , human tissues (7. muscle; 8, brain: 9, ovary: 10, aorta); lane 11, marker. For each sample, amounts equivalent to 25 mg protein were applied. 


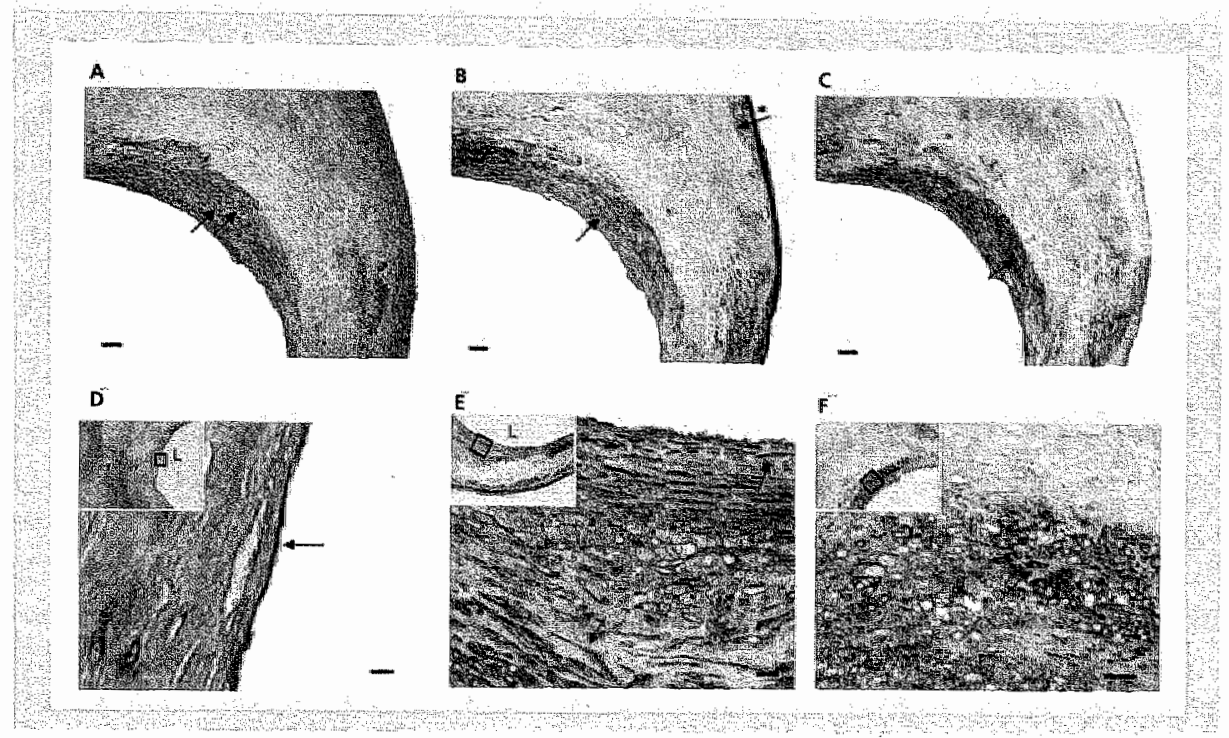

Figure 7: Localisation of vasculin and $5546-b$ protein in the vascular wall.

A-D. Cross-sections of an atherosclerotic plaque stained by immunohistochemistry. A) Vasculin andror SSH6-B is visualized in red (black arrows). B) Combined immunohistochemical staining for vasculin and/or 55H6-B (red) and anti-smooth muscle actin demonstrating SMC (blue). Pronounced vasculin/SSHE- $\beta$ signals are observed in neointimal' SMC (black arrow), whereas wasculin/5S46- $\beta$ signals are minimal in medial SMC (arrow with *). Co Combined immunohistochemical staining of vasculin andlor $55 \mathrm{HG}-\beta$ with anti-CO68 (b/ve) demonstrates the presence of SSH6 gene products in monocytes/macrophages, as indicated by an arrowhead. D) Combined immunohistochemical staining of vasculin and/ar $55 H 6-B$ with anti-CD31 (blue) shows vasculin/S5H6m in endothelial cells. The arrow indicates an endothelial cell expressing wasculin/SSH6-19. Inset: averwew picture with region in D outhined with a box. E-F) Cross-sections of the adventitia of an artery. E) Staning for vasculin andfor 55 HG- $\beta$ (red). Arrows indicate SMC, the arrow with * indicates an endothelial cell of a small vessel inside the adventitia. F) Negative control (without primary antibody SCFV-2AA) for the staining in E. Bars in pictures $A_{*}, B_{1} C$ and the inset in $D$ represent $100 \mu \mathrm{mm}$; bars in $D, E$ and $F$ correspond to $10 \mu \mathrm{mm}$.

. 2D-gelelectrophoresis and subsequent Western blot analysis (fig. 5) of lysates from atherosclerotic plaques containing whole artery segments demonstrated the presence of at least five vasculin variants with a pl ranging between 5.5 and 6.5 , indicating the occurrence of various posttranslational modifications. In addition, we demonstrated at least three posttranslational variants of $55 \mathrm{H} 6-\beta$. Analysis of three stable and three plaques with a thrombus suggested no difference in posttranslational modification between the respective plaque types (data not shown).

In addition to the tissue specific expression of vasculin mRNA, evidence for a differential expression pattern of vasculin and SSH6- $\beta$ in various human tissues and cell 
lines was deduced from Western blot analysis on the respective lysates (fig. 6). Vasculin was highly expressed in plaques and human umbical vein endothelial cells and was present to a lower extent in ovary and aorta. Most interestingly, vasculin was also detected at high levels in human plasma. In contrast, vasculin was not observed in a vascular smooth muscle cell line, colon nor lung carcinoma, and was absent in skeletal muscle and brain lysates. On the ather hand, 5SH6- $\beta$ was identified in all samples.

To localise vasculin and SSH6- $\beta$ protein in the vascular wall, immunohistochemical analysis was performed with 5CFV-2A4 (fig. 7A). Immunohistochemical analysis of vascular samples revealed immunoreactivity in the cytoplasm of vascular endothelial cells, SMC and macrophages, as confirmed by a combined staining of 5CFV-2A4 and anti-CD31-antibodies (endothelial cells), anti-smooth muscle cell actin (SMC), or anti-CD68-antibodies (macrophages/monocytes), respectively (fig. 7 B-D). In non-diseased arteries vasculin and/or $55 \mathrm{H6}-\beta$ were localised essentially in (a subpopulation of) medial SMC and in vascular endothelial cells. Interestingly, very strong immunohistochemical signals were observed in the endothelium and the SMC of small vessels inside the adventitia (fig. $7 E$ ). In atherosclerotic arteries, immunohistochemical staining was observed also in neointimal SMC and in macrophages. Strikingly, signals were more intense in neointimal SMC than in medial SMC (fig. $7 \mathrm{~B}, \mathrm{C}$ ). In negative controls, omitting incubation with scFv-2A4, no signals were detected (fig. 7F).

Immunohistochemical analysis of vasculin and/or SSH6- $\beta$ in a wide range of human tissues, including ovary, testis, colon, salivary gland and small intestine, demonstrated the presence of (one or both of) these proteins in other types of smooth muscle and endothelial cells, whereas a positive signal was also obtained in secretory cells (data not shown).

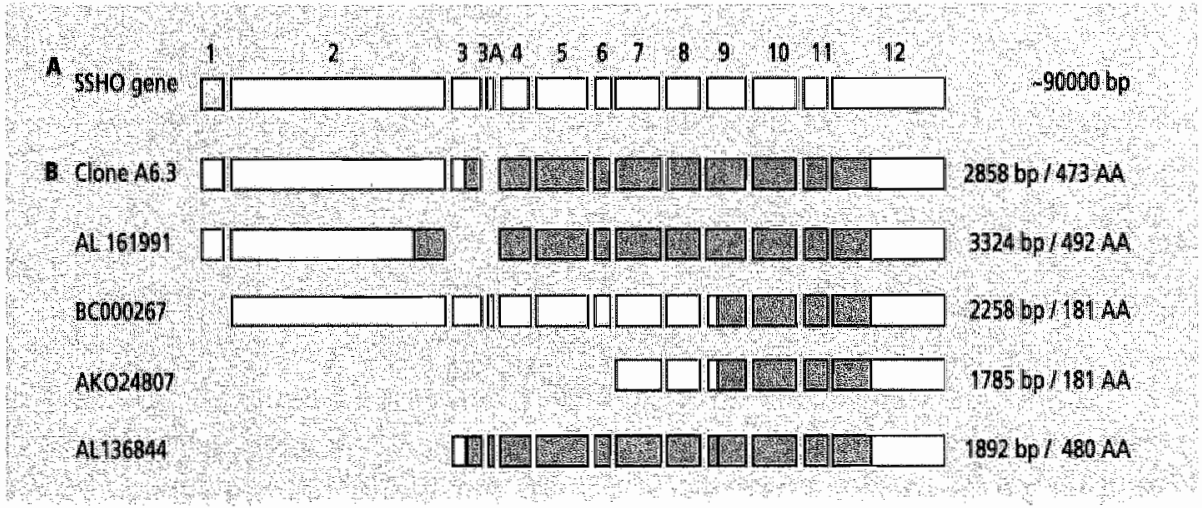

Figure 8 .

Schemetical presentation of puthic domain IRNA transcripts homologous to vasculin mRNA (clone A6.3). A) Scemetical overwiew of the exons of the 5546 gene (Tabte 2). B) Exon use of known splice wariants. ORFs corresponding to the hyothetical protein sizes are indicated. 


\section{Discussion}

In a previous study ${ }^{15}$, a first inventory was made of genes differentially expressed in whole mount human plaques with a thrombus versus stable atherosclerotic lesions. One of the identified CDNAs, coding for part of a previously unidentified ORF, was chosen for further investigations because of its pronounced up regulation in plaques with a thrombus versus stable plaques, as validated by macro-array and RT-PCR analysis on individual samples. The current study concentrates on this novel RNA/protein, which was entitled vasculin, as an acronym for vascular wall linked protein.

Multiple tissue Northern blot analysis, in combination with genomic analysis, revealed that vasculin differs from other splice variants of the 5546 gene due to alternative splicing of exon 3, which is demonstrated to be expressed exclusively in the vascular wall. This is not surprising since expression of alternatively spliced mRNA variants in specific cells and tissues, or even at specific stages of development, are reported frequently to contribute to the functional diversity of human genes 2 . Extensive bio-informatical analysis confirmed the existence of various splice variants of the SSH6 gene. As mentioned before "s., vasculin is homologous to clone AlL16199126, except for the unique 120 bp fragment corresponding to exon 3 . Recent analyses of two other CDNA clones that are also homologous to vasculin (BCD00267. I and AK024807), revealed a putative ORF for a 181 AA protein, corresponding to AA294-AA473 of vasculin. In addition, a vasculin CDNA homologue originating from a testis CDNA library (clione AL $136844{ }^{26}$ ) has been identified as being nearly identical to vasculin, with the exception of a 21 bp insertion, located at the connection between exon 3 and 4 of vasculin mRNA. Genomic analysis demonstrated that this insert might correspond to an additional exon of the SSH6 gene (exon 3A, fig. 8). Interestingly, Northern blot analysis performed in the current study does not validate the existence of an exon 3 containing SSH6 mRNA variant in testis. Therefore, it is not unlikely that AL136844 originates from vascular SMC, ubiquitously present in the strongly vascularised testicular tissue. Very recently, computational gene prediction analysis of genomic NCBI contig NT_006431 resulted in the model reference sequence $X M \_042059$. The AA sequence of the resulting hypothetical protein is identical to the sequence of vasculin.

The presence of various SSH6 splice variants in the MRNA databases correlates to our Western blot data rewealing various $55 \mathrm{H} 6$ variants at the protein level (Figure 4), including vasculin ( $45 \mathrm{kDa}$ ) and $55 \mathrm{H} 6-\beta$ ( $34 \mathrm{kDa}$ ). 5trikingly, the size of $55 \mathrm{H6}-\beta$ exactly matches a translation product of $302 \mathrm{AA}$ using the internal methionine at position 172 of vasculin as an alternative start. However, further analysis is required to identify unambiguously the AA sequence of vasculin and $55 \mathrm{H} 6-\beta$ and to clarify whether $55 \mathrm{H} 6-\beta$ expression is regulated at the transcriptional, transiational or post-translational level. Western blot analysis validated the vascular wall specific expression pattern for vasculin, as it is detected mainly in arteries, and demonstrated a ubiquitous expression profile for 
SSH6- 3 . Interestingly, analysis of arteries displaying various stages of atherosclerosis indicated an increase of the ratio vasculin wersus $55 \mathrm{H} 6-\beta$ throughout the various stages of atherogenesis (fig. 4 d), suggesting a switch from 5 SH6- $\beta$ into vasculin during the development of an atherosclerotic plaque. In this respect it should be noted that the amount of vasculin is negligible in veins, which are not susceptible for atherosclerosis.

The 5 SH6- $\beta \rightarrow$ vasculin switch may be the result of an alternative exon use of the 5SH6 gene, whereby vascultin is the major transcriptional variant in advanced atherosclerotic plaques and plaques with a thrombus. Interestingly, exon switching in the scavenger receptor CD36 gene is also suggested to be involved in the activation of SMC during the formation of atherosclerotic lesions ${ }^{25}$. Alternatively, 5 SH6- $\beta$ may be considered as a cleavage product from vasculin. In this view, the SSH6- $\beta \rightarrow$ vasculin switch during atherogenesis may reflect a decreased processing of vasculin, resulting in a pro-atherogenic stimulus of vasculin or in the inhibition of an anti-atheragenic effect of $55+16-\beta$.

Apart from the presence of vasculin in phaques, vasculin is also observed in human plasma. The lack of a wel-defined signal peptide, for as far as predicted by computational analysis, complicates the query for the origin of plasma wasculin. One of the hypotheses is that circulating vasculin originates from vascular endothelial cells or vascular SMC via transcytosis or as a consequence of cell damage, leading to the release of intracellular vasculin into the circulation. However, quantitative analysis to evaluate vasculin plasma levels in patients and healthy individuals will shed more light on the (patho)physiological importance of vasculin in blood.

Despite these observations suggesting a significant role for vasculin in atherogenesis, the key question remains what the function of vasculin is. At this moment, we cannot assign vasculin to any established gene or protein family. Therefore, we can only speculate about its function. Firstly, the ubiquitous expression profile of $55 \mathrm{H6}$ splice variants hints at a function in the basal cell machinery. The presence of $55 \mathrm{H} 6$ related expressed sequence tags in the two-cellular stage of development, as demonstirated by electromic Northern analysis, supports this hypathesis. In this context, the vascular wall specific. N-terminal segment of vasculin might have a regulatory function that is specific for the development of vascular SMC. It may for example interact with other SMC particular agents, or make vascular SMCs susceptible for atherogenic stimuli. Secondly. bio-informatical analysis revealed the presence of SSH6 related genes (homology over $85 \%$ ) in the murine and rat genome, indicating that this protein (familly) has vastly expanded in vertebrates. On the other hand, we were not able to identify SSH6 homologues in "model systems" like C. elegans and Saccharomyces cerevisae, suggesting that SSH6 has no direct counterpart in lower life forms. A final clue comes from its cytoplasmatic locallisation, as indicated by immunohistochemical staining and 
corresponding to our bio-informatical data, showing no obvious nuclear (transmembrane) signal sequence. These findings suggest that vasculin is not involved in intranuclear processes. Together, our data insinuate that the $\$ 5 \mathrm{HG}$ gene is involved in an essential but unexplored pathway in cell biology of vertebrates in general, and that vasculin might play an important role in vascular biology in particular.

\section{Acknowledgements}

The authors want to thank Marjo Donners for performing two-dimensional electrophoresis and Dr. Heather Griffin (MRC Centre for Protein Engeneering. Cambridge, UK) for the Griffin.1 library. 


\section{$>$ References}

1. Adams 10 , Geary RL, McManus B, Schwartz SM. A comparison of aorta and vena cava medial message expression by CDNA array analysis identifies a set of 68 consistently differentially expressed genes, all in aortic media. Circ Res. 2000;87:623-631

2. Hiftunen $\mathrm{MO}_{i}$ Niemi M, Yla-Herttuala S. Functional genomics and DNA array techniques in atherosclerosis research. Curr Opin Lipidol. 1999;10:515-5:19

3. MCCaffrey TA, Fu C. Du B, Eksinar S, Kent KC, Bush H, Jr., Kreiger K, Rosengart T, Cybullsky $M I_{x}$ Silverman ES, Collins T. High-level expression of Egr-11 and Egr-1-inducible genes in mouse and human atherosclerosis. I Clin Invest. 2000;105:653-662

4. Shiffman D, Mikita T, Tai JT, Wade DP, Porter JG, Seilhamer J., Somogyi R, Liang S, Lawn RM. Large scale gene expression analysis of cholesterol-loaded macrophages. I Biol Chem. 2000;275:37324-37332

5. Kreeft AJ, Moen CJ, Hofker MH, Frants RR, Vreugdenhil Ex Gijbels MJ. Havekes LM, Datson NA. Identification of differentially regulated genes in mildly hyperlipidemic ApoE3-Leiden mice by use of serial analysis of gene expression. Arterioscler Thromb Vasc Biol. 2001:21:1984-1990

6. de Vries CJ, van Achterberg TA, Horrevoets AJ, ten Cate JW, Pannekoek H. Differential Display Identification of 40 Genes with Altered Expression in Activated Human Smooth Muscle Cells: Local Expression in Atherosclerotic Lesions of smags, Smooth Muscle Activation-specific Genes. J Biol Chem. 2000;275:23939-23947

7. Horrewoets AJ, Fontijn RD, van Zonneveld AJ, de Wries CJ, ten Cate JW, Pannekoek $H$. Vascular Endothelial Genes That Are Responsive to Tumor Necrosis Factor-alpha In Vitro Are Expressed in Atherosclerotic Lesions, Including Inhibitor of Apoptosis Protein-1, Stannim, and Two Novel Genes. Blood. 1999:93:3418-3:431

8. Yashisue H, Suzuki K, Kawabata A, Ohya T, Zhao H. Sakurada K, Taba Y, Sasaguri T, Sakai N, Yamashita $S$, Matsuzawa $Y$, Nojima $H$. Large scale isolation of non-uniform shear stress-responsive genes from cultured human endothelial cells through the preparation of a subtracted cDNA library. Atherosclerosis. 2002;162:323-334

9. Agaton $C$, Unneberg P, Sievertzon M, Holmberg A, Ehn M, Larsson M, Odeberg I, Uhlen $M$, Lundeberg J. Gene expression analysis by signature pyrosequencing. Gene. 2002;289:31-39

10. Lutgens E, Daemen MJ. CD40-CD40L interactions in atherasclerosis. Trends Cardiovasc Med. $2002 ; 12: 27-32$

11. Kockx MM, Herman AG. Apoptosis in atherosclerosis: beneficial or detrimental? Cardiovasc Res. 2000:45:736-7.46

12. Galis 25, Khatri JJ. Matrix metalloproteinases in vascular remodeling and atherogenesis: the good, the bad, and the ugly. Circ Res. 2002;90:251-262

13. Rosenteld ME, Polinsky $P$, Virmani $R$, Kauser $K$, Rubanyi $G$, Schwartz SM. Advanced atherosclerotic lesions in the innominate artery of the ApoE knockout mouse. Arteriascler Thromb Vasc Biol. 2000;20:2587-2592

14. Winter $G$, Griffiths $A D$, Hawkins RE, Hoogenboom HR. Making antibodies by phage display technology. Annu Rev Immunol. 1994:12:433-455 
15. Faber BC, Cleutjens KB, Niessen RL, Aarts PL, Boon W, Greenberg AS, Kitslaar PJ, Tordoir JH, Daemen $M J$. Identification of genes potentialily involved in rupture of human atherosclerotic plaques. Circ Res. 2001;89:547-554

16. Virmani $R$, Kolodgie FD, Burke AP, Farb A, Schwartz SM. Lessons from sudden coronary death: a comprehensive morphological classification scheme foir atherasclerotic lesions. Arterioscler Thromb Vasc Biol. 2000;20:1262-1275

17. Bennett MR, Evan GI, Schwartz SM. Apoptosis of human vascular smooth muscle cells derived from normal vessels and coronary atherosclerotic plaques. J Clin Invest. 1995,95:2266-2274

18. Peneff $C$, Lefranc MP, Dariavach P. Characterisation and specificity of two single-chain Fv antibodies directed to the protein tyrosine kinase Syk. J Immunol Methods. 2000:236:105-115

19. Griffiths $A D$, Williams $S C$, Hartley $D$, Tomlinson IM, Waterhouse $P$, Crosby WL, Kontermann RE, Jones PT, LOW NM, Allison TJ, et. al. Isoilation of high affinity human antibodies directly from large synthetic repertoires. Embo I. 1994;13:3245-3260

20. Marks JD, Hoogenboom HR, Bonnert TP, MCCafferty J, Griffiths AD, Winter G. By-passing immunization. Human antibodies from Vagene libraries displayed on phage. I Mol Biol. $1991 ; 222: 581-597$

21. Roovers $R C$, Henderikx $P_{\text {, Helfrich }} W_{k}$ van der Linden $E$, Reurs $A$, de Bruine AP, Arends IW, de Leij $L$, Hoogenboom HR. High-affinity recombinant phage antibodies to the pan-carcinoma marker epithelial glycoprotein-2 for tumour targeting. Br J Cancer. 1998;78:1407-1416

22. Jönsson $U$, Malmqvist $M$. Real time biospecific interaction analysis. The integration of surface plasmon resonance detection, general biospecific interfacechemistry and microfluids into one analytical system. lin: A. T, ed. Advances in biosensors. London: JAI Press; 1992:291-336

23. Heeneman S, Haendeler J, Saito $Y$, Ishida M, Berk BC. Angiotensin Il induces transactivation of two different populations of the platelet-derived growth factor beta receptor. Key role for the p66 adaptor protein Shc. J Biol Chem. 2000;275:15926-15932

24. Strehler EE, Zacharias DA. Role of alternative splicing in generating isoform diversity among plasma membrane calcium pumps. Physiol Rev. 2001;81:21-50

25. Zingg JM, Ricciarelli R. Andomo E, Azzi A. Novel 5. exon of scavenger receptor CD36 is expressed in cultured human vascular smooth muscle cells and atherosclerotic plaques. Arterioscler Thromb Vasc Biol. 2002:22:412-417

26. Wiemann S, Weil $B$, Wellenreuther $R$, Gassenhuber J, Glassl $S$, Ansorge $W$, Bocher $M$, Blocker $H$, Bauersachs S, Blum $H$, Lauber J, Dusterhoft $A$, Beyer $A$, Kohrer $K$, Strack $N$, Mewes HW, Ottenwalder B, Obermaier B, Tampe l, Heubner $D$, Wambutt $R$, Korn B, Klein $M$, Poustka $A$. Toward a catalog of human genes and proteins: sequencing and analysis of 500 novel complete protein coding human CDNAs. Genome Res. 2001;11:422-435 


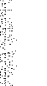

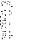

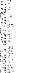


CHAPTER 9

GENERAL DISCUSSION 
In this thesis we investiglate genes and molecular pathways that are involved in human and mouse atherosclerosis. Although cardiovascular disease is the number one cause of death in western society and has been the subject of extensive research, the molecular mechanisms underlying this disease still remain largely unknown. The current availability of gene expression profiling methods like DNA micro-array, suppression suppressive hybridisation $(55 \mathrm{H})$, differential display and SAGE could provide a detailled and complete overview of the molecular events that take place during atherogenesis. The majority of gene-expression profiling studies focus on cell lines subjected to pro-atherogenic stimuli. Although these cell lines represent the main cell types present in the atherosclerotic lesion, the effect of cell-cell interactions and the influence of multiple organ systems involved in lipid metabolism, immune responses or blood pressure are lacking. This thesis describes three independent studies assessing gene expression profilles during atherogenesis based on whole mount vascular specimens. Using the SSH technology we were the first to show that differences in gene expression do occur between human advanced but stable lesions and lesions containing a thrombus (chapter 3). In chapter 4 the gene expression profiles of early lesions and lesions containing a thrombus were compared to stable lesions by DNA micro-array analysis. Comparison of these SSH and DNA micro-array data showed that different gene pools were isolated. By SSH we predominantly identified EST fragments, whereas DNA micro-array analysis mainly revealed known genes. Chapter 5 describes the differential gene expression profiles during lesion development in the ApoE deficient mouse, a well recognized and commonly used model of atherogenesis. In addition to the differential gene expression that accompanies lesion progression in time, the effect of a high fat diet and cholesterol withdrawal on gene expression profiles were determined in murine atherosclerotic lesions. These data support the main hypothesis that atherosclerosis can be characterized by specific gene expression profiles.

Three basic sets of genes were identified by the studies described in chapters 3,4 and 5 . The first group contains known genes and pathways that have already been described in the process of atherogenesis. The second group contains known genes that were not previously linked to atherogenesis. The last group contains the novel genes and the EST fragments which function remains illusive. 
In chapter 6 we describe the role of the lysosomal cysteine protease cathepsin $K$ in atherosclerosis. Sukhowa et al. ' already showed that cathepsin $K$ expression was enhanced in the shoulder region of advanced human atherosclerotic lesions. We found the cathepsin $K$ gene to be present in the stable $55 \mathrm{H}$ library. $n n$ addition, DNA micro-array analysis and macro-array analysis revealed elevated cathepsin $K$ mRNA. expression in stable lesions compared to early lesions and lesions containing a thrombus (chapter 4,6 ). In addition to the cathepsin $K$ gene, the active form of the cathepsin $K$ protein was also enhanced in stable lesions. The function of cathepsin $K$ in atherosclerosis was assessed in mice deficient in both ApoE and cathepsin $K$. These mice showed a $45 \%$ reduction in plaque burden when compared to the ApoE single knock out. Furthermore, a remarkable shift in lesion type was observed. In the ApoE and cathepsin $K$ deficient mice the majority of the lesions represented initial lesions $(58 \%)$. whereas in ApoE deficient mice advanced lesions were the predominant lesion type (73\%). Moreover, the ApaE and cathepsin $K$ deficient mice showed a reduced macrophage content, an increased collagen content and a thicker fibrous cap. These data suggest an important role for cathepsin $K$ in lesion progression. Cathepsin $K$ is the only human protease capable of cleaving interstitial collagen in the triple helix domain ${ }^{2-4}$. The initial cleavage of collagen by cathepsin $K$ may facilitate further cleavage of collagen by other collagenases. Therefore, it is tempting to speculate that cathepsin $k$ facilitates cell migration by the initial cleavage of collagen. However, the net proteolytic activity of cathepsin $K$ is not only dependent on the levels of active cathepsin $K$, but is the result of the balance between cathepsin $K$ and its natural inhibitors like cystatin $C$. Cystatin $C$ expression has previously been described to be high in normal arteries, while its expression was reduced in advanced lesions ${ }^{5}$. In our DNA micro-array experiments we found cystatin $B$ to be upregulated in stable lesions whereas a down regulation was observed in lesions containing a thrombus. Cystatin $B$ is a known inhibitor of the cathepsins $B, H, L$ and $S$, whereas its role in cathepsin $K$ inhibition is not yet established. Since the expression patterns of cystatin $B$ and cathepsin $K$ are similar during lesion progression, we might speculate that the net proteolytic activity of cathepsin $K$ is also influenced by cystatin $B$. The role of cathepsin $K$ on cell migration can be further assessed in an in vitro experiment in which the migration capacity of macrophages derived from ApoE and cathepsin $K$ deficient mice are compared to the macrophages of ApoE mice. Furthermore, the presence of the natural inhibitors of cathepsin $K$ needs further investigations. In contrast to inhibition of MMPs, which might even lead to enhanced atherosclerosis in mice (chapter 2), our data suggest that inhibition of cathepsin K leads to reduced lesion progression. Furthermore, cathepsin $K$ deficiency in ApoE deficient mice resulted in a more stable plaque phenotype. Cathepsin $K$ might therefore act as an important new therapeutical target that might reduce lesion progression and possibly leads to plaque stabilization in lesions. Since elevated cathepsin $k$ levels were also observed in human aneurysms, cathepsin $K$ inhibition may therefore lead to reduced 
aneurysm formation. Deficiency of cathepsin K leads to pycnodysostosis in humans and mice . Post-menopausal woman have an increased susceptibility for both osteoporosis and atherosclerosis. In ovarectomized rats, inhibition of cathepsin $K$ prevented bone matrix resorption ". In combination with the decreased lesion progression abserved in the ApoE and cathepsin $K$ deficient mice, inhibition of cathepsin $K$ may have dual beneficial effects on atherosclerosis and osteoporosis. Based on the results described in chapter 6 we hypothesize that cathepsin $K$ can be used as a therapeutical target to prevent cardiovascular everts.

\section{$>$ Known genes previously not linked to atherogenesis}

As described in chapter 3 the perilipin gene was found to be uniquely expressed in lesions containing a thrombus. This study was the first to link perilipin to atherogenesis. Perilipin was initially identified as a phosphoprotein present on the surface layer of lipid droplets in adipocytes and steroidogenic cells ${ }^{12}, 1$. In adipocytes perilipin plays a regulatory rale in hormone sensitive lipase (HSL) mediated lipolysis. In the pre-adipocytes adipocyte differentiation related protein (ADRP or adipophilin) covers the lipid droplet and is thought to be involved in stabilization of the lipid droplet or to facilitate uptake of fatty acids ${ }^{14: 16}$. In mature adipocytes ADRP is replaced by perilipin that serves as a barrier for enzymes involved in lipolysis ${ }^{15}$. After lipolytic stimulation perilipin is hyperphosphorylated, resulting in an increased accessibility of the lipid droplet for lipolytic enzymes like HSL ${ }^{17-19}$. Lipid and cholesterol accumulation are important characteristics of atherosclerotic lesions ${ }^{20.2 \%}$. Cholesterol is taken up by macrophages via the scavenger receptors ${ }^{22}{ }^{23}$. Once inside the macrophage free cholesterol is esterified by acyl:coenzymeA (ACAT) (fig. 1). The esterified cholesterol can be hydrolysed and removed from the cell. This process is mediated by the ATP binding cassette $A 1$ transporter ( $A B C A-1$ ). Hydrolysis of esterified cholesterol also occurs in the lysosomes. Our finding that perilipin is expressed in atherosterotic lesions,

Figure 1: Schematical overview of lipid metabolism in foam cells.

OxLDL is taken up via a scawenger receptor famong others SR-A or CDS6h. Once inside the macrophage. lipud ausociated cholesterol ester is hydrohysed by a lysosomal acidic awholesterol ester hydrolase and free cholesterol (FC) is formed. Free chalesterol is modified to cholesteral esters (CE) by acyl coenzymeA cholesterol acylransferase (ACAV). Subsequenty cholesteryl esters can be hydrolysed by a neutral cholesterof ester hydrolase possibly hormone sensitive hipase an enzyme which tunction is regulated by perilioin. The ATP binding cassette A-I transporter (ABCA-1) mediates free cholesterol efflux. Subsequently the free cholesterol is travsferved to HDL. A) in the macrophage that starts to accumulate hords, the cholesterol ester droplets are covered by adipocyte differentiation related protein (ADRP). After differentiation of macrophages into a foam cells Hoid accumulation increases and ADRP is replaced by perilipin. B) When perilpin is hyperphosphonyated. the chotesterd ester is inydrolysed by and free chotesterol can be nemoved from the cell. Cl Basal phosphorylated peritipin inhibits $45 \mathrm{~L}$ mediated cholesterol ester hydrolysis as a result cholestrol exrers accumulate in the cell. of Disturbed cholesterol effux results in the accumulation of cholesterol in the cell. 

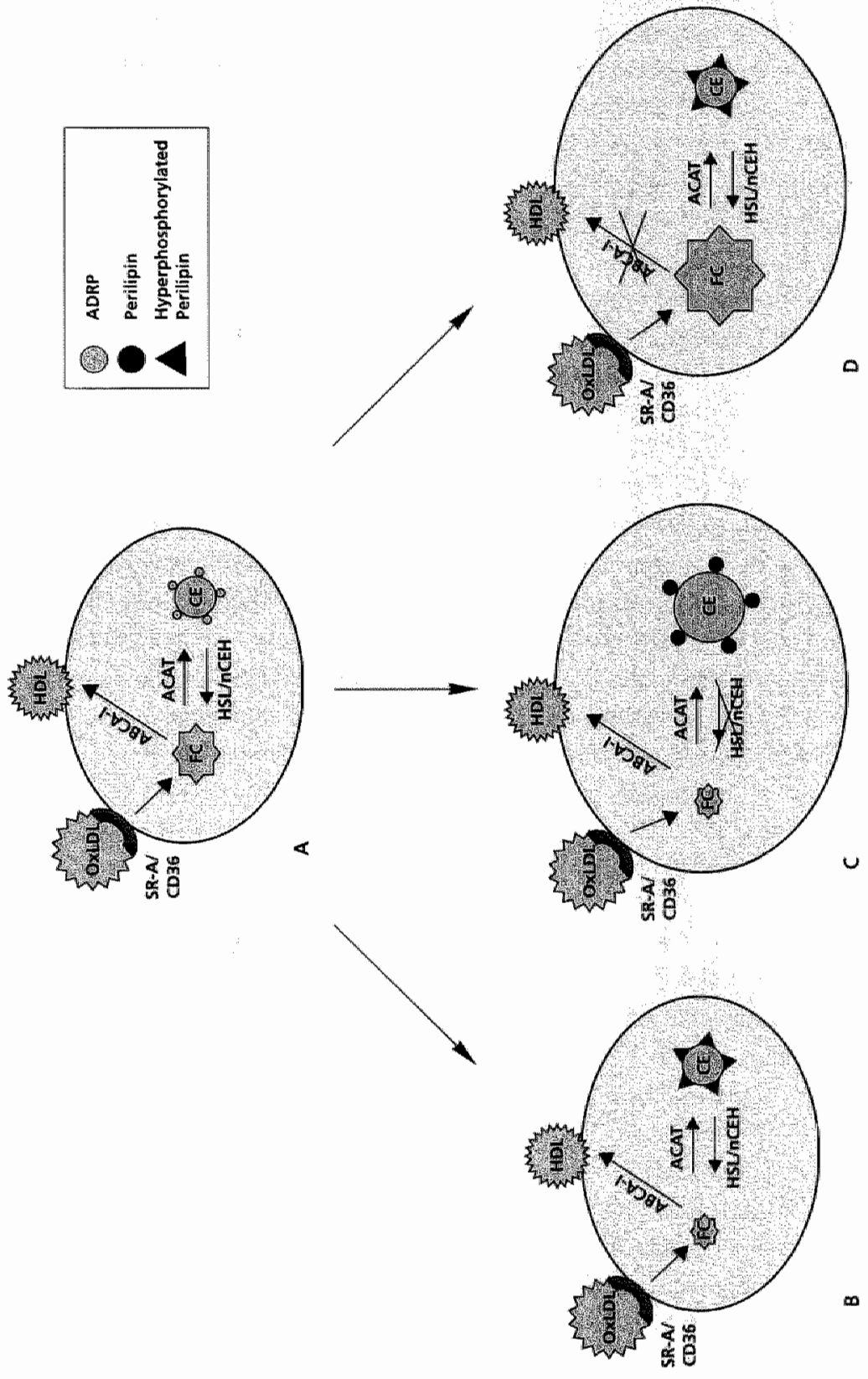
suggests a role for neutral lipid metabolism in atherogenesis. In addition other regulators of neutral lipid metabolism, like ADRP and HSL, were also linked to atherosclerosis ${ }^{2 a .20}$. In chapter 7 we evaluated the expression pattern of these regulators of neutral lipid metabolism during human atherogenesis. ADRP expression was found in macrophages infiltrating the vascular wall that start to engulf lipids. Furthermore, ADRP was expressed in macrophages at the rim of the lipid core. In macrophages with an increased lipid accumulation. lipid droplets were covered by perillipin. Perillipin was co-expressed with $\mathrm{HSL}$ which might be indicative for a regulatory role of perilipin in $\mathrm{HSL}$ mediated lipolysis. These observations indeed suggest a role for neutral lipid metabolism in atherosclerosis. Whether increased lipolysis within an atherosclerotic lesion is beneficial or detrimental to a lesion remains an open question. One might speculate that a low level of lipolysis, possibly by the presence of perilipin on the lipid droplet, increases the lipid content of a lesion, which is a risk factor for rupture of a lesion ${ }^{21}$. In contrast, high levels of lipolysis, mediated by HSL or an other neutral cholesterol hydrolase, in the presence of sufficient amounts of the ABCA1 transporter and the cholesteral acceptor HDL, might increase the lipid efflux (fig. 1). Increased lipid efflux leads to a reduced lipid content of the lesion which is beneficial. In contrast, when free cholesterol is not sufficiently removed from the cell the lipid accumulation in the cell increases (fig. 1). Furthermore, the presence of high levels of free cholesterol might result in a pro-inflammatory response. As increased lipid burden and increased inflammation are risk factors for plaque rupture, we hypothesise that inadequate neutral lipid metabolism is detrimental for atherosclerosis.

\section{$>$ Novel genes in atherogenesis}

Using the SSH technology, as described in chapters 3 and 4 , up to $60 \%$ of the genes isolated represented EST fragments and novel sequences. These EST fragments and novel sequences might encode novel proteins or even novel pathways that might fill some of the lacunae in our present knowledge of atherosclerosis. As a consequence of this "novelty", tools to elucidate the role of these genes in atherosclerosis are lacking, which makes the unravelling of the function of these sequences very laborious. Only few groups $2 * 3$ reported on novel genes expressed during atherogenesis. Follow-up studies that might reveal the function of these genes are still lacking.

In chapter 8 we describe the analysis of such a novel gene $55 \mathrm{H} 6$, a gene preferentially expressed in lesions containing a thrombus (20\% vs $80 \%$ ). Sequence analysis showed that $\$ 546$ contains an insertion of 120 nucleotides, including a start codon, that is not present in the majority of the homologous sequences in the databases. Multiple-tissue northern blot analysis revealed that SSH6 mRNA was ubiquitously expressed. The alternative splice variant, containing exon 3, was exclusively expressed in the vascular 
wall. This splice variant was called vasculin an acronym for vascular wall linked protein. Western blot analysis verified the presence of 2 splice variants, the $45 \mathrm{kDa}$ vasculin and the $34 \mathrm{kDa}$ variant $55 \mathrm{H} 6-\beta$. Vasculin was expressed primarily in vascular tissue and was present at high levels in plasma, whereas $5546-\beta$ expression was ubiquitous. During the development of atherosclerosis the protein expression of $5 \mathrm{SH} 6-\beta$ diminished, while vasculin protein expression increased. Remarkably vasculin was absent in veins, which are not susceptible to atherosclerosis. This may hint towards a function of vasculin in the development of atherosclerosis. However, the exact function of vasculin needs to be established. Overexpression of vasculin in cell lines might lead to different behaviour of the cells with respect to growth, migration or production of cytokines. The role of vasculin in atherosclerosis can be further assessed in mice lacking the vasculin and ApoE gene. However, generating double knock out mice may take years. The use of small interference RNA ${ }^{30}$ to inhibit vasculin in a cuff model of atherosclerosis ${ }^{31}$ is a relative fast method to study the function of vasculin. In analogy, the effects of vasculin overexpression on atherosclerosis can be determined by the use of adenoviral construct transfer of vasculin.

Our study on vasculin clearly demonstrates that novel genes can have a potential interesting role in atherosclerosis. Undoubtedly, the analysis of a complete new gene without any functional hints is very laborious and might even lead to a dead end. Despite these risks we think that knowledge on the function of these EST fragments is indispensable for a complete understanding of atherogenesis. To reduce the failure rate in the follow up of unknown genes, a system that screens the function of genes early in the selection process would be of great help. One possibility is to generate a mammalian expression library to transfect macrophages and VSMC. The effect of the intracellular and/or secreted proteins on important functions in atherogenesis such as matrix iurnover and cytokine production can than be evaluated in high throughput assays. It is our believe that direct functional screening of the genes expressed during atherogenesis will lead to a faster identification of important regulators of in human atherosclerosis.

\section{Identification of genes commonly present in vascular disease}

Information on gene expression in whole mount atherosclerotic specimens remains sparse ${ }^{32: 36}$. The published studies compare gene expression of normal arteries to advanced lesions, early lesions to advanced lesions and fibrous cap to media. Since most of these studies were of a rather small scale, they revealed only 128 genes with a differential expression pattern. The studies described in chapter 3 and 4 are unique in comparing stable lesions to lesions containing a thrombus. Only 11 of these 128 genes (9\%) 
showed consistent differential expression between the studies described in chapters 3 and 4 and the published studies ${ }^{\text {sins. }}$. This rather low overlap might be explained by the fact that most studies used membrane spotted arrays, which is a less sensitive method. Also, the membrane based arrays contain fewer genes than the DNA micro-array used in our studies. Furthermore, it is possible that not all differentially expressed genes were published, which would lead to an under-estimation of the consistency of differential expression.

Large scale gene expression studies enable the assessment of functional clusters of genes that are important in atherosclerosis. As described in chapters 2 and 4 , among other, genes inwolved in matrix turnover, lipid metabolism, inflammation and cell adhesion have been associated with lesion initiation, lesion progression and rupture of an atherosclerotic lesion. In chapter 2 we hypothesise that atherosclerosis, aneurysm formation and neointima formation are different processes with different underlying molecular mechanisms. To test this hypothesis we compared the results of our atherasclerosis related gene expression profiling studies (chapter 3 and 4) to the results of gene expression profille studies on aneurysms ${ }^{37.39}$ and neointima formation ${ }^{39}$, wh. Six genes (ApoE, Cathepsin H, IL8, MMP-9, MMP-12, pleckstrin) were differentially expressed in both atherosclerosis and aneurysm formation. Three of these genes are involved in matrix degradation. Matrix degradation is believed to play an important role in aneurysm formation and rupture of an atherosclerotic lesion. As expected these genes were upregulated during aneurysm formation. Rather unexpectedly, a downregulation was observed in lesions containing a thrombus. Three genes involved in cell adhesion, cytoskeleton and matrix synthesis (syndecan 2, versican and thrombospondin 4) were modulated in both atherogenesis and neointima formation. No overlap in gene expression was observed for genes present in the clusters of lipid metabolism and inflammation. Although only a few currently published studies describe differential expression in vascular specimens, one might speculate that atherosclerosis, aneurysm formation and neointima formation have, at least in part, different underlying molecular mechanisms.

\section{- Comparison of differentially expressed genes in atherogenesis and cell lines}

In contrast to whole mount vascular specimens, cell lines provide a widely accessible and stable pool of mRNA. Many groups studied the expression profiles of cell lines given an atherogenic stimulus. In this paragraph we compare the results of our own whole mount gene expression studies to 12 different cell line based studies 28.79 .41 .50$. Four studies were performed on endothelial cells (yielding 259 genes). 5 used VSMC (yielding 59 gienes) and 3 studies focussed on macrophages (yielding 389 genes). 
Twenty-five of these 707 differentially expressed genes (3.5\%) were modulated both during human atherogenesis and in cell lines given an atherogenic stimulus. Of these 25 differentially expressed genes, 21 could be assigned to either endothelial cells, VSMC or macrophages respectively. This might imply that these genes are only differentially regulated within one single cell type. Only 4 genes were differentially modulated in two different cell lines. Ferritin heavy chain, ferritin light chain and fibronectin were differentially expressed both in endothelial cells and macrophages, whereas laminin $\beta-1$ expression was modulated in VSMC and macrophages. These four genes may represent genes that are ubiquitously expressed after an atherogenic stimulus. The majority (14) of the 25 genes were differentially expressed in macrophages, which might imply that these cells are the predominant cell type in the lesions or that the macrophages are the most active cell type. However, we have to bear in mind that the gene expression studies on VSMC only yielded 59 genes that were differentially modulated. This results in an underestimation of the VSMC associated genes involved in in vivo atherogenesis. If we would like to predict the cellular content of a lesion based on the expression profiles we have to extend the gene expression studies both on cell lines and whole mount vascular specimens. If we compare the studies described in chapters 3 and 4 to the literature on whole mount vascular specimens and the literature on cell lines, a better correlation seems to occur between our study and the whole mount studies ( $9 \%$ identical clones) than the cell line based studies ( $3.5 \%$ identical clones). This suggests that although cell line based studies are easy to perform, some genes may be missed. A possible explanation could be the lack of interactions between the different cell types. Furthermore, the physiological milieu of cells within a plaque can never be completely mimicked in in vitro experiments. It is also widely accepted that the phenotype of cells change in culture. In conclusion we believe that gene expression studies on whole mount tissue represent a more realistic view on the molecullar processes involved in atherogenesis.

\section{Comparison of human and mouse atherosclerosis}

In chapters 4 and 5 the Incyte DNA micro-arrays, Unigene $V$ and Mouse Unigene 1. that contain over 8000 genes, were used to asses gene expression profiles during human and ApoE- $/$ - atherogenesis. This technique yielded 329 genes differentially regulated during human atherogenesis and 498 genes differentially regulated atherosclerosis in ApoE-/- mice. Remarkably, only 29 genes $(6 \%)$ showed differential expression during atherogenesis in both species. For example, the cathepsins were upregulated in human stable lesions and after 4.5 months in ApoE deficient mice. This suggests an important role for the cathepsins in advanced lesions. Only very recently a draft version of sequence of the mouse genome was published ${ }^{52}$. The human ${ }^{52,53}$ and 
at the protein level because of differences in protein translation and degradation. Furthermore, the function of a protein cam depend on posttranslational modifications like phosphorylation and glycosilation. Therefore, several groups started to analyse protein expression profiles in atherosclerosis. Our group successfully used 2-dimensional (2-D) electrophoresis to identify differences in protein expression between stable lesions and lesions containing a thrombus. Skehel et al. ${ }^{\text {s. }}$ used 2-D electrophoresis to identify differences in serum proteins between the atherosclerotic ApoE*3-Leiden mice and control mice.

lin analogy of the DNA micro-array technology protein arrays have been constructed. However, these protein arrays contain relatively few proteins. Recently, Robinson et al. ${ }^{5 / 7}$ used a protein auray that contained autoantigens to characterize the autoantibody response in eight autoimmune diseases. In atherosclerosis, an autoimmune response to oxLDL, heat shock protein 60/65, B2-glycoprotein I and cardiophilin has been observed as. The presence of antibodies against HSPG5 and OxLDL is associated with increased atherosclerosis. Therefore an atherosclerosis autoantigen array might be beneficial for assessing the severity of the disease. We are currently working on the identification of antigens specific for or upregulated in lesions containing a thrombus using serological antigen selection technology ${ }^{62}$. An other protein based method is the phage display technology. This technique was used in an atherosclerotic mouse ${ }^{\circ}$ and in a patient" to select peptides that specifically home into the wasculature. Petricoin and colleagues " posted the idea that pathological changes within an organ could be reflected in specific proteomic patterns in serum. They successfully used the SELDI-TOF technology to identify proteomic patterns specific for ovarian cancer in serum. It is tempting to speculate that such a proteomic pattern can also be observed in the serum of patients that have lesions with a thrombus or vulnerable lesions. In condusion, both genomics and proteomics, although the latter is still rather difficult to perform, will be very helpful to reveal the molecular mechanisms involved in atherogenesis.

\section{$>$ Concluding remarks and outlook}

This thesis provides insight in the molecular mechanisms involved in atherosclerosis. Many genes have been identified that were differentially expressed during human atherosclerosis (chapters 3 and 4) and atherosclerosis in mice lacking the ApoE gene (chapter 5). Comparison of these results to the currently available literature on gene expression in atherosclerosis identified 65 genes that were consistently modulated in models of atherosclerosis. Furthermore, in chapter 2 we describe three mechanisms (extra cellular matrix tumover. cell turnover and lipid metabolism) that are potentially involved in plaque rupture. Several genes, involved in these three mechanisms, interfering in the process of plaque rupture were identified 
The results described in this chapter and chapters $2,3,4$ and 5 will enable us to develop an atherosclerotic specific DNA-array. Such a custom DNA micro-array will thus contain genes that are proven to be differentially expressed in atherosclerosis. Using this array we will be able to develop a "molecular fingerprint' for each specific plaque type. If a specific fingerprint is assigned to a certain plaque type, we will be able to predict the plaque stage according to its gene expression profile. We might even be able to identify morphological stable lesions that have a gene expression fingerprint resembling that of a lesion containing a thrombus. These lesions might represent the so-called vulnerable lesions. Since it is very difficult to identify vulnerable lesions based on morphology, this custom array can become a valuable tool in the identification of these lesions.

Elevated inflammatory markers, like CD4O ligand ${ }^{n 3}$ and C-reactive protein ${ }^{24}$, in serum correlate with the presence of unstable angina. In addition. Petricoin and colleagues ${ }^{\prime}$ identified proteomic patterns that were specific for ovarian cancer in serum ${ }^{72}$. We speculate that cells in the blood might have specific gene expression profiles that correlate with unstable angina. In analogy to the prognostic DNA micro-arrays developed for breast cancer ${ }^{75}$, we would like to use a DNA micro-array containing these unstable angina specific genes as a diagnostic tool to screen patients for the presence of lesions containing a thrombus.

Visualization of lesions in the vasculature may help to identify the culprit lesion responsible for clinical events like myocardial infarction and stroke. Several methods have been developed to visualize atherosclerotic lesions in vivo. The most commonly used technique is the $X$-ray angiogram. Although this technique can reveal advanced lesions, the composition of the lesion remains illusive. Techniques like intravascular ultrasound, magnetic resonance imaging (MRI) and near infrared spectroscopy are potentially capable of determining the composition of an atherosclerotic lesion $" z$. Some groups used characteristics of inflammation such as, increased temperature low $\mathrm{pH}^{\mathrm{B}}$ and upregulation of certain surface receptors on activated leukocyles ${ }^{\circ}$ to identify lesions that are highly inflamed. Furthermore, molecular imaging can be used to detect inflamed atherosclerotic lesions. Van Kooi and colleagues used MRI to detect ultrasmall superparamagnetic particles of iron-oxide (USPIO) that are taken up by macrophages in an atherosclerotic lesion. Since increased lipid accumulation in a lesion is a risk factor for plaque rupture and oxLDL creates a pro-inflammatory environment Tsimikas et al used radioactive llabelled antibodies directed towards oxLDL to identify those lesions that contain a high level of oxLDL. Taken together, these techniques allow a better insight in the composition of a plaque. However it still remains difficult to identify the vulnerable lesion.

In conclusion, by SSH and DNA micro-array analysis we identified 118 genes that were upregulated in lesions containing a thrombus (chapters 3 and 4). Further analysis of these clones might identify targets that can be used as biomarkers. These targets 
have to be specific for lesions containing a thrombus or lesions that are at risk for rupture. Furthermore, these targets have to be accessible, preferably from the bloodstream. The targets, and thus the lesions containing them, have to be visualized. In analogy to the visualization of oxLDL by specific antibodies, specific antibodies or peptides that recognize these targets have to be developed. Besides radiolabeling of the antibodies or peptides for visualization purposes, they can also be used for site specific delivery of agents that are capable of stabilizing the lesion. Furthermore, enzymatic activity can be visualized using imaging beacons in near infrared

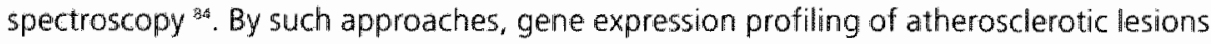
may not only reveal novel pathways and novel therapeutic targets but also improve the diagnosis of atherosclerosis. 
1. Sukhova GK, Shi GP, Simon DI, Chapman HA, Libby P: Expression of the elastolytic cathepsins $S$ and $\mathrm{K}$ in human atheroma and regulation of their production in smooth muscle cells. $\mathrm{J}$ Clin Invest 1998, 102:576-83.

2. Kafienah W, Bromme D, Buttle DJ, Croucher L. Hollander AP: Human cathepsin K cleaves native type 1 and II collagens at the N-terminal end of the triple helix. Biochem J $1998,331: 727-32$.

3. Lecaille $F$, Choe Y, Brandt W, Li Z, Craik CS, Bromme D: Selective inhibition of the collagenolytic activity of human cathepsin $K$ by altering its 52 subsite specificity. Biochemistry 2002,41:8447-5.4.

4. Garnero P, Borel O, Byrjalsen I, Ferreras M, Drake FH, McQueney MS, Foged NT, Delmas PD, Delaisse IM: The collagenolytic activity of cathepsin $K$ is unique among mammalian proteinases. J Biol Chem 1998,273:32347-52.

5. Shi GP, Sukhova GK, Grubb A, Ducharme A, Rhode LH, Lee RT, Ridker PM, Libby P, Chapman HA: Cystatin $C$ deficiency in human atherosclerosis and aortic aneurysms. I Clin Invest 1999,104:1191-7.

6. Salvesen G, Parkes $C$. Abrahamson M, Grubb A. Barrett AJ: Human low-Mr kininogen contains three copies of a cystatin sequence that are divergent in structure and in inhibitory activity for cysteine proteinases. Biochem J 1986,234:429-34.

7. Turk V, Brzin J, Lenarcic B, Locnikar P, Popowic T, Ritonja A, Babnik J, Bode W, Machleidt W: Structure and function of lysosomal cysteine proteinases and their protein inhibitors. Prog Clin Biol Res 1985, 180:91-103.

8. Gelb BD, Shi GP, Chapman HA, Desnick RJ: Pycnodysostosis, a lysosomal disease caused by cathepsin K deficiency. Science 1996,273:1236m8.

9. Saftig $P$, Hunziker $E x$ Wehmeyer $O$, Jones S, Boyde A, Rommerskirch W, Moritz JD, $S c h u P_{n}$ won Figura $K$ : Impaired osteoclastic bone resorption leads to osteopetrosis in cathepsin-K-deficient mice. Proc Natl Acad Sci U S A 1998,95:13453-8

10. Gowen M, Lazner F, Dodds R, Kapadia R, Feild J, Tavaria M, Bertoncello I, Drake F, Zavarselk $S$, Tellis I, Hertzog P. Debouck $C$, Kola I: Cathepsin $K$ knockout mice develop osteopetrosis due to a deficit in matrix degradation but not demineralization. I Bone Miner Res 1999.14:1654-63.

11. Lark MW, Stroup GB, James IE, Dodds RA, Hwang SM, Blake SM, Lechowska B.A, Hoffman SI, Smith BR, Kapadia R, Liang X, Erhard K. Ru Y, Dong X, Marquis RW, Veber D, Gowen M: A potent small molecule, nonpeptide inhibitor of cathepsin $K$ (SB 331750 ) prevents bone matrix resorption in the ovariectomized rat. Bone 2002,30:746-53.

12. Greenberg AS, Egan 10, Wek SA, Garty NB, Blanchette-Mackie EJ, Londos C: Perilipin, a major hormonally regulated adipocyte-specific phosphoprotein associated with the periphery of lipid storage droplets. J Biol Chem 1991,266:11341-6.

13. Blanchette-Mackie El, Dwyer NK, Barber T, Coxey RA, Takeda T, Rondinone CM, Theodorakis IL. Greenberg AS, Londos C: Perilipin is lacated on the surface layer of intracellular lipid droplets in adipocytes. J Lipid Res 1995,36:1211-26. 
14. Jiang HP, Serrero G: Isolation and characterization of a fullilength CDNA coding for an adipose differentiation-related protein. Proc Natl Acad Sci U S A 1992,89:7856-60.

15. Brasaremle DL, Barber $T$, Wolins NE, Serrero G, Blanchette-Mackie EJ, Londos C: Adipose differentiation-related protein is an ubiquitously expressed lipid storage droplet-associated protein. I Lipid Res 1997,38:2249-63.

16. Giâ ل. Serrero G: Adipose differentiation related protein (ADRP) expressed in transfected COS-7 cells selectively stimulates long chain fatty acid uptake. I Biol Chem 1999,274:16825-30.

17. Souza SC, Muliro KV, Liscum L, Lien P, Yamamoto MT, Schaffer JE, Dallal GE, Wang $X_{\text {, }}$ Kraemer FB, Obin M, Greenberg AS: Modulation of hormone-sensitive lipase and protein kinase A-mediated lipolysis by perilipin A in an adenowiral reconstituted system. I Biol Chem $2002,277: 8267-72$.

18. Clifford GM, Londos C, Kraemer FB, Vernon RG, Yearnan SJ: Translocation of hormone-sensitive lipase and perilipin upon lipolytic stimulation of rat adipocytes. J Biol Chem 2000, 275:5011-5.

19. Belkner J. Stender H. Holzhutter HG, Holm C, Kuhn H: Macrophage cholesteryl ester hydrolases and hormone-sensitive lipase prefer specifically oxidized cholesteryl esters as substrates over their non-oxidized counterparts. Biochem J 2000,352 Pt 1:125-33.

20. Lusis Aj: Atherosclerosis. Nature 2000,407:233-41.

21. Davies MJ, Richardson PD, Woolf $\mathrm{N}$, Katz DR, Mann J: Risk of thrombosis in human atherosclerotic plaques: role of extracellular lipid, macrophage, and smooth muscle cell content. Br Heart J 9993.69:377-81.

22. de Winther MP, Hofker MH: New mouse models, for lipoprotein metabolism and atherosclerosis. Curr Opin Lipidol 2002,13:191-7.

23. Linton MF, Fazio S: Class A scavenger receptors, macrophages, and atherosclerosis. Curr Opin Lipidol 2001,12:489-95.

24. Harte RA, Hulten LM, Lindmark $H$, Reve K, Schotz MC, Khoo J, Rosenfeld ME: Low level expression of hormone-sensitive lipase in arterial macrophage-derived foam cells: potential explanation for low rates of cholesteryl ester hydrolysis. Atherosclerosis 2000,149:343"5.0.

25. Reue K. Cohen RD, SchotzMC: Evidence for hormone-sensitive lipase MRNA expression in human monocyte/macrophages. Arterioscler Thromb Vasc Biol 1997, 17:3428-32.

26. Escary IL. Choy HA, Reue $K$. Wang XP, Castellani LW, Glass CK, Lusis AJ, Schotz MC: Paradoxical effect on atherosclerosis of hormone-sensitive lipase owerexpression in macrophages. J Lipid Res 1999,40:397-404.

27. die Vries CA, van Achterberg TA, Horrevoets A., ten Cate WW, Pannekoek H: Differential Display Identification of 40 Genes with Altered Expression in Activated Human Smooth Muscle Cells: Local Expression in Atherosclerotic Lesions of smags, Smooth Muscle Activation-specific Genes. I Bial Chem 2000.

28. Horrevoets AJ, Fontijn RD, van Zonneveld AI, de Vries CJ, ten Cate JW, Pannekoek H: Vascular endothelial genes that are responsive to tumor necrosis factor-alpha in vitro are expressed in atherosclerotic lesions, including inhibitor of apoptosis protein-1, stannin, and two novel genes. Blood 1999.93:3418-31. 
29. Yoshisue $H$, Suzuki K, Kawabata A, Ohya T, Zhao H, Sakurada K, Taba Y, Sasaguni T, Sakai $N$, Yarnashita S, Matsuzawa $Y$. Nojima H: Large scale isolation of non-uniform shear stress-responsiwe genes from cultured human endothelial cells through the preparation of a subtracted CDNA library. Atherosclerosis 2002, 162:323-34.

30. Couzin J: Breakthrough of the year. Small RNAs make big splash. Science $2002,298: 2296 \% 7$.

31. won der Thusen $J \mathrm{H}$, van Berkel $\mathrm{TJ}_{*}$ Biessen EA: Induction of rapid atherogenesis by perivascular carotid collar placement in apolipoprotein E-deficient and low-density lipoprotein receptor-deficient mice. Circulation 2001.103:1164-70.

32. Hiltunen $M$, Tuomisto $T$. Niemi M, Brasen J, Rissanen T, Toronen P, Vajanto I, Yla-Herttuala 5 : Changes in gene expression in atherosclerotic plaques analyzed using DNA array. Atherosclerosis 2002,165:23.

33. Martinet W, Schrijvers DM, De Meyer GRY, Thielemans J, Knaapen MWM, Herman AG, Kockx MM: Gene expression profing of apoptosis-related genes in human atherosclerosis. Upregulation of death-associated protein kinase. Arteriosclerosis Thrombosis and Vascular Biology 2002,22

34. Tyson KL, Weissberg PL, Shanahan CM: Heterogeneity of gene expression in humam atheroma unmasked using CDNA representational difference analysis. Physiol Genomics 2002,9:121-30.

35. McCaffrey TA, Fu C, Du B, Eksinar S, Kent KC, Bush H, Jr, Kreiger K, Rosengart T, Cybulsky MI. Silverman ES, Collins T: High-level expression of Egr-1 and Egrm-inducible genes in mouse and human atherosclerosis. I Clin Invest 2000, 105:653-62.

36. Hiltunen MO. Niemi M, Yla-Herttuala S: Functional genomics and DNA array techniques in atherosclerosis research. Curr Opin Lipidol 1999,10:515-9.

37. Tung WS, Lee $\mathbb{K}$. Thompson RW: Simultaneous amalysis of 1176 gene products in normal human aorta and abdominal aortic aneurysms using a membrane-based complementary DNA expression array. I Vasc Surg 2001,34:143-50

38. Armstrong PJ, Joharning JM, Calton WC, Jr., Delatore JR, Franklin DP. Har DC, Carey DJ. Elmore IR: Differential gene expression in human abdominal aorta: Aneurysmal versus occlusive disease. IVasc Surg 2002,35:346-355.

39. Yajima $N$, Masuda M, Miyazaki M. Nakajima $N$, Chien 5, shyy $\mathbb{N}$ : Oxidative stress is inwolved in the development of experimental abdominal aortic aneurysm: A study of the transcription profile with complementary DNA microarray. J Wasc Surg 2002,36:379-385.

40. Geary RL, Wong JM, Rossini A, Schwartz SM, Adams LD: Expression profiling identifies 147 genes contributing to a unique primate neointimal smooth muscle cell phenotype. Arterioscler Thromb Vase Biol 2002,22:2010-6.

41. Haley KJ, Lilly CM, Yang JH, Feng Y, Kennedy SP, Tuni TG, Thompson JF, Sukhova GH, Libby $P$, Lee RT: Overexpression of eotaxin and the CCR3 receptor in human atherosclerosis: using genomic technology to identify a potential novel pathway of vascular inflammation. Circulation 2000, 102:2185-9.

42. Zhang 5, Day $\mathbb{N}$, Ye S: Microarray analysis of nicatine-induced changes in gene expression in endothelial cells. Physiol Genomics 2001, 5:187-92. 
43. Feng $Y$, Yang $J H$, Huang $H$, Kennedy SP, Juri TG, Thompson IF, Libby P, Lee RT: Transcriptional profite of mechanically induced genes in human vascular smooth muscle cells. Circ Res 1999,85:1118-23.

44. de Vries CJ, van Achterberg TA, Horrevoets AJ, ten Cate JW, Pannekoek H: Differential display identification of 40 genes with altered expression in activated human smooth musde cel|s, Local expression in atherosclerotic lesions of smags, smooth muscle activation-specific genes. I Biol Chem 2000,275:23939-47.

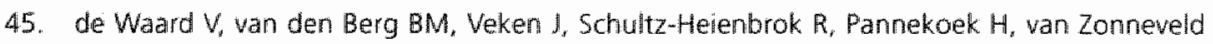
AJ: Serial analysis of gene expression to assess the endothelial cell response to an atherogenic stimulus. Gene 1999,226:1-8.

46. Shiffman D, Mikita T, Tai JT, Wade DP, Porter JG, Seithamer J), Somogyi R, Liang S, Lawn RM: Large scalle gene expression analysis of cholesterol-loaded macrophages. I Biol Chem 2000,275:37324-32.

47. Garcia-Cardena G, Comander II, Blackman BR, Anderson KR, Gimbrone MA: Mechanosensitive endothelial gene expression profiles: scripts for the role of hemodynamics in atherogenesis? Ann $N$ Y Acad Sci 2001,947:1-6.

48. Dekker RJ, wan Soest S, Fontiin RD, Salamanca S, de Groot PG, VanBavel E, Pannekoek $H$, Horrevoets AJ: Prolonged fluid shear stress induces a distinct set of endothelial cell genes, most specifically lung Kruppel-like factor (KLF2). Blood 2002, 100:1689-98.

49. Mikita T, Porter G, Lawn RM, Shiffman D: Oxidized low density lipoprotein exposure alters the transcriptional response of macrophages to inflammatory stimulus. I Biol Chem 2001,276:45729-39.

50. Lu K., Ramos KS: Identification of genes differentially expressed in vascular smooth muscle cells. following benzolalpyrene challenge: umplications for chemical atherogenesis. Biochem Biophys Res Commun 1998,253:828-33.

51. Waterston RH, Lindblad-Toh K, Birney E, Rogers J, Abril JF, Agarwall P, Agarwala R, Ainscough R. Alexandersson M. An P. Antonarakis SE. Attwood J. Baertsch R, Bailey J, Barlow K, et al: Intial sequencing and comparative analysis of the mouse genome. Nature 2002,420:520 562 .

52. Lander ES BB, Nusbaum, C, Zody M, Baldwin J, Devon K, Dewar K, Doyle M, Fitzhugh W, Funke, R, Gage D, Harris $K$. Heaford A. Howland $H$ et al.: Initial sequencing and analysis of the human genome. Nature 2001, 409:860-921.

53. Wenter JC. Adams MD, Myers EW, LI PW, Mural RJ, Sutton GG, 5mith HO, Yandell M, Evans CA, Holt RA, Gocayne JD. Amanatides P, Ballew RM. Huson DH, Wortman JR, et al.: The Sequence of the Human Genome. Science 2001,291:1304-1351.

54. Rosenfeld ME, Polinsky P, Vimani R, Kauser K, Rubanyi G, Schwartz SM: Advanced atherosderotic lesions in the innominate artery of the ApoE knockout mouse. Arterioscler Thromb Vasc Biol 2000,20:2587-92.

55. Johnson IL, Jackson CL: Atherosclerotic plaque rupture in the apolipoprotein E knockout mouse. Atherosclerosis 2001,154:399-406. 
56. Williarns $H_{4}$ Johnson $\mathrm{JL}$, Carson $\mathrm{KG}$, Jackson $\mathrm{Cl}$ : Characteristics of intact and ruptured atherosclerotic plaques in brachiocephalic arteries of apolipoprotein $E$ knockout mice. Arterioscler Thromb Vasc Biol 2002,22:788-92.

57. Lutgens E, Garcia de Frutos P, Apericio C, Moons L, Daemen M, Collen D, Carmeliet P: Gas6-/m/ApoE-/- Mice Develop a Collagen-Rich, Disorganized Plaque Phenotype. Prone to Intra-Plaque Hemorrhage. circulation 2000,102:1138 abstract 170.

58. Lutgens $E$, Gijbelis $M$, Smook $M$. Heeringa $P$, Gotwals $P$, Koteliansky $V$, Daemen I: Transforming growth factor-beta mediates balance between inflammation and fibrosis during plaque progression. Arteriascler Thromb Vasc Bial. 2002,22:975-982.

59. Braun A, Trigatti BL, Fost MJ, Sato K, Simons M, Edelberg JM, Rosenberg RD, Schrenzel M, Krieger $M$ : Loss of SR-Bl expression leads to the early onset of ocdusive atheroscierotic coronary artery disease, spontaneous myocardial infarctions, severe cardiac dysfunction, and premature death in apolipoprotein E-deficient mice. Circ Res 2002,90:270-6.

60. won der Thusen JH, wan Vlijmen BJ, Hoeben RC, Kockx MM, Havekes LM, van Berkel TI, Biessen EA: Induction of atherosclerotic plaque rupture in apolipoprotein E* mice after adenovirus-mediated transfer of p53. Circulation 2002, 105:2064-70.

61. Virmani $R$, Kolodgie FD, Burke AP, Farb A, Schwartz SM: Lessons from sudden coronary death: a comprehensive morphological classification scheme for atherosclerotic lesions. Arterioscler Thromb Vasc Bioll 2000,20:1262-75.

62. Stary $H C$, Chandler $A B$, Dinsmore RE, Fuster $V$, Glagov $S$ "Insull $W$, Mr., Rosenfeld ME, Schwartz CJ. Wagner WD. Wissler RW: A definition of advanced types of atherosclerotic lesions and a histological classification of atherosclerosis. A report from the Committee on Vascular Lesions of the Councill on Arteriosclerosis, American Heart Association. Arterioscler Thromb Vasc Biol 1995, 15:1512-31.

63. Stary HC: Natural history and histological classification of atherosclerotic lesions: an update. Arterioscler Thromb Vasc Biol 2000,20:1177-8.

64. Trogan $E_{1}$ Choudhury RP, Dansky HM, Rong JX, Breslow IL, Fisher EA: Laser capture microdissection analysis of gene expression in macrophages from atherosclerotic lesions of apolipoprotein E-deficient mice. Proc Natt Acad Sci U S A 2002,99:2234.9.

65. Skehel JM, Schneider $K_{*}$ Murphy $N$. Graham $A_{*}$ Benson GM, Cutler $P$, Calmilleri $P$ : Phenotyping apolipoprotein $E^{*} 3$-leiden transgenic mice by twomdimensional polyacrylamide gel electrophoresis and mass spectrometric identification. Electrophoresis 2000,21:2540-5.

66. Zhu $H$, Bilgin M, Bangham $R$, Hall D, Casamayor A, Bertone P, Lan $N$, Jansen $R$, Bidlingmaier S, Houfek T. Mitchell T, Miller P. Dean RA. Gerstein M, Snyder M: Global analysis of protein activities using proteome chips. Science 2001,293:2101-5.

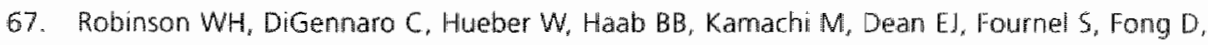
Genovese MC, de Vegvar HE, Skriner $K$, Hirschberg DL, Morris Rl, Muller $S$, Prüin Gl, et all: Autoantigen microarrays for multiplex characterization of autoantibody responses. Nall Med $2002,8: 295-301$. 
68. Shaenfeld Y, Sherer $Y$, George J. Harats D: Autoantibodies associated with atherosclerosis. Anin Med 2000,32 Suppl 1:37-40.

69. Hufton SE, Moerkerk PT, Brandwijk R, de Bruine AP, Arends JW, Hoogenboom HR: A profile of differentially expressed genes in primary colorectal cancer using suppression subtractive hybridization. FEBS Lett 1999,463:77-82.

70. Houston P. Goodman J, Lewis. A. Campbell CJ, Braddock M: Homing markers for atherosclerosis: applications for drug delivery, gene delivery and vascular imaging. FEBS Lett 2001,492:73-7.

71. Arap W. Kolonin MG. Trepel M, Lahdenranta J, Cardo-Vila M. Giordano RJ, Mintz PJ, Ardelt PU, Yao Vs, Vidal $\mathrm{Cl}$, Chen L, Flamm A, Valtanen $\mathrm{H}$, Weavind LM, Hicks ME, et al.: Steps toward mapping the human vasculature by phage display. Nat Med 2002,8:121-7.

72. Petricoin EF, Ardekani AM, Hitt BA, Levine PJ, Fusaro VA, Steinberg SM, Mills GB, simone $C$. Fishman DA, Kohn EC, Liotta LA: Use of proteomic patterns in serum to identify ovarian Cancer. Lancet 2002,359:572-7.

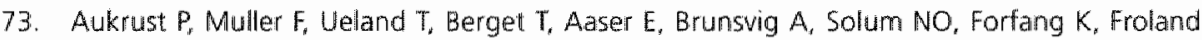
S5, Gullestad L: Enhanced levels of soluble and membrane-bound CD4O ligand in patients with unstable angina : possible reflection of $\pi$ lymphocyte and platelet involvement in the pathogenesis of acute coronary syndromes. Circulation 1999, 100:614-20.

74. Biasucci LM, Liuzzo G, Grillo RL, Caligiuni G, Rebuzzi AG, Buffon A, summaria F, Ginnetti F, Fadda $G$, Maseri $A$ : Elevated levels of $C$-reactive protein at discharge in patients with unstable angina predict recurrent instability. Circulation 1999.99:855-60.

75. wan 't Veer LJ, Dai H, van de Vijver MJ. He YD, Hart AA, Mao M, Peterse HL, van der Kooy K, Marton MJ, Witteveen AT, Schreiber GJ, Kerkhoven RM, Roberts C, Linsley PS, Bernards R, Friend $5 \mathrm{H}$ : Gene expression profiling predicts clinical outcome of breast cancer. Nature 2002,415:530-6.

76. Fayad ZA, Fuster $W$ : Clinical imaging of the high-risk or vulnerable atherosiclerotic plaque. Ginc Res 2001,89:305-16

77. Choudhury RP, Fuster V, Badimon 1), Fisher EA, Fayad ZA: MRI and characterization of atherosclerotic plaque: emerging applications and molecular imaging. Arterioscler Thromb Vasc Biol 2002,22:1065-74.

78. Stefaradis C. Diamantopoulos L, Vlachopoulos C. Tsiamis E, Dernellis I, Toutouzas K, Stefanadi $E$, Toutouzas $P$ : Thermal heterogeneity within human atherosderotic coronary arteries detected in vivo: A new method of detection by application of a special thermography catheter. Circulation 1999,99:1965-71.

79. Stefanadis C. Diamantopoulos $L_{*}$ Demellis J. Economou E, Tsiamis $E$, Toutouzas $K$, Vachopoulos C, Toutouzas P: Heat production of atherosclerotic plaques and inflammation assessed by the acute phase protens in acute coronary syndromes. I Mol Cell Cardiol $2000,32: 43-52$. 
80. Naghavi $M$, John $R_{n}$ Naguib $S$, Siadiaty MS, Grasu $R_{r}$ Kurian $K C_{n}$ van Winkle WB, Soller $B$, Litowsky $S$. Madjid M. Willerson JT. Casscells W. pH Heterogeneity of human and rabbit atherosclerotic plaques; a new insight into detection of vunerable plaque. Atherosclerosis $2002,164: 27-35$.

81. Lindner JR: Detection of inflamed plaques with contrast ultrasound. Am J Cardiol $2002,90:$ L32-5.

82. Cappendijk $V$, Cleutjens $K, I \vee E$, Daemen $M$, Kitslaar $P$, Kessels $F$, Borgers $M$, Koo $E$ : In viwo MRI of accumulated macrophages in human atherosclerotic plaque with ultrasmall superparamagnetic iron-oxide particles. Circulation 2002,106:115:24.

83. Tsimikas 5: Noninvasive imaging of oxidized Low-Density Lipoprotein in atherosclerotic plaques with tagged oxidation-specific antibodies. Am I Cardiol 2002,90:L22 7.

84. Chen J. Tung CH, Mahmood U. Ntziachristos V. Gyurko R, Fishman MC. Huang PL, Weissleder $\mathbb{R}$ : In vivo imaging of proteolytic activity in atherosclerosis. Circulation 2002,105:2766-71. 



\section{Summary}

Atherosclerosis and its related complications, like myocardial infarction and stroke, have become the main cause of death in western society. Atherosclerosis is a slow progressive disease of the arteries that is already initiated early in life. Although advanced but stable lesions can grow sufficiently large to block blood flow, rupture of an atherosclerotic lesion and subsequent thrombus formation predominantly account for most dinical complications. Therefore a better understanding of the pathophysiology of lesion progression and subsequent thrombus formation will result in improved therapy and diagnosis. The different stages of atherosclerosis are morphologically well described. However, the molecular mechanisms involved are still largely unknown. Over the last few years many groups focused on gene expression profiles of several cell lines, like macrophages, smooth muscle cells and endothelial cells, given an atherogenic stimulus. However, only limited information is available on the in vivo situation. Few groups studied the differences in gene expression between whole mount normal and atherosclerotic artery and early atherosclerotic lesions and advanced lesions. Until now information regarding the molecullar mechanisms that underlie the transition of a stable lesion to a lesion with a thrombus is lacking.

The main hypothesis of this thesis is that each athereosclerotic lesion type is a ccompanied by a specific gene expression profile. The first part of this thesis focuses on the gene expression profiles that accompany the different stages of atherosclerosis in human and the ApoE deficient mouse. In the second part of this thesis, the function of three of the differentially expressed genes (cathepsin $K$, perilipin, varcullin) in atherogenesis is further evaluated.

An inventory of the genes that are potentially involved in rupture of an atherosclerotic lesion is described in chapter 2. Based on recent literature regarding gene expression profiles on whole mount vascular tissue, we postulate that at least three mechanisms are involved in rupture of an atherosclerotic lesion. These mechanisms are (1) a disturbed balance in extracellular matrix turn-over. (2) a disturbed regulation of cell turn-over and (3) processes involved in lipid metabolism. Animal models exhibiting features of rupture of an atherasclerotic lesion reflect the invalvement of these mechanisms. Furthermore, intervention studies in mechanisms involved in extracellular matrix turn-over suggest that the processes of atherosclerosis, aneurysm formation and neointima formation have different underlying molecular mechanisms.

In chapters 3 and 4 we studied the different gene expression profiles between early lesions and stable lesions (chapter 4) and stable lesions and lesions containing a thrombus (chapters 3 and 4) using suppression subtractive hybridisation (SSH) and DNA micro-array analysis. The $55 \mathrm{H}$ procedure resulted in two libraries containing 5000 genes that showed either enhanced expression in stable lesions or in lesions containing a thrombus. Subsequent analysis using a second independent method, the macro-array 
analysis, revealed that approximately ten percent of these genes were truly differentially expressed during lesion progression. Additional RT.PCR analysis on individual lesions revealed that the gene coding for perilipin was exclusively expressed in lesions containing a thrombus: Furthermore, clone $\$ 5 H 6$ (vasculin) was expressed in $80 \%$ of the lesions containing a thrombus while only $20 \%$ of the stable lesions tested positive. DNA micro-array analysis on early lesions versus stable lesions and stable lesions versus lesions containing a thrombus showed that 329 genes were differentially expressed (at least 1.7 fold difference in expression). Remarkably, comparison of the results obtained by SSH and DNA micro-array analysis revealed that $60 \%$ of the SSH derived genes encoded EST fragments or novel sequences while as little as $11 \%$ of the DNA micro-array derived genes coded for EST fragments. Furthermore, only fibronectin and TGF $\beta$ binding protein 1 showed consistent differential expression in both methods. These results indicate that different sets of genes were identified using both methods. Functional clustering of the differentially regulated genes resulted in at least 8 different clusters of which the clusters of genes involved in 1) lipid metabolism 2) matrix turn-over and protein degradation, 3) the immune system and 4) growth factors were the most predominant. In general, three sets of genes can be recognized: known genes that were previously linked to atherosclerosis, known genes previously not liked to atherosclerosis and novel genes involved in atherosclerosis.

Since the ApoE deficient mouse is a commonly used model in atherosclerosis research, large scale gene expression analysis was performed on the aortic arches of ApoE deficient mice and wild type C57B16 mice (chapter 5). These mice were fed a normal chow diet or a western type diet for $3,4.5$ and 6 months. To identify genes affected by cholesterol withdrawal one ApoE- $/$ group was fed a western type diet for 4.5 months and this diet was replaced by a normal diet for 1.5 months. In total 498 genes showed differential regulation ( $>2$ fold) in at least one group. In the normal chow diet group the number of differentially regulated genes correlated with plaque area, number of cells, number of macrophages and number of T-cells. These correlations were not observed in the western type diet group. After cholesterol withdrawal the number of genes that were differentially expressed decreased. Since cholesterol lowering is thought to result in placue stabilization, these cholesterol withdrawal sensitive genes might be important for therapy. Functional clustering resulted in. among others, groups of genes involved in (1) lipid metabolism (2) matrix turn-over and protein degradation, (3) the immune system and (4) cytokines. In contrast to the identical functional gene clusters, only few genes show identical gene expression profiles during human and murine atherosclerosis.

From chapters 3, 4 and 5 we can conclude that the different stages of atherosclerosis are accompanied the expression of specific sets of genes. However, the use of different methods may result in the identification of different gene pools. 
In the next three chapters we focussed on the role of individual genes that were differentially expressed during human atherogenesis. In chapter 6 we evaluated the role of the lysosomal cysteine protease cathepsin $K$ in atherosclerosis. Cathepsin $K$ is an example of a gene that was already linked to atherosclerosis. We found enhanced expression of this gene in human stable lesions compared to early lesions and lesions. containing a thrombus. The role of cathepsin $K$ in atherosclerosis was assessed in mice that were deficient in both $A p o E$ and cathepsin $K$. We report that deficiency in cathepsin $K$ results in a $45 \%$ reduction in plaque burden. In addition a shift in lesion type was observed. The initial lesion was the predominant lesion type in double knock out animals, whereas the majority of the lesions in ApoE deficient mice represented advanced lesions. Furthermore, lesions of cathepsin K/IApoE deficient mice showed a reduced macrophage content, an increased collagen content and a thicker fibrous cap. In conclusion, cathepsin $\mathrm{K}$ plays an important role in lesion progression since deficiency for this gene results in reduced lesion progression. Thus, the present study indicates that cathepsin $K$ might be useful as a therapeutic target to prevent cardiovascular events.

Our finding that perilipin mRNA expression was restricted to atherosclerotic lesions containing a thrombus was the first to link this gene to atherosclerosis. In chapter 7 we made an inventory of the MRNA and protein expression profiles of perilipin in non diseased artery, early lesions, stable lesions and lesions containing a thrombus. Perilipin is a protein that is involved in neutral lipid metabolism. Therefore we also included two other proteins inwolved in neutral lipid metabolism. HSL and ADRP, in this study. We observed that (1) perilipin MRNA was predominantly expressed in lesions containing a thrombus, while perilipin protein was expressed in foam cells of early lesions, the shoulder region of stable lesions and near the site of rupture in lesions containing a thrombus. (2) HSL MRNA and protein expression increased during lesion progression and collocalized with perilipin. (3) ADRP MRNA and protein was abundantly present in all lesion types. The spatio-temporal expression of perilipin. HSL and ADRP in the different stages of lesion progression suggests a role for neutral llipid metabolism in human atherogenesis.

The SSH procedure as dlescribed in chapter 3 resulted in the identification of many EST fragments. One of the EST fragments, 5 SH6, was predominantly expressed in lesions containing a thrombus. In chapter 8 we expand our analysis on this gene. We showed that SSH6 contains an insertion of 120 nucleotides, including a start codon, in exon 3. This insertion is not present in the majority of the homologous sequences. The mRNA of the alternative splice variant, including exon 3, was exclusively expressed in the vascular wall. This splice variant was called vasculin an acronym for vascular wall linked protein. Vasculin protein was primarily expressed in wascular tissue and in plasma, 
whereas the variant that lacked exon $3(5 \mathrm{SH} 6-\beta)$ was ubiquitously expressed. During the progression of atherosclerosis SSH6- $\beta$ expression diminished, while vasculin expression increased. In conclusion, the regulated expression of vasculin during atherosclerogenesis suggests a role for this protein in atherosclerosis. Furthermore, its presence in the plasma might be useful as a marker for atherosclerosis.

In chapter 9 the experimental chapters are discussed and put into a broader context. Comparison of our gene expression studies and the gene expression studies described in literature, both performed on whole mount human atherosclerotic tissue, show that $9 \%$ of the genes show consistent regulation. Furthermore, we observed only a minute overlap of genes that show identical regulation between atherosclerosis and aneurysm formation or between atherosclerosis and neointima formation. This supports the hypothesis posted in chapter 2 that these vascular diseases have different underlying molecular mechanisms. Comparison of our whole mount vascular tissue approach with gene expression profiling studies on cell lines given an atherosclerotic stimulus, show only a minute overlap (3.5\%) of the differentially regulated genes. This might indicate that the processes in whole mount vascular tissue and cell lines given an atherosclerotic stimulus are not identical. Finally, we compared the gene expression profiles during human atherosclerosis to that of the ApoE deficient mice. Six percent of the genes were differentially modulated during atherosclerosis in both species. Remarkably, no genes showed identical expression profiles in lesions containing a thrombus and in advanced murine lesions. This might suggest that murine lesions do not rupture because of at least partially different molecular mechanisms that underlie the disease.

The studies described in this thesis show that each stage in atherogenesis is accompanied by specific gene-expression profiles. Functional clustering revealed that genes involved in lipid metabolism, matrix turn-over/ protein degradation and the immune systern are important in atherogenesis. In addition, we assessed the importance of cathepsin $K_{\text {, in }}$ lesion progression. Therefore, this cysteine protease might be an important therapeutic target to stabilize atherosclerotic lesions. Furthermore, the gene expression profiling studies resulted in the identification of a gene previously not linked to atherosclerosis, perilipin, and the EST fragment vasculin. Both genes are potentially important in atherosclerosis. Therefore, we conclude that the gene expression profiling studies as described in this thesis are very important to unravel the molecular mechanisms involved in atherosclerosis. 
De complicaties van atherosclerose (aderverkalking) zoals het hartinfarct en het herseninfarct zijn de belangrijkste doodsoorzaak in de Westerse wereld. Atherosclerose is een langzaam progressieve aandoening die al in de eerste decennia van het leven geïnitieerd wordt. In het proces van atherosclerose kunnen verschillende stadia onderscheiden worden. Vroege atherosclerotische lesies worden gekarakteriseerd door kleine vetophopingen en de infiltratie van ontstekingscellen in de vaatwand. Deze vroege lesies veroorzaken geen klinische complicaties. Stabiele lesies bevatten een kern van vet, cholesterol en dade cellen (ook well necrotische kern genoemd), die bedekt wordt met een laagje fibreus bindweefsel (de fibreuze kap). Tevens kunnen de stabiele lesies kalk en fibreus bindweefsel bevatten. Wanneer de stabiele lesie te groot wordt, kan deze de bloedstroom belemmeren en daardoor bijvoorbeeld pijn op de borst of etalagebenen veroorzaken. De belangrijkste oorzaak van klinische complicaties is het ruptureren van een lesie. Hierdoor wordt een bloedprop (trombus) gevormd, wat tot totale afsluiting van het bloedvat kan leiden. Deze lesies worden de lesies met een trombus genoemd. Hoewel de morfologische karakteristieken van de diverse lesiestadia goed beschreven zijn, is er weinig bekend over de onderliggende moleculare mechanismen. Wanneer we zouden kumnen achterhalen welke mechanismen van belang zijn bij de vorming van een lesie met een trombus kan dat mogelijk resulteren in een verbeterde therapie en diagnose. Door de ontwikkeling van nieuwe technieken, zoals bijvoorbeeld de DNA-chip, kunnen de moleculaire mechanismen op grote schaal bestudeerd worden. Veel onderzoeksgroepen hebben de genexpressieprofielen bestudeerd van cellen zoals, macrofagen, gladde spiercellen en endotheelcellen die een atherogene stimulus kregen. Hoewel deze cellen deel uit maken van de lesie geeft dit niet het gehele beeld van de in vivo situatie weer. Een klein aantal onderzoeksgroepen heeft daarom gekeken naar de verschilen in het genexpressieprofiel tussen een normale vaatwand en een atherosclerotische vaatwand, en vroege lesies en stabiele lesies. Hierbij werd gebruik gemaakt van stukjes vaatwand. Het verschil in genexpressieprofiel tussen de stabiele lesies en de lesies met een trombus is tot nu toe niet bestudeerd.

De belangrikste hypothese van dit proefschrift is dat de verschillende types atherosclerotische lesies een specifiek genexpressiepatroon beztten. In het eerste gedeelte van dit proefschrift worden de genexpressiepatronen van de verschillende stadia in humane artherosclerose bestudeerd. Tevens is het genexpressieprofiel tijclens de progressie van atherosclerose bestudeerd in een muismodel van atherosclerose, te weten de ApoE deficiënte muis, bestudeerd. In het tweede gedeelte van dit proefschirift wordt de functie van drie differentieel tot expressie komende genen (cathepsine $k$, perilipine en vasculine) in atherosclerose verder bestudeerd. 
In hoofdstuk 2 hebben we een inventarisatie gemaakt van de genen die mogelijk betrokken zijn bij het ontstaan wan een atherosclerotische lesie met een trombus. op basis van recente literatuur over genexpressiestudies in vaatweefsel, veronderstellen we dat er ten minste drie mechanismen betrokken zijn bij het ruptureren van een atherosclerotische lesie. Deze mechanismen zijn (1) een verstoorde balans in de turnover van extracellulaire matrix, (2) een verstoorde balans in de turnover van cellen en (3) processen betrokken bij vetmetabolisme. Diermodellen die kenmerken vertonen van de worming vam een trombus in een vat, bevestigen de betrokkenheid van deze mechanismen. Tevens doen studies die ingrijpen in het mechanisme van extracellulaire matrix turnover vermoeden dat er verschillen zijn in de onderliggende moleculaire mechanismen van de verschillende wataandoeningen zoals atherosclerose, vorming van aneurysma's en vorming van een neointima.

De verschillen in genexpressiepatronen tursen vroege lesies en stabiele lesies en stabiele lesies en lesies met een trombus worden bestudeerd in hoofdstuk 3 en 4 . Daarbij werd gebruik gemaakt van twee verschillende technieken, de suppressieve subtractie hybridisatie (SSH) en de DNA-chip. Door middel van de SSH techniek werden twee bibliotheken geconstrueerd die 5000 genen bevatten die magelijk verschillend tot expressie komen tussen stabiele lesies en lesies met een trombus. Met een tweede onafhankelijke techmiek, de macro-array, toonden we aan dat ongeveer tien procent van deze genen reproduceerbaar verschillend tot expressie komen tussen de verschillende lesie types. RT-PCR analyse van individuele lesies toonde vervolgens aan dat het gen dat codeert voor perilipine alleen tot expressie komt in lesies met een trombus. Het gen SSH6 (vasculine) komt tot expressie in $80 \%$ van de lesies met een trombus, terwijl in maar 20\% van de stabiele lesies S5H6 tot expressie komt. De DNA-chip techniek, waarin vroege lesies vergeleken werden met stabiele lesies en stabiele lesies met lesies met een trombus, toonde aan dat 329 genen verschillend tot expressie komen. Vergelijking van de resultaten van de $55 \mathrm{H}$ en de DNA chip toonde aan dat 60\% van de SSH genen codeer: voor EST fragmenten (onbekende genen) of nieuwe sequenties, terwill maar $11 \%$ wan de DNA-chip genen codeerden woor deze EST fragmenten. Alleen de genen die coderen voor fibronectine en het TGFB bindend eiwit 1 vertoonden vergelijkbare expressiepatronen in beide methoden. Functionele clustering van de genen die verschillend tot expressie komen resulteerde in tenminste 8 verschillende clusters waarvan de clusters van genen betrokken bij (1) vetmetabolisme, (2) extracellulaire matrix turnover en eiwit degradatie, (3) het immuunsysteem en (4) celgroei, het belangrijkste lijken. Over het algemeen kunnen drie groepen genen onderscheiden worden: de bekende genen die al beschreven zijn in atherosclerose, de bekende genen die nog niet beschreven zijn in atherosclerose, en nieuwe genen die mogelijk betrokken zijn bij atherosclerose. 
Omdat de ApoE deficiente muis een veel gebruikt model is in het onderzoek naar atherosclerose, hebben we ook de genexpressieprofielen bepaald in de aortabogen van de ApoE deficiente muis en de wildtype muis, de C57Bl6 muis (hoofdstuk 5). De muizen kregen gedurende 3, 4.5 en 6 maanden een normal dieet of een hoog vet dieet. Om genen te kunnen identificeren die beïnvloed worden door verlaagde cholesterol concentraties, kreeg een groep gedurende 4.5 maanden een hoogvet dieet waarna dit dieet wervangen werd door een normaal dieet gedurende 1.5 maand. Wij vonden dat 498 genen werschillend tot expressie kwamen in tenminste een van deze groepen. In de groep muizen die een normaal dieet hadden gekregen, werd een correlatie gevonden tussen het aantal genen dat verschillend tot expressie kwam en het lesieoppervlakte, het aantal cellen, het aantal macrofagen en het aantal T-cellen. Deze correlaties werden niet gevonden in de hoog vet dieet groep. In de groep waarbij het cholesterol uit het dieet verwijderd was, nam het aantal genen dat verschillend tot expressie kwam af. Omdat gedacht wordt dat verlaging van de hoeveelheid cholesterol leidt tot stabilisatie van een atherosclerotissche lesie, kunnen deze genen van belang zijn voor therapeutische doeleinden. Functionele clustering van de genen die een verschillend genexpressiepatroon vertoonden, resulteerde onder andere in de volgende clusters van genen betrokken bij: (1) vetmetabolisme, (2) extracellulaire matrix turnover en eiwit degradatie, (3) het immuunsysteem en (4) cytokines. In tegenstelling tot de identieke functionele clusters in mens en muis, waren er maar weinig genen die zowel in de mens als de muis vergelijkbare expressiepatronen vertoonden.

Uit hoofdstuk 3, 4 en 5 kunnen we concluderen dat de verschillende stadia in atherosclerose worden vergezeld door expressie van specifieke sets van genen. Echter, het gebruik van verschillende methoden kan leiden tot de identificatie van verschillende genen.

In de volgende drie hoofdstukken wordt de rol van drie individuele genen die verschillend tot expressie komen bij humane atherosclerose besproken. In hoofostuk 6 bestuderen we de rol van cathepsine $K$, een lysosomaal cysteine protease dat in staat is collageen 1 af te breken, in atherosclerose. Cathepsine $K$ is een voorbeeld van een gen dat al beschreven was in atherosclerose. Wij vonden een verhoogde cathepsine $K$ expressie in stabiele lesies wanneer deze vergeleken werden met vroege lesies en lesies met een trombus. De rol van cathepsine $K$ in atherosclerose werd bestudeerd in een muis die deficiënt is voor zowel ApoE en cathepsine $K$. Aangetoond werd dat muizen zonder cathepsine $k 45 \%$ minder lesies hadden. Tevens werd een verschuiving in het type lesie gevonden. Terwijl de vroege lesie het meest woorkomende lesie type in cathepsine KJApoE deficiënte muizen was, was het merendeel wan de liesies in de ApoE deficiënte muis vergevorderd. Ook bevatten de lesies van de cathepsine K/ApoE deficiënte muizen minder macrofagen, meer collageen en cen dikkere fibreuze kap. Omdat afwezigheid van cathepsine $K$ resulteert in een verminderde lesie progressie, 
kunnen we stellen dat cathepsine $k$ een belangrijke rol speelt in de progressie van atherosclerose. Daarom zou cathepsime $K$ gezien kunnen worden als een therapeutisch doel in de preventie van cardiovasculaire aandoeningen.

De studie zoals beschrewen in hoofdsfuk 3 toonde als eerste aan dat perilipine tot expressie komt in humane atherosclerose. Wij wonden dat dit gen voornamelijk tot expressie komt in atherosclerotische lesies met een trombus. In hoofdstuk 7 wordt een inventarisatie gemaakt van het genexpressie en eiwitexpressiepatroon wan onder andere perilipine in normale arterien, vroege lesies, stabiele lesies en lesies met een trombus. Perilipine is een eiwit dat betrokken is bij het neutrale vetmetabolisme in de cel. Omdat er meer eiwitten betrokken zijn bij het neutrale vetmetabolisme hebben wij ook het expressiepatroon van twee andere eiwitten bepaald. Deze eiwitten zijn hormoon sensitief lipase (HSL) en adipocyt differentiatie gerelateerd eiwit (ADRP). Wij hebben gevonden dat (1) het perilipine-gen voornamelijk tot expressie komt in lesies met een trombus. Het eiwit claarentegen, komt tot expressie in schuimcellen (cellen die vet hebben opgenomen) van vroege lesies, in de schouderregio van stabiele lesies en in de buurt van de ruptuur in lesies met een trombus. (2) De expressie van zowel het HSL-gen als het HSL-eiwit neemt toe tijdens de lesie progressie. Tevens werd een co-lakallisatie wan perilipine en HSL vastgesteld. (3) Zowel het ADRP-gen als het ADRP-eiwit komen hoog tot expressie in alle lesie types. De expressie van perilipine, HSL en ADRP op specifieke locaties en tijd in lesie progressie suggereert dat het neutrale vetmetabolisme een rol speelt bij atherosclerose.

Zoals beschreven in hoofdstuk 3 resulteerde SSH methode in de identificatie van veel EST-fragmenten. Een van deze EST-fragmenten, te weten SSH6, kwam waker tot expressie in lesies met een trombus dan in stabiele lesies. De analyse van dit gen wordt uitgebreid beschreven in hoofdstuk 8. Wij toonden aan dat S5H6 een insertie bewat in exon 3 van 120 nucleotiden, inclusief een startcodon. Deze insertie is niet aanwezig in het merendeel van de bekende homologe sequenties. De insertievariant wan het $55 \mathrm{H} 6$-gen wordt exclusief tot expressie gebracht in de vaatwand. Daarom hebben we deze variant vasculine genoemd, als een acroniem voor vascular wall linked protein. Het vasculine eiwit kolnt voornamelijk tot expressie in de vaatwand en in bloedplasma. Dit in tegenstelling tot de variant zonder de insertie $(55-16-\beta)$, welke in alle geteste weefsels voorkomt. Gedurende de progressie van atheresclerose neemt de expressie van \$SH6- $\beta$ af, terwijl de expressie van vasculine toeneemt. Op basis wan die gereguleerde expressie van vasculine tijdens atherosclerose suggereren we dat dit eiwit een rol speelt in het proces van atherosclerose. Bovendien zou de aanwezigheid van vasculine in bloedplasma gebruikt kunnen worden als een marker voor atherosclerose. 
In hoofdstuk 9 worden de experimentele hoofdstukken van dit proefschrift bediscussieerd. Vergelïking van onze genexpressiestudies en de genexpressiestudies uit de literatuur, waarbij beicle gebruik wordt gemaakt van humaan vaatweefsel, lieten zien dat $9 \%$ van de genen consistent verschillend tot expressie komt. Een zeer kleine overlap in de genen die verschillend tot expressie komen, werd aangetoond tussen atherosclerose en andere vasculaire aandoeningen zoals aneurysma en neointima vorming. Deze observatie ondersteunt de hypothese dat deze vasculaire aandoeningen verschillende moleculaire mechanismen bezitten. Wanneer onze genexpressiestudies op humaan vaatweefsel vergeleken worden met genexpressiestudies uitgevoerd op cellijnen, vinden wij maar een hele kleine overlap $(3,5 \%)$ in de genen die verschillend tot expressie komen. Dit is een indicatie de processen in de vaatwand en in cellen die een atherogene stimulus hebben gekregen niet identiek zijn. Tenslotte hebben we onze humane studies vergeleken met de genexpressiestudie in de ApoE deficiënte muis. Zes procent van de genen vertoonde differentiële expressie in zowel de mens als de muis. Opmerkelijk was dat geen enkel gen differentieel tot expressie kwam in zowel humane lesies met een trombus als in vergevorderde muizenlesies. Dit kan mogelijk betekenen dat de muizenlesies niet ruptureren omdat er verschillende maleculaire mechanismen betrokken zijn bij atherosclerose in de muis en de mens.

De studies beschreven in dit proefschrift tonen aan dat de verschillende stadia van atherosclerose vergezeld worden van specifieke genexpressiepatronen. Clustering. gebaseerd op de functie van de genen toonde aan dat genen betrokken bij vetmetabolisme, matrix/eiwit turnover en het immuunsysteem belangrijk zijn in atherosclerose. Ook toonden we aan dat cathepsine $K$ belangrijk is in lesie progressie. Hierdoor is dit enzym potentieel aantrekkelijk voor therapeutische doeleinden. De genexpressiestudies resulteerden ook in de identificatie van een gen dat niet eerder beschreven was in atherosclerose, te weten perilipine, en het EST fragment vasculine. Beide genen zijn mogelijk belangrijk in atherosclerose. Hierdoor kunnen we concluderen dat genexpressie studies kunnen bijdragen aan het ontrafelen van de moleculaire mechanismen die betrokken zijn bij atherosclerose. 


\section{$>$ Dankwoord}

De proefjes zijn gedaan, de resultaten geanalyseerd, het proefschrift geschreven... de hoogste tijd voor het dankwoord. Want zonder de steun en hulp van velen zou dit proefschrift nooit in deze worm tot stand gekomen zijn. Omdat dit dankwoord natuurlijk op het laatste moment geschreven wordt, heb ik niet de illusie dat ik niemand zal vergeten, daarom voor deze mensen alvast bedankt!!!

Als eerste wil ik natuurlijk milin promotor Mat Daemen en co-promotor Kitty Cleutjens bedanken. Na een anderzoek dat niet van de grond kwam, hebben jullie het aangedurfd mij een compleet nieuw project te geven. Dankzij jullie weet ik weer dat onderzoek doen leuk is!! Jullie wisten me op de juiste momenten te stimuleren of juist af te remmen. Ondanks het vroege tijdstip van onze dinsdagochtend bespreking, waren deze altijd weer vol van goede discussies en ging $i k$ altijd weer de deur uit met duizend-en-een nieuwe ideeën. Ook hebben jullie me geleerd hoe je van een 'uitgebraakte tekst.' een wetenschappelijk artikel maakt. Dat jullie het vaak met elkaar eens zijn blijkt wel uit de bijna identieke correcties die ik terug kreeg. Kitty, ik heb het enorm gewaardeerd dat ik altijd bij je terecht kon. Kortom, ik had geen ander 'promotieteam' gewild.

Zonder de hulp van 'het lab" zou dit boekje aanzienlijk minder pagina"s en figuren bevat hebben. Allereerst wil ik natuurlijk Wendy bedanken, niet alleen voor je praktische inzet (herken je de figuren?) maar ook voor de gezelligheid op het lab (de droppot was een fantastische idee). Ron, we hebben maar kort samengewerkt maar het was wel de aanzet tot dit boekje. Monique, de eerste twee jaar hebben we samen ontdekt dat fagen (en vooral die met antilichamen) erg weerbarstig kunnen zijn. Barry, niet alleen woor bedankt voor de blotjes, maar ook voor de keren dat de computer weer op hol sloeg en jij hem weer aan de praat kreeg. Ruben, we zullen de fagen klein krijgen!! Anique, Petra, Ine, Coby, Anouk en Mat: bedankt voor de hulp bij immuno's, in situ's, advies, helpen zoeken als ik weer eens iets kwijt was en natuurlijk voor de gezelligheid. Jack bedankt voor de hulp bij de fotomicroscoop.

Ook wil ik Esther L. bedanken, samen weekend aan weekend aan de muizen, het heeft toch een mooi hoofdstuk opgeleverd! Ann-Pascale en Kitty, bedankt voor het 'lenen" van jullie artikels, het geeft voldoening te zien dat uit dit onderzoek nieuw onderzoek voortvloeit. Sylvia en Robertwan, bedankt voor het lezen van de artikelen, door jullie commentaar zijn de artikellen absoluut beter geworden. Jullie legden de winger precies op die stukken die "rammelden', maar waarvan ik hoopte dat ik er wel mee weg kwam.

Het onderzoek uit dit proefschrift is in nauwe samenwerking met Organon uitgevoerd. Eerst in Oss en daarna in Newhouse. In Oss wil ik dan ook Anneke Sijbers, Guido Zaman en Jan Meijerink bedanken voor de prettige samenwerking en goede discussies. 
I would also like to thank the people from Organon Newhouse. Especially, Darcey Black. Donald Dunbar, Angela Fisher and Clive Long for their help and discussions regarding. the micro-array studies, the bioinformatic analysis and cathepsin $\mathrm{K}$. I am very pleased that our cooperation continues during the SAS project!

I would like to thank Andy Greenberg, for providing the antibodies directed towards perilipin, HSL and ADRP. Without your help and advice, chapter 7 wouldn't exist in its present form.

Furthermore, I would like to thank Gordon Porter of Incyte Genomics for the opportunity to perform the mouse arrays.

Ook Chris. Evelo en de studenten wil ik hartelijk bedanken voor de bioinformatica die ze toegepast hebben op de humane en de muizen arrays.

Natuurlijk zij er nog een aantal mensen die ik niet mag vergeten. De uitdrukking Cor/Elly regelt dat wel heb ik vaak gehoord. Bedankt dat jullie dat ook echt gedaan hebben. Prof. Dr. Kitslaar, Dr. Tordoir, de mensen op de OK, Piet, Mirjam, de assistenten en natuurlijk de studenten dankzij jullie medewerking was het magelijk dit onderzoek uit te voeren.

In de 7 jaar dat ik op pathologie rondloop heb ik de grote waarde van kamergenoten ondervonden. Als eerste Veerle, jij was het die mij elke keer weer opbeurde als de experimenten weer niet gingen zoals gehoopt. Daarnaast was het altijd leuk om onder het genot van koffie alles en iedereen door te spreken. Ik ben dan ook blij dat je mijn paranimf wilt zijn. Solange, ook al woon je al jaren niet meer in Nederland, we blijven elkaar gelukkig regelmatig zien. Je kan er helaas niet bij zijn, maar je hebt een goede reden, ik kom hem/haar snel bewonderen. Verder natuurlijk Cherida (het is nu jouw beurt, jammer dat je het onderzoek verruilt voor het studentenleven), Ann-Pascale (veel lol en hard werken gaan dus wel samen), Rob, Sigrid, Sylvia, Meindert, Marjo, Linda en Ference bedankt voor alle klets/lach/klaag sessies. Kamer 5.03 is nu overgenomen door de 'nieuwe garde' AlO's. Ik hoop dat juilie net zoveel plezier aan het onderzoek beleven als ik heb gehad.

De avondjes RPBS met hippie, le cock, de nek, tetu, foggy d'n Els en bottom waren onvergetelijk. Dankzij jullie weet ik dat de letste een zeer rekbaar begrip is...

De congressen, eerst samen de zenuwen delen voor de presentaties en dan eropuit! Met Esther $C$. Amerika door. $\mathrm{k}$ heb nog geprobeerd de band van Bourbon Street te regelen maar dat is helaas niet gelukt. Esther $L$. en Cherida, de trip door de Rocky's was onvergetelijk, ik weet nu dat chipmunks erg gevaarlijk zijn en dat leeuwen een natuurlijk verschijnsel in Amerika zijn. In de stad van Bobby Ewing met Esther $C$. en Ann-Pascale steak gegeten en ge-linedanced, hoe Amerikaanser kan het? 
Pap en mam, bedankt voor de kansen, steun en interesse die jullie me altijd gegeven hebben. Peter, Karin en Kirsten jullie zijn de beste broer en zussies die je maar kan hebben. Ik hoop dat dit boekje het 'iets' duidelijker maakt war ik de afgelopen jaren mee bezig ben geweest. Karin, dankzij jou ziet het boekje er geweldig uit, bedankt dat je er avonden en weekenden in hebt willen steken (ik hoop dat de scouts je nog herkennent. Ik ben blij dat je mijn paranimf wilt zijn.

Lieve Raphaell. Je bent niet gillend weggelopen als ik woor de duizendste keer zei: 'ik heb geen tijd, ik moet werken'. Je was er 'gewoon' altijd als ik je nodig had, je beseft niet half hoe belangrijk dat woor me was. 


\section{Curriculum Vitae}

\section{Birgit Faber}

28 October 1969 Born in Eindhoven

\section{Education}

1982-1988 WWO-B, van der Puttlyceum Eindhoven.

1988-1992 BSC (HLO) at the Hogeschool Larenstein, Wageningen.

1992-1995 MSC in biology at the Agricultural University of Wageningen.

\section{Research positions}

1996-1999

1999-2003

2003-present
Research assistant at the Department of Pathology (CESAME), Maastricht University.

PhD student, at the Department of Pathology (CARIM), Maastricht University.

Postdoctoral fellow department of Pathology (CARIM). Maastricht University.

\section{Full articles}

Faber BCG, Cleutjens KBJM, Niessen RLJ; Aarts PLJW, Boon W, Greenberg AS, Kitslaar PJEHM, Tordoir JHM, Daemen MJAP. Identification of Genes Potentially Involved in Rupture of Human Atherosclerotic Plaques. 2001 Circ. Res. 89, 547-554.

Faber BCG, Heeneman S, Daemen MJAP, Cleutjens KBעM. Genes potentially involved in plaque rupture. 2002 Current Opinion in Lipidology 13, 545-552.

Heeneman S, Cleutjens IPM, Faber BCG, Creemers EE, van Suylen RI, Lutgens E, Cleutjens KBIM, Daemen MIA.P. The dynamic extracellular matrix - intervention strategies during heart failure and atherosclerosis. J of Pathology, 2003 (In press). 
Lutgens $E$, wan Suyten 1, Faber BCG, Bijnens APJ, Cleutjens KBJM, Daemen MJAP. Plaque rupture in human and mice: definition and pathophysiology. Arterioscler Thromb Vasc Biol. 2003 (Inwited review).

Binens APJ, Gils A, Jutten B, Faber BCG, Heeneman $S$, Kitslaar PJEHM, Tordoir JHM, de Vries CIM, Daemen MJAP, Cleutjens KBMM. Vasculin, a novel vascular protein differentially expressed in human atherosclerosis (Provisionally accepted in Blood).

Faber BCG, Greenberg AS, Heeneman S, Kitslaar PIEHM, Tordoir JHM, Daemen MIAP, Cleutjens KB.IM. Spatio temporal expression of perilipin, adipocyte differentiation related protein and hormone sensitive lipase in human atherosclerosis (Submitted).

Faber BCG, Dunbar D, Black D, Evelo C, Daemen MJAP, Cleutjens KBJM. Large scale gene expression profiling of human atherogenesis (\|n preparation).

Faber BCG/ Lutgens E, Evelo C, Porter G, Daemen MJAP, Cleutjens KB.JM. Unique gene expression patterns characterize cholesterol challenge and atheroscleratic plaque progression in ApoE deficient mice (In preparation).

Cleutjens KBJM, Faber BCG, Lutgens $E$, Jutten $B$, Heeneman 5 , Gijbels $M$, Fisher $A_{\text {* }}$ Long CJ, Saftig P, Bilach D, Daemen MIJAP. Disruption of the cathepsin $K$ gene reduces the progression of atherosclerosis (In preparation).

\section{Abstracts}

Faber BCG, Dunbar D, Black D, Daemen MJAP, Cleutjens KBJM. Gene expression profiles during human atherogenesis; $A$ role for the Lif-receptor in lesion progression? 2002, Supplement to Circulation, Vol. 106, No 19, Abstract No 217.

Faber BCG, Dunbar D, Black D, Evelo C, Daemen MJAP, Cleutjens KBJM. Gene expression profiles during human atherogenesis. 2002, On line issue (vol. 22, 4, abstract 15) of ATVB. New investigators award.

Faber BCG, Cleutjens KBIM, Boon W, Kitslaar PJEHM, Tordoir JHM, Greenberg AS and Daemen MIAP. Ruptured plaque specific gene expression: a role for perilipin/ADRP and HSL mediated lipolysis? 2001. Supplement to Circulation, Vol. 104, No 17, Abstract No 42. 
Faber BCG, Cleutjens KBIM, Boon W. Kitslaar PJEHM, Tordoir JHM, Greenberg AS and Daemen MJAP. Enhanced expression of perilipin in ruptured human atherosclerotic plaques. 2001, On line issue (vol. 21, 4, abstract P266) of ATVB. New investigators award.

Faber BCG, Cleutjens KBJM, Janssen A, Boon W, Kitslaar PJEHM, Tordoir JHM, and Daemen MJAP. Identification of genes differentially expressed in either stable or ruptured human atherosclerotic plaques. 2000, ATVB p140.

Faber BCG, Niessen R, Kitslaar PJEHM, Tordoir HHM, Daemen MJAP, Cleutjens KBJM. Identification of genes that are specifically expressed in either stable or ruptured human atherosclerotic plaques. 1999, Supplement to Circulation, Vol 100, No 18 , Abstract No 2856. 